\title{
PHYLOGENY, CLASSIFICATION, MESOZOIC FOSSILS, AND BIOGEOGRAPHY OF THE LEIINAE (DIPTERA: MYCETOPHILIDAE)
}

\author{
SARAH SIQUEIRA OLIVEIRA \\ Departamento de Ecologia \\ Instituto de Ciências Biológicas \\ Universidade Federal de Goiás \\ DALTON DE SOUZA AMORIM \\ Departamento de Biologia \\ Faculdade de Filosofia, Ciências e Letras de Ribeirão Preto \\ Universidade de São Paulo
}

BULLETIN OF THE AMERICAN MUSEUM OF NATURAL HISTORY

Number 446, 108 pp., 107 figures

Issued March 16, 2021 


\section{CONTENTS}

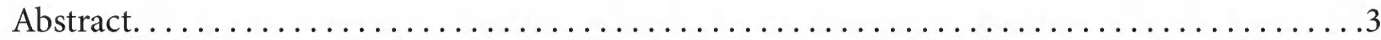

Introduction. . . . . . . . . . . . . . . . . . . . . . . . . . . . . . . . . . . .

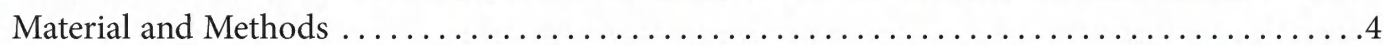

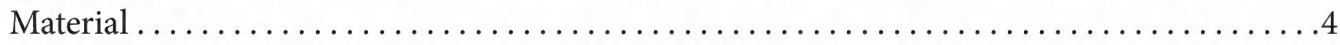

Preparation of specimens and morphology documentation. . . . . . . . . . . . . . . . . 5

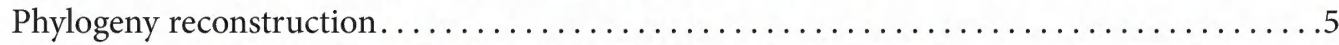

Character sampling and morphological terminology $\ldots \ldots \ldots \ldots \ldots \ldots \ldots \ldots \ldots \ldots \ldots \ldots \ldots \ldots \ldots \ldots$

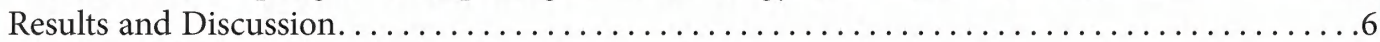

Relationships among subfamilies of Mycetophilidae ......................

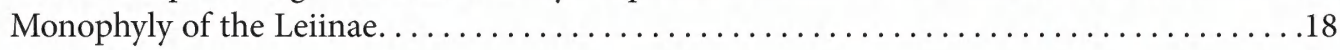

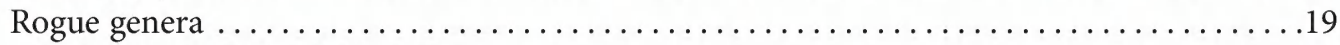

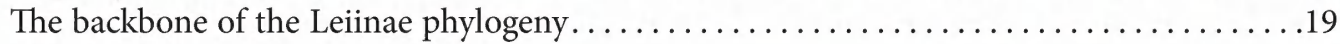

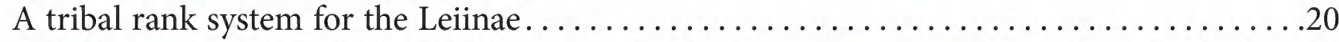

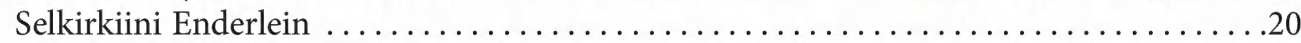

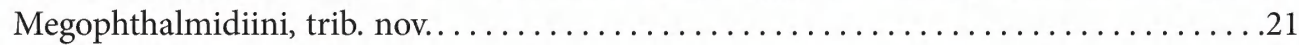

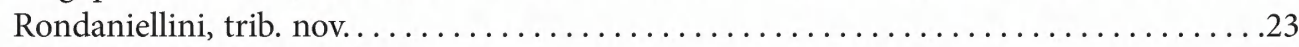

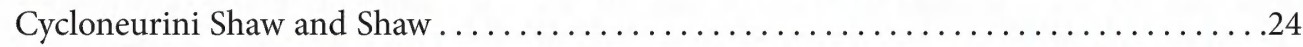

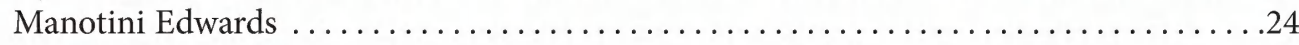

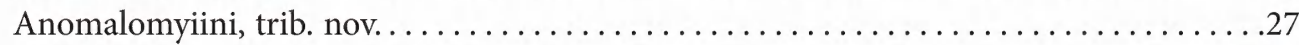

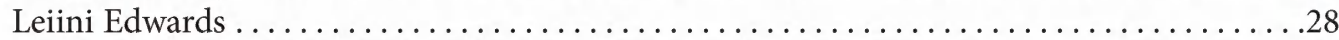

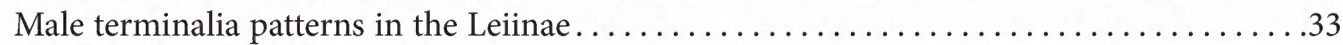

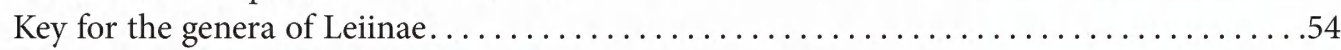

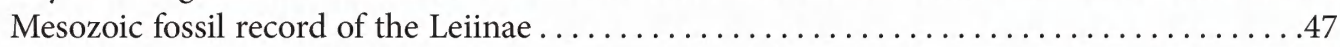

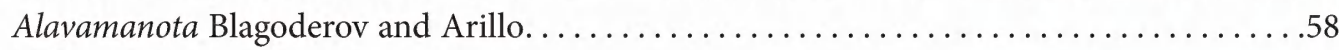

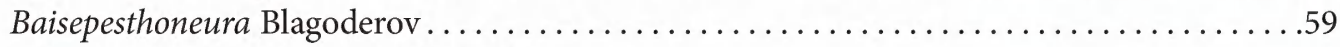

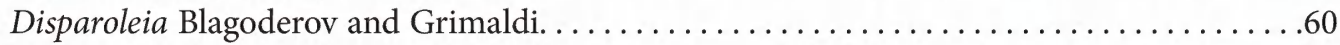

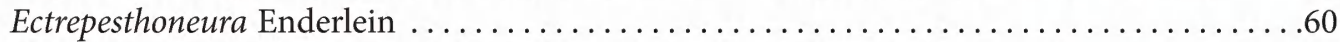

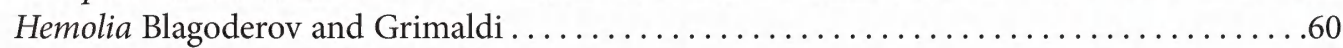

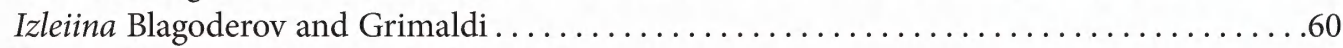

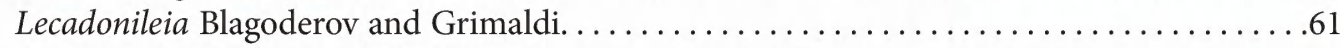

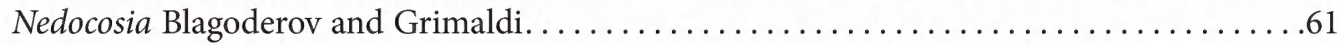

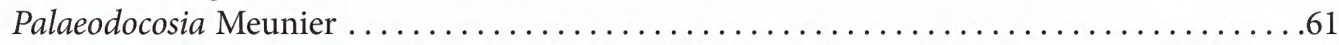

Protragoneura Blagoderov and Grimaldi .................................. 62

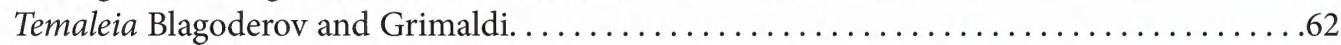

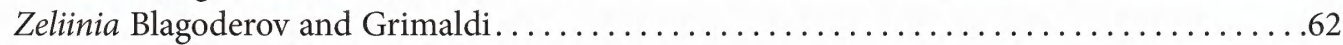

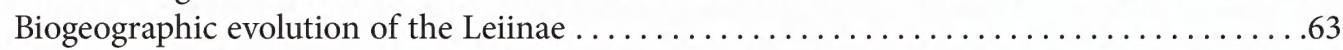

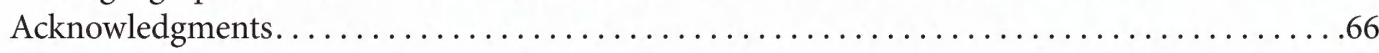

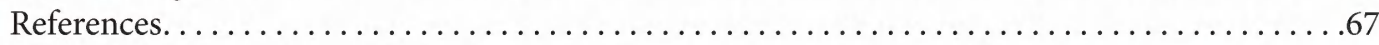

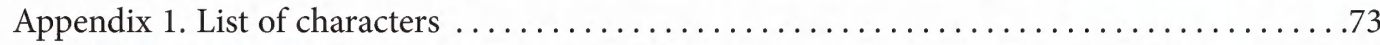

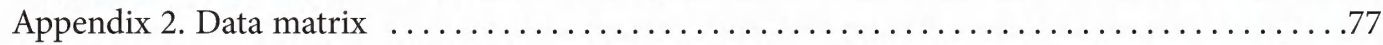

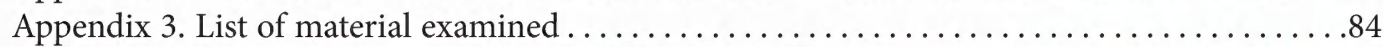

Appendix 4. Mycetophilid fossils (modified from Evenhuis, 2014) assignable to subfamilies. 100 Appendix 5. Age and location of mycetophilid amber and compression fossil sites....... 108 


\begin{abstract}
The relationships among the genera of fungus gnats in the mycetophilid subfamily Leiinae are unclear, and the monophyly of this group is questionable. This monograph provides an extensive phylogenetic study of the Leiinae based on morphological data from a large taxonomic sample, including all genera that have ever been assigned to the subfamily and a wide outgroup sampling to properly test subfamilial monophyly. A data matrix with 128 morphological features of 117 terminal taxa was carried out under parsimony using different implicit weight schemes. All recovered topologies support a monophyletic Leiinae that is more restricted than the usual delimitation of the subfamily. We found no consistent evidence that a clade with Docosia Winnertz, Novakia Strobl, Ectrepesthoneura Enderlein, and Tetragoneura Winnertz group together with the remaining genera of Leiinae. A name with subfamily rank-Tetragoneurinae, already present in the literature-is used here to refer to this group. The allactoneurine genera Sticholeia Søli and Allactoneura de Meijere form a clade with the leiine genus Leiella and the genera of Manotinae, which is deeply nested within the Leiinae. The male terminalia patterns found within the subfamily are analyzed and illustrated. A classification for the Leiinae is proposed grouping 33 genera in seven clades ranked as tribes: Selkirkiini Enderlein, Megophthalmidiini, trib. nov., Rondaniellini, trib. nov., Cycloneurini Shaw and Shaw, Manotini Edwards, Anomalomyiini, trib. nov., and Leiini Edwards. A key for the world genera of Leiinae is also provided. The Cretaceous mycetophilid fossil record is revisited and the biogeographic evolution of the Leiinae is discussed.
\end{abstract}

\section{INTRODUCTION}

Fungus gnats of the family Mycetophilidae have immature stages mostly associated with the fruiting bodies, hyphae or spores of fungi. The Mycetophilidae are the second most species-rich family of the suborder Bibionomorpha (see Amorim and Yeates, 2006), with 233 genera and about 4500 species, described from all biogeographic regions (Pape et al., 2011), second in number of species only to the Cecidomyiidae. They are known in the fossil record from the Cretaceous through the Cenozoic, where they are diverse and sometimes abundant (Amorim and Silva, 2002; Blagoderov and Grimaldi, 2004; Evenhuis, 2014). The family is clearly monophyletic (e.g., Søli, 1997; Rindal et al., 2009a) and often divided in the subfamilies Sciophilinae, Gnoristinae, Mycomyiinae, Leiinae, Manotinae, Allactoneurinae, and Mycetophilinae (Tuomikoski, 1966; Hennig, 1973; Väisänen, 1984; Matile, 1989; Rindal et al., 2009a).

Phylogenies have been published for the mycetophilid subfamilies Manotinae (Hippa et al., 2005), Mycetophilinae (Rindal and Soli, 2006; Rindal et al., 2007, 2009b), Sciophilinae (Borkent and Wheeler, 2013), Gnoristinae, and Mycomyinae (Kaspřák et al., 2019), based on morphological and/or molecular information. The Leiinae have so far not shown up on the phylogenetic radar.

The composition of the Leiinae accepted by most authors comprises 37 genera and about 550 species worldwide (Oliveira and Amorim, 2012). There are 54 species of the subfamily known from fossils, which include 12 additional extinct genera, eight of which are in Cretaceous amber (Blagoderov, 1998a, 1998b, 2000; Blagoderov and Grimaldi, 2004; Evenhuis, 2014).

A tribal rank for the Leiinae was originally proposed by Edwards (1925), who established that a short $\mathrm{R}_{1}$ (usually shorter than $\mathrm{r}-\mathrm{m}$ ) and a longitudinal $r-m$ aligned with the second section of Rs would be diagnostic for the group. Edwards (1925) himself, however, pointed out that there are some exceptions for these features, e.g., Rondaniella Johannsen, Docosia, and Tetragoneura.

Hendel (1936) gave subfamily rank to the Leiini, but the generic composition and the diagnosis of the group have been repeatedly questioned (Tuomikoski, 1966; Hennig, 1973; Søli, 1997; Søli et al., 2000; Hippa et al., 2005; 
Jaschhof and Kallweit, 2009). Tozoni (1998) recovered a monophyletic Leiinae, supported by the reduction of the length of $R_{5}$, the first section of Rs nearly transverse, $\mathrm{R}_{4}$ missing, and an incomplete mediopleural suture, which is not produced on its lower fourth. The taxon sampling of studies of the phylogenetic relationships among mycetophilids in general (e.g., Søli, 1997; Tozoni, 1998; Hippa et al., 2005; Rindal et al., 2009a; Ševčík et al., 2013), however, has been considerably limited and none of these studies had a wide sampling of leiine genera.

A proper test for the monophyly of the Leiinae and establishing the relationships among its genera to provide a robust classification for the subfamily is entirely dependent on: (1) a wide sampling of the genera of the subfamily; and (2) a proper choice of outgroups to have a reliable test of its monophyly. This paper conducts a formal phylogenetic analysis of the Leiinae based on morphological information of 117 terminal taxa-all genera currently in the subfamily, all extant genera that may have been referred to as possibly connected to the leiines and a large number of outgroups, including allactoneurines and manotines.

\section{MATERIAL AND METHODS}

\section{MATERIAL}

Specimens used in our study were obtained from the following collections (including acronyms used in the text):

AMSA Australian Museum, Sydney, Australia

ANIC Australian National Insect Collection, Canberra, Australia

CEUA Colección de Entomología of the University of Antioquia

CNC Canadian National Collection of Arachnids, Nematodes and Insects, Ottawa, Canada

DZUP Coleção de Entomologia Padre Jesus Santiago Moure da Universidade Federal do Paraná, Curitiba, Brazil
FMNH Finnish Museum of Natural History, Zoological Museum, University of Helsinki, Helsink, Finland

IAvH Instituto de Investigación de Recursos Biológicos Alexander von Humboldt, Bogota, Colombia

INPA Instituto Nacional de Pesquisas Amazônicas, Manaus, Brazil

LMED Laboratório de Morfologia e Evolução de Diptera, Faculdade de Filosofia, Ciências e Letras de Ribeirão Preto da Universidade de São Paulo, Ribeirão Preto, Brazil MNHN Muséum National d'Histoire Naturelle, Paris, France

MZUSP Museu de Zoologia da Universidade de São Paulo, São Paulo, Brazil

NHM Natural History Museum, London, United Kingdom

NMSA Kwa-Zulu-Natal Museum South Africa, Pietermaritzburg, South Africa

NZAC New Zealand Arthropod Collection, Auckland, New Zealand

SAMC Iziko South Africa Musuem, Cape Town, South Africa

SMOC Silesian Museum, Opava, Czech Republic

Properly verifying the monophyly of the Leiinae requires a wide sampling of genera that at any time have been assumed to be connected with the subfamily. Particularly, Tetragoneura and allied genera (as Novakia, Ectrepesthoneura, and Docosia) have been accepted either as leiines, gnoristines or as an independent group. The initial delimitation of an ingroup for the analysis here included 95 species of all 37 "Leiinae s.l." genera (including Tetragoneura, Ectrepesthoneura, Novakia, and Docosia). Whenever possible, we tried to use the type species of each leiine genus in the analysis. The genera Allactoneura and Sticholeia have often been placed in a subfamily of their own, but their relationship to the leiines (see discussion below) has been stressed by different authors. The fact that the manotines have often been associated with the Allactoneurinae also makes 
it indispensable that all of its genera should be integrated into the analysis.

Outgroup sampling is a key issue, since there is no consensus in the literature about the position of the Leiinae in the phylogeny of the Mycetophilidae. Our outgroup list includes nine species of five genera of Sciophilinae, six species of six genera of Gnoristinae, two species of two genera of Mycomyiinae, and four species of four genera of Mycetophilinae (two Exechiini and two Mycetophilini). One species of Keroplatidae was used to root the entire tree. The full matrix includes 117 terminal taxa. Complete information of the specimens used in this study is included in the appendix 3 . The list of characters is in appendix 1 and the data matrix is in the appendix 2. A complete list of known Mycetophilidae fossils (appendix 4) and their fossil deposits (appendix 5) were used to infer the age of the main nodes of the backbone of the Leiinae phylogeny. Over a hundred additional species of mycetophilids were slide-mounted and studied, although not formally included in the matrix.

\section{Preparation of Specimens, Morphology \\ Documentation, and Abbreviations}

When available, both males and females of each species were studied. Most specimens were dissected and mounted on permanent slides. Specimens were cleared with $\mathrm{KOH}$, dehydrated in ethanol, and mounted in Canada balsam (modified from Walker and Crosby, 1988; Huber and Reis, 2011). In some cases, after clearing, the terminalia were studied in temporary slide mounting with glycerine or gelatin with phenol (modified from Zandler, 2003).

The habitus of the specimens and morphological details of the structures were studied using light microscopy and were photographed with a Leica DC500 camera attached to a Leica stereomicroscope model MZ-16 or a compound microscope model Leica DM2500. Photos were stacked with Helicon Focus 6. The morphological structures were drawn using a camera lucida attached to the compound microscope. Images were edited with Adobe Photoshop CC. All terminal taxa had specimens studied except of the fossils species and the genus Paramanota. Data for Paramanota in the matrix were taken from the literature except for the wing, obtained from a photograph kindly made available by Jan Ševčík.

Along the discussion of male terminalia patterns in the Leiinae, we refer to published illustrations for most genera. Some leiine genera do not have any published illustrations of male terminalia. We include here stacking photographs of 27 species of 20 genera in the subfamily. Slide mounts show relatively transparent structures at different focus levels and stacking does not work as with pinned specimens: structures at different levels often blur together. Our photographs provide illustrations of the general pattern of the male terminalia of part of the leiine genera and we refer to illustrations as they appear published on paper. A full study of the details of the male terminalia morphology in each genus or species, however, is beyond the scope of this paper. Abbreviations for male terminalia plates as follows: adlgc, apico-dorsal lobe of gonocoxite; allgc, apico-lateral lobe of gonocoxite; avlgc, apico-ventral lobe of gonocoxite; aed, aedeagus; allgc, apico-lateral lobe of gonocoxite; avlgc, apico-ventral lobe of gonocoxite; cerc, cercus; ej ap, ejaculatory apodeme; epand, epandrium; gonocx, gonocoxite; gonocx apod, gonocoxite apodeme; gonst, gonostylus; gsdl, gonostylus dorsal lobe; gsl, gonostylus main lobe; gsml, gonostylus medial lobe; gsvl, gonostylus ventral lobe; hypd, hypandrium; ldlep, laterodistal lobe of epandrium; pm, paramare; pm apod, parameral apodeme; st9, sternite 9; syngcxm, syngonocoxite medial sclerite; teg, tegmen.

\section{Phylogeny Reconstruction}

The character matrix was constructed using WinClada (version 1.89). Characters were treated as unordered; unobserved states and inapplicable 
data were coded respectively as "?" and "-." Some characters were coded as absent or present, in some cases causing interdependence. We retain these characters as separate in order to extract pertinent phylogenetic data from the morphological differences we observed (Lee and Bryant, 1999; Strong and Lipscomb, 1999).

The phylogenetic analyses of the matrix were made under Fitch parsimony (1971), implemented using TNT (Tree Analysis Using New Technologies-Willi Hennig Society Edition; Goloboff et al., 2008). Topologies in TNT were obtained using New Search Technology (Goloboff, 1999; Nixon, 1999; Goloboff et al., 2008), recommended for matrices with more than 100 terminals. According to Goloboff (1999) and Nixon (personal commun.), the new technologies should be used together; Drifting and Ratchet are very similar and the best method for complex data sets is Ratchet (Nixon, 1999). The following parameters were used for the analyses: Max. trees 10,000; Random seed 0; Random addition sequences 200, Sectorial search (sect: slack7); Ratchet 200 interactions; Tree fusing 5 cycles.

The rooting procedure followed Nixon and Carpenter (1993) using an unequivocal outgroup, in this case a species of Keroplatidae. Final trees files were obtained using WinClada software, edited in Adobe Illustrator CC. Bremer support (Bremer, 1994) was calculated for the strict consensus tree using TNT to indicate the extra steps required to collapse a branch. Suboptimal trees with 1-20 extra steps with TBR (Tree Bissection Reconnection) were used to calculate Bremer support values.

We used implied weighting schemes to reduce the potential influence of incongruent characters over nested characters (Goloboff, 1993). In other words, properties of the data were used to reduce the chances that random association between incongruent characters outperform nested characters under equal weight. Initial analyses of the data matrix were made in TNT under different $\mathrm{k}$ values-between 1 and 10, 15, 20, and 25-as well as an analysis with equal weight to assess its effect on the final topology. A tree was also obtained using the script "setk.run" (available from Salvador Arias, unpublished data, to choose the best $\mathrm{k}$ value) with TNT based on our dataset, which resulted in $\mathrm{k}=24.22175$. The tree used to discuss character evolution was the majority consensus of the equal weight analysis.

\section{Character Sampling and Morphological Terminology}

The matrix (appendix 2) has morphological characters of male and female adults. Some of the characters used here were proposed in the phylogenetic analyses of the Mycetophilidae by Søli (1997), Tozoni (1998), Rindal and Søli (2006), Amorim and Rindal (2007), and Borkent and Wheeler (2013). Several characters are proposed here for the first time. The morphological terminology follows Cumming and Wood (2017), while structures particularly of the thorax and male terminalia features follow Søli (1997), Amorim and Rindal (2007), and Matile (1990). We use here the term "spines," in accordance with Cumming and Wood (2017), for hardly sclerotized bristles. Unnamed clades on the phylogeny are referred to using the group+ artifact (Amorim, 1982), in which, e.g., the group $(A+(B+(C+(D+E))))$ is shortened to "group- $A^{+}$," i.e., the clade including $A$ plus its sister group.

\section{RESULTS AND DISCUSSION}

This is the first cladistic study of the Leiinae with a complete generic sampling and a substantial number of characters. The need for a study of the Leiinae with a comprehensive sampling was made clear in the literature (e.g., Jaschhof and Kallweit, 2009). Our study includes a wider sampling within some of the more speciose genera to address the question of their monophyly. The generic sampling outside the Leiinae was particularly designed to test of the monophyly and, hence, the generic composition of the subfamily. 

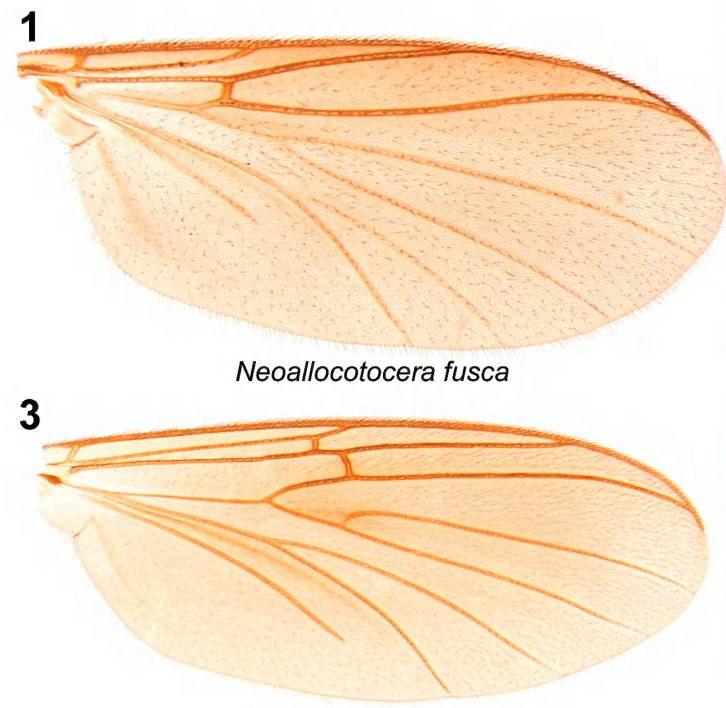

Tasmanina gracilis

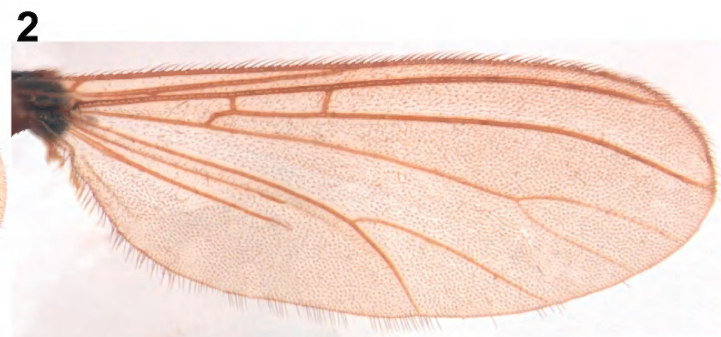

Aneura sp.

4

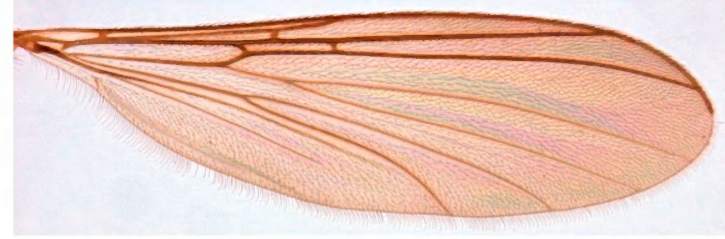

Eudicrana splendens

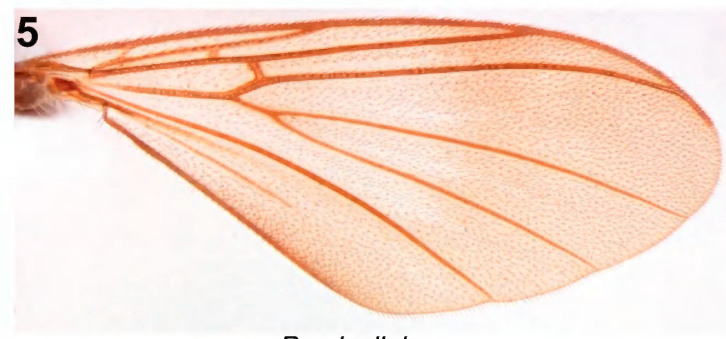

Parvicellula sp.

FIGS. 1-5. Wings of Sciophilinae species. 1. Neoallocotocera fusca Tonnoir. 2. Aneura sp. 3. Tasmanina gracilis Tonnoir. 4. Eudicrana splendens Lane. 5. Parvicellula sp.

A series of plates with the wings of all Leiinae genera were included here (figs. 1-63), for ease in following the wing characters in the list of characters and for using the key to the genera of the subfamily.

The data matrix (appendix 2) has a total of 128 characters (73 binary and 55 multistate), of which 34 are from head structures, 43 from thorax (including legs), 43 from wing, and 8 from male terminalia (appendix 1). In most cases, the state " 0 " already corresponds to the most plesiomorphic condition found within the Mycetophilidae. The analysis under equal weights resulted in 119 most-parsimonious trees, which majority consensus is in figure 96 and the strict consensus is in figure 97. The consistency index for the majority consensus tree is 0.19 , while the retention index is 0.76 , with 1,132 steps. Figure 97 shows the Bremer support for all nodes. The implied weight analysis under $\mathrm{k}=3$ resulted in one most parsimonious tree (fig. 98), while the script "setk.run" $\mathrm{k}=24.22175$ results in a single most parsimonious tree (fig. 99). Both these trees are very similar in topology to the majority consensus tree of the equal weight analysis.

We used the majority consensus for the discussion, since it provides slightly more information in a phylogenetic framework. The majority consensus keeps some of the clades not present in the strict consensus, which have been justified in the literature. We also carefully considered the differences between the tree topology of the tree 
6

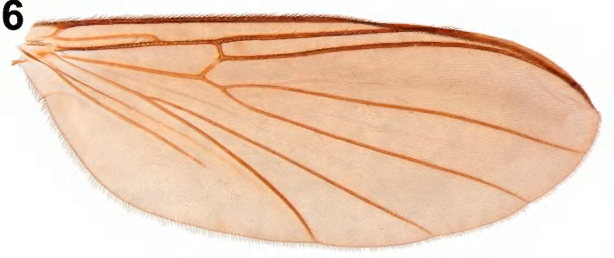

Palaeodocosia vittata

8

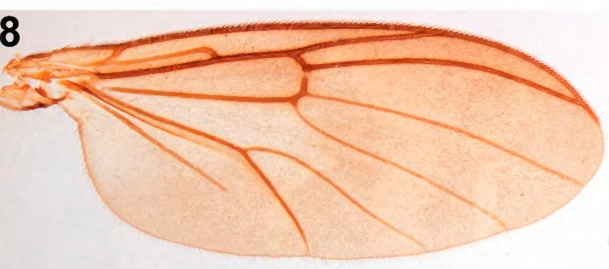

10

Schnusea caiabii

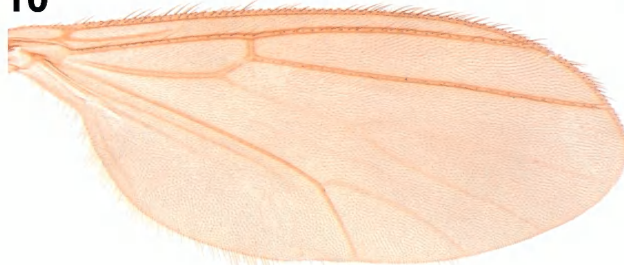

12

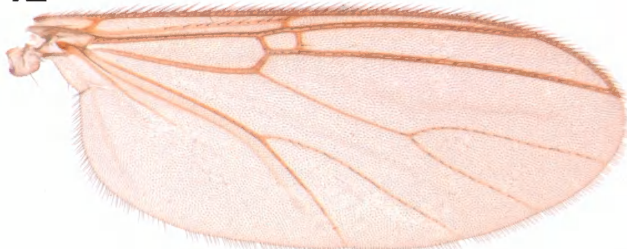

14

Mycomya sp.

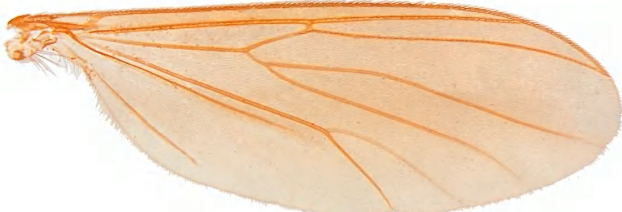

Rymosia sp.

16

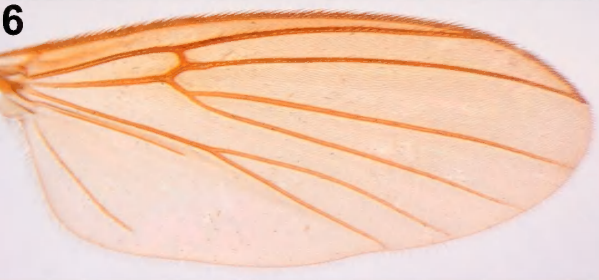

Mycetophila sp.

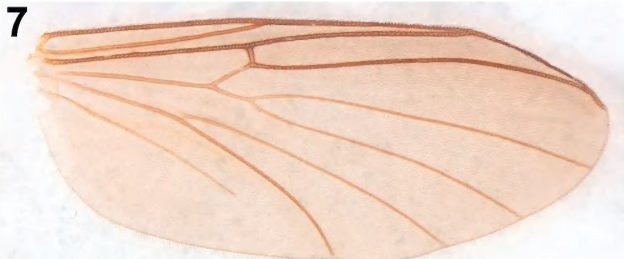

Boletina obscura

9

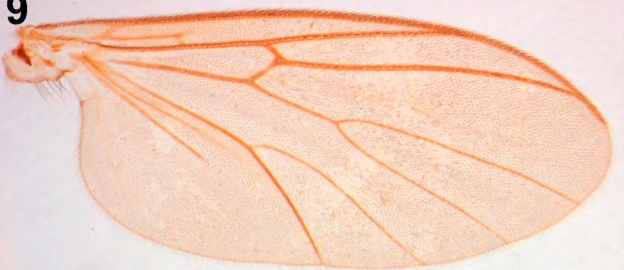

11

Dziedzickia metallica

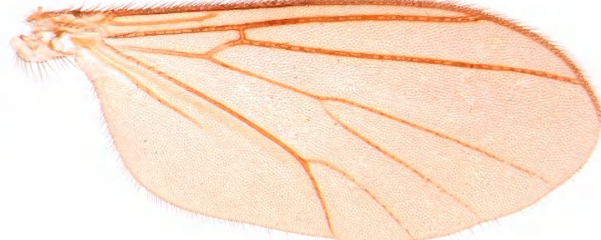

13

Synapha sp.

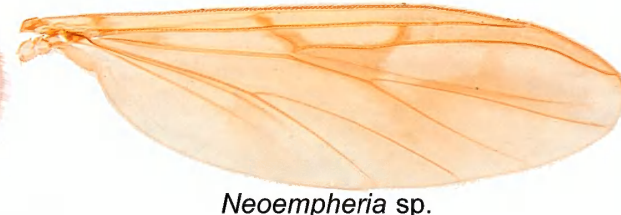

15

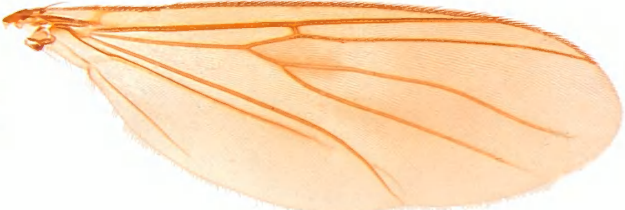

Exechiopsis sp.

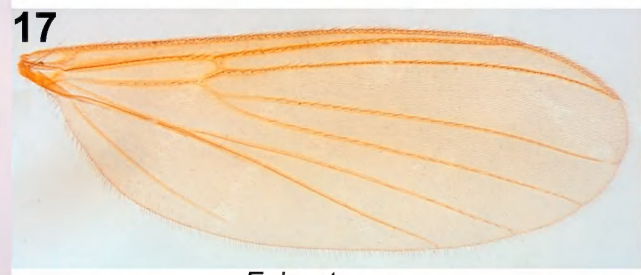

Epicypta sp.

FIGS. 6-17. Wings of Gnoristinae, Mycomyinae, and Mycetophilinae species. 6. Palaeodocosia vittata (Coquillett). 7. Boletina obscura Johannsen. 8. Schnusea caiabii Lane. 9. Dziedzickia metallica Lane. 10. Austrosynapha hirta Tonnoir. 11. Synapha sp. 12. Mycomya sp. 13. Neoempheria sp. 14. Rymosia sp. 15. Exechiopsis sp. 16. Mycetophila sp. 17. Epicypta sp. 


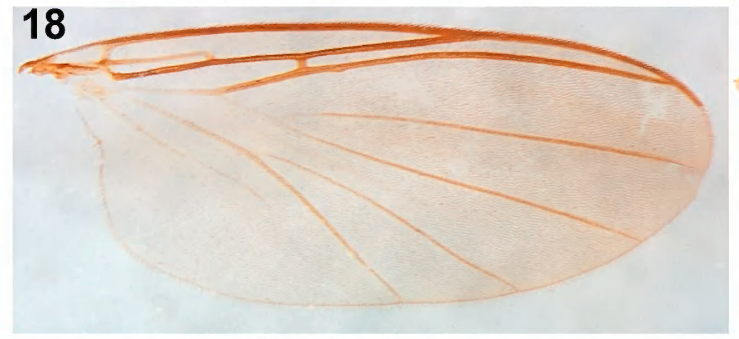

Docosia sciarina

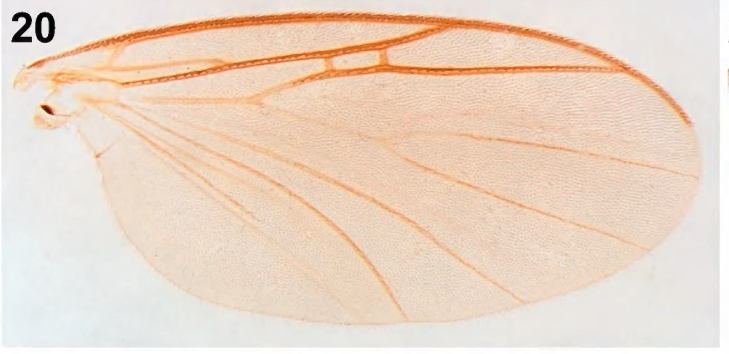

Ectrepesthoneura colyeri

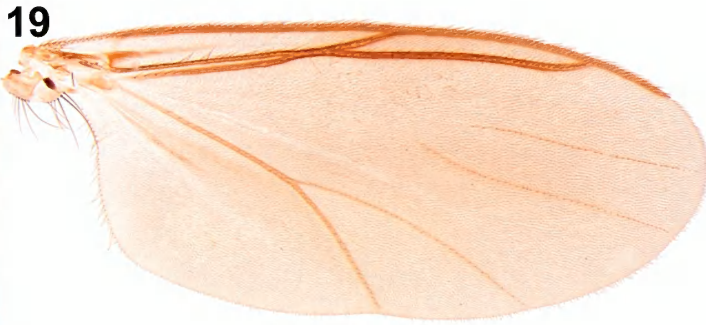

Novakia miloi

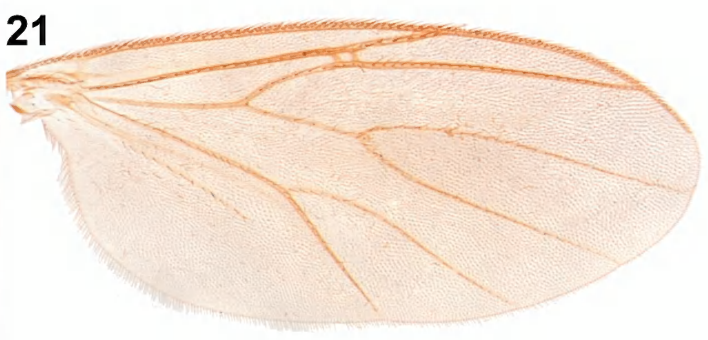

Tetragoneura borgmeieri

FIGS. 18-21. Wings of tetragoneurine species. 18. Docosia sciarina (Meigen). 19. Novakia miloi Kerr. 20. Ectrepesthoneura colyeri Chandler. 21. Tetragoneura borgmeieri Edwards.

in figure 96 and the trees obtained with $\mathrm{k}=3$ (fig. 98) and with $\mathrm{k}=24.22175$ (fig. 99).

Phylogenies are complex reconstructions that integrate into a single tree a set of individual hypotheses about relationships between the terminals (i.e., hypotheses on smaller clades). Nested subgroups of hypotheses and mutually independent hypotheses are present in any cladogram-e.g., the potential paraphyly of Mycetophila Meigen does not contradict a hypothesis of monophyly of the Mycetophilinae. The robustness of each node, hence, is often not affected by the weakness or robustness of clades in other parts of the tree. The assessment of the reliability of different clades in a phylogeny should be made case by case while considering their respective hypotheses.

The consistency index in the tree is relatively low (0.19), expressing the relatively high character plasticity. The retention index, however, is relatively high (0.75), indicating that incongruent characters are not significantly affecting the backbone of the tree. That explains the considerably good values for the Bremer support for most larger clades within the Leiinae tree (fig. 97).
Four names of the seven taxa with tribal rank in our classification (fig. 100) were already proposed in the literature (Manotini Edwards, 1925; Leiini Edwards, 1925; Selkirkiini Enderlein, 1940; Cycloneurini Shaw and Shaw, 1951). Each of the tribes is considered in detail in the discussion below, and we provide a formal diagnosis for each tribe. The analytical procedures used here to deal with the data matrix, with different $\mathrm{k}$ values for weighting schemes, allows spotting the genera that change their position in topologies with different parameters (i.e., different $\mathrm{k}$ values). Instead of considering as correct the position of these rogue genera in any particular tree (and to reflect it in the classification), we preferred to keep them unplaced in our tribal classification of the Leiinae.

Very few male terminalia characters were included in the analysis. The reason is that gathering male terminalia information at this stage for all terminals would result in a matrix with a high proportion of missing data-due to noncomparable features, to access to information and to unsolved homology issues. Our 
22

\section{4}

Garretella shermani

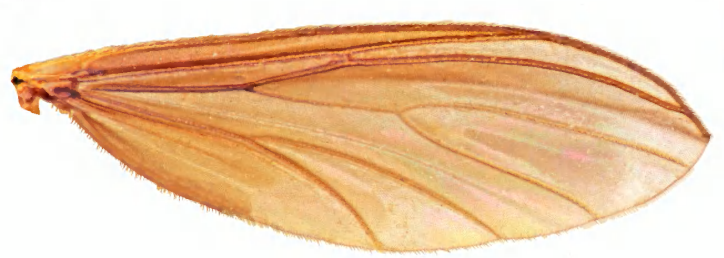

Thoracothropis cypriformis

26

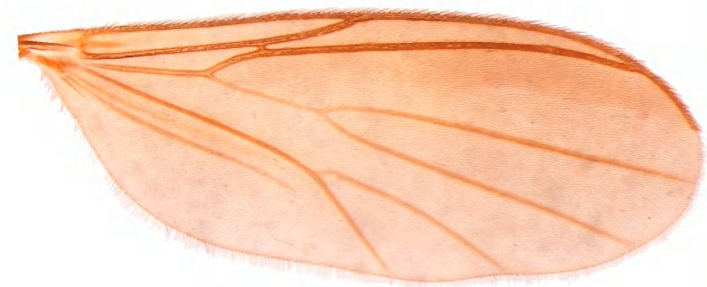

28

Trichoterga monticola

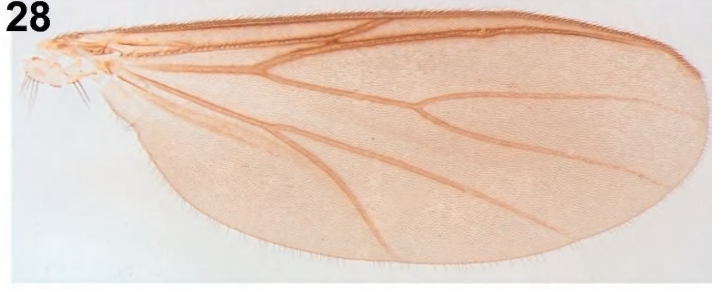

Mohelia matilei

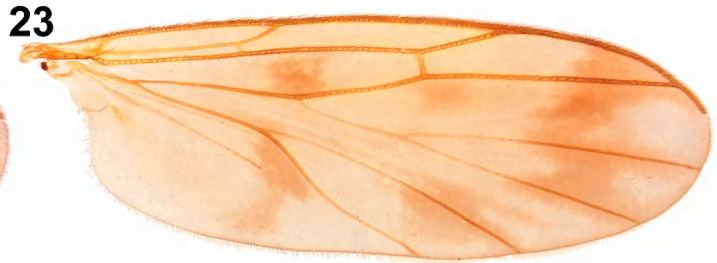

Paraleia nubilipennis

25

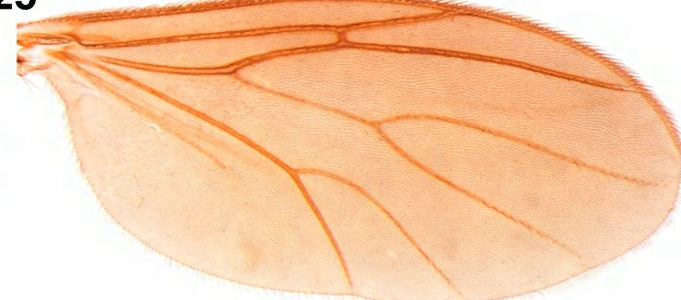

Gracilileia redunda

27

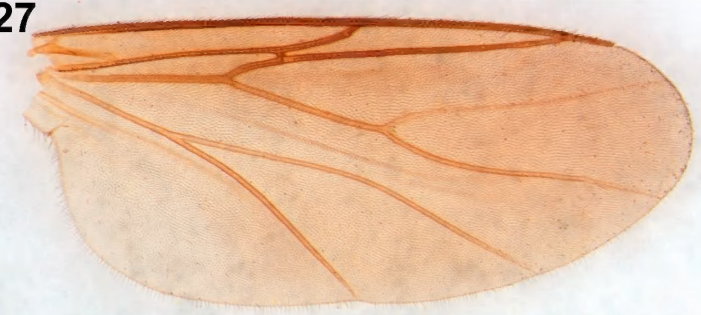

Megophthalmidia nigra

29

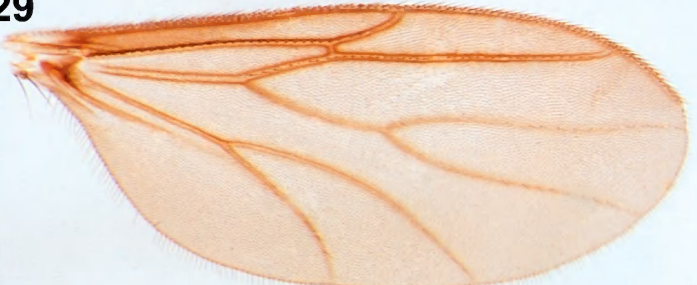

Aphrastomyia shannoni

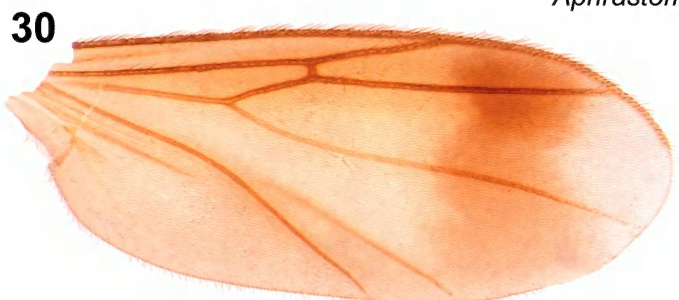

Paracycloneura apicalis

FIGS. 22-30. Wings of Leiinae species of Selkirkiini, Megophthalmiini and rogue genera. 22. Garretella shermani (Garrett). 23. Paraleia nubilipennis (Walker). 24. Thoracothropis cypriformis Freeman. 25. Gracilileia redunda Matile. 26. Trichoterga monticola Tonnoir and Edwards. 27. Megophthalmidia nigra Freeman. 28. Mohelia matilei Oliveira. 29. Aphrastomyia shannoni Lane. 30. Paracycloneura apicalis Tonnoir and Edwards. 


\section{1}

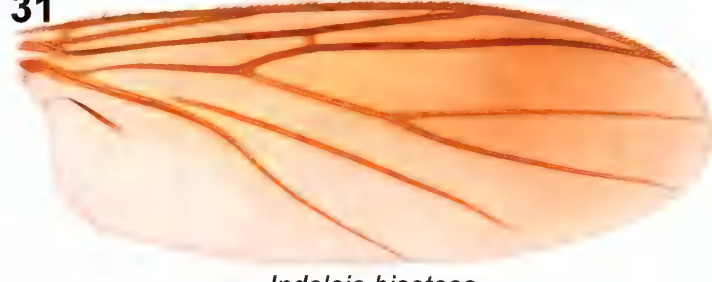

Indoleia bisetosa

33

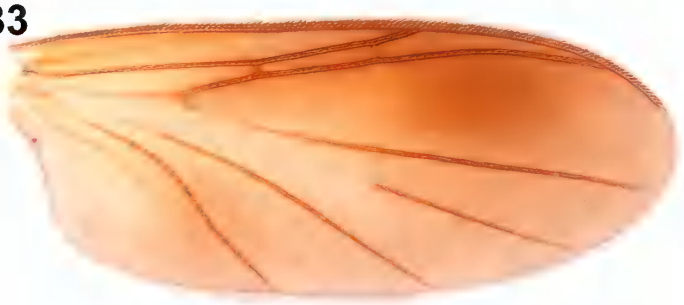

Waipapamyia elongata

35

37

Sigmoleia melanoxantha

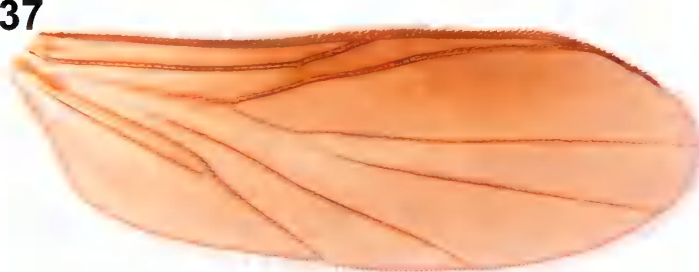

Paradoxa fusca

39

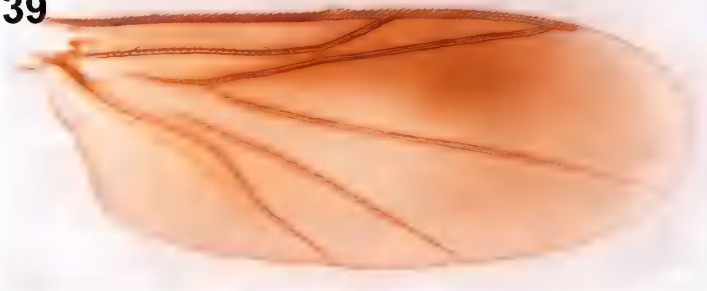

Tonnwardsia aberrans

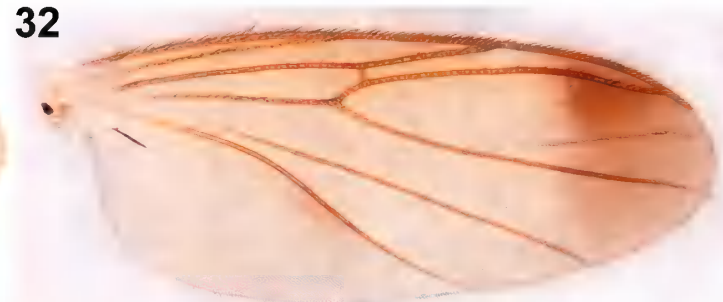

Rondaniella dimidiata

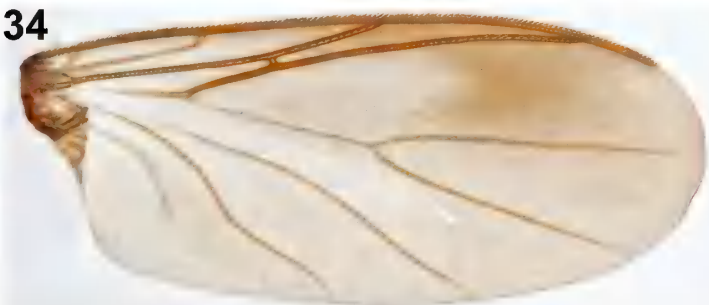

Cawthronia nigra

36

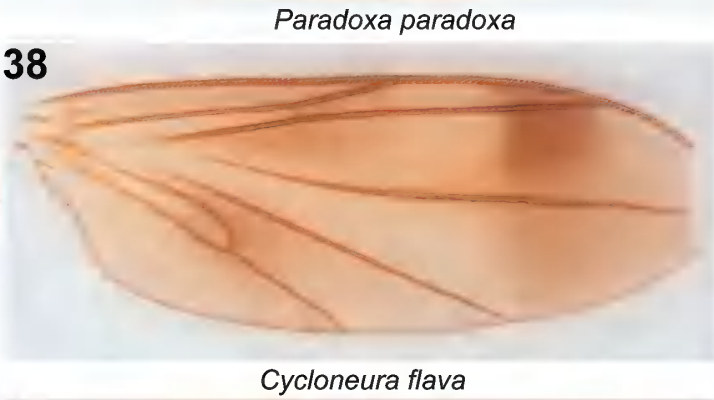

40

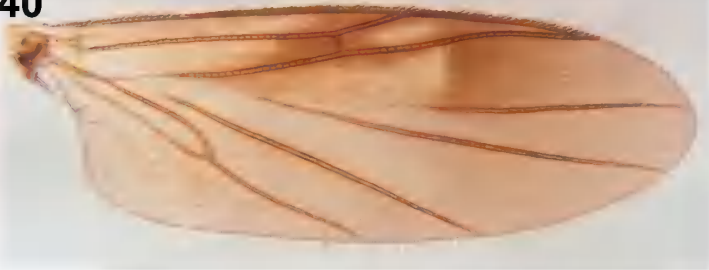

Procycloneura sp.

FIGS. 31-40. Wings of Leiinae species of Rondaniellini and Cycloneurini. 31. Indoleia bisetosa (Edwards). 32. Rondaniella dimidiata (Meigen). 33. Waipapamyia elongata Jaschhof and Kallweit. 34. Cawthronia nigra Tonnoir. 35. Sigmoleia melanoxantha Tonnoir and Edwards. 36. Paradoxa paradoxa Jaschhof. 37. Paradoxa fusca Marshall. 38. Cycloneura flava Marshall. 39. Tonnwardsia aberrans (Tonnoir). 40. Procycloneura sp. 
41

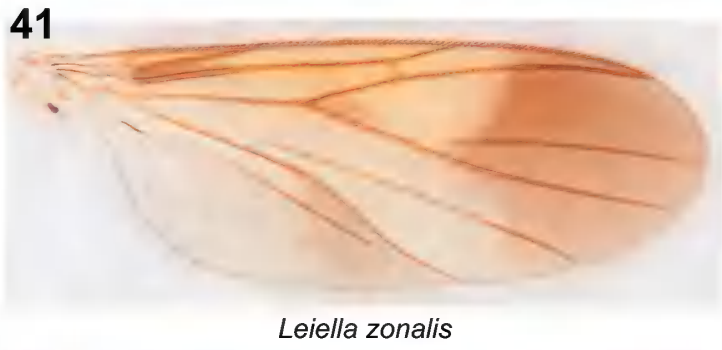

43

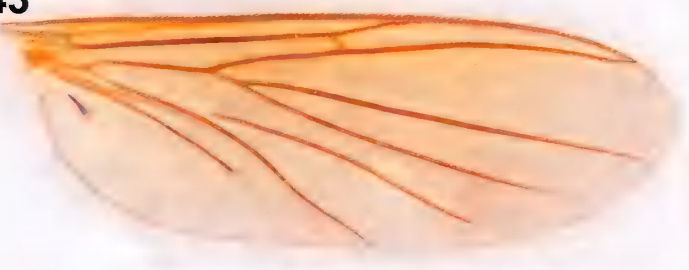

Sticholeia cheesmanae

45

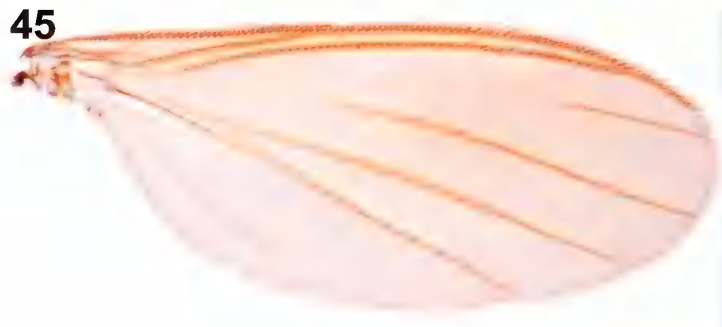

Manota sp.

47

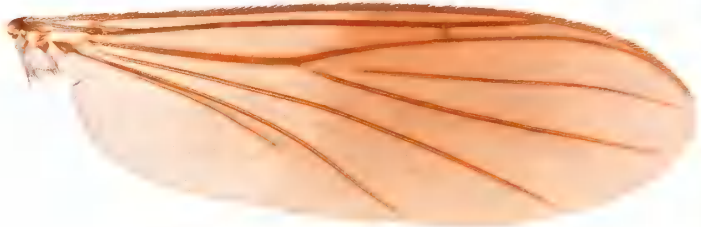

Eumanotasp.
42

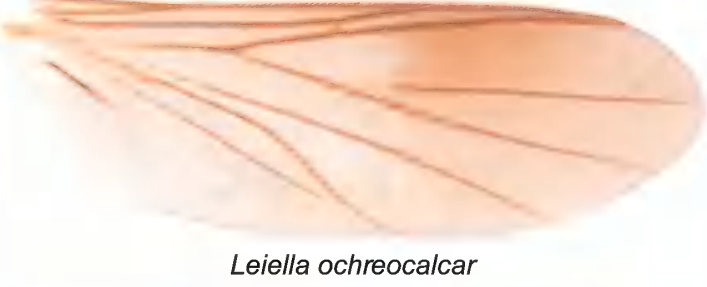

44

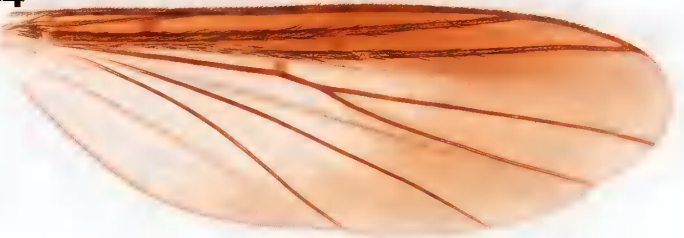

Allactoneura papuensis

46

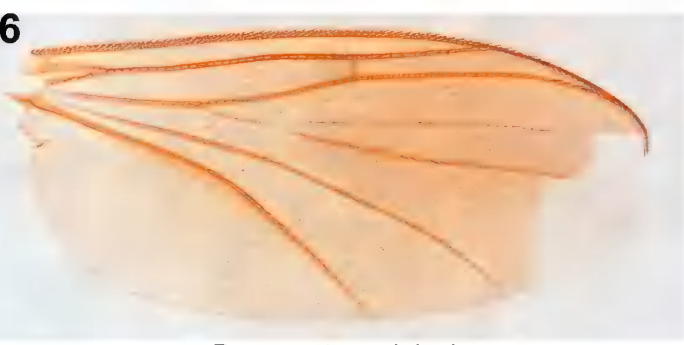

Promanota malaisei

48

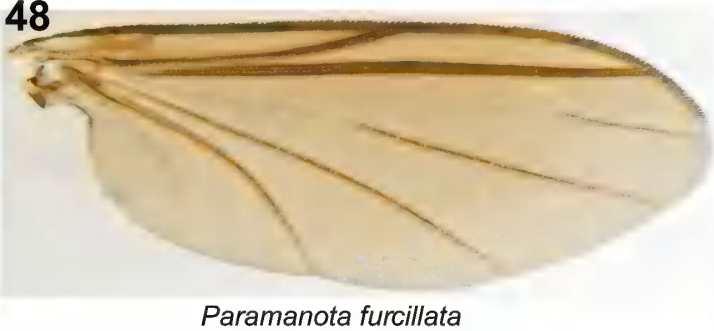

FIGS. 41-48. Wings of Leiinae species of Manotini. 41. Leiella zonalis Edwards. 42. Leiella ochreocalcar Enderlein. 43. Sticholeia cheesmanae Søli. 44. Allactoneura papuensis Bechev. 45. Manota sp. 46. Promanota malaisei Tuomikoski. 47. Eumanota sp. 48. Paramanota furcillata Hippa.

efforts during the early stages of this analysis with a larger number of male terminalia characters were not encouraging. Missing data have a damaging effect on phylogenetic analyses, with loss of information. We preferred instead to have a section in the paper to address specifically male terminalia patterns in the Leiinae. Since most of the characters correspond to features that define male terminalia patterns at the generic level, sometimes below the level of genus, the decision does not affect much the backbone of the phylogeny.

The same approach applies to the presence of fossils as terminals. There is no chance to avoid large amounts of missing data in the matrix while including fossils in the data matrix. Again, our attempts at earlier stages of this study to include fossils in the matrix 


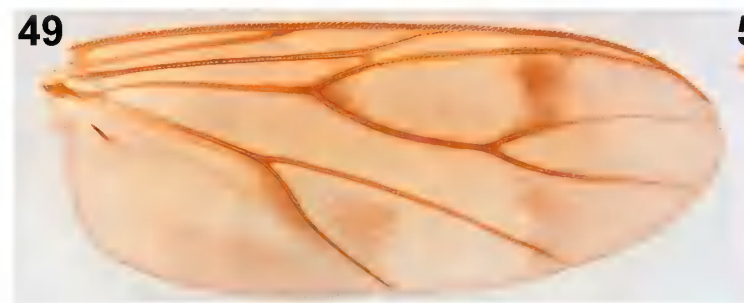

50

Anomalomyia guttata

Ateleia spadicithorax

\section{1}

\section{Acrodicrania angustifurca}

FIGS. 49-51. Wings of Leiinae species of Anomalomyiini. 49. Anomalomyia guttata (Hutton). 50. Ateleia spadicithorax Skuse. 51. Acrodicrania angustifurca Skuse.

resulted in polytomies, losing information even at the level of clades with subfamily rank. The fossil genera, hence, are discussed one by one ahead in a separate section, comparing the features available in the descriptions to the characters in the analysis.

\section{Relationships among Subfamilies of MyCETOPHILIDAE}

In the majority consensus (but not in the strict consensus) tree (fig. 96), the group of sciophiline genera sampled here forms a single clade. A monophyletic sciophiline was obtained by Borkent and Wheeler (2013), but Søli (1997: 49) found that Paratinia Mik and Drepanocercus Vockeroth do not comprise a monophyletic group with the remaining sciophilines. We do not have Paratinia and Drepanocercus in our taxon sampling and, hence, our analysis does not conflict with or confirm Søli's (1997) or Borkent and Wheeler's (2013) conclusions about the monophyly of the Sciophilinae. There is, however, a large core group of sciophiline genera that comprise a well-defined clade, as stated by Søli (1997) and Borkent and Wheeler (2013).
Plesiomorphies have been often used as diagnostic features of some of the mycetophilid subfamilies, resulting in confusion over the position of some genera in the system. Doubts have been repeatedly raised particularly about the monophyly of the Gnoristinae and about its position in the phylogeny of the mycetophilids (e.g., Väisänen, 1986; Søli, 1997; Søli et al., 2000; Rindal and Søli, 2006; Jaschhof and Kallweit, 2009). It should be no surprise, then, that, even with our limited sampling of gnoristines, the genera of the subfamily fit into two separate clades in our tree, one of them closer to the clade (Mycomyinae + Mycetophilinae) than the other. Borkent and Wheeler's (2013) phylogeny of the Sciophilinae is rooted in Mycomya Rondani, so their result cannot be used for the relationships among mycetophilid subfamilies. All trees in Søli's (1997) study also show the gnoristines as paraphyletic. Kasprák et al. (2019) have the gnoristines as a grade (i.e., a paraphyletic group) within which the mycetophilines are nested.

The position of the Mycomyinae as sister to the Mycetophilinae (fig. 101) was also recovered by Rindal and Søli (2006) based both on morphological and molecular data. In their study, Manota 
52

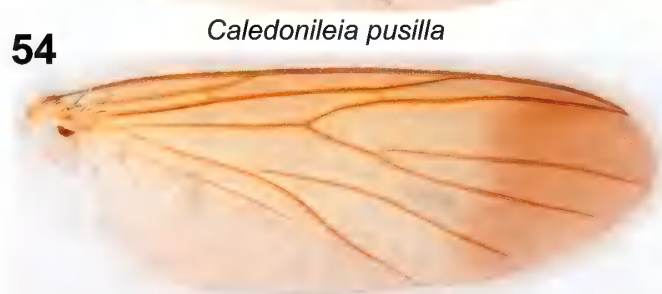

56

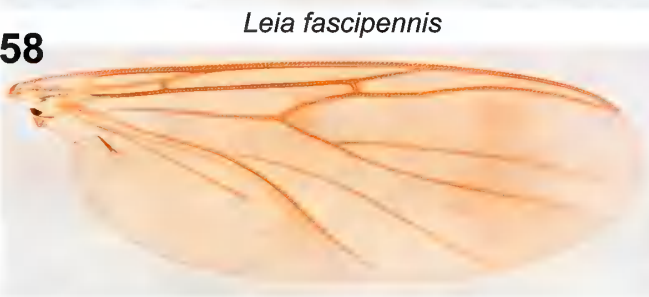

60

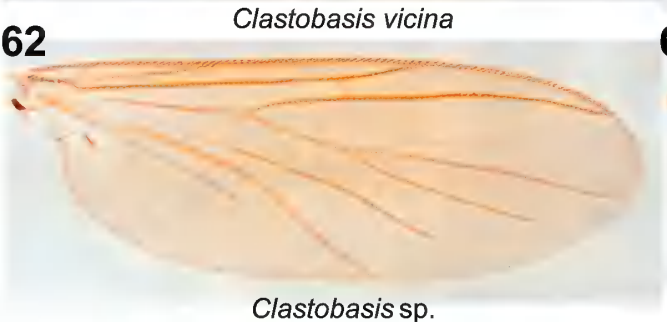

53
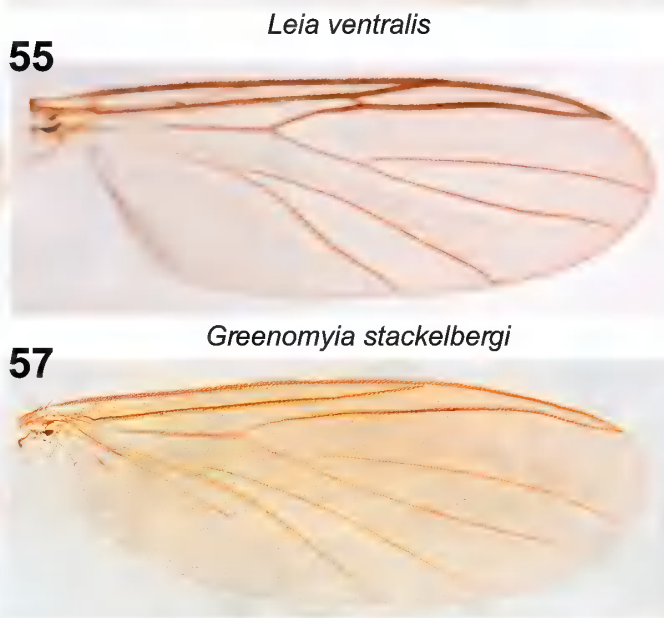

59

Clastobasis alternans
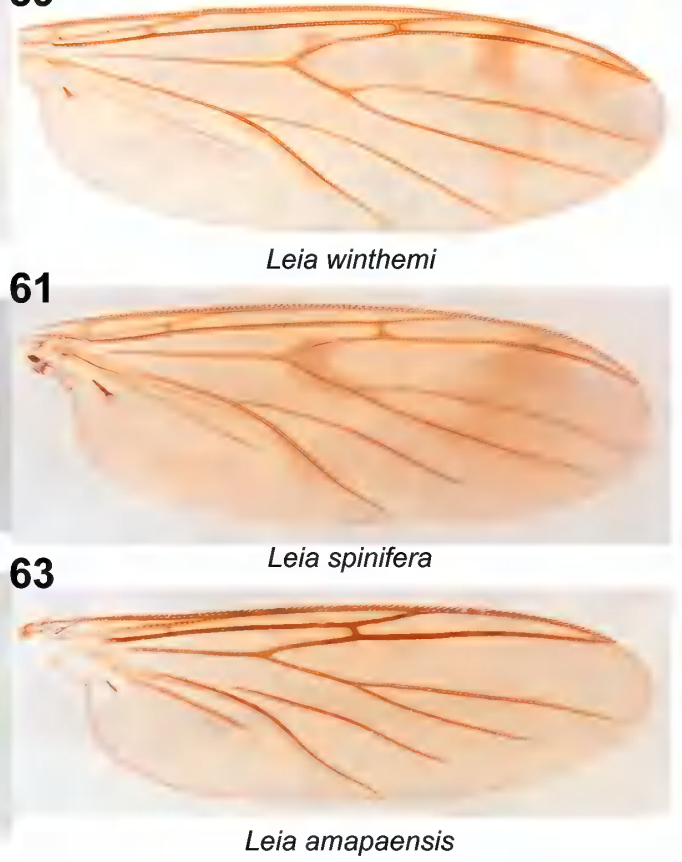

FIGS. 52-63. Wings of Leiinae species of Leiini s.s. 52. Caledonileia pusilla Matile. 53. Leia ventralis Say, with a teratology, M4 missing. 54. Neoclastobasis kamijoi (Sasakawa). 55. Greenomyia stackelbergi Zaitzev. 56. Leia fascipennis Meigen. 57. Clastobasis alternans (Winnertz). 58. Leia arsona Hutson. 59. Leia winthemi Lehmann. 60. Clastobasis vicina Matile. 61. Leia spinifera Edwards. 62. Clastobasis sp. 63. Leia amapaensis Lane. 
Williston and Tetragoneura behave as rogue taxa, either close to the base of the family or nested within the sciophilines. The possible paraphyly of the Gnoristinae and the monophyly of a clade (Mycomyinae + Mycetophilinae) are beyond the scope of this study, but it is interesting that the results here are consistent with Rindal and Søli's (2006) study based on very different matrices. The monophyly of a clade including Mycomyinae, Mycetophilinae, and a paraphyletic Gnoristinae was also found by Kasprák et al. (2019) using molecular data, although their tree has the Mycomyinae as sister of the "Gnoristinae" plus Mycetophilinae. In their study, they sampled two species of manotines that compose a grade at the base of the Mycetophilidae phylogeny.

Kaspř́a et al. (2019) obtained Allactoneura as the sister of Leia Meigen, both comprising together the sister clade of Garretella-these are the only leiines sampled in their study. The position of both manotine species in their tree greatly differs from what was found here with a wider sampling of manotine and nonmanotine leiine genera and of mycetophilids of other subfamilies. Their results also disagree with the phylogeny of the Exechiini (Burdíková et al., 2019) obtained with molecular data, in which, among the outgroups, the sciophilines compose a grade at the base of the mycetophilids, with one species of Manota coming out as sister of a clade including (Rondaniella + Leia) and (Mycomyiinae + Gnoristinae + Mycetophilinae). Finally, the results from Kaspřák et al. (2019) also disagrees from the reconstruction from Ševčík et al. (2013), in which all four manotine genera group in a clade with the remaining sampled leiine genera (1.00 posterior probability). The node with the sciophilines joining gnoristines +mycomyiines in Ševčík et al.s (2013) paper has low support $(0.68$ posterior probability). In that study, as was found here, Ectrepesthoneura, Docosia, and Novakia do not group with the leiines, but with the gnoristine and mycomyiines (no mycetophilines were included in their analysis).

The question of the monophyly of the Leiinae and its position in the system is the core of this paper. Edwards (1925) commented on the similarities between Tetragoneura and Ectrepesthoneura, keeping both genera in the Leiinae. This position was later followed by Hackman et al. (1988), Søli (1997), and Kurina (2004). Tuomikoski (1966) mentioned that both these genera should be excluded from the Leiinae, placing them with Synapha Meigen in the Gnoristinae. Väisänen (1986) placed Tetragoneura and Ectrepesthoneura in the Gnoristinae, but retained Docosia within the Leiinae, a position also held by Bechev (2000). Chandler (1994), Chandler and Blasco-Zumeta (2001), Chandler (2004), and Chandler et al. (2006) kept Novakia and Docosia in the Leiinae, while Chandler (2004) and Chandler et al. (2006) have Tetragoneura and Ectrepesthoneura in the Gnoristinae. In Tozoni's (1998) phylogenetic study of the family, Ectrepesthoneura is the sister group of Novakia, inside a clade also including Tetragoneura, Trichoterga Tonnoir and Edwards, Aphrastomyia Coher and Lane, Thoracotropis Freeman, Impleta Plasmann, and Docosia. Jaschhof and Kallweit (2009) also proposed that Tetragoneura and Novakia (with some other genera) would have gnoristine affinities. The sampling of Gnoristinae genera in this study is relatively small (6 of 29 genera) and the question of the monophyly of the Gnoristinae still needs proper scrutiny.

The position of the Tetragoneura group of genera in the phylogeny of the Mycetophilidae is pending, but not the monophyly of this group nor its position outside the Leiinae. There are several apomorphic features-characters 29:1, 35:1, 63:2, 74:1, 87:1, 93:1-supporting the clade (Docosia + (Novakia + (Ectrepesthoneura + Tetragoneura))), with a Bremer support of 2 . The position of Novakia nested within the group has a Bremer support of 4 and corroborates many views in the literature about its relationships with other genera-in fact, the wing venation of these genera is considerably similar (figs. 18-21). Moreover, several features support that Ectrepesthoneura and Tetragoneura are sister genera.

Regarding the position of this clade in the evolution of mycetophilids, we could not find definite evidence that (Docosia + (Novakia + 
(Ectrepesthoneura + Tetragoneura))) would be sister to the core leiines-although this position cannot be entirely excluded. In none of our trees, however, does this clade nest within the Leiinae. Both the majority consensus (fig. 96) and the strict consensus trees (fig. 97) show these four genera composing a clade in a polytomy with the Leiinae and the clade (Gnoristinae + Mycomyinae + Mycetophilidae). Indeed, one of the possible solutions for this trichotomy is with the clade with Tetragoneura as sister of the remaining leiines, but this is not our conclusion with the currently available data.

This position of the Tetragoneura group raises the problem of its status within the Mycetophilidae. Meunier (1900) proposed a taxon of subfamily rank-Tetragoneurinae-that applies to this clade (see Sabrosky, 1999). On the one hand, if Tetragoneura and related genera collectively correspond to a leiine subclade, we would have to follow Vockeroth (1981), who showed that the name Tetragoneurinae has priority over Leiinae-proposed by Edwards (1925). On the other hand, if this small clade is sister to the Leiinae or sister to a larger clade that includes two or more subfamilies, as appears in our results, it can have subfamily status, separate from the remaining mycetophilid subfamilies, which is the position taken here.

In dealing with the Cycloneura group, Jaschhof and Kallweit (2009) advocated that the problem of the Leiinae is broader and that a proper analysis should encompass additional genera. They stated that the two characters described by Edwards (1925) to delimit the leiines-short $R_{1}$, usually shorter than the length of $r-m$ and a longitudinal $r-m$, aligned with the second sector of Rs-were solid enough to delimit the group for the genera known at Edwards's time, but we now know genera that do not properly fit into this definition. However, Sigmoleia Tonnoir and Edwards (fig. 35), in one hand, has $R_{1}$ longer than $r-m$ and $r-m$ is not aligned to $R_{5}$. On the other hand, an elongate $r-m$ aligned with the second sector of Rs is present in tetragoneurine genera (and in some degree also seen in the Exechiini mycetophilines).
In Jaschhof and Kallweit's (2009) opinion, genera such as Aphrastomyia (fig. 29), Gracilileia Matile (fig. 25), Mohelia Matile (fig. 28), Nova kia (fig. 19), and Tetragoneura (fig. 21) should be excluded from the "Leiini." In most of these genera, Sc generally "ends in R" (not in C)actually, the tip of Sc beyond sc-r is lost, so Sc continues through sc-r to reach $b R$. This feature is typically seen in Gnoristinae (although present elsewhere). Our analysis supports their view on Novakia and Tetragoneura.

The position of Allactoneura (fig. 44) and Sticholeia (fig. 43) deeply nested within the Leiinae (together with the Manotinae) should not at all be a surprise. Edwards's (1925) original placement for Allactoneura was actually as a manotine. Shaw and Shaw (1951) understood that Allactoneura shares similarities with Procycloneura Edwards, especially in the thoracic pleura, assuming leiine affinities for the genus. This position was clearly defended later by Tuomikoski (1966), who considered the genus a member of the Leiinae. Zaitzev's (1982a: 912) revision of Allactoneura indicated that the genus is "sufficiently isolated from representatives of the tribe Leiini both by a whole complex of characters of the imago and of the larva," but concludes that "judging by the figure of the wing venation (Johannsen, 1909) and the structure of the thoracic sclerites (Shaw and Shaw, 1951), the genus Allactoneura is apparently close to the New Zealand genus Cycloneura Marshall." This shows that Zaitzev (1982a) probably had a slightly more restrictive concept of the Leiinae (possibly with Leia and more close allies), but he understood that Allactoneura belongs to a wider leiine arrangement. Matile (1993) accepted Allactoneura as part of the "Leiini s.l."

In Søli's (1997: fig. 45) phylogeny of the Mycetophilidae, obtained with majority consensus, Leia and Rondaniella come out together sister to Allactoneura, the clade with these three genera sister to Eumanota Edwards. This leeine clade is sister to the genera of Mycetophilinae. This led Søli (1997) to reject the "Allactoneurini" as proposed by Väisänen (1986). When Søli (1996: 4) 
described Sticholeia, he specifically assigned the genus to the Leiinae, mentioning that "the combination of strong, recurved bristles behind the eyes and a regular arrangement of the tibial trichia makes Sticholeia key out as Eumanota (subfamily Manotinae) in most available keys." He also stated that Sticholeia has "a combination of characters found in members of the subfamily Manotinae and in Allactoneura de Meijere, 1907, and some other genera in the tribe Leiini [s.l.]." Søli (1996: 10) added further ahead, "like Allactoneura and Leiella, Sticholeia has a very short stem of the median fork and a costa not produced beyond the tip of $\mathrm{R}_{4+5}$. In Allactoneura and Leiella, the abdomen is densely clothed by scalelike setae, a character not present in other groups of mycetophilids. Available evidence thus suggests that Sticholeia is the sister group of Allactoneura and Leiella Enderlein combined."

Jaschhof and Kallweit (2009) extensively discussed features shared by Allactoneura and Sticholeia with other leiines (especially Leiella and Procycloneura), and considered Allactoneura "properly placed" within the leiines. Finally, in Ševčík et al.s (2013) molecular phylogeny of mycetophilids, dealing with a limited taxon sampling, the Manotinae are sister to a clade with species of Leiinae (including only Leia and Clastobasis Skuse) mixed with Allactoneura and Sticholeia-mycomyines and mycetophilines were not part of the analysis.

We consistently found a clade in which Sticholeia is sister to (Allactoneura + (Manotinae)) deeply nested within the Leiinae. A similar conclusion emerges from Hippa et al's (2005) study, as considered below. Apparently, the distinctiveness of Manota and Allactoneura is the main reason for these two genera to have been placed in a separate subfamily. The consequence, however, was that, accepting Manotinae and Allactoneurinae as separate subfamilies, plesiomorphies had inevitably to be used as diagnostic features for the Leiinae, corresponding to a paraphyletic leiine.

Manota is at the core of this discussion. The wing venation of the genus is rather highly mod- ified compared to other mycetophilids (fig. 45), while the other three manotine generaEumanota, Promanota Tuomikoski, and Para manota Tuomikoski (respectively figs. 47, 46, and 48) - are much less derived. Edwards (1933) and later Ševčík et al. (2013) clearly stressed that Eumanota forms "a transition between Manotinae and Leiinae" (Ševčík et al., 2013: 4). Hippa et al.'s (2005) analysis established the relationships among the genera of Manotinae. Their sampling of nonleiine genera was intended to root their analysis of the phylogeny of the Manotinae, not to recover the position of the manotines within the mycetophilids. Our analysis recovers exactly the same results for the relationships among the manotine genera obtained by Hippa et al. (2005), but it is conceivable that Promanota could be sister to Manota. In their analysis, Procycloneura is sister to the "Manotinae," while the other sampled leiine genera fit in two other clades. One of these clades has Ectrepesthoneura, Aphrastomyia, and Mohelia in a clade sister to (Procycloneura + Manotinae). The other clade has Mycetophila as sister to a clade with leiines including Leiella and Rondaniella together sister of (Leia + Greenomyia Brunetti) and (Allactoneura + Sticholeia).

In our results, the clade including allactoneurines and manotines, as mentioned above, is deeply nested within the Leiinae. This appears consistently in trees obtained with all weighting schemes. The lack in the literature of a formal phylogenetic analysis of the Leiinae with wide taxon sampling and a proper selection of outgroups is probably behind the decision of many authors to keep the Allactoneurinae and the Manotinae separate from the Leiinae, despite evidence of the leiine-manotine-allactoneurine connection. We here ranked the clade of allactoneurines and manotines as a tribe within Leiinae.

Matile (1978) referred to groups of genera that could be excluded from the Leiini s.l., mentioning Allactoneura, the Cycloneura group, and the Tetragoneura group. These are indeed some of the groups that appear as major clades in our tree. Matile (1978) recognized different mono- 
phyletic groups of genera visualizing "leiines" as a much smaller, core clade-Leia, Clastobasis, Greenomyia, and Neoclastobasis Ostroverchovaseparate from the remaining groups.

\section{Monophyly of the Leinnae}

The monophyly of a Leiinae clade-including the genera of the allactoneurines and manotines, and excluding genera of tetragoneurines-is undisputed in our analysis. The monophyly of this group is recovered under all weighting schemes (figs. 96-99, 101). A feature traditionally used to define the Leiinae-the displacement of the base of the radial sector (Rs) distally in the wing, shortening $R_{1}$ (char. 88:2 or 3)-is present in most but not all genera of Leiinae. The obvious plesiomorphic condition in mycetophilids for this character, consistently seen in all other subfamilies, is a long $\mathrm{R}_{1}$, more than three times longer than $\mathrm{r}-\mathrm{m}$. This condition is present within the Leiinae only in Sigmoleia. This condition in Sigmoleia seems more a result of a secondary reduction in the length of $\mathrm{r}-\mathrm{m}$ than to the presence of a "long $R_{1}$ " States 1,2 , or 3 of character 88 are also present in the genera of Tetragoneurinae. This is probably one of the reasons for these genera to have been seen in part of the literature as leiines-together with $\mathrm{r}-\mathrm{m}$ aligned to the second sector of Rs. Within the Leiinae, the condition 1 of character 88 is known in Thoracothropis (fig. 24), Megophthalmidia Dziedzicki (fig. 27), Paracycloneura Tonnoir and Edwards (fig. 30), Indoleia Edwards (fig. 31), Rondaniella (fig. 32), Cawthronia Tonnoir and Edwards (fig. 34), Allactoneura (fig. 44), and Caledonileia Matile (fig. 52). This means that the conditions 2 and 3 originated more than once even within the evolution of the Leiinae.

As was discussed above, on one hand, Thoracotropis, Trichoterga, and Paracycloneura behave as rogue genera in our analysis-their present position in the tree is still not fully reliable-and their relatively long $\mathrm{R}_{1}$ could be truly plesiomorphic. A relatively long $\mathrm{R}_{1}$ in Megophthalmidia, Indoleia, Rondaniella, Cawthronia, Allactoneura, and Caledonileia, on the other hand, may be either the consequence of a secondary extension of $R_{1}$ or a secondary reduction of the length of $\mathrm{r}-\mathrm{m}$. These are, as suggested by Jaschhof and Kallweit (2009), cases of secondary changes in the wing venation in the Leiinae.

There are five synapomorphies for the Leiinae in our tree (14:0, 50:2, 55:1, 62:1, and 101:2), two of which are uniquely derived for the subfamily-the ventral region of the mesepimeron ending at level of the mesopleurotrochantin (50:2) and the mesopleurotrochantin visible laterally (55:1) (fig. 102). The mesopleurotrochantin is a feature seen in some nematocerous families, but they are often much smaller than the condition in the Leiinae. A bauplan of the Diptera thorax is presented by Matile (1990: 40, fig. 18) and the Leiinae thorax pattern is in Oliveira and Amorim (2012: 6, fig. 2). The condition of the pleurotrochantin in the leiines is certainly secondary, i.e., apomorphic. It is worth noting that some apomorphic features present in some leiine genera and in other mycetophilids may have brought confusion. This includes, for example, the long bristle at the apical posterior margin of the antenna pedicel (17:1), the katepisternum with a posterior angle that fits into the mesepimeron (62:1), C ending at level of tip of $R_{5}$ (82:1), a long $\mathrm{r}-\mathrm{m}$ (96:2), and an elongated $\mathrm{M}_{1+2}$ (101:2).

Our analysis also shows that most decisions made in the literature concerning generic status given to leiines were well founded. With only two clear exceptions, leiine genera proposed in the literature correspond to clades, not to specialized subclades (that received generic rank) inside other taxa also of generic rank, rendering the latter paraphyletic. There are plenty of examples. Garretella Vockeroth is a Nearctic representative that shows up sister to Paraleia Tonnoir, known from Australia and South America. Mohelia is an Afrotropical genus sister to the Neotropical Aphrastomyia. Waipapamyia Jaschhof and Kallweit, from New Zealand, proposed as a separate genus by Jaschhof and Kallweit (2009), is sister to the set of the remainder genera of the Cycloneura Marshall group from 
the Australasian and Neotropical regions. Hence, in terms of the monophyly of genera, most leiines are very well delimited and were shown to be monophyletic. The only two problems, discussed in more detail ahead, concern Leia and Clastobasis. Leia, as delimited today, is paraphyletic in relation to Neoclastobasis, Greenomyia, and Clastobasis, while Clastobasis is itself polyphyletic, intertwined among the species of Leia.

\section{Rogue Genera}

Larger clades within the Leiinae in our analysis have good support, and their position and composition are stable under different weighting schemes. There are still four genera (figs. 102103), however, which position in the tree changes depending on the weighting scheme-Thoracothropis (fig. 24), Gracilileia (fig. 25), Trichoterga (fig. 26), and Paracycloneura (fig. 30). We want to make this particularly clear, keeping these genera unplaced in the tribal system proposed for the subfamily. The problem of the position of these genera in our analysis is not due to missing data in the matrix. More probably there is an issue of a limited character sampling at these particular levels of the tree.

Thoracothropis is a monotypic genus known only from Chile (Freeman, 1951), more recently redescribed in detail (Oliveira et al., 2012) (fig. 24). The genus is indeed plesiomorphic for many features that characterize higher leiine clades. As mentioned above, Tozoni (1998) found Thoracotropis in the Gnoristinae. It could be the case that a wider sampling of gnoristine genera could move Thoracotropis out of the leiines. Gracileia is a genus endemic to New Caledonia, presently known from five species (Matile, 1993) (fig. 25). In our phylogeny this genus is sister to the clade Trichoterga ${ }^{+}$. Matile (1993) considered the similarities of Gracilileia with Tetragoneura (although the short, incomplete Sc directed toward bR in Gracilileia is similar to what is seen in some Manotini, see ahead). It is possible that Gracilileia indeed belongs in the Tetragoneurinae. Trichoterga is known only from New Zealand (Tonnoir and Edwards, 1927) and has a single species described (and some additional known undescribed species in collections). The genus is definitely not a typical higher leiine and its position more or less close to the base of the Leiinae should not be surprising. Jaschhof and Kallweit (2009) assumed that the genus very probably belong in the Leiinae. Finally, Paracycloneura has two described species from New Zealand-one described by Tonnoir and Edwards (1927) and one described more recently by Jaschhof and Kallweit (2009). The genus is actually quite apomorphic for some features and in our tree Paracycloneura is sister to the Rondaniellini ${ }^{+}$. Many of the features mentioned by Jaschhof and Kallweit (2009) shared among the genera of their Cycloneura group are absent in Paracycloneura. It could be the case that the genus is a Cycloneurini, but it would probably be necessary to have some more characters in the analysis to solve the question.

\section{The Backbone of the Leinnae Phylogeny}

If we remove the rogue taxa-Thoracotropis, Gracilileia, Trichoterga, and Paracycloneurafrom the majority consensus tree, the main nodes of the backbone of the Leiinae phylogeny are the clades Megophthalmidiini', Rondaniellini $^{+}$, Cycloneurini $^{+}$, Manotini ${ }^{+}$, and Anomalomyiini $^{+}$, with the Selkirkiini sister of the remainder of the subfamily (figs. 99, 101-105). When these genera are removed from the tree, characters of the nodes below and above each genus are brought together as synapomorphies of the same node. This increases the number of characters, e.g., for the Megophthalmidiini ${ }^{+}$and for the Rondaneillini ${ }^{+}$- but does not change the picture for the Cycloneurini ${ }^{+}$, the Manotini ${ }^{+}$, or the Anomalomyiini ${ }^{+}$.

The sequence of clades diverging along the backbone of the Leiinae does not particularly contradict the informal knowledge (i.e., not 
derived from a formal numerical analysis) about the group in the literature. The Selkirkiini is one of the least understood and least known groups of leiines. Restricted to a single Nearctic species and a clade with one species in Australia and a speciose clade in temperate South America, the Selkirkiini is sister to the clade with the set of other Leiinae groups in all trees recovered. The next clade is Megophthalmidiini (fig. 103). They are definitely not "core leiines" in their appearance, which may have been the reason for them to be moved in and out of the Leiinae by different authors. The following clade is Rondaniellini, which looks slightly more typical of higher leiines (fig. 103). The strict consensus has Rondaniellini, Cycloneurini, and (Manotini + Anomalomyiini + Leiini s.s.) in a polytomy. The Cycloneurini appears next (fig. 104), as sister of (Manotini + Anomalomyiini + Leiini s.s.). Finally, there is good support for the Manotini (fig. 105) to be sister to a clade including Anomalomyiini and Leiini (fig. 106).

Unique to the Megophthalmidiini ${ }^{+}$is the displacement of the foramen magnum (char. 2:1), a feature with a single origin in Leiinae evolution, and a secondary loss in the group Sticholeia ${ }^{+}=$ Manotini except Leiella) and in the clade (Neoclastobasis + Greenomyia). Another interesting feature is the flattened hind femur (char. 71). This feature is part of what may be referred to as the "leiine look." The first apomorphic condition of this character is shared by all members of the group Megophthalmidiini ${ }^{+}$and Gracilileia (with some secondary losses), with a further change to "strongly flattened" in some subgroups.

\section{A Tribal Rank System for the Leinnae}

We present below the clades in our tree to which we attribute tribal rank. Diagnoses are provided for each group, as well as their generic composition, geographical distribution, and a discussion of the relationships among their genera. Four of the seven clades accepted here as tribes already had tribal status given before in the literature.

\section{Selkirkiini Enderlein}

Selkirkiini Enderlein, 1940: 670.

Type Genus: Selkirkius Enderlein (= junior synonym of Paraleia Tonnoir).

GENERA INCLUded: Garretella (figs. 22, 64) and Paraleia (figs. 23, 65).

Diagnosis: Three ocelli arranged in line, no interocellar setae present. Clypeus not projecting beyond the gena. Sc complete, ending at $\mathrm{C}$, sc-r present; $\mathrm{R}_{1}$ short, $\mathrm{r}-\mathrm{m}$ almost longitudinal; basal sector of Rs transverse, almost at distal third of wing; second sector of Rs well separated from anterior wing margin, originating very distal. Gonocoxites projecting well beyond base of gonostylus, strong spines present on gonocoxites and on gonostylus.

Selkirkius is a junior synonym of Paraleia, but the tribe name remains valid. Paraleia was described by Tonnoir (1929) for Paraleia fulvescens, from Australia. Later, 17 additional Neotropical species were gradually added to the genus by different authors (see Oliveira and Amorim, 2014). Garretella was erected by Vockeroth (1980) for Leia shermanni Garrett due to important differences he found between this and other species of Leia. While the distribution of Paraleia corresponds to an amphinotic track (see Cranston, 2005), Garretella occurs in slightly higher latitudes in the western Nearctic region, from California to British Columbia. Garretella has macrotrichia on the posterior half of the wing membrane, but Vockeroth (1980: 540) did not consider any connection of the genus to the Sciophilinae. Quite surprisingly, the similarities between Garretella and Paraleia went unnoticed in the literature. Our results corrobotate Vockeroth's (1980) conclusion that a taxon of generic rank was needed for Leia shermanni. There are apomorphies shared by both genera in the morphology of the head, thorax, and wing. The conspicuous differences 


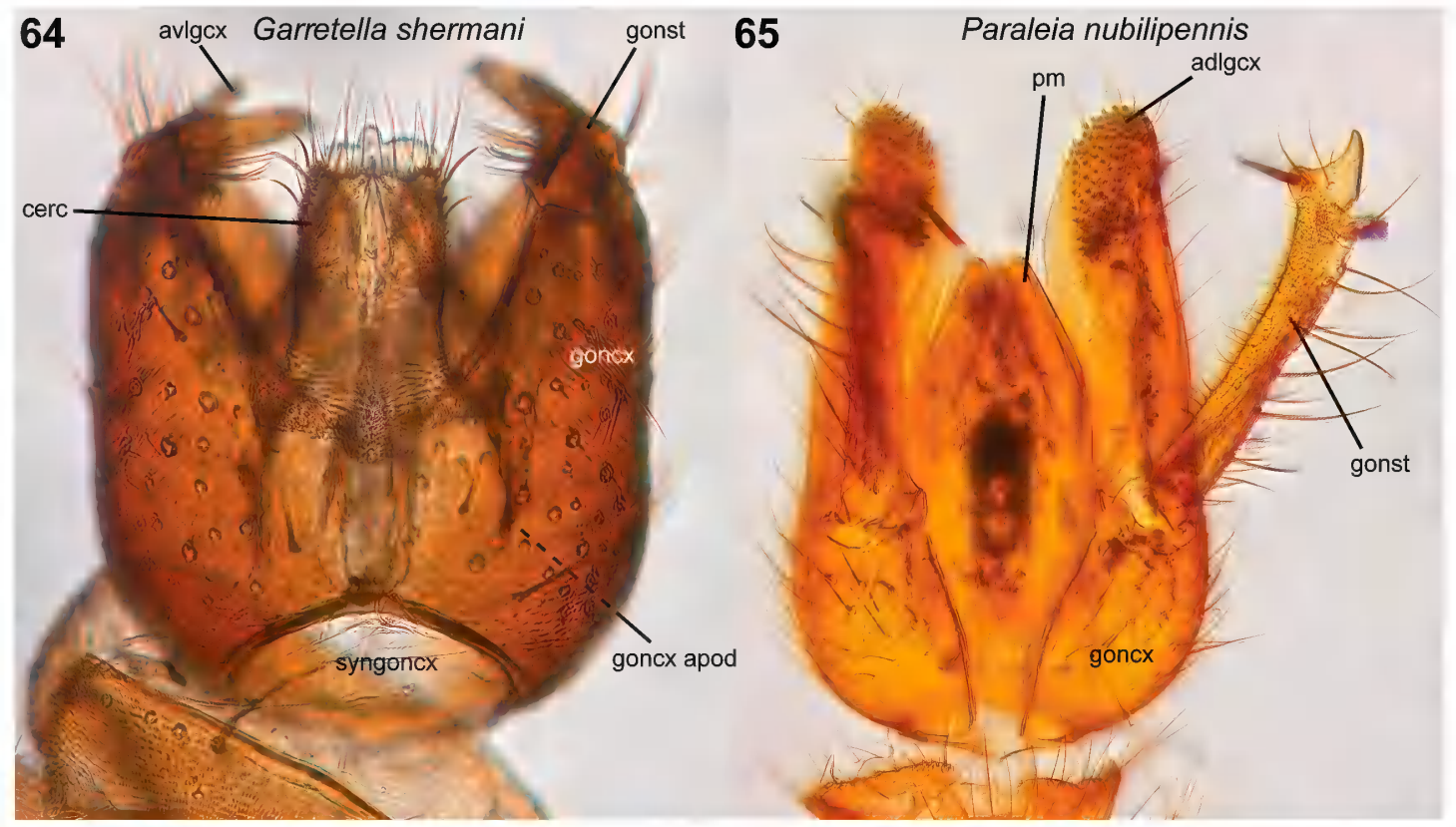

FIGS. 64-65. Male terminalia of Leiinae Selkirkiini genera. 64. Garretella shermani (Garret), dorsal view. 65. Paraleia nubilipennis (Walker), ventral view.

in the male terminalia, mainly in the shape and extent of the gonostylus, justify the generic status proposed by Vockeroth (1980).

\section{Megophthalmidiini, trib. nov.}

Type Genus: Megophthalmidia Dziedzicki.

Genera inCluded: Megophthalmidia (figs. 27, 67), Mohelia (figs. 28, 68), and Aphrastomyia (figs. 29, 69).

DiAGNosis: Male antenna as long as or shorter than head and thorax together. Mouthparts at least slightly elongate, forming a short proboscis. Foreleg about half the length of mid- and hindlegs; forefemur flattened anteroposteriorly; hind tibia distally with a posterior row of stronger setae regularly arranged. Sc short, incomplete, inclined toward $\mathrm{R}$ but ending free; $\mathrm{R}_{1}$ short, curved toward wing margin. Male terminalia flexed in relation to abdomen.

A close relationship among Megophthalmidia, Aphrastomyia, and Mohelia was recognized by Matile (1978). Megophthalmidia is known from the
Neotropical, Nearctic, and Palearctic regions (see Kerr, 2014), with undescribed species known from the Oriental region and New Zealand. Aphrastomyia is a genus endemic from the Neotropics, with 11 described species (Oliveira and Amorim, 2014), and Mohelia is a genus endemic to the Afrotropics, with four known species (Oliveira, 2015). Matile (1978) and Jaschhof and Kallweit (2004) assumed that Aphrastomyia and Mohelia would be sister genera, whereas Jaschhof and Kallweit (2009) proposed that Aphrastomyia and Mohelia should be removed from the Leiinae, keeping Megophthalmidia in the subfamily. Kerr (2014), in a paper on the North American Megophthalmidia, while referring to the views in the literature, seems to support a leiine affinity of this group of genera.

Our analysis indicates that these three genera together compose a monophyletic group and that the clade is well nested within the Leiinae. There are 13 synapomorphies that support the monophyly of the tribe, of which eight have independent origins within the leiines and five are uniquely derived in the Megophthalmidiini. 


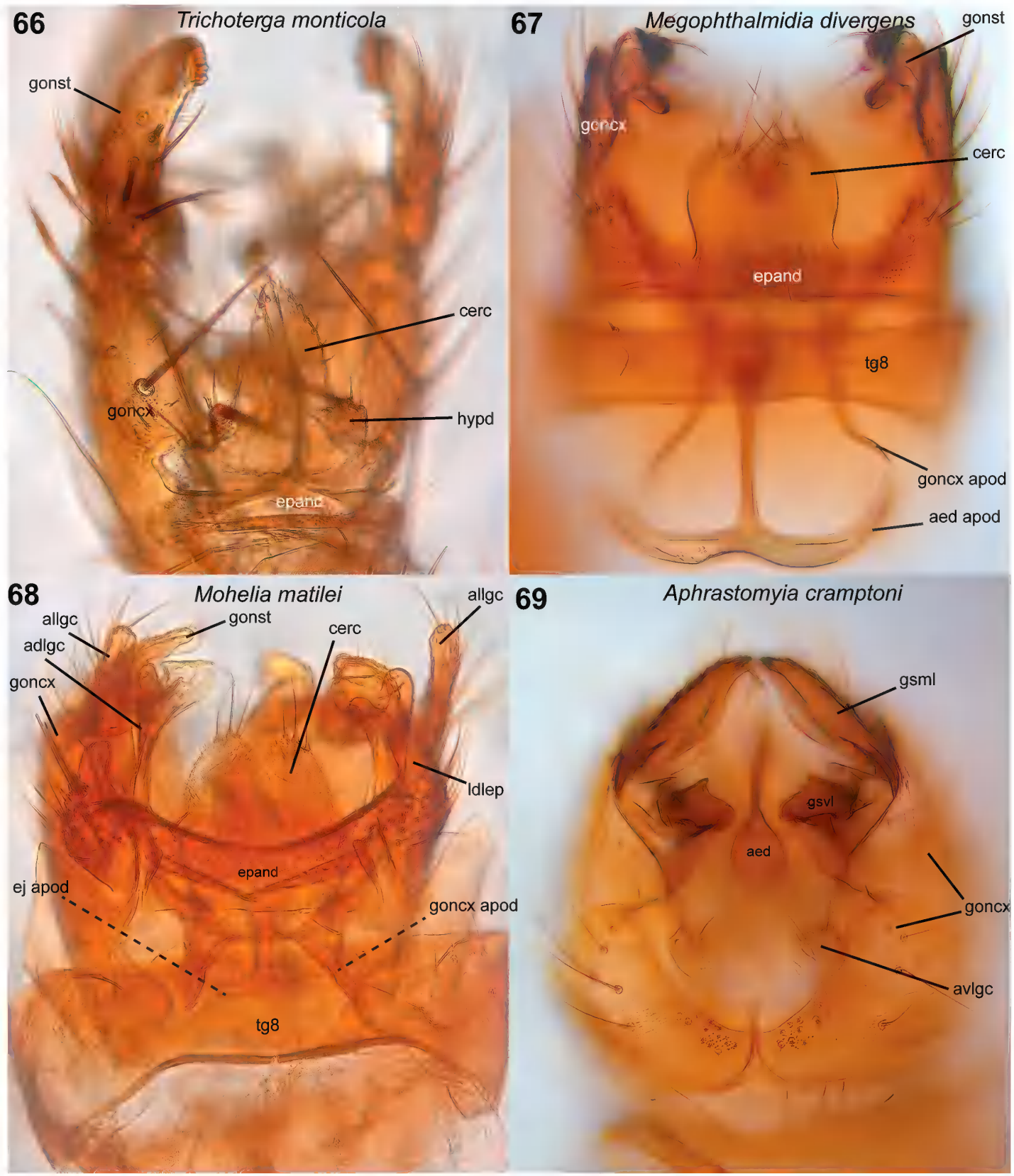

FIGS. 66-69. Male terminalia of Trichoterga and of Megophthalmidiini genera. 66. Trichoterga monticola Tonnoir, dorsal view. 67. Megophthalmidia divergens Edwards, dorsal view. 68. Mohelia matilei Oliveira, dorsal view. 69. Aphrastomyia cramptoni Coher and Lane, ventral view. 


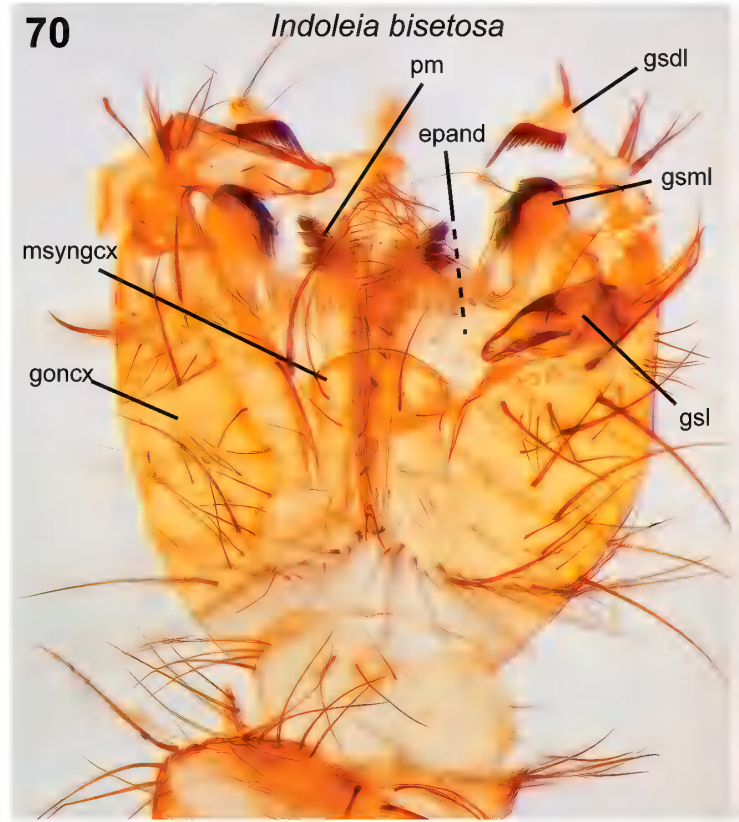

FIGS. 70-71. Male terminalia of Rondaniellini genera. 70. Indoleia bisetosa Edwards, ventral view. 71. Rondaniella dimidiata (Meigen), ventral view.

There are no exclusive apomorphic features bringing together Mohelia and Aphrastomyia and the clade is supported by four apomorphic features that also appear elsewhere.

Rondaniellini, trib. nov.

TyPE GENUS: Rondaniella Johannsen.

Genera InCluded: Indoleia (figs. 31, 70) and Rondaniella (figs. 32, 71).

DiAgNosis: Antennal flagellomeres slightly longer than wide; third palpomere slightly elongated. Sc setose. $\mathrm{R}_{1}$ relatively long, quite longer than $\mathrm{r}-\mathrm{m} ; \mathrm{M}_{1+2}$ about as long as medial fork; first sector of $\mathrm{CuA}$ (from wing base to fork) short, $\mathrm{M}_{4}$ originating well before basal tip of $\mathrm{r}-\mathrm{m}$; $\mathrm{CuP}$ sinuose, curved posteriorly after level of origin of $\mathrm{M}_{4}$.

Rondaniella is a small genus, known until quite recently from one European species that supposedly also occurs in the United States and Mexico (Vockeroth, 1981, 2009; Søli et al., 2000; Oliveira and Amorim, 2014), one species from

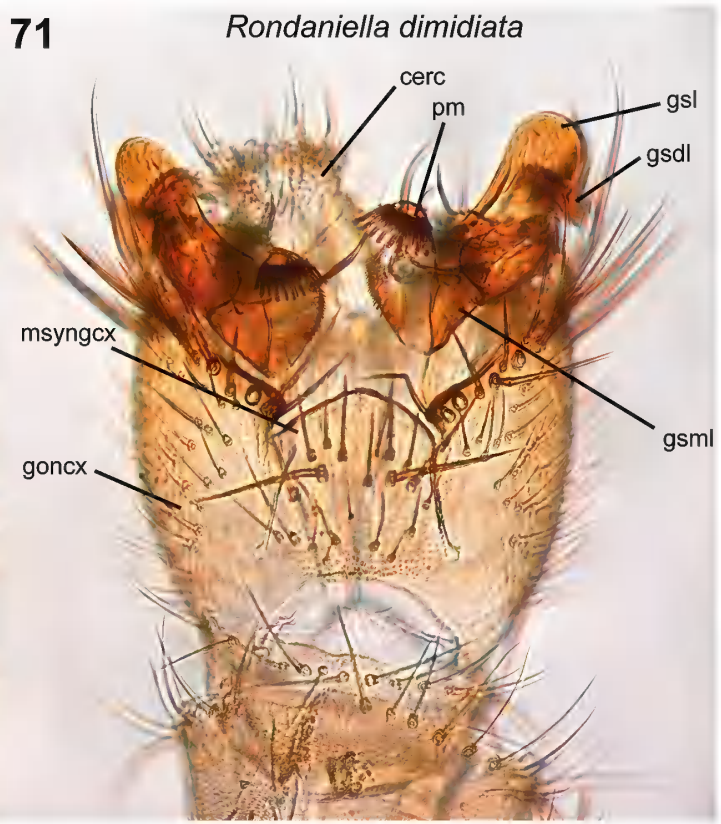
Java (Edwards, 1932), and one species from Japan (Matsumura, 1915; Okada, 1939), besides one Baltic amber species (Loew, 1850). The genus now includes 11 species, with additional seven species described from China (Yu et al., 2004, 2008; $\mathrm{Yu}$ and $\mathrm{Wu}, 2009)$. The genus was originally proposed by Johannsen (1909) for Winnertz's (1863) concept of Leia (see Edwards, 1925). Indoleia is a genus even more restricted in distribution, originally described by Edwards (1928) as a subgenus of Leia based on a species collected in Malaysia (Pahang) and Indonesia (Java). A second species described in Leia by de Meijere (1913) from the Maluku Islands was transferred to Indoleia by Matile (1989). Interestingly, Edwards (1928: 7) had already clear that Indoleia "is obviously related to Rondaniella, though differing in having $\mathrm{M}_{1}$ complete."

The clade with these two genera is recovered only in the majority consensus tree (sister to a clade with all Leiinae tribes except Selkirkiini and Megophthalmidiini). The alternative trees have Indoleia in a polytomy with Rondaniella 
and a clade with the higher leiines. Nevertheless, there is additional evidence that they compose a clade. The male terminalia of both genera correspond to a shared pattern (see above). Edwards's (1928) comments, as mentioned above, suggest evidence that both genera come together. There is no evidence suggesting any alternative tree in which Rondaniella or Indoleia fit any other clade with tribal rank in the Leiinae.

\section{Cycloneurini Shaw and Shaw}

Cycloneurini Shaw and Shaw, 1951: 3, 15.

Type genus: Cycloneura Marshall.

Genera included: Waipapamyia (fig. 33), Cawthronia (fig. 34), Sigmoleia (fig. 35), Paradoxa Marshall (figs. 36, 37), Cycloneura (fig. 38), Tonnwardsia Jaschhof and Kallweit (figs. 39, 72), and Procycloneura (figs. 40, 73-75).

Diagnosis: Last antennal flagellomere with a pair longer setae (except Sigmoleia). Laterotergite bare (except for Sigmoleia). Forefemur flattened anteroposteriorly. $\mathrm{R}_{1}$ shorter than $\mathrm{r}-\mathrm{m}$; first sector of Rs transverse; CuA sinuose, in some genera with $\mathrm{CuP}$ fusing to it, forming a secondarily closed cell.

The genera included in this tribe are known mostly from New Zealand. A thorough review of the Cycloneura group was published by Jaschhof and Kallweit (2009), with descriptions and redescriptions of species, illustrations, redescription of known genera, and description of two new genera. Waipapamyia is known from three species and Tonnwardsia from one species. Cawthronia, described by Tonnoir and Edwards (1927), is monotypic. Paradoxa has one species known from New Zealand (Marshall, 1896) and another from South Africa (Jaschhof, 2006). Cycloneura is known from two New Zealand species-with known additional undescribed species indicated by Jaschhof and Kallweit (2009) - whereas Sigmoleia has four species described from New Zealand and two from New Caledonia (Matile, 1993). Procycloneura has four species, described from southern
Chile and Argentina, Peru, and southern Brazil, but there is a large number of undescribed species from southern Brazil and Colombia (Oliveira and Amorim, in prep.).

The Cycloneura group of Jaschhof and Kallweit (2009)-a group to which tribal rank was earlier given by Shaw and Shaw (1951) - was largely supported in our analysis except for the inclusion of Paracycloneura. In our results, this genus is persistently excluded from the clade. The Neotropical genus Procycloneura was not included in Jaschhof and Kallweit's (2009) review, but they mentioned a number of features of the Cycloneura group that are clearly shared by the Neotropical genus. Jaschhof and Kallweit (2009) referred to two additional undescribed Cycloneura-like leiines in Australia that may correspond to taxa of generic rank in the group, and we are also aware of one new genus of the clade from the Colombian Andes. One important feature justifying the delimitation we make here of the Cycloneurini is the pair of longer bristles on the last antennal flagellomere (char. 21:1), a feature absent in Paracycloneura (but present in Leiella). The monophyly of the Cycloneurini has good support, with a Bremer index $=3$. The relationships among the genera within the tribe, however, should be considered carefully and a larger taxon sampling of species within the genera is desirable. Nodes grouping the genera of Cycloneurini still have low support and additional input is necessary.

\section{Manotini Edwards}

Manotini Edwards, 1925: 509, 544.

Type Genus: Manota Williston.

Genera included: Leiella (figs. 41-42, 76-77), Sticholeia (fig. 43), Allactoneura (figs. 44, 78-79), Manota (fig. 45), Eumanota (figs. 47, 80-81), Promanota (fig. 46), and Paramanota (fig. 48).

DiAGNOSIs: Thorax strongly depressed dorsoventrally. Proepimeron connected to ventralposterior end of pronotum along almost its entire extension; dorsoposterior angle of katepi- 

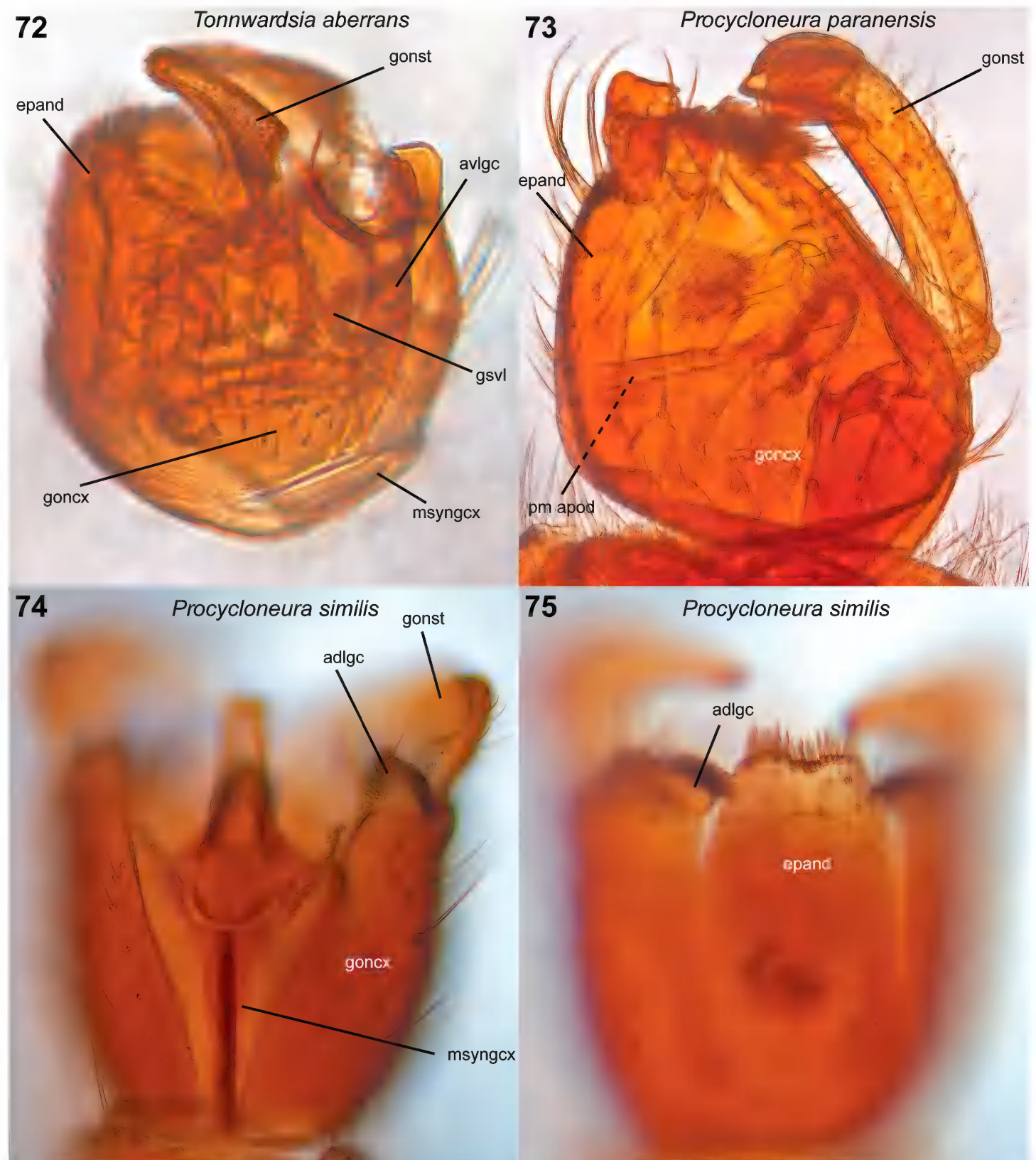

75

Procycloneura similis

FIGS. 72-75. Male terminalia of Cycloneurini genera. 72. Tonnwardsia aberrans (Tonnoir), lateral view. 73. Procycloneura paranensis Edwards, lateral view. 74. Procycloneura similis Freeman, ventral view. 75. Procycloneura similis Freeman, dorsal view. 


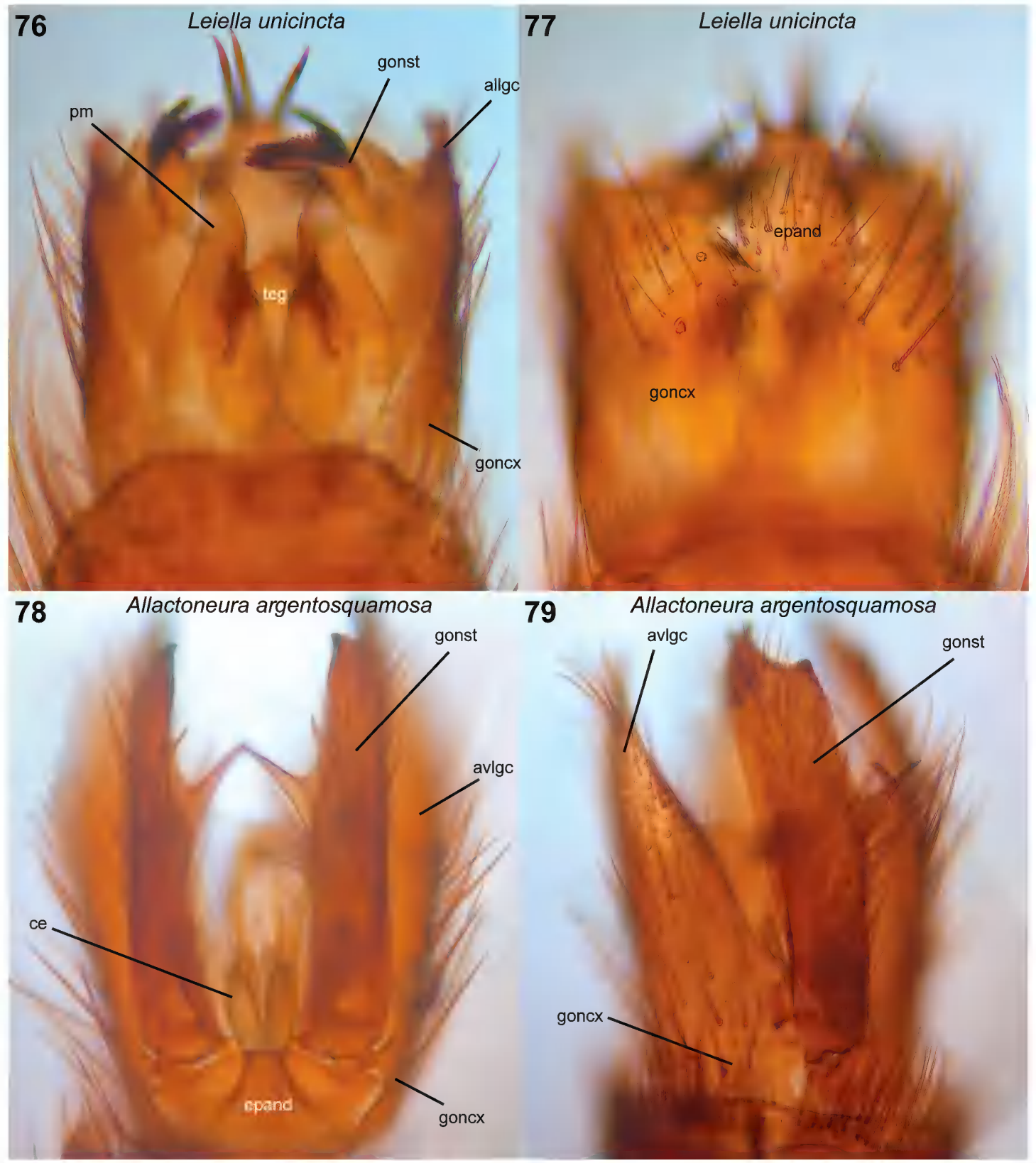

FIGS. 76-79. Male terminalia of Manotini genera. 76. Leiella unicincta Edwards, ventral view. 77. Leiella unicincta Edwards, dorsal view. 78. Allactoneura argentosquamosa (Enderlein), dorsal view. 79. Allactoneura argentosquamosa (Enderlein), ventral view. 
sternum with a groove where the anteroventral end of mesepimeron fits. Apex of fore- and midcoxae with long bristles regularly distributed. $\mathrm{M}_{4}$ basally disconnected from CuA (except in Manota),

Leiella is known from 10 Recent Neotropical species. They are known from southern temperate (e.g., Osorno, in southern Chile), but also nontemperate areas in the Neotropics (as Panama and Costa Rica), and from Dominican amber (Oliveira and Amorim, 2014). Sticholeia is known from three species, one from the Vanuatu Archipelago, one from Papua New Guinea and Indonesia (New Guinea) (Søli, 1996), and one from the Maluku Islands (Søli, 2002a). Allactoneura is known from seven recent species-East Africa, Madagascar, the Seychelle Islands, Mauritius, large portions of the Oriental region (including Taiwan), and parts of the Australasian-Oceanian region, including Salawati, Sulawesi, the Solomons, northern Queensland in Australia, Sula, and Buru (Zaitzev, 1982a; Bechev, 1995)-and a remarkable species from the France Oligocene (Théobald, 1937). Promanota and Paramanota are exclusively Oriental. Eumanota is also basically Oriental, with one species in the Molucca Islands (Søli, 2002b), one in Papua New Guinea (Papp, 2004), and one species recently described from the high Andean forests in Colombia (Amorim et al., 2018). Finally, Manota is almost worldwide in distribution, although more species rich in tropical areas, currently comprising over 300 described species (Kurina et al., 2018, 2019).

We discussed extensively above the question of the position of this clade within the Leiinae. This analysis leaves no doubt about the monophyly of the clade that groups the two allactoneurine genera and the group (Manota + Eumanota + Paramanota + Promanota). Our analysis also endorses the relationship of Leiella with the allactoneurine/manotine clade proposed in the literature. The relationships among the four genera of Manotinae proposed by Hippa et al. (2005) is corroborated here.
Discussing the relationships of the Manotinae with other mycetophilids, Søli (2002b: 52) stated that "the row of strong bristles bordering the back of the head and, to a certain extent, the regular arrangement of the tibial and tarsal trichia are probably less unique [to Eumanota and Manota]. Sticholeia Soli, 1996 has both, and seems to confirm the close relationship between "Manotinae" and the tribe Leiini. Interestingly, Sticholeia also has an outline of basisternum 1 quite similar to that in Eumanota." Jaschhof and Kallweit (2009) stated that Leiella would be a typical Leiinae, not related to the Cycloneura group, but sister to Allactoneura. The concept of "Allactoneurinae" means that Sticholeia and Allactoneura would come together in a clade, but we found Allactoneura closer to the higher manotines. Indeed, the basal part of the wing in Allactoneura, at the connection of $\mathrm{bM}$ to $\mathrm{Cu}$, show changes also seen in the higher manotines, while Sticholeia seems more plesiomorphic, similar to the condition seen in Leiella.

Anomalomyiini, trib. nov.

Type genus: Anomalomyia Hutton.

Genera included: Anomalomyia Hutton (fig. 49), Ateleia Skuse (figs. 50, 82), and Acrodicrania Skuse (figs. 51, 83).

DiAGNosis: Occipital foramen displaced dorsally; three ocelli arranged in line; pedicel with long posterior bristle apically. Hind femur slightly flattened anteroposteriorly. Microtrichia distinctly arranged in regular rows on wing membrane; medial fork short, $\mathrm{M}_{1+2}$ length 0.5 1.0 medial fork length.

Anomalomyia has 14 known species, 10 from New Zealand described by Tonnoir and Edwards (1927) and four from New Caledonia described by Matile (1993). There is nearly nothing in the literature about Ateleia, a genus with a single species described from Australia (Skuse, 1888). Acrodicrania has four species described from Australia (Skuse, 1890), with one additional species described by Edwards (1925) from South Africa, and three Oriental species (Brunetti, 

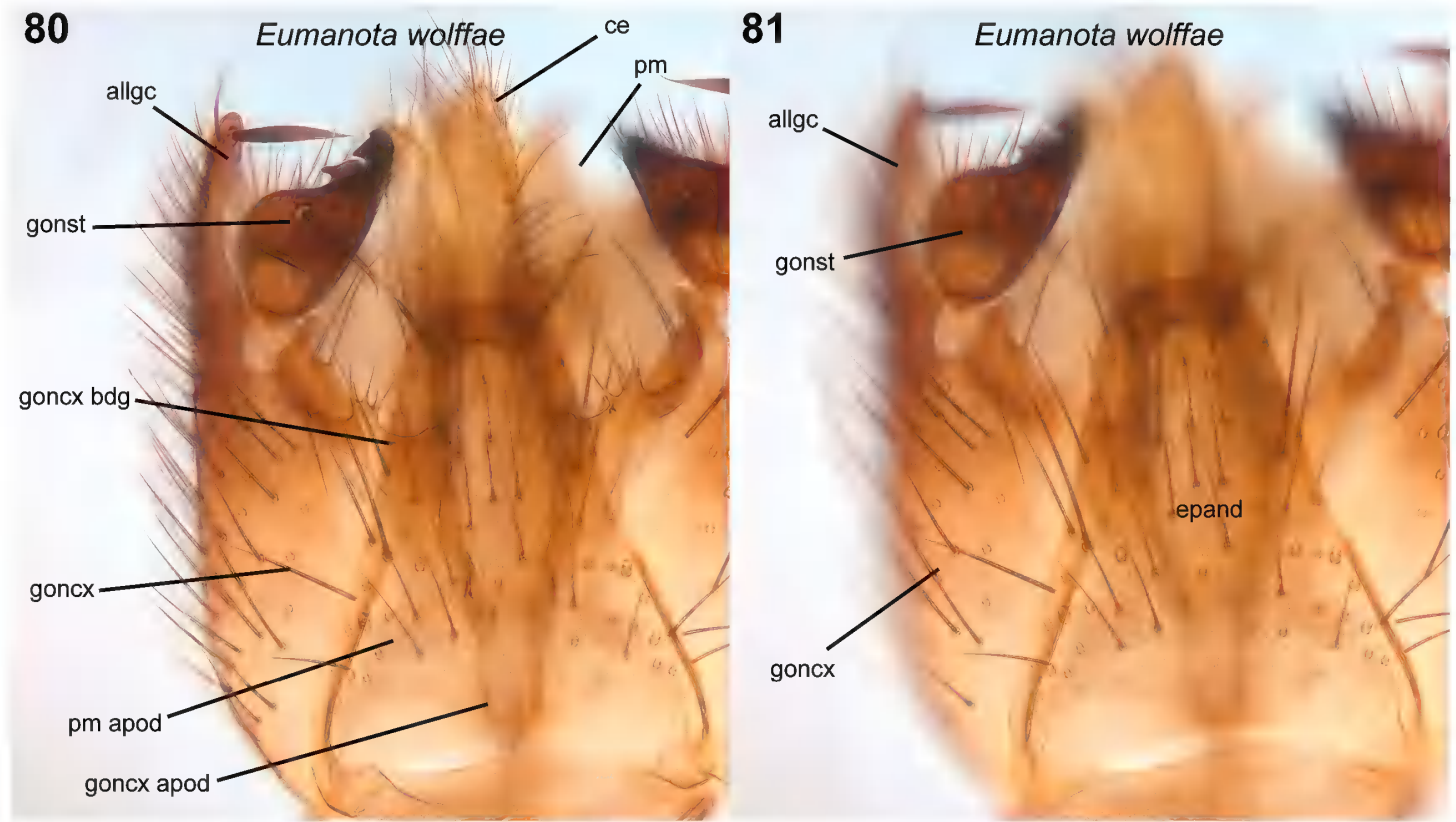

FIGS. 80-81. Male terminalia of Manotini, Eumanota wolffae Amorim, Oliveira, and Henao-Sepúlveda. 80. Ventral view. 81. Dorsal view.

1912; Edwards, 1928). The support of the clade with these three genera is not high and the clade is not present in the strict consensus-which has, instead, Anomalomyia in a polytomy with the clade Ateleia $a^{+}$and the Leiini s.s. Tonnoir and Edwards (1927) already mentioned that Anomalomyia would be closely related to Acrodicrania. The proximity of Ateleia and Anomalomyia, Acrodicrania and Leia (a group that in large extent corresponds to the clade Anomalomyiini ${ }^{+}$) was already proposed by Marshall (1896) - although he added the gnoristine genus Coelosia Winnertz to this group. Jaschhof and Kallweit (2009) had clear that, within the Leiinae, Anomalomyia would not join the clade of the Cycloneura group.

\section{Leiini Edwards}

Leiini Edwards, 1925: 547.

Type Genus: Leia Meigen.

Genera included: Caledonileia (fig. 52), Neoclastobasis (figs. 54, 86), Greenomyia (figs. 55,
87), Leia (figs. 53, 56, 58-59, 61, 63, 84-85, 92-95), and Clastobasis (= Rhymoleia Edwards) (figs. 57, 60, 62, 88-91).

DiAgnosis: Proepimeron and ventral-posterior end of pronotum connected by a very narrow region; proepimeron shape digitiform (e.g., Jaschhof and Kallweit, 2009: 16, fig. 36). C ending at $\mathrm{R}_{5}$; first sector of Rs oblique; $r-\mathrm{m}$ with a curve midway between Rs and $\mathrm{M}_{1+2}$; origin of $\mathrm{M}_{4}$ more distal than apex of $\mathrm{Sc}$; second sector of $\mathrm{CuA}$ with a small median depression. Gonostylus simple, with no spines.

This is the core group of leiines and is apparently what some authors visualized when they referred to the "Leiinae s.s." Caledonileia is currently known from a single species described by Matile (1993) from New Caledonia. Greenomyia is more speciose, with 10 species described, mostly from the Palearctic region, but also with two Nearctic and two Oriental species (Kurina et al., 2011). Neoclastobasis is known from two European and one species from Japan (www. sciaroidea.info). Leia is the second largest leiine 


\section{2}

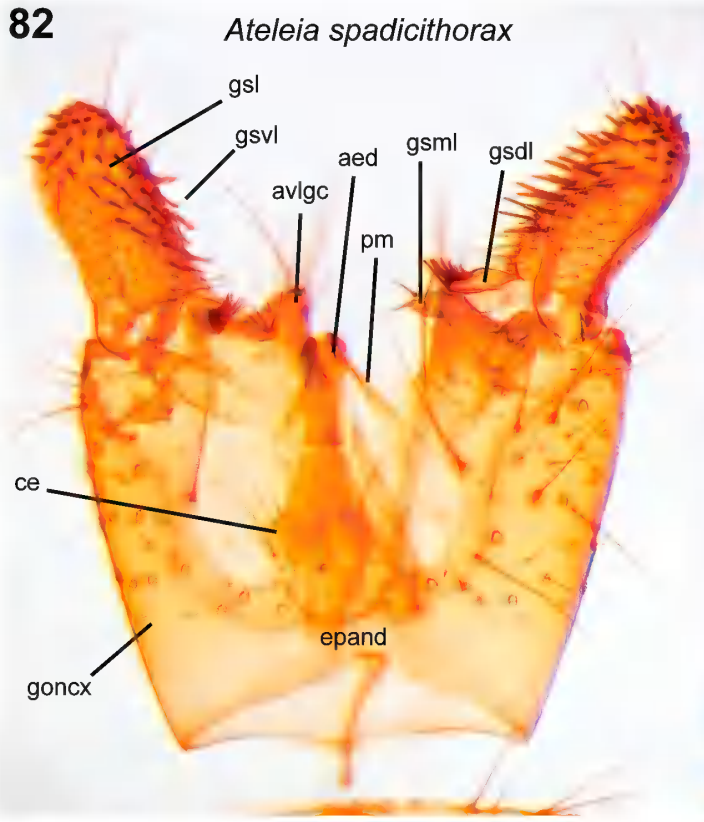

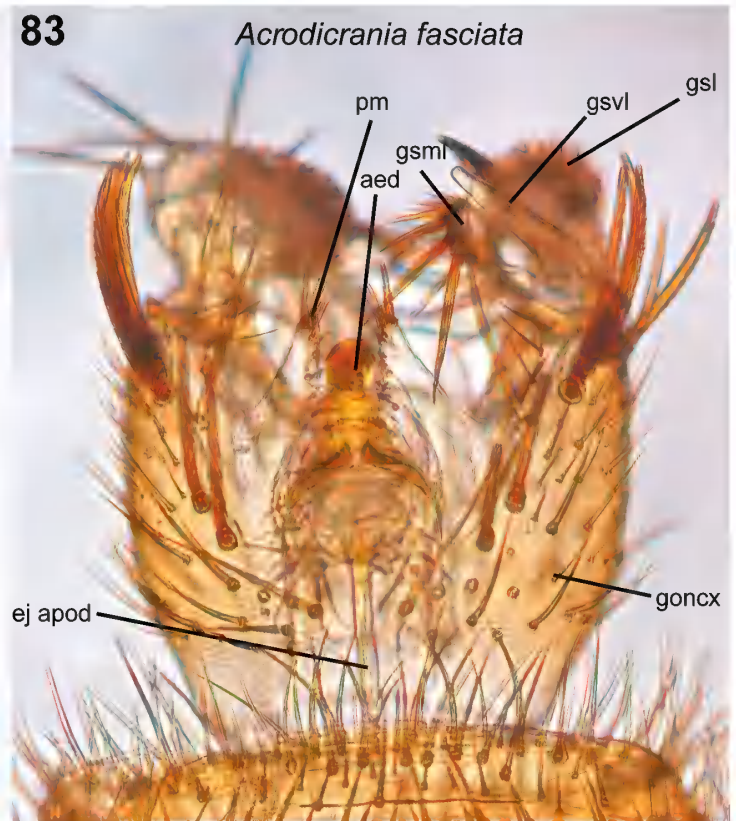

FIGS. 82-83. Male terminalia of Anomalomyiini genera. 82. Ateleia spadicithorax Skuse, dorsal view. 83. Acrodicrania fasciata Skuse, ventral view.

genus, with over 140 extant species described worldwide, while Clastobasis is formally known of about 20 species from all regions except from the Nearctic and Neotropical regions. There are hundreds of undescribed species that fit into these two latter genera.

A tribe "Clastobasiini" was proposed by Ostroverkhova (1970), joining Clastobasis and Neoclastobasis. These two genera do not compose together a clade in any of our trees. Neoclastobasis and Greenomyia composes a well supported small monophyletic group within the tribe and our results corroborate Matile's (1978) synonymy of Clastobasiini to the Leiini.

Not much has been published about Caledonileia. In his original description of the genus, Matile (1993) mentioned that Caledonileia shares the presence of only two palpomeres with Sigmoleia and Thoracotropis, with significant differences among these three genera in the wing venation, in the condition of the ocelli, and of the setation of the laterotergite. The results obtained here agree that a reduction in the num- ber of palpomeres occurred independently in the evolution of the Leiinae-a feature also present in many other sciaroid clades. Matile's (1993) discussion disclosed an uncertainty about the position of Caledonileia. In our majority consensus (fig. 96), Caledonileia is sister of a clade including Greenomyia and Neoclastobasis (and Leia ventralis Say), while the strict consensus (fig. 97) shows Caledonileia at a polytomy at the base of the Leiini s.s., together with most species of Leia and some species of Clastobasis. The results supports Caledonileia as a member of the Leiini s.s, but its precise position within the tribe suggests the need of further investigation.

Matile (1978: 170) accepted that Neoclastobasis "has its natural place in the Leiini and in fact in the group Leia-Greenomyia, where they seem to be closer to the latter." Matile's (1978) statement at the same time corroborates that Neoclastobasis belongs in this higher leiine clade and that there is a closer connection between Neoclastobasis and Greenomyia. Kurina et al. (2011: 32) supported this view when they indicated that "Greenomyia 


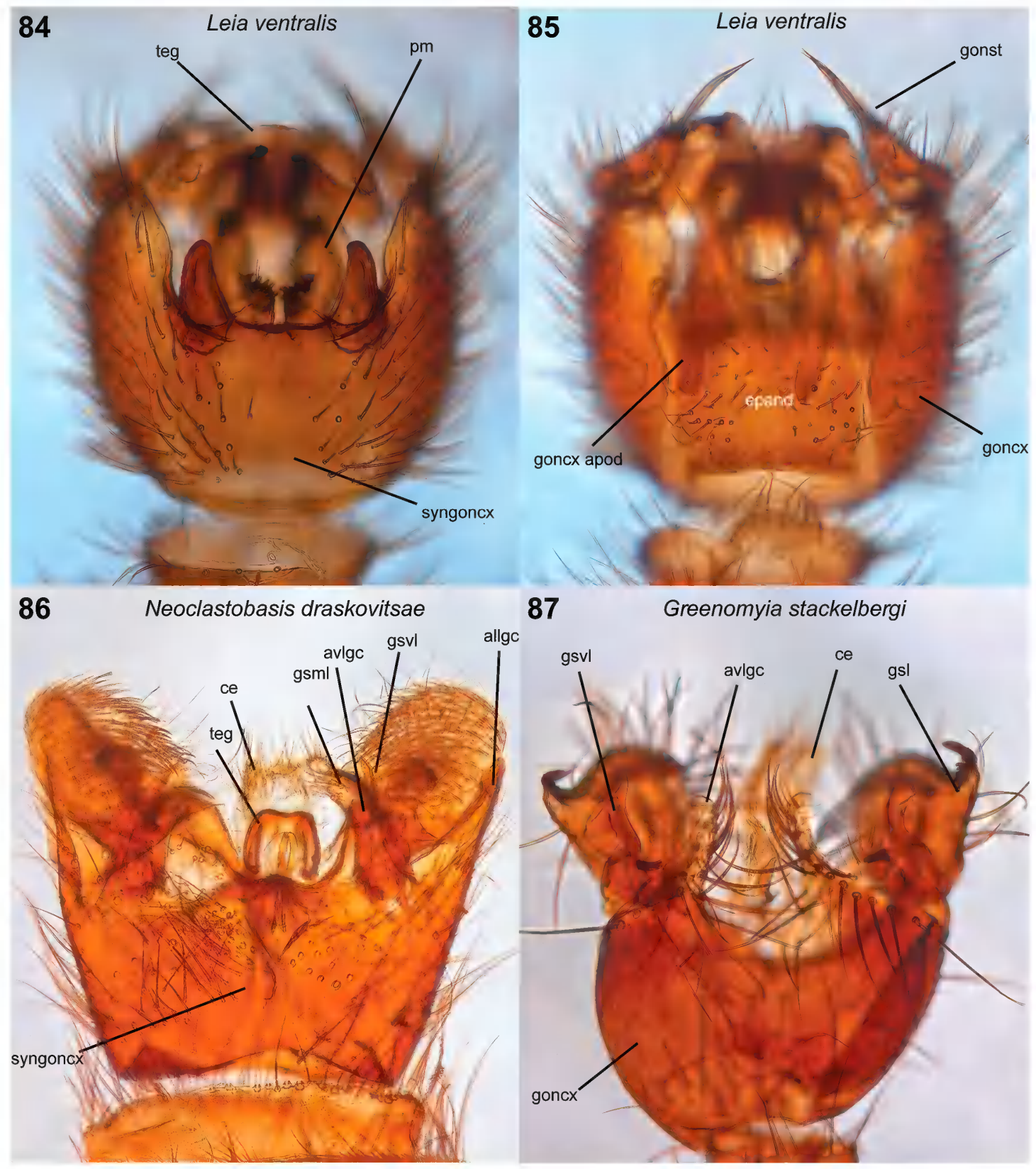

FIGS. 84-87. Male terminalia of Leiini genera. 84. Leia ventralis Say, ventral view. 85. Leia ventralis Say, dorsal view. 86. Neoclastobasis draskovitsae Matile, ventral view. 87. Greenomyia stackelbergi Zaitzev, ventral view. 

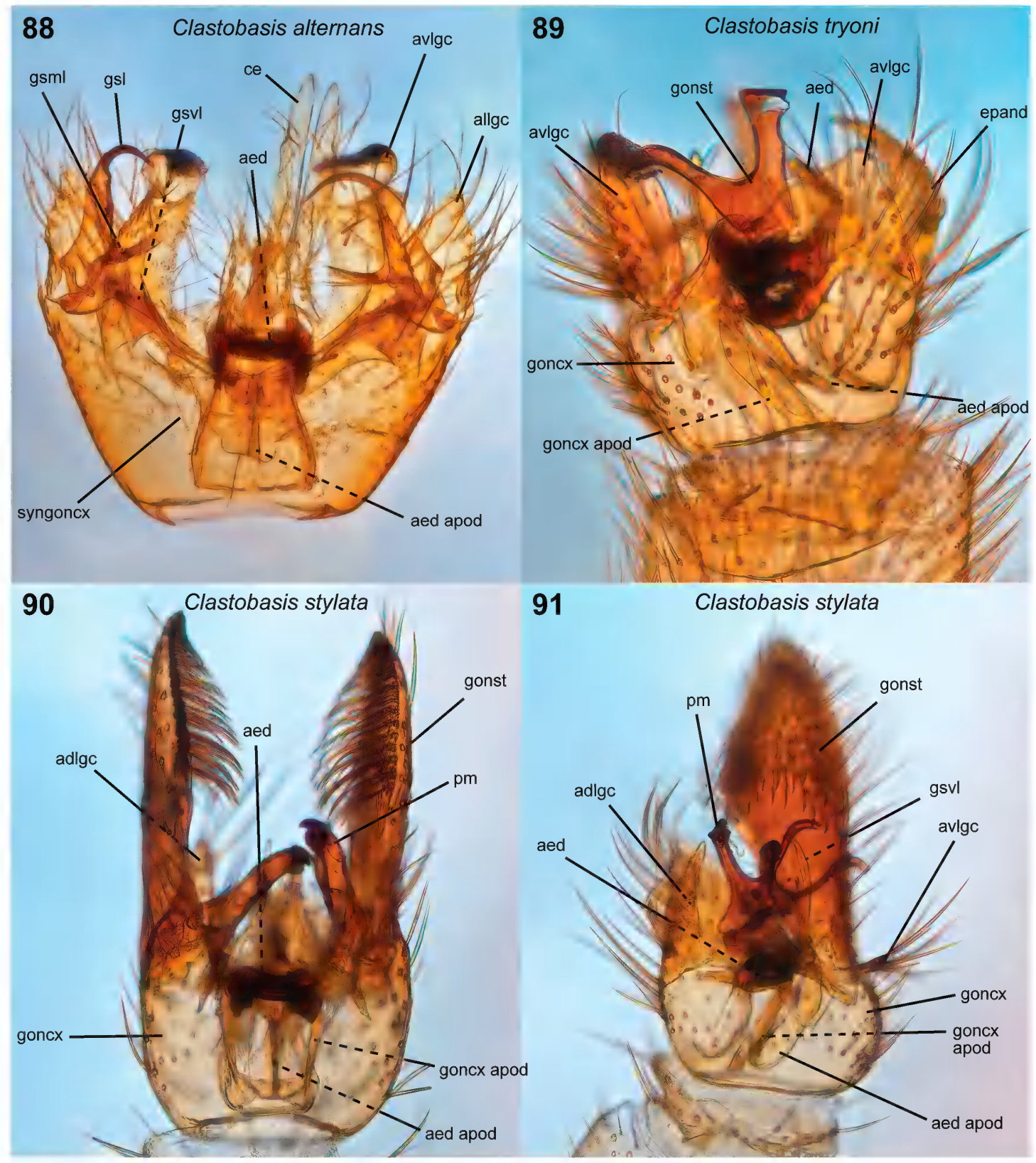

FIGS. 88-91. Male terminalia of Leiini genera. 88. Clastobasis alternans (Winnertz), ventral view. 89. Clastobasis tryoni Skuse, ventral view. 90. Clastobasis stylata Matile, ventral view. 91. Clastobasis stylata Matile, lateral view. 


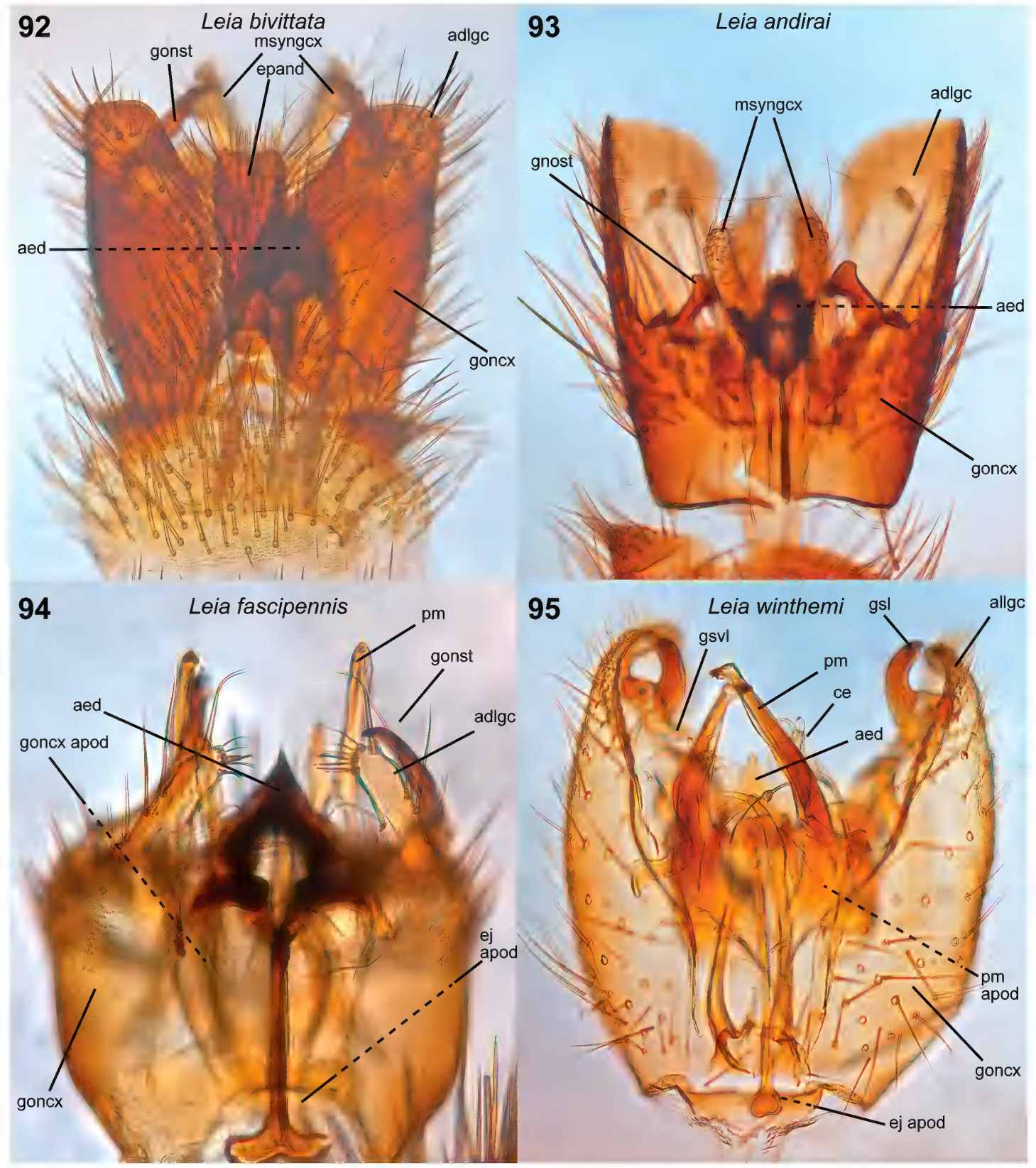

FIGS. 92-95. Male terminalia of Leiini genera. 92. Leia bivittata Say, dorsal view. 93. Leia andirai Lane, ventral view. 94. Leia fascipennis Meigen, dorsal view. 95. Leia winthemi Lehmann, ventral view. 
appears most closely related to the genus Neoclastobasis Ostroverkhova." In their review of the European species of Greenomyia, Kurina et al. (2011) also concluded that the characters used to separate the two genera are not satisfactory, with differences mainly in the male terminalia. It is still necessary to reevaluate the position of the species in both these genera. A wider taxon sampling at the species level may conclude that their present composition could render one or both as paraphyletic. In our majority consensus tree, Leia ventralis groups with Greenomyia and Neoclastobasis. A separate genus is probably necessary for that species. The wing of Leia ventralis illustrated (fig. 53) has a teratology and misses $\mathrm{M}_{4}$. Other specimens of this species have the $\mathrm{M}_{4} / \mathrm{CuA}$ fork as in other genera of Leiini.

Finally, Leia and Clastobasis represent the most complex taxonomic problem of the Leiinae. The usual diagnoses for these two genera are subtle and are fairly effective only for the Palearctic fauna-in a worldwide perspective, these differences get blurred. The study of the diversity of Leia suggests, as was earlier advocated by Tozoni (1998), that the genus is not a natural group. Indeed, many Neotropical species of Leia largely fit into the delimitation of Clastobasis. The terminal "Clastobasis sp." in our matrix, for example, is a Neotropical species that runs into Clastobasis in Søli et al.s (2000) key for the Palearctic mycetophilids and into Leia in Vockeroth's (2009) key for the mycetophilids of Central America. A proper solution for this problem demands quite an extensive study of the diversity of species of both genera from all regions. One solution would be to synonymize both genera, but this would lose taxonomic information already available. There is no question, however, that Clastobasis and most species of Leia come together in a clade with good support within the Leiini s.s.

\section{Male Terminalia Patterns in the Leinae}

We address in this section male terminalia patterns that can be recognized in the Leiinae genera or groups of genera. Characters 121-128 in our list (appendix 1) refer to male terminalia features. Features of the terminalia most often referred to in published papers are: the size and shape of the gonocoxites, fusion of the gonocoxites medially at the ventral face of the terminalia, presence of gonocoxite lobes and projections and presence of modified setae and spines on the gonocoxite; place of insertion of the gonostylus on the gonocoxite and size, shape, and presence of setae and spines on the gonostylus; size, shape, and position of tergite 9 and, in some particular cases, presence of tergite 9 lobes and setation; and size, placement, shape, and position of the cerci. There is large variation of the size, shape, and degree of sclerotization of the parameres and the aedeagus, the size and placement of their apodemes and of the gonocoxal apodemes, as well as the size and degree of sclerotization of the sternite 10 . These features are not known well enough across the subfamily and less emphasis is given to these structures along the discussion below. This section is supposed to be particularly useful while dealing with fossils.

We tried to be consistent here with the morphological nomenclature for lobes and branches of the gonocoxites and gonostyli found in the literature. They should not, however, be taken as strictly correspondent to homology between different genera or tribes in the leiines. That will be correct in some some cases (e.g., the bladelike ventral branch of the gonostylus in Anomalomyiini and the Leiini), but not in others (e.g., the ventral-distal lobes of the gonocoxites in genera in different tribes). These lobes should be seen basically as topological descriptions.

In the Selkirkiini, the male terminalia of Garretella differs considerably from that of species of Paraleia. Vockeroth's (1980) original description of the genus has an illustration of the wing and a detailed general description of the species, but there are no illustrations of the male terminalia. In Garretella shermanni (Garrett), the gonocoxites have distally at the ventral face a lobe extending to the level of the tip of the gonostylus. The gonostylus is relatively small, with some elongate 
setae at a short basal expansion dorsally. The tergite 9 is indistinguishably fused laterally to the gonocoxites and the cerci are slightly elongate (fig. 64). In Paraleia, including the Australian species, P. fulvescens Tonnoir (Tonnoir, 1929: text-fig. 7), the gonocoxites have a long distal expansion dorsally beyond the base of the gonostylus, and the gonostylus is typically elongate, often falciform (Freeman, 1951: figs. 146-150; Oliveira and Amorim, 2012). Many species have a large number of spines scattered at the inner face of the dorsal expansion of the gonocoxites and there is a long spine distally at the inner face of the gonostylus. The gonocoxites are separate from each other at the ventral face of the terminalia. Details of the shape of the gonostylus vary considerably between species, as well as the shape of the aedeagus, the parameres, and the cerci (fig. 65).

The four rogue genera in our tree have quite divergent male terminalia patterns, as expected. As far as we are aware, there are only two known specimens of Thoracothropis cypriformis Freeman, the only known species in the genus, in entomological collections-the holotype and a specimen of the José Pedro Duret collection at the MNHN. The male terminalia is illustrated in Freeman (1951: fig. 156) and in Oliveira et al. (2012: figs. 7-10). The gonocoxites are relatively short, with a medial deep separation between them ventrally. The gonostylus is digitiform, with an elongate, pointed distal dorsal projection and a ventral distal projection with a tooth. The parameres have a long, thin extension twice as long as the terminalia itself, a unique feature in mycetophilids.

The male terminalia of all four known species of Gracilileia Matile were illustrated by Matile (1993: figs. 25-26, 28-32). The gonocoxites are fused to each other medially at the ventral face along the anterior two thirds of the terminalia. The medial area extends internally toward the aedeagal-parameral complex. The aedeagalparameral complex is short except in G. tillierorum Matile, where its distal end projects between the gonostyles. In some species, the gonostylus is almost twice as long as the gonocoxite, with a complex, strongly sclerified, sometimes trifid basal lobes. In two species, the gonostylus is short but also bears a basal projection. Tergite 9 is well developed laterally and has a deep posterior medial incision, with short and wide cerci. As mentioned above, it may be the case that Gracilileia belongs in the Tetragoneurinae.

The male terminalia of Trichoterga monticola Tonnoir differ from that of other rogue genera and as well does not properly fit in the pattern of any of the tribes of Leiinae. Tonnoir and Edwards (1927: fig. 244) illustrated the terminalia in ventral view. We illustrate here (fig. 66) the terminalia in dorsal view. The gonocoxite is longer than wide and the terminalia has an overall elongate shape. The gonostylus has a pretty large basal branch ventrally and there is a row of short spines distally on the gonostylus. Tergite 9 is very short, with a pair of digitiform cerci touching together medially. The aedeagus is elongate, extending slightly beyond the midpoint of the gonocoxites (fig. 66).

The male terminalia of Paracycloneura apicalis Tonnoir was illustrated by Tonnoir and Edwards (1927: fig. 213) and in much more detail by Jaschhof and Kallweit (2009: figs. 71-79). The gonocoxites are complex, with spines and well-developed setae. The gonocoxites have three posterior lobes, of which the dorsal lobe has at its inner face a row of pointed macrosetae and scattered spinules. The gonostylus is simple, digitiform, not hardly sclerotized, with only fine setae. The tegmen of the aedeagal-parameral complex is subtriangular distally and the gonocoxal apodemes are typically short. Tergite 9 has a pair of developed lateral arms at the posterior margin projected beyond the tip of the gonosty-

FIG. 96. Majority consensus of the 119 most parsimonious trees obtained with equal weight, the taxa accepted as subfamilies in most classifications highlighted, as well as the Tetragoneura group ranked as a subfamily. The Gnoristinae generic sample in the analysis groups in two separate clades that do not conform a monophyletic group. 


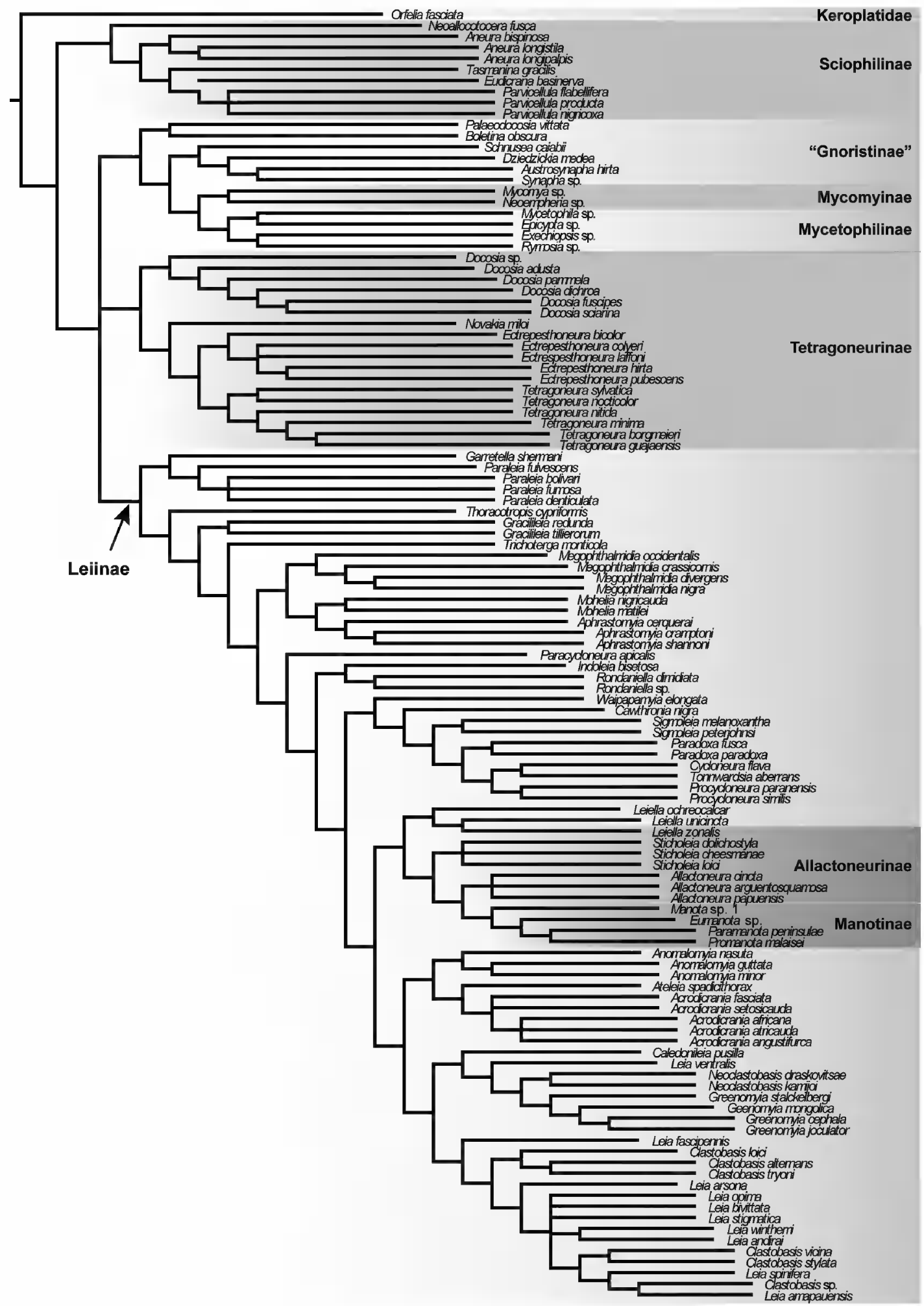


lus, with a deep incision between them. The cerci are placed at the distal margin of a membrane connecting the gonocoxal dorsoposterior lobes.

In the Megophthalmidiini, Megophthalmidia has a complex male terminalia, studied in detail by Kerr (2014) for Nearctic species. In most Nearctic and Palearctic species, the gonocoxite is elongate, with a dorsolateral distal expansion into which the proportionally small gonostylus fits. The gonocoxites may have a deep, slender gap between them medially or may entirely close the ventral face of the terminalia (as in Megophthalmidia divergens; fig. 67). Even though the gonostylus is relatively small, it can be quite complex, with branches, a strong sclerotized distal part and some additional ornamentation (also see Chandler et al., 2006). The internal parts of the terminalia are also complex, particularly the aedeagus (see Kerr, 2014). Tergite 9 may either be complex, the posterior margin having a pair of arms projected ventrally, or it may be short and slender. The cerci are not particularly modified. The elongate shape of the terminalia in most Holarctic species is not seen in some of the southern South America species (Lane, 1962: fig. 2 ), although the gonostylus is almost always considerably complex (see, e.g., Lane, 1954a: figs. 1-2)-our figure 67.

The male terminalia of Mohelia nigricauda Matile was illustrated by Matile (1978: figs. 35-36). In that species, the gonocoxites are large, projected laterodistally much beyond the tip of the aedeagus, with an elongate gonostylus that fits into the distal end of the gonocoxite, apparently bifid basally. The ventral face of the terminalia has the inner border of the gonocoxites close together, also seen in Megophthalmidia. Tergite 9 in $M$. nigricauda is short laterally and has a pair of projections more medially at the posterior margin. The aedeagus is subtriangular, tapering to the distal end, and the gonocoxal apodemes are well developed. In Mohelia matilei Oliveira (Oliveira, 2015: fig.
11A-D), the distal projection of the gonocoxite is much shorter (fig. 68), but in M. amorimi Oliveira and $M$. chandleri Oliveira the gonocoxite is large, with a laterodistal projection, as in M. nigricauda. Most species of the genus have a pair of conspicuous groups of setae on tergite 9. The bifid, usually complex gonostylus, is a feature shared by all species of the genus.

The male terminalia of Aphrastomyia have been carefully described and illustrated by Jaschhof and Kallweit (2004: figs. 7-17). The gonocoxites are fused medially at the anterior margin and the terminalia is wider than the gonocoxite length. The gonocoxite do is not project much beyond the base of the gonostylus and there are short ventral and dorsal distal lobes. The gonostylus is not particularly complex, but has a basodorsal lobe that gives, as in the remaining Megalophthalmiini, a general bifid shape to the gonostylus (fig. 69). In some species, the tergite 9 has a short projection on the posterior margin that may be slightly more sclerotized than the remainder of the sclerite and with a concentration of setulae. The cerci are typically small, rounded, and separate from each other.

Both genera of Rondaniellini have a similar, very complex male terminalia. This shared pattern supports the hypothesis of a clade connecting these two genera in a tribe Rondaniellini. There are no published illustrations of male terminalia of most species of Rondaniella and there is no published illustration of the terminalia of Indoleia. The terminalia of the Chinese species of Rondaniella were illustrated by Yu et al. (2004, 2008) and Yu and Wu (2009). Indoleia bisetosa (fig. 70) shares with Rondaniella dimidiata (Meigen), the type species of the genus (fig. 71), the slightly longer than wide gonocoxites, with a considerably wide sclerite medially between them at the ventral face of the terminalia. The posterior margin of the syngonocoxite ventrally at each side is slightly more sclerotized than the rest of the gonocoxite and bears a row of distinc-

FIG. 97. Strict consensus of the 119 most parsimonious trees obtained with equal weight, the Leiinae highlighted. Bremer support indicated for nodes within the Mycetophilidae (the monophyly of the Mycetophilidae is the result of the a priori election of the keroplatid to root the tree). 


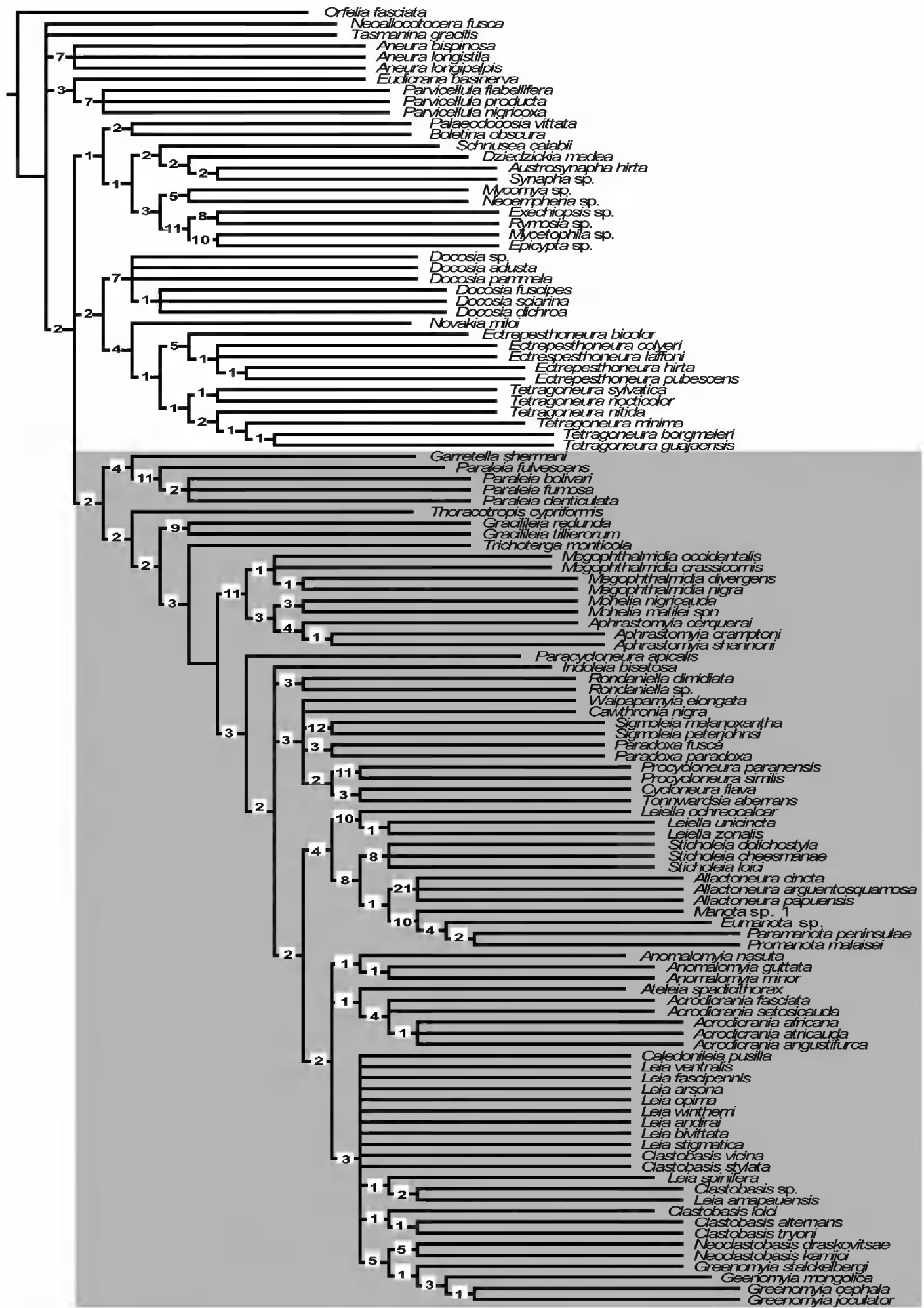


tive, longer setae. The gonocoxite does not project beyond the base of the gonostylus. The gonostylus is fairly complex, at least in some species with a dorsal lobe and a medial lobe in additional to the main gonostylar lobe. Some of the lobes of the gonostylus have only regular fine setae and some have combs of spines and groups of sclerotized, strong setae. The parameres are also strongly modified, with a distal comb of spines. The tergite 9 and the cerci have pretty standard shape and size.

Most genera of Cycloneurini have the male terminalia only slightly elongate, encapsulate, i.e., without appendages or parts projecting outside the terminalia. Jaschhof and Kallweit (2009) carefully illustrated the terminalia of Waipapamyia, Cawthronia, Sigmoleia, and Paradoxa. Tonnoir and Edwards (1927: figs. 236 -237) illustrated the terminalia of two species of Cycloneura. The male terminalia of Tonnwardsia has not been illustrated so far.

The male terminalia of Waipapamyia is fairly simple. The gonocoxites are relatively longer than wide, with a deep V-shaped medial incision between the gonocoxites that reaches the anterior margin of the terminalia ventrally. The gonostylus is more or less palmate in lateral view, with a hardly sclerotized distal tooth or spine and with some strong setae, with details varying among species of the genus. Tergite 9 has a pair of extensions at the posterior margin, each projection having a pair of long setae apically (Jaschhof and Kallweit, 2009: figs. 90-93, 97-103). The aedeagus is standard, with a tegmen distally, sided by a pair of elongated parameres that connect to each other, extending anteriorly into the parameral apodemes.

The male terminalia of Cawthronia (Jaschhof and Kallweit, 2009: figs. $80-85,88$ ) is also simple, in a certain extant similar to that of Waipapamyia. The incision between the gonocoxites ventrally is not as deep, while the gonostylus is also slightly palmate, but without any ornamentation other than the distal tooth.
Tergite 9 is subtriangular, almost trapezoid, while the parameres are reduced to a pair of apodemes connected medially. As in Waipapamyia, the gonostylus has a distal position on the gonocoxite.

In Sigmoleia (Jaschhof and Kallweit, 2009: figs. 55-58, 63-64, 65-67, 69-70), the general shape of the terminalia is also slightly elongate, but the gonocoxite has a long, digitiform extension lateroventrally ending beyond the tip of the gonostylus, with a distinctive distal short seta. The distal lobe of the gonocoxite partially covers the gonostylus. The gonostylus has a short basal stalk, with a large body arising from it; the enlarged distal part of the gonostylus is ornamented with a number of spines at its inner face. The gonocoxal apodemes are fairly elongate. The aedeagus is subtriagular or subquadrate distally, with a pair of apodemes extending laterally at the anterior end. Tergite 9 is more or less rectangular, with a pair of short lobes on the posterior margin or entirely divided into a pair of lobes.

The male terminalia of Paradoxa is about as long as wide. The gonocoxite has a dorsolateral extension beyond the base of the gonostylus, the tip of the gonocoxite and of the gonostylus ending at about the same level. There is a deep incision between the gonocoxites, almost reaching the anterior end of the terminalia ventrally, quite wide at the distal margin. The gonocoxite in $P$. fusca, the type species of the genus, from New Zealand, has an additional short lobe at the inner face, dorsally to the base of the gonostylus, bearing scattered short spines (Jaschhof and Kallweit, 2009: figs. 45, 47, 50-51). In $P$. paradoxa, from southern Africa, the gonocoxite also has short spines along the inner face of the distal projection dorsally to the gonostylus (Jaschhof, 2006: figs. 5, 7-9). The gonostylus can be seen in ventral view in both species. In $P$. fusca, it is elongate, more or less flattened, without distal lobes; in P. paradoxa, the gonostylus is digitiform, with three short distal lobes and one elongate distal spine on one of the lobes. The

FIG. 98. Resulting tree of the analysis with implicit weight with $\mathrm{k}=3$, the Leiinae highlighted. The Tetragoneurinae appears as sister of the Leiinae plus the clade ("Gnoristinae" + Mycomyinae + Mycetophilinae). 


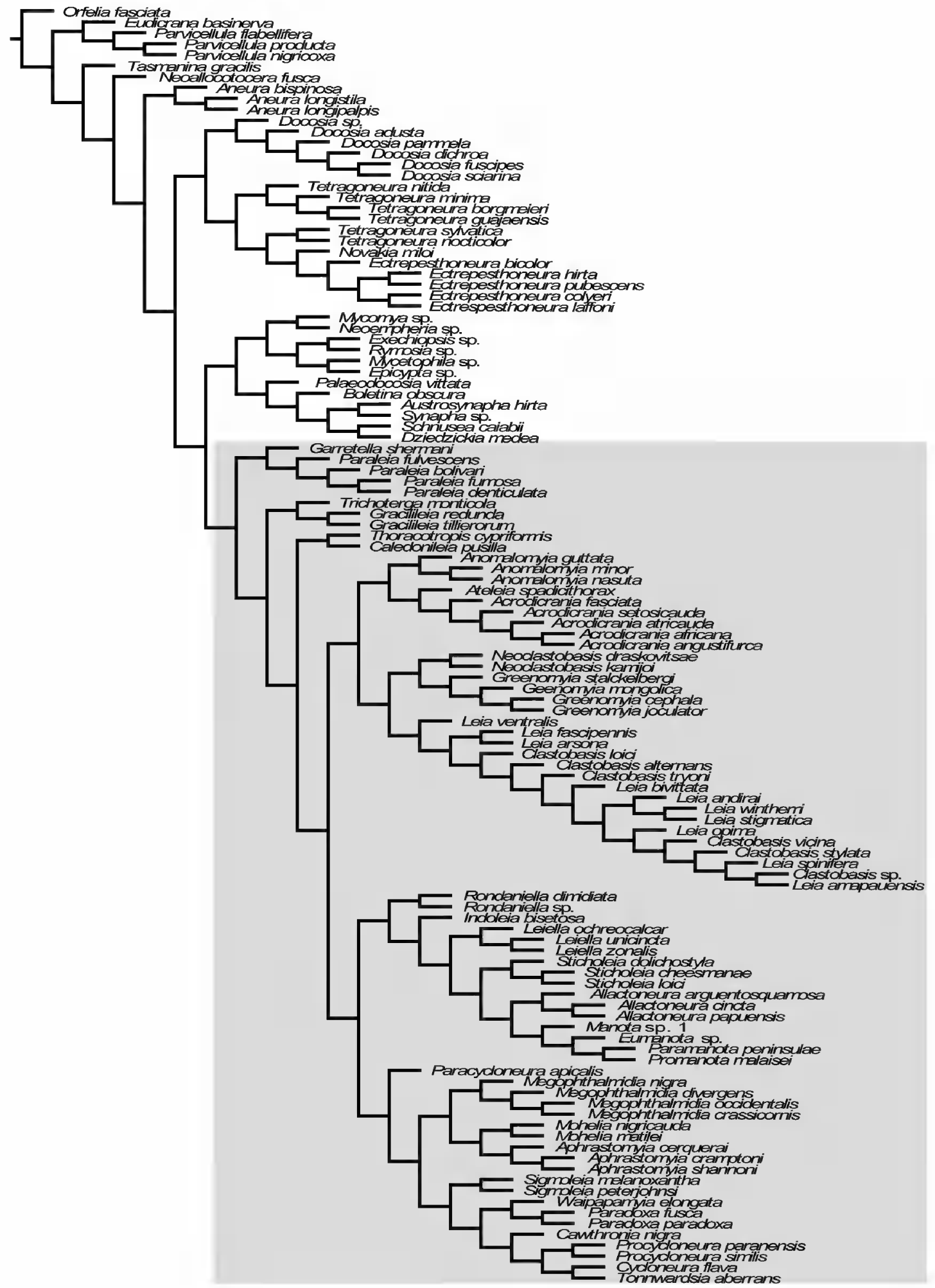


parameres have the typical $\mathrm{H}$-shape, with a pair of slender blades projecting distally and a pair of parameral apodemes projecting anteriorly, with a medial connection between them. The aedeagus is cylindrical, elongated distally. Tergite 9 is rectangular, much longer than wide, the distal margin reaching the level of the tip of the gonocoxites.

The male terminalia of Cycloneura has more or less elongate gonocoxites. In C. flava, the gonocoxites are connected at the ventral face of the terminalia along the anterior half, diverging distally; in C. triangulata, gonocoxites are more or less parallel and connected along the anterior three fourths of the terminalia (Tonnoir and Edwards, 1927: figs. 236-237). There is a short projection of the posterior border of the gonocoxite ventrally in $C$. triangulata, extending slightly beyond the base of the gonostylus. The gonostylus is quite short in both species, distally much wider than at the base, especially in $C$. flava, and there are scattered short spines at the inner face of the gonostylus.

In Tonnwardsia, the terminalia is rather compact and also has the gonostylus inserted at the distal end of the gonocoxite. There is a pair of elongate, bifid processes emerging quite anteriorly at the inner margin of each gonocoxite. The gonocoxites apparently are indistinguishably fused laterodorsally to the tergite 9. The gonostylus is simple, elongate, bent at the basal third, without spines, but with a basal, bladelike ventral lobe. The aedeagal-parameral complex is elongate and sclerotized. The cerci are largely in contact medially (fig. 72).

Edwards $(1932,1933)$ did not illustrate the male terminalia of both Procycloneura species he described, but there are good illustrations of the Chilean species in Freeman (1951: figs. 154-155). In this genus, the male terminalia is rather compact. The gonocoxites are separated by a deep $\mathrm{V}$-shaped incision that reaches the anterior end of the terminalia. In some species, there is a pair of short, digitiform projections emerging medially at the inner border of the gonocoxites. There is also a short projection of the gonocoxite dorsally extending beyond the base of the gonostylus. The gonocoxites have at the inner face of the distal border dorsally modified short spines. The gonostylus is typically falciform, but details of the shape and size of the gonostylus vary considerably between species. In some species, the basal part and the distal part of the gonostylus have similar length, while in others the basal section is much longer than the curved distal section. The gonostylus distally may have long setae and a comb of spines. The tegmen is slender distally. Tergite 9 is as long as the gonocoxites dorsally, with some stronger setae at the distal margin (figs. 73-75).

The Manotini have a wide array of male terminalia patterns, much more diversified than seen in the Cycloneurini. Leiella is quite conservative, with more or less encapsulated terminalia. In several papers Lane provided illustrations of L. unicincta (1952: fig. 5; 1954b: fig. 1), of $L$. catharensis, L. fulva, and L. shannoni (1954b: figs. 2-4), and of L. arnaudi (1962: fig. 4). The gonocoxite is slightly longer than wide and extends laterally only slightly beyond the base of the gonostylus. The gonocoxites are fused to each other along the entire medial line ventrally. The distal end of the gonocoxites laterally may have a row of strong setae or spines. The gonostylus is small, slightly elongate, with combs of small spines, in some species also with a strong distal spine. The aedeagal-parameral complex is modified, with a wide tegmen and wide parameral blades. The gonocoxite dorsal margin is well developed and tergite 9 is slender, elongate, with some few strong setae at the posterior margin. The cerci are hardly visible (figs. 76-77).

Both known species of Sticholeia have a unique male terminalia pattern, which were carefully described and illustrated by Søli $(1996,2002 a)$. They have extremely elongate cerci and lateral

FIG. 99. Resulting tree of the analysis with implicit weight with the setk script value of $\mathrm{k}=24.22175$, the Leiinae highlighted. The Tetragoneurinae appears as sister of the Leiinae and ("Gnoristinae" + Mycomyinae + Mycetophilinae) appears as sister of (Tetragoneurinae + Leiinae). 
2021

OLIVEIRA AND AMORIM: THE LEIINAE (DIPTERA: MYCETOPHILIDAE)

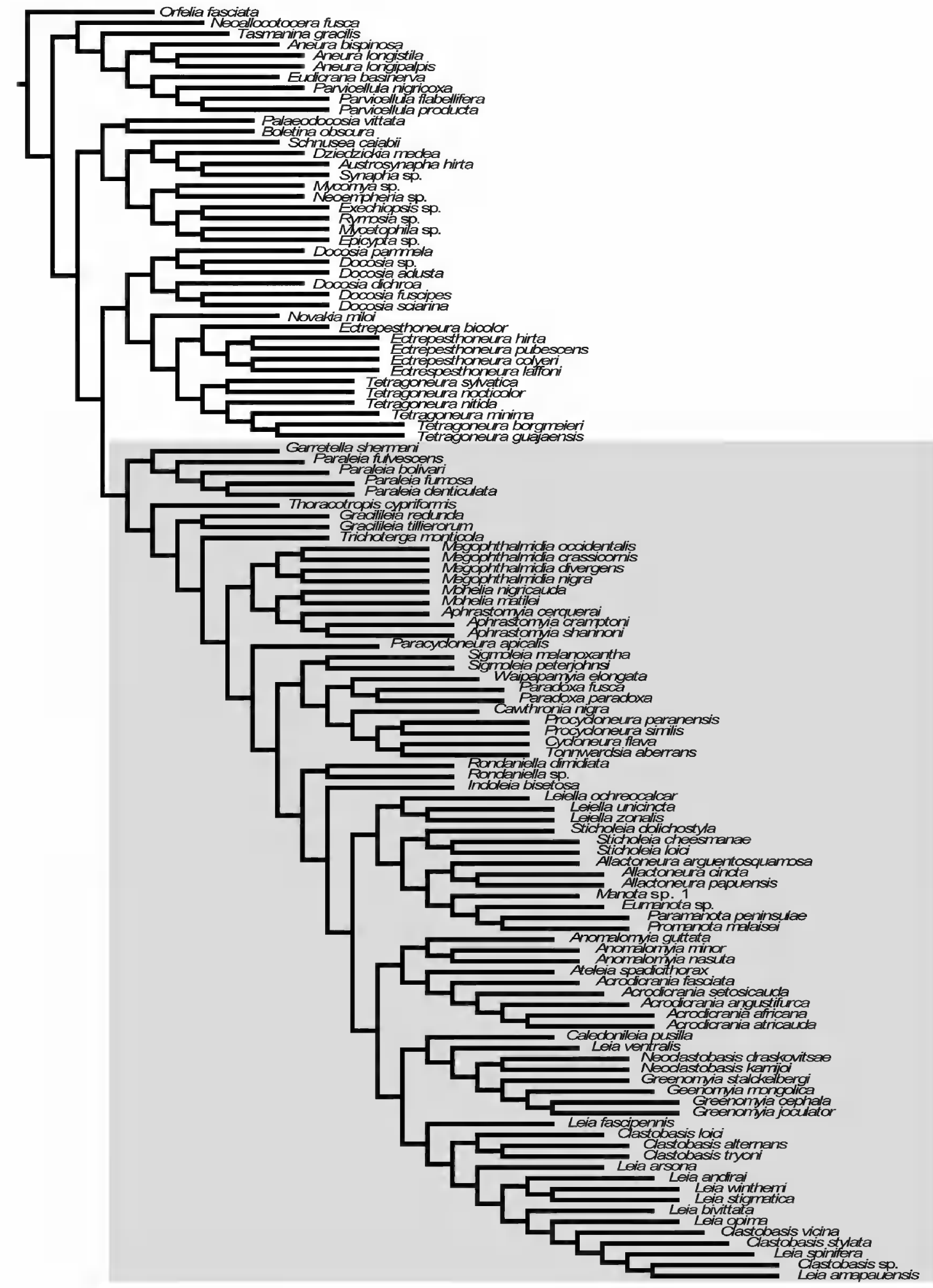




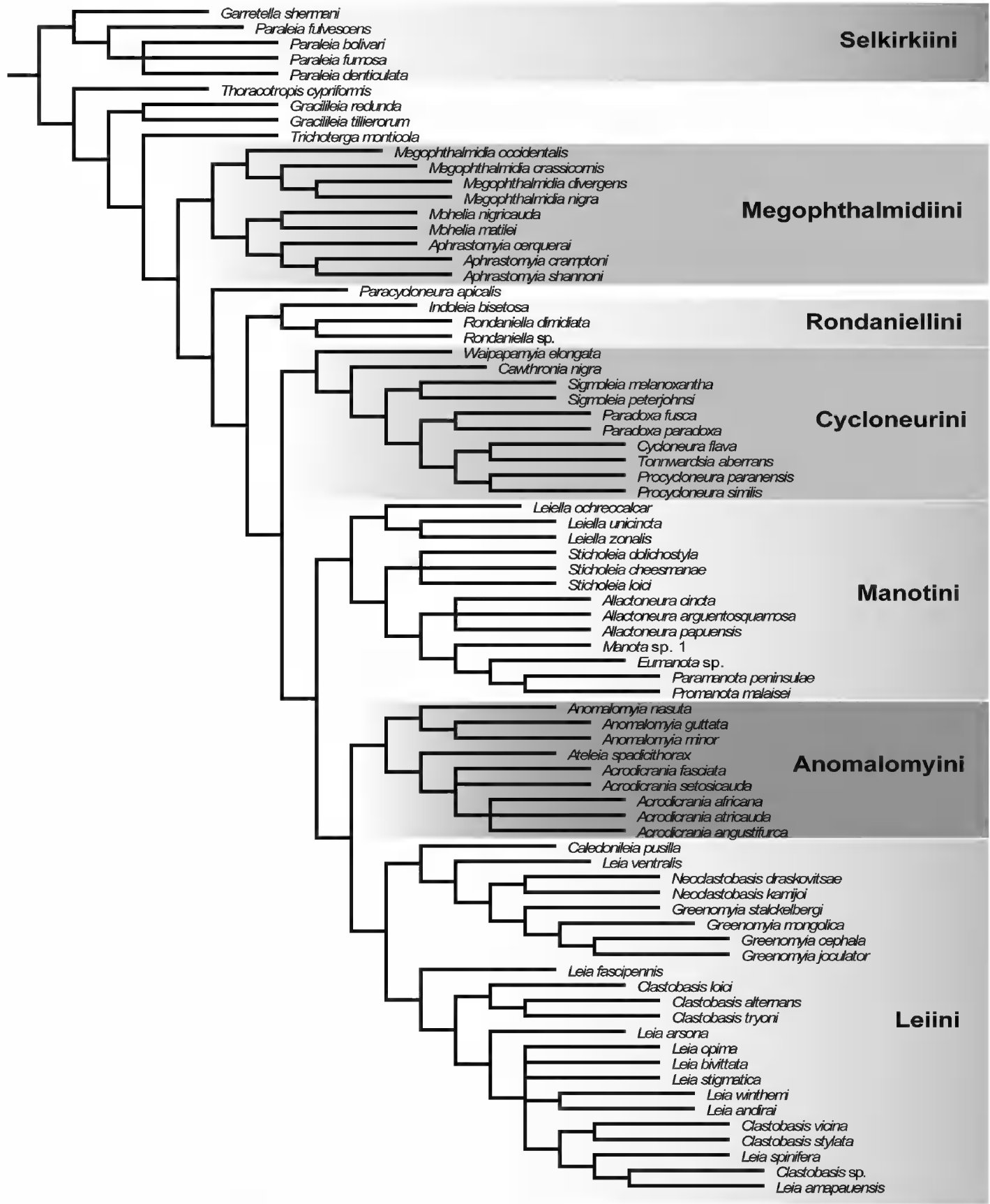

FIG. 100. Phylogenetic classification of the Leiinae, with indication of clades to which tribal rank was given (majority consensus of the 119 most parsimonious trees obtained with equal weight analysis). 


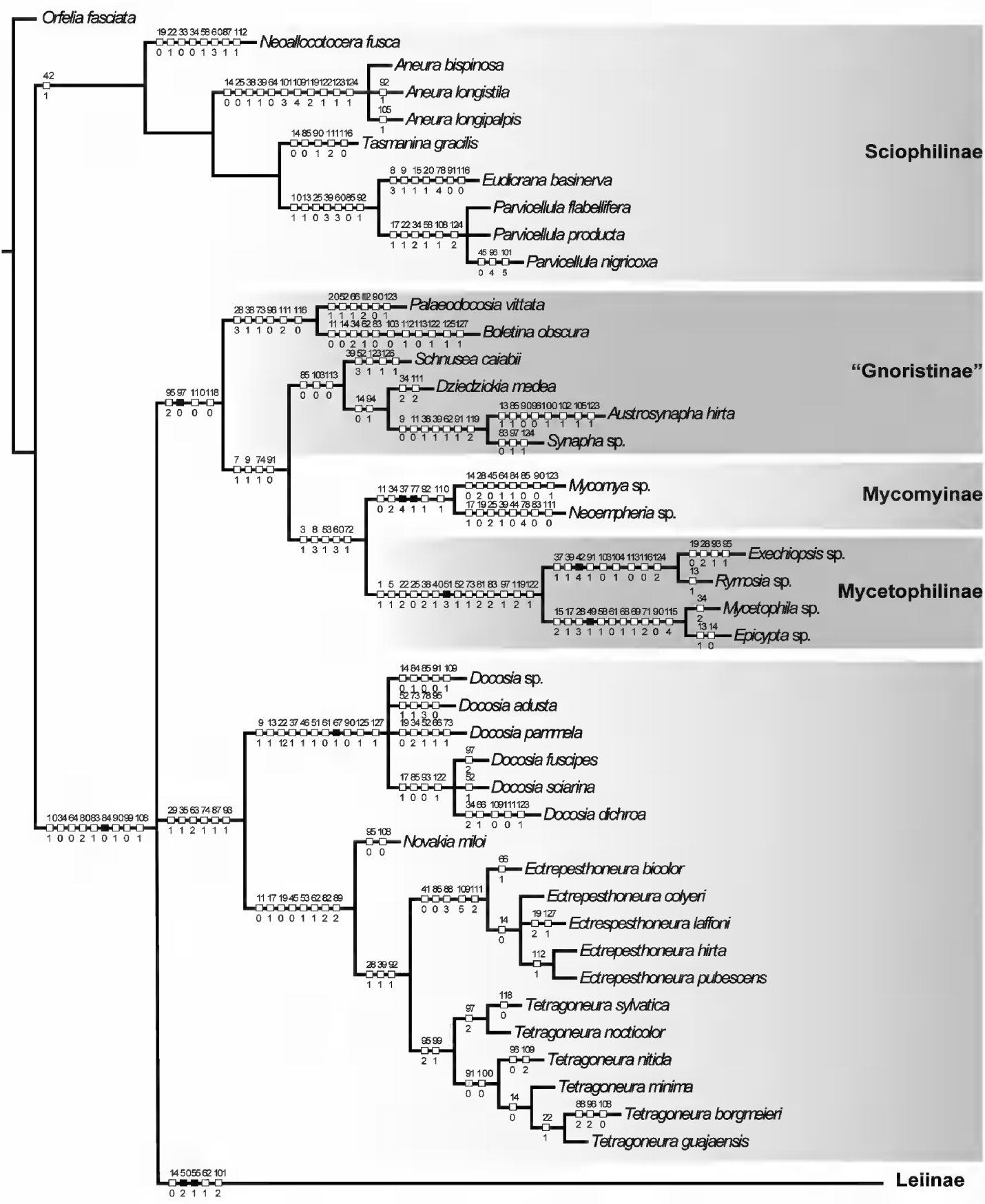

FIG. 101. Character distribution in the tree with the relationships among Mycetophilidae subfamilies in the majority consensus of the 119 most parsimonious trees obtained equal weight analysis. 


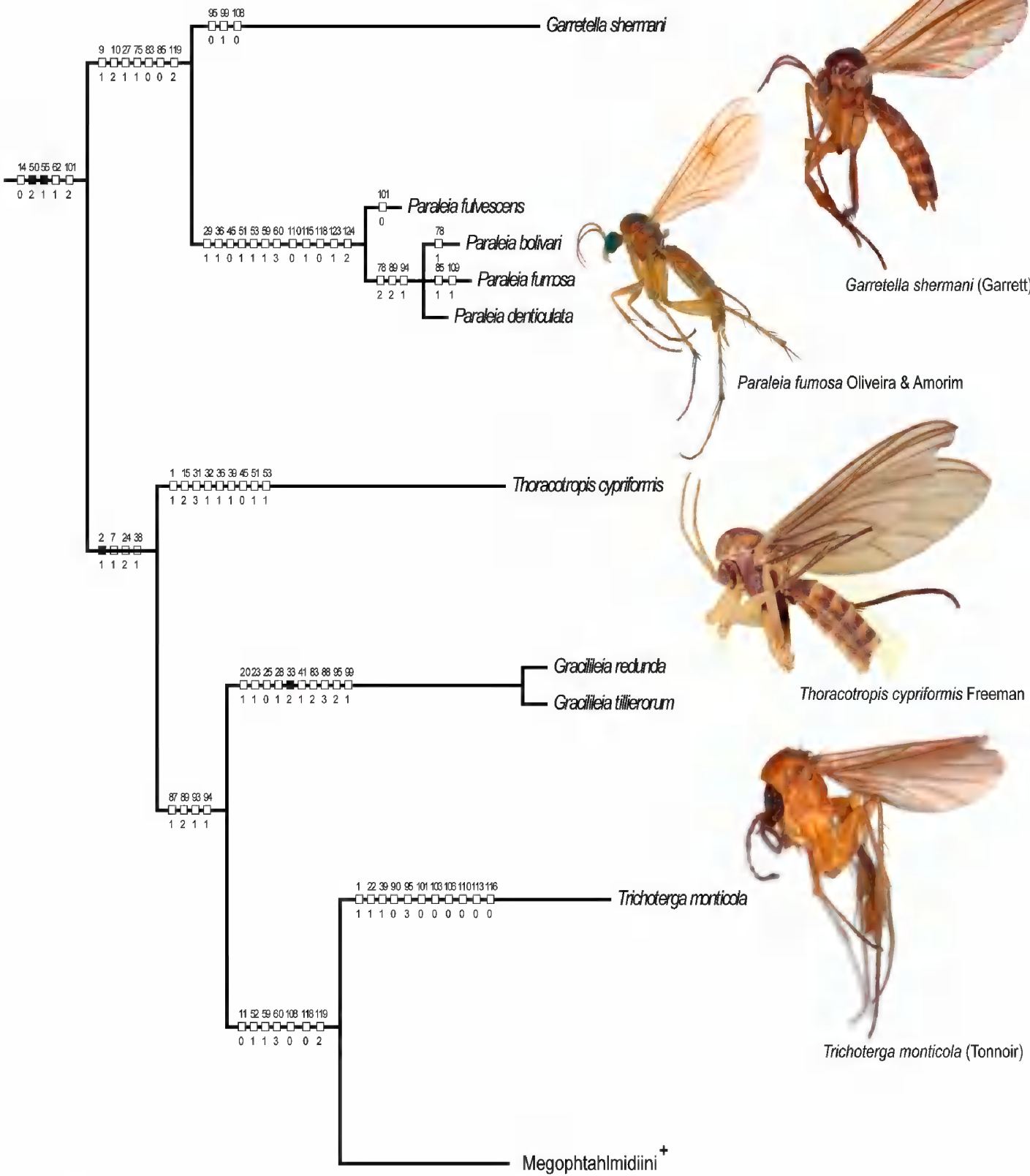

FIG. 102. Character distribution in the tree of the relationships in the majority consensus of the 119 most parsimonious trees obtained with equal weight analysis, the Megophthalmidiini ${ }^{+}$as a terminal. 


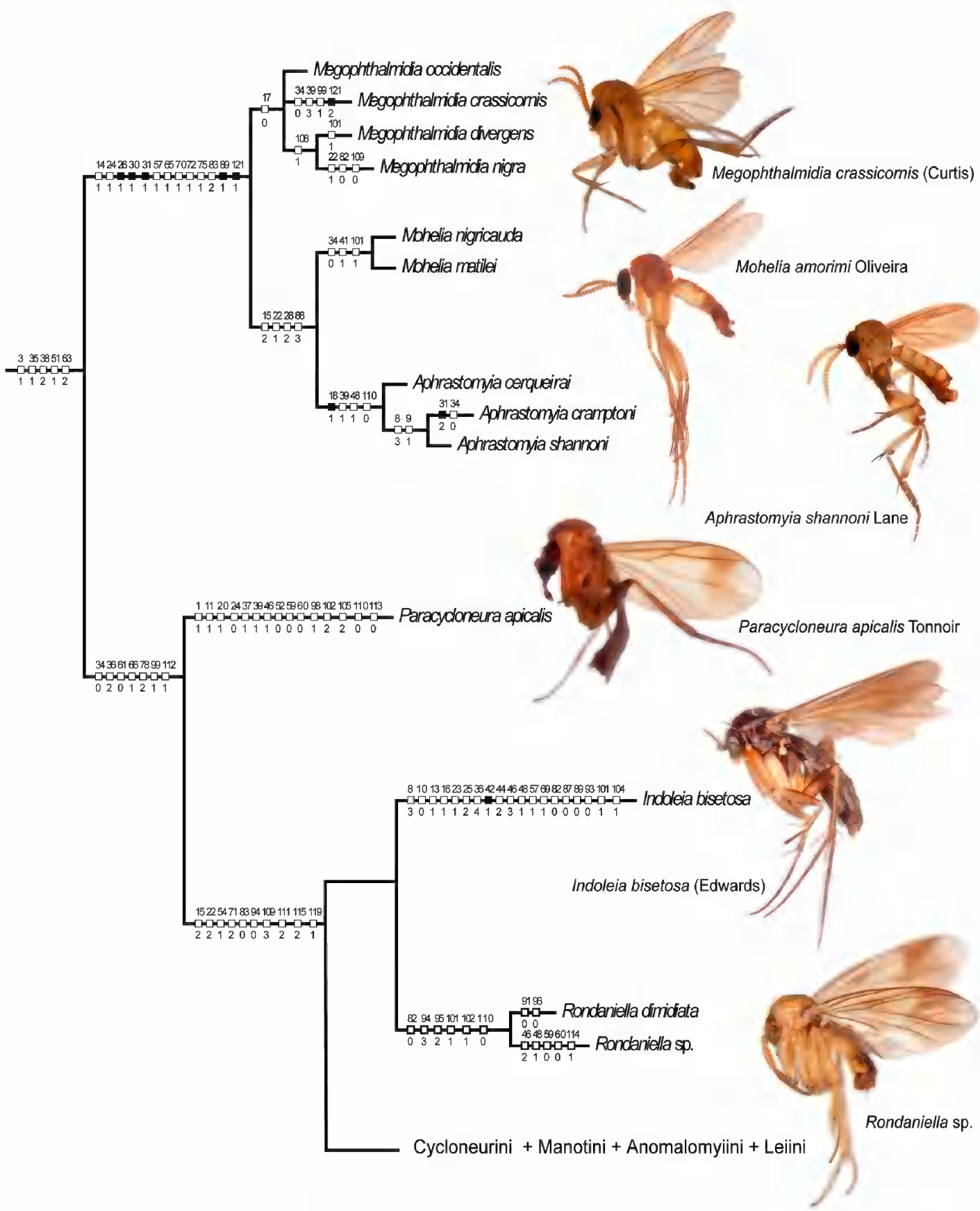

FIG. 103. Character distribution in the tree of the Megophthalmidiini ${ }^{+}$in the majority consensus of the 119 most parsimonious trees obtained with equal weight analysis, the Cycloneurini ${ }^{+}$as a terminal. 


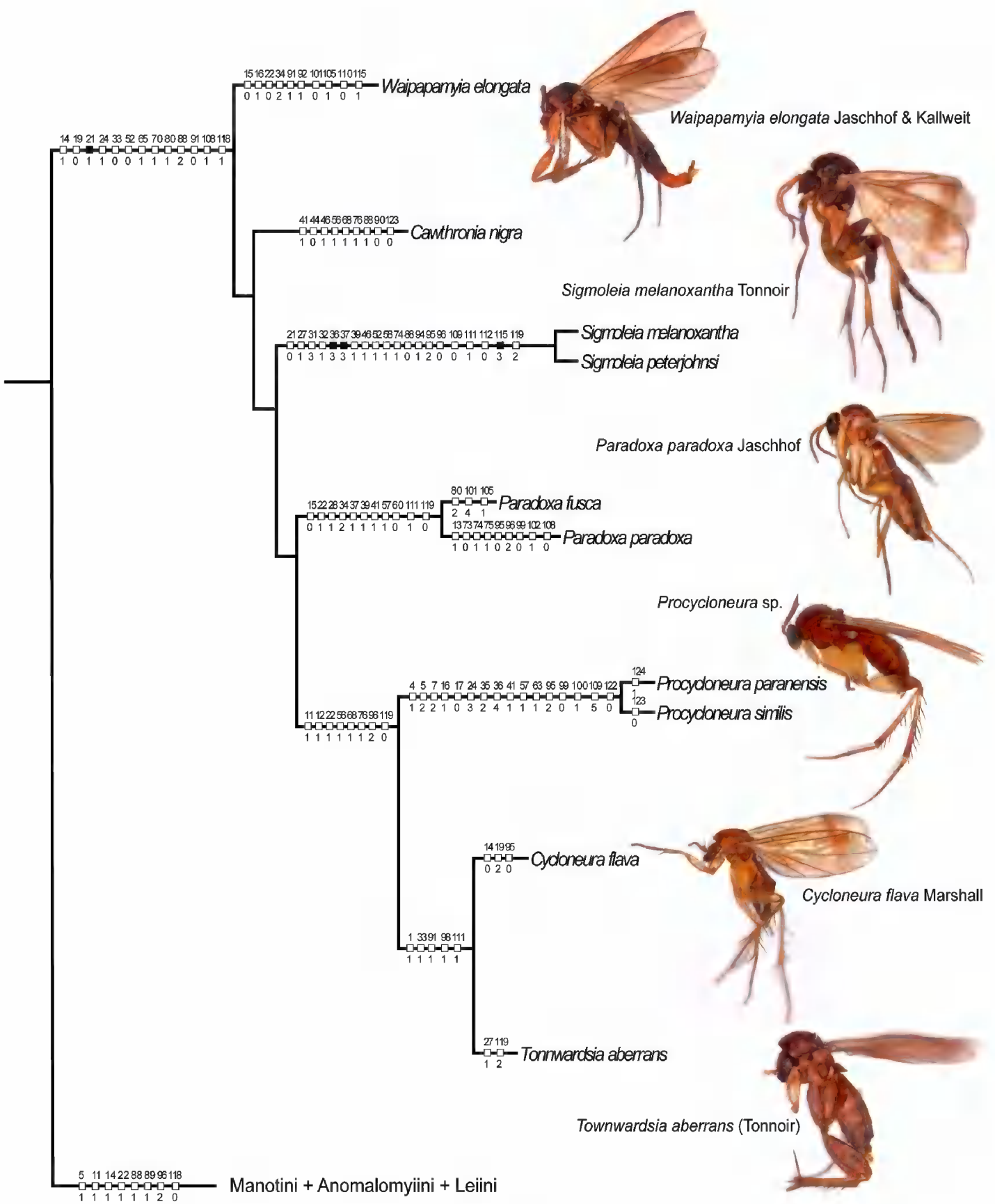

FIG. 104. Character distribution in the tree of the Cycloneurini ${ }^{+}$in the majority consensus of the 119 most parsimonious trees obtained with equal weight analysis, the Manotini ${ }^{+}$as a terminal. 


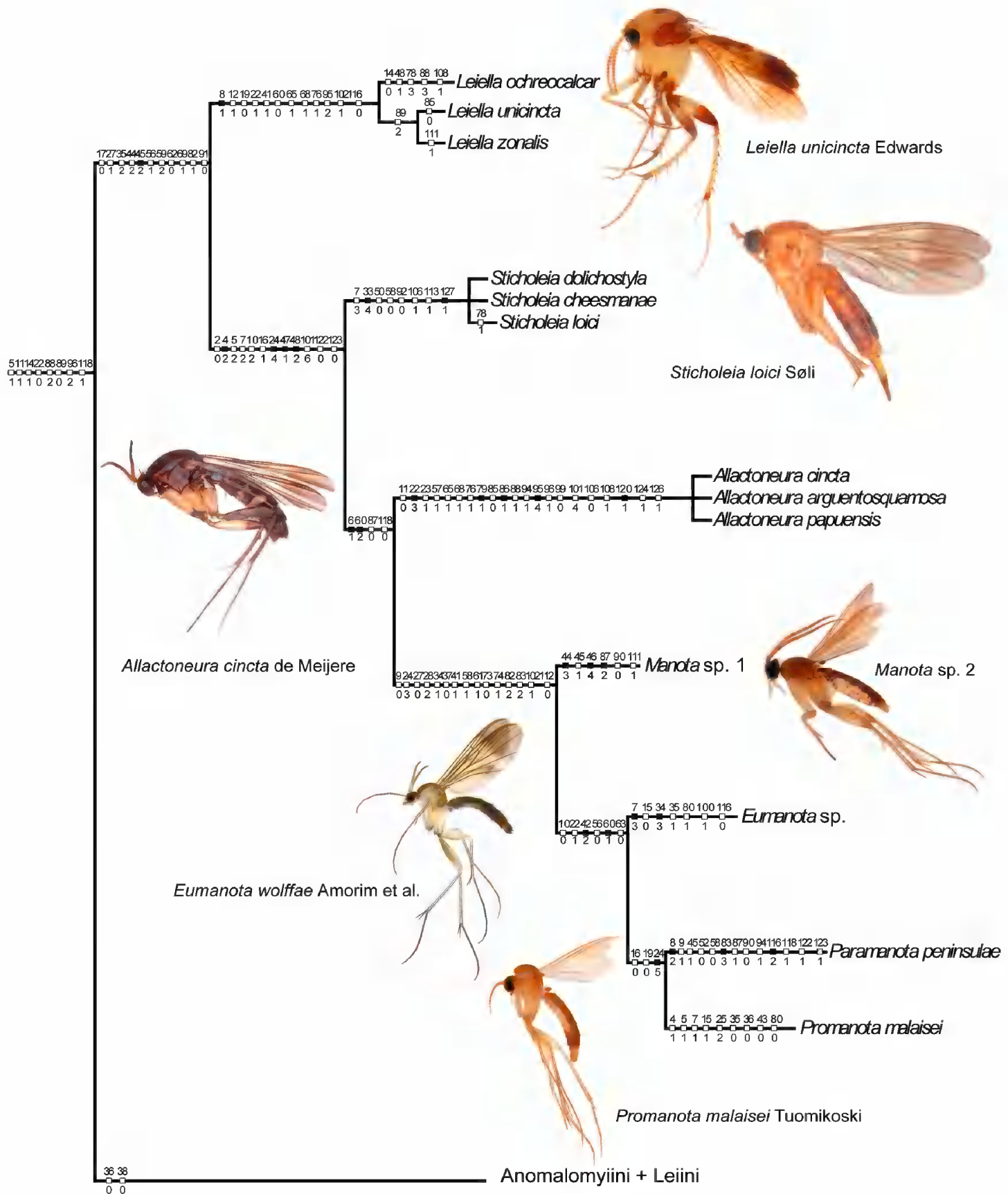

FIG. 105. Character distribution in the tree of the Manotini ${ }^{+}$in the majority consensus of the 119 most parsimonious trees obtained with equal weight analysis, the Anomalomyini ${ }^{+}$as a terminal (habitus of Eumanota wolffae, photo Andrea Carolina Henao-Sepúlveda). 


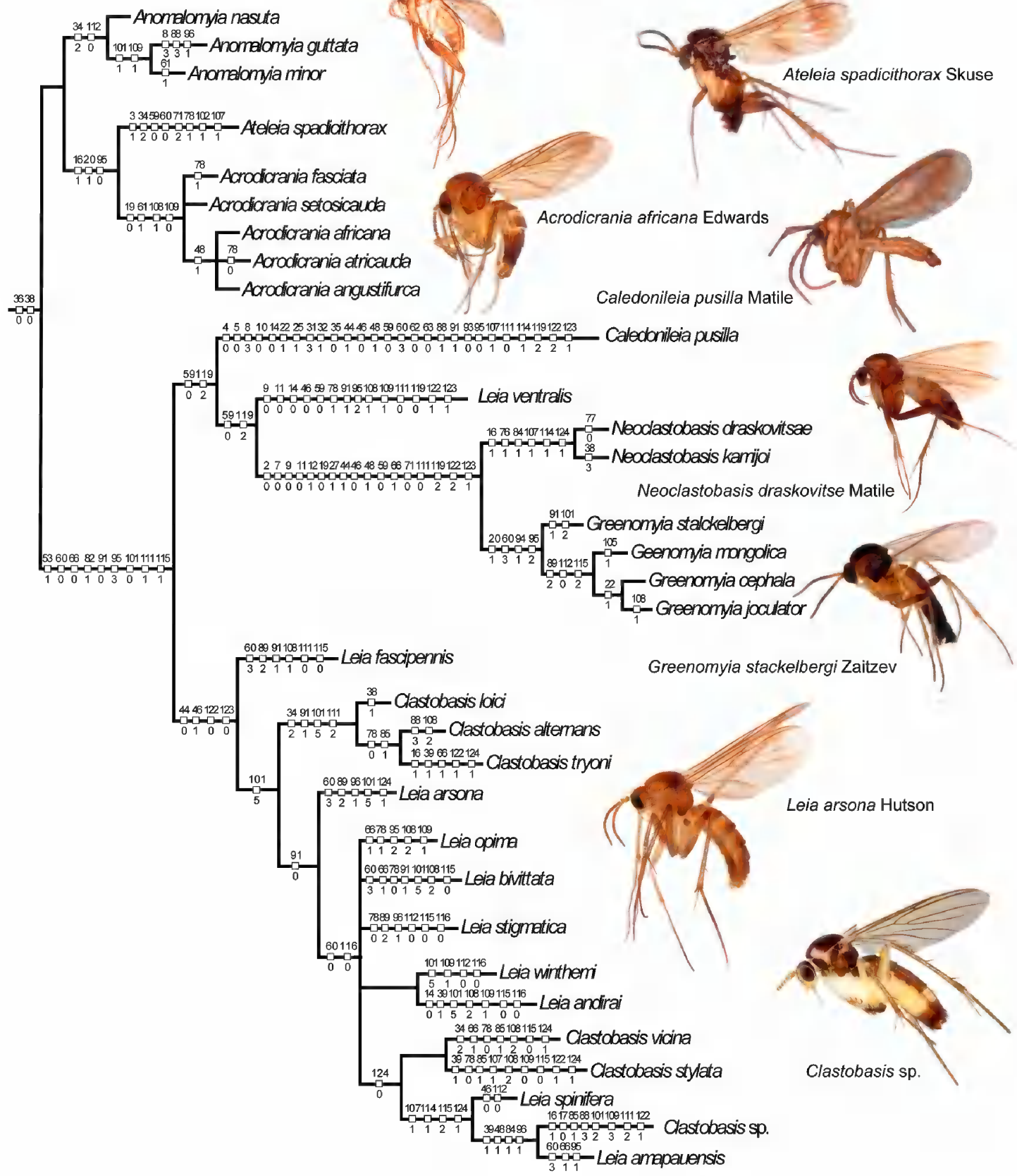

FIG. 106. Character distribution in the tree of the Anomalomyini+ in the majority consensus of the 119 most parsimonious trees obtained with equal weight analysis. 
extensions of the gonocoxites that are equally long (interpreted as extensions of tergite 9 by Søli, 1996, 2002a). The gonocoxites are fused medially to each other along the entire ventral face. The gonocoxite extensions are from nearly three to five times the length of the body of the terminalia itself. The gonocoxites have a long row of slender spines placed along the inner face of the distal half of the gonocoxite extension. The syngonocoxite ventrally has a pair of projections with a long seta at the apex and two additional digitiform lobes of the gonocoxite at each side, close to the base of the gonostylus. The gonostylus is small, elongate, slightly bent midway to apex, slightly widened distally, with only a few fine setae. The aedeagus is subtriangular, quite slender distally. The parameres are not easy to recognize, but they seem to be wide and laminar. Tergite 9 is reduced to a small sclerite between the dorsal borders of the gonocoxites dorsally, at the base of the cerci. The cercus is thin and elongate, with long, curved setae on its internal face along its entire length. This pattern is unique among the leiines.

There are good illustrations of the male terminalia of Allactoneura in the original descriptions of species, but without much discussion on homology of the sclerites of its complex male terminalia. Bechev (1995: figs. 1-2) included illustrations of the terminalia in lateral view and of the tip of the gonostylus of A. papuensis. Zaitzev (1982a) has illustrations of the male terminalia of $A$. ussuriensis Zaitzev, A. formosa (Enderlein), and A. cincta de Meijere in lateral view (respectively figs. 1.1, 2.2, 3.1) and of the tip of the gonostyle in lateral view (figs. 1.6, 2.3, 3.2) and the of the terminalia of $A$. cincta in ventral view (fig. 2.1). Sasakawa (2005: figs. 6-7) illustrated the male terminalia of $A$. akasakana Sasakawa in lateral view and in ventral view, respectively. The most important discussion on the homology of the male terminalia was made by Søli (1997, fig. 33B). The male terminalia in Allactoneura is rotated, meaning that the gonocoxites are largely developed, occupying the entire original ventral face of the terminalia, extending far beyond the level of the tip of the cerci. The gonostyli are displaced dorsad and partially articulating directly to tergite 9. The gonostylus is about as long as the gonocoxites or longer. The aedeagal-parameral complex is rectangular, well sclerotized, and also elongated, about half the length of the gonocoxites. Tergite 9 is always relatively small at the original dorsal face of the terminalia, placed anteriorly to the base of the gonostylus. The cerci are small, slightly elongate, placed medially at the posterior margin of tergite 9 (figs. 78-79). There is an Oligocene fossil of this genus known from France (Théobald, 1937). A fossil specimen of a male belonging to a species of the crown group of the genus is not difficult to recognize.

The male terminalia of four species of Eumanota were carefully described and illustrated by Søli (2002b: figs. 5-19), while Papp (2004: figs. $1-8$ ) described and illustrated the terminalia of two species of the genus. Hippa et al. (2005) redescribed the terminalia of E. leucura (fig. 5C, D) and of two additional species (figs. 4B, 5A, B). More recently, Amorim et al. (2018) included detailed illustrations of the terminalia of the Neotropical species of the genus, E. wolffae Amorim, Oliveira, and Henao-Sepúlveda, from Colombia. The gonocoxites of Eumanota species are fused medially along at least part of the ventral face of the terminalia. There are some projections at the posterior margin of the gonocoxites ventrally and laterally. The tip of the gonocoxite in some species extends beyond the base of the gonostyle laterally. The gonostylus may be digitiform, club shaped or with ornamentation, only with fine setae or with some few additional stronger setae. The aedeagus may be tubular distally and the parameres may be ornamented. Tergite 9 is trapezoid, elongate, with well-developed cerci placed distally (figs. 80-81).

In a good extension, the general pattern of the male terminalia of Eumanota applies to Promanota. In Promanota, the terminalia is more or less elongate, encapsulate, the trapezoid tergite 9 with well-developed cerci placed at its posterior margin. In both known species of Promanota, the gonocoxite extends laterodistally to the level of the tip of the gonostylus (Tuomikoski, 1966: figs. 1-2; Hippa et al., 2005: figs. 6a-c; Papp, 2004: figs. 9-12). 


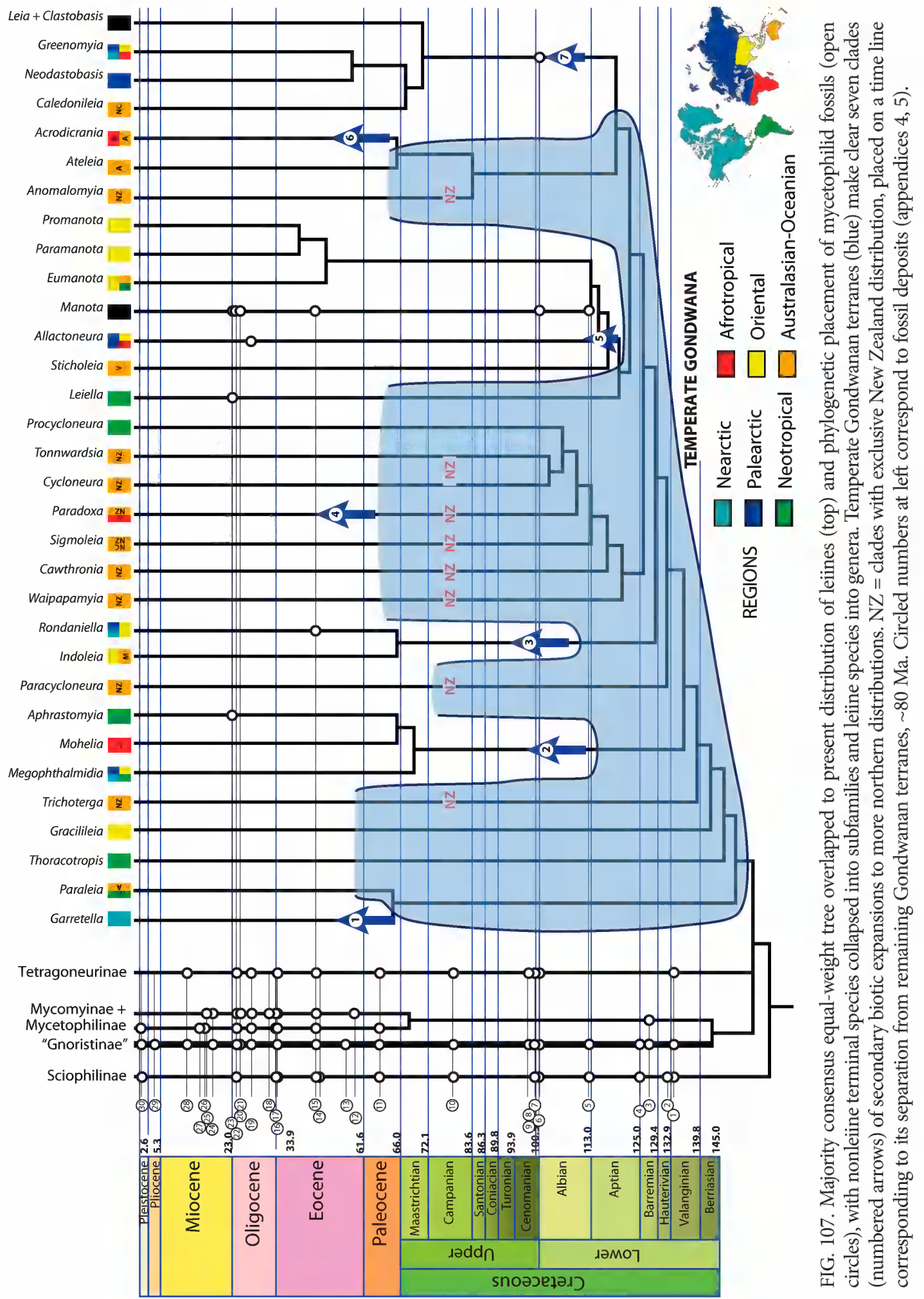


This pattern of the male terminalia of Paramanota is quite divergent from these other two Manotini genera. In Paramanota, the gonocoxites are well-developed laterally but are separated medially by a wide membranous area, in some species covering almost entirely the ventral face of the terminalia. Hippa (2010: 48) mentioned that the ventral lobe in Paramanota is similar to "sternite 9" in Manota (e.g., Hippa, 2009: fig. 2 d) - except for the fact that the gonocoxites in Paramanota are divided ventrally into these two separate halves. It is interesting to note that, as happens with in the wing venation, there are some derived similarities in male terminalia features shared between Paramanota and Manota. Paramanota orientalis Tuomikoski, the type species of the genus, shows the gonocoxites largely developed ventrally (Tuomikoski, 1966: figs. 3-4; Hippa, 2010: figs. 5C-E). From a dorsal view, it is possible to see spines at the inner face of the gonocoxites. The gonocoxites may have a digitiform projection of the posterior margin of gonocoxite laterally at its ventral face, as in P. bifalx Hippa (Hippa, 2010: fig. 2C-D), medially, as in P. furcillata Hippa (Hippa, 2010: fig. 3D) and P. schachti Papp (Papp, 2004: fig. 29), or at an inner face, as in P. orientalis (Hippa, 2010: fig. 5D), in P. awanensis Hippa et al. (2005: fig. 9a, b) and P. sumatrana Hippa et al. (Hippa et al., 2005: fig. 11a). Neither $P$. rodzayi Hippa et al. or P. trilobata Hippa et al. (Hippa et al., 2016: figs. 1A-D, 2A-C) have the distal-lateral digitiform extension of the gonocoxite. The gonostylus is small compared to the gonocoxite and is particularly complex, with branches and a comb of spines. The aedeagus and the parameres are fused together, forming a subquadrangular, slightly elongate scleritedetails of the aedeal-parameral complex vary among species. Tergite 9 is subquadrate, with the cerci well developed, visible distally in $P$. schachti Papp (Papp, 2004: figs. 26-30). The fossil $P$. grandaeva is a female, so male terminalia features cannot be verified in the holotype. In its own way, this is also a unique male terminalia pattern in the Leiinae.
There are now over 300 described species of Manota worldwide (Kurina et al., 2019), with an important number of photos and illustrations of the male terminalia. There is considerable variation on the morphology of different sclerites of the male terminalia in the genus. It can be fairly simple, as in Manota ctenophora Matile (Matile, 1993: figs. 65-66), or quite complex, e.g., as in M. palpalis Lane (Kurina et al., 2018: figs. 22B, $\mathrm{C})$, in which the gonocoxite has a parastylar lobe, a medial lobe, a large platelike lobe and a posterolateral lobe, ornamented with juxtagonostylar megasetae, spathulate subapically geniculate megasetae, the gonostylus having a lateromedial expansion, a subapical digitiform lobe and a subapical ventral small lobe with twisted setae. In a large number of species, the gonocoxites are separate medially, with a sclerite in between (referred to as sternite 9). This sclerite is smaller in some species and considerably well developed in others (e.g., M. peltata Kurina and Hippa (Kurina and Hippa, 2014). The gonocoxites in some cases extend much beyond the tip of the gonostylus (as in $M$. carioca Kurina, Hippa and Amorim) or may end almost at the level of the insertion of the gonostylus (e.g., $M$. hirta Kurina, Hippa and Amorim). The gonostylus is usually small, but with different kinds of ornamentation-i.e., branches and setae. In some few species, as in $M$. forceps Hippa and Papp, the gonostylus is largely developed. The aedeagus is often elongate, subtriangular, with or without lateral shoulders. The aedeagal apodemes can be recognized, but the aedeagalparameral complex is not particularly sclerotized or easy to be identified. Only some few species have a recognizable tergite 9 (e.g., $M$. atlantica) and in most descriptions tergite 9 is not even mentioned; it is usually fused to the gonocoxite at the lateral margins. The cerci are present in a more distal position in the terminalia dorsally, usually elongate and close to each other. Most recent papers describing species of Manota from the Oriental (Hippa and Papp, 2007; Hippa and Ševčík, 2010; 2013; Hippa and Saigusa, 2016; Hippa and Kurina, 2018;), Afro- 
tropical (Jaschhof and Mostovski, 2006; Hippa, 2008; Hippa and Kurina, 2012; Kurina and Hippa, 2014), Neotropical (Jaschhof and Hippa, 2005; Hippa and Kurina, 2013; Hippa et al., 2017; Kurina et al., 2017, 2018), Australian (Hippa, 2007; Jaschhof and Jaschhof, 2010; Ševč́k et al., 2014; Kurina and Hippa, 2015) and Holarctic (Jaschhof et al., 2011) regions are richly illustrated.

In the Anomalomyiini, the shape of the male terminalia largely fits into a general mycetophilid standard, but some details are shared among the three genera of the tribe (fig. 82-83). In Anomalomyia, the gonocoxites together are $\mathrm{V}$-shaped, with a deep and wide separation between them ventrally, connected medially only at the anterior end of the terminalia (Tonnoir and Edwards, 1927: figs. 232-235; Matile, 1993: figs 2-3). The gonostylus is placed distally at the gonocoxite, i.e., there are no gonocoxites lobes projecting beyond the base of the gonostylus. The gonostylus is complex, with a large variation between the species. There are three basal lobes on the gonostylus, with combs of spines, setae, and scattered spines. The ventral lobe is consistently bare, bladelike. The parameres have a distal projection extending beyond the tip of the tegmen. Tergite 9 is fused laterally to the gonocoxites.

There are no illustrations of Ateleia in the literature to date. The male terminalia of Ateleia are considerably similar to that of Anomalomyia. The gonocoxites are also widely separated ventrally. The gonostylus is basically digitiform, with some short basal lobes, including a bladelike, bare ventral lobe. There is a small comb of spines distally on one of the lobes and there are scattered short spines at the inner face of the gonostylus distally. Tergite 9 is also fused to the gonocoxites laterally (fig. 82).

The male terminalia of Acrodicrania is slightly more complex, but the changes are relatively minor in relation to the pattern seen in the other two genera of Anomalomyiini. A. fasciata Skuse has a row of strong setae along the inner margin of the gonocoxite at the ventral face of the terminalia, but this is lacking in other Australian species or in A. africana Edwards, the type species of the genus. The gonostylus is placed at the distal end of the gonocoxite and has basal lobes, as in the other two genera of Anomalomyiini; the ventral lobe is also bare and bladelike, the other two with comb of spines and strong setae. The inner face of the main lobe of the gonostylus has scattered shorter spines. The aedeagus is cylindrical, the distal third more slender than the proximal two thirds. The parameres extend beyond the tip of the aedeagus and have fine and strong setae distally (fig. 83). There are no published illustrations of the male terminalia of any of the four Australian species, the Afrotropical species or the three Oriental species of Acrodicrania.

The Leiini have some variation of male terminalia general format and of the shape and ornamentation of their sclerites as well (figs. 84-95). The only known species of Caledonileia has features (Matile, 1993: figs. 21-22) that make its placement within the Leiini likely. The gonocoxites are quite separate medially on the posterior two thirds of the terminalia at the ventral face and are fused together on the anterior third. The syngonocoxite extends itself medially toward the aedeagal-parameral complex, a condition similar to that seen in Neoclastobasis (fig. 86). The gonostylus is suboval, with a pair of basal lobes, the ventral one bladelike and bare, the dorsal one digitiform, with a comb of spines. Indeed, the basal lobes of the gonostylus in Caledonileia are similar to those in Neoclastobasis (fig. 86) and in Greenomyia (fig. 87), and much as in the genera of Anomalomyiini (figs. 82-83). The distal end of the aedeagal-parameral complex is well sclerified dorsally. The aedeagal apodeme extends anteriorly to reach the segment VIII. Tergite 9 cannot be recognized dorsally and seems to be entirely fused laterally to the dorsal borders of the gonocoxites.

It is worth considering the male terminalia of Leia ventralis separate from the rest of the species of Leia (figs. 84, 85) and Clastobasis (figs. 88-95). The gonocoxites are largely fused 
together along the anterior half of the terminalia ventrally and there is no suture of the fusion or evidence of a medial syngonocoxite sclerite. Each gonocoxite extends laterally beyond the medial posterior margin of the syngonocoxite, with the gonostyli placed apically at each gonocoxite. There is a pair of very large spines (apparently articulated into sockets) at the posterior margin of the syngonocoxite medially. The gonostylus is relatively simple, with a main lobe wider at base that becomes slender toward the apex, but also with basal lobes. There are scattered setae on the gonostylus and a long, stronger seta at the apex. The parameres are well developed and sclerotized, apparently with a pair of protuberances with short dark spines ventrally on the internal margins. The gonocoxal apodemes are well separated. Tergite 9 is elongate, separate laterally from the dorsal borders of the gonocoxites. The differences between the male terminalia of $L$. ventralis and those of other species of Leia and of Clastobasis, Neoclastobasis, Greenomyia, and Caledonileia suggest that this species may belong to a separate genus.

Neoclastobasis has more open male terminalia, with a clear $\mathrm{V}$-shape of the syngonocoxite (Matile, 1978: figs. 1-2; Zaitzev, 1982b: figs. 2.4$6,3.1-3)$. The gonocoxites are connected together medially on their basal third and there is a conspicuous distal extension of the gonocoxite at the ventral face, partially covering the base of the gonostylus. The gonostylus is palmate, with a pair of elongate lobes basally, the ventral one bare and bladelike and the other one with a group of distal short spines. The entire inner face of the main body of the gonostylus is covered with dense, stiff setae. The aedeagal-parameral complex is subquadrate, sclerotized distally. The cerci are projected dorsally slightly beyond the tip of the aedeagus (fig. 86).

In Greenomyia, the terminalia is slightly longer than wide and the gonostylus is also placed distally at the gonocoxite (Zaitzev, 1982b: figs. 1.1-2, 2.1-2; Matile, 2002: figs. 1-3). The gonocoxites with few exceptions are not in contact medially except close to the anterior margin of the terminalia. In most cases, there is a distal extension of the gonocoxite internal margin, which shape varies among species. The gonostylus is complex, subquadrate, with a bladelike, bare ventral lobe and a dorsal lobe with strong apical setae; the main body of the gonostylus has elongate setae along the distal margin and a comb of spines at the inner face. Dorsally, the gonocoxites are fused to tergite 9. The cerci extend at least to the level of the base of the gonostylus (fig. 87).

Taxon sampling here was designed to generate phylogenetic information along the Leiinae backbone, and seems adequate to demonstrate that the Leia-Clastobasis complex corresponds to a clade within the tribe Leiini. The sampling of species within each of these genera, however, is not enough to provide a full solution for the relationship within the clade with these two genera. Because understanding of homology is largely illuminated by hypotheses of phylogeny, not solving the problem of the paraphyly or polyphyly of these two genera weakens our attempts to solve some of the issues of homology concerning male terminalia in the clade.

We can distinguish morphologically two main patterns in the clade-a "standard Leia pattern" and a "standard Clastobasis pattern." There are species in either genera, however, that clearly do not fit well into either of the patterns and there are species that combine some of the features in both patterns. The terminalia in both genera are considerably wide in lateral view due to the gonocoxite well developed along its ventral-dorsal axis. The standard Leia pattern can be recognized by the aedeagal-parameral complex with a well-sclerotized "arrow-headed" distal end, quite easily recognizable in the terminalia of many species, with a considerably simple gonostylus. This is the condition seen in the type species of the genus, Leia fascipennis (fig. 94). The usual Clastobasis pattern has a well-developed medial syngonocoxite sclerite, often bifid, in some species projecting beyond the tip of the laterodistal end of the gonocoxite, 
with the gonostylus often quite developed, as in the type species of the genus, Clastobasis tryoni Skuse (fig. 89). There are, however, species of Clastobasis with a well-sclerotized aedeagus distal end-as in C. alternans (Winnertz) (Chandler, 2001: figs. 15, 17) (fig. 88)-and species of Leia with a well-developed medial syngonocoxite sclerite projecting posteriorly-as in L. flavipennis Laštovka and Matile and L. rufiptera Ostroverkhova (Polevoi and Salmela, 2016: figs. 1 and 5, respectively). This seems to reinforce the hypotheses that both genera are paraphyletic or polyphyletic to each other.

In Clastobasis, the general shape of the male terminalia in most species is encapsulated, similar to that of most Leia. The medial sclerite of the syngonocoxite, however, is conspicuous in most species and is sometimes bifid distally, e.g., Clastobasis alternans (Winnertz) (Chandler, 2001: figs. 15-17) and C. tanganyikae (Matile) (Matile, 1973: fig. 8), but also may be absent, as in C. tryoni. In some groups of species, there is a posterior extension of the gonocoxite ventrally, e.g., C. tryoni (fig. 89) and C. alternans (Chandler, 2001: figs. 15-17), or dorsally, e.g., C. maculicoxa Matile (Matile, 1978: fig. 37), with concentrated spines or modified setae. The gonostylus in some species is particularly long, as in C. stylata Matile (Matile, 1993: fig. 16), but in most Clastobasis species the gonostylus is much smaller, as in C. loici Chandler (Chandler, 2001: figs. 18-20). The gonostylus in some cases has branches or lobes, as in C. brunhesi Matile (Matile, 1993: fig. 40), but in many cases it is rather simple, "Leia-like" in size and shape, as in C. alternans. An aedeagal-parameral complex that distally is hardly sclerotized is seen, for example, in C. alternans, C. villiersi Matile, C. tryoni, C. stylata, C. loici, etc. The length and shape of tergite 9 and the cerci varies considerably between species (figs. 88-91).

Leia fascipennis Meigen was carefully illustrated by Kurina (2008: figs. 27-30) and $L$. winthemi Lehmann was illustrated by Søli (1997: fig. 31A) (fig. 94). There are additional good illustrations of species of Leia, e.g., in
Polevoi and Salmela (2016). In many species of Leia, the gonocoxites are about twice as long as wide in ventral view. The inner and outer margins of the gonocoxite ventrally are more or less parallel to each other in most species and many species have a medial process projecting between the gonocoxites. The shape and the length of this process is considerably variable. The gonostylus is well sclerotized and elongate in most species, and at rest it more or less fits across the distal end of the terminalia as a lid on each side (Kurina, 2008: fig. 28). There are species in which the gonostylus is not digitiform and assumes other shapes, e.g., subtriangular, bifid, etc. Only rarely Leia species have modified, spinose setae on the gonostyle, having at most elongate fine setae. Apparently, no species of Leia has a basal, bladelike projection of the gonostylus, as seen in Greenomyia and in Neoclastobasis. If we assume that this blade is a synapomorphy of the Anomalomyiini ${ }^{+}$, the condition in Leia would be due to a secondary loss of this blade. Tergite 9 is largely independent from the gonocoxites laterally, usually trapezoid and elongate. In some cases, a pair of slightly elongate cerci project beyond the level of the base of the gonostylus. The parameres are connected anteriorly and project beyond the distal end of the well-sclerotized aedeagus (figs. 92-95). In some species, as L. nigricornis van Duzee, this typical enclosed shape of the male terminalia is not seen (Polevoi and Salmela, 2016: figs. 4A-C).

\section{Key for the Genera of Leitnae}

An identification key for the genera of Leiinae as delimited here is included below. This key is largely modified from Vockeroth (1981, 2009) and Søli et al. (2000). Abbreviation for geographical distribution of genera as follows: PA, Palaearctic Region; NE, Nearctic Region; OR, Oriental Region; AF, Afrotropical Region; NT, Neotropical Region; AU, Australasian/Oceanian Region. 
1. All postgenal setae long; face rectangular, wide; basisternum in lateral view, laterally to proepisternum, shieldlike, well developed, wide; basisternum pubescent, with dense setae over entire surface ... 2

- Postgenal ventral setae all short or with 2 or 3 setae longer than the others; face shape variable, not as above; basisternum in lateral view, laterally to proepisternum, weakly developed, present as a narrow band; basisternum pubescent, with microtrichia and scattered setae, without bristles, or with setae and bristles scattered

2(1). Occiput flat; katepisternum squared; male cercus extremely elongated, many times longer than the length of distal projection of gonocoxite (fig. 43) ....... Sticholeia Søli (AU)

- Occiput depressed; katepisternum triangular; male circus not elongated as described above

...3

3(2). Three longitudinal folds on wing, one across $\mathrm{r}-\mathrm{m}$, one posterior to $\mathrm{M}_{2}$ and one posterior to $\mathrm{CuA}$ (fig. 44); cerci bilobate, ovoid .....Allactoneura de Meijere (PA, OR, AF, AU)

- Wings without longitudinal fold (figs. 45-48)

4(3). $M_{1}$ present, not connected to $M_{2} ; M_{1+2}$ not connecting to $r-m ; R_{5}$ originating very basally in the wing, running very close to $\mathrm{C}$ (fig. 45); proepimeron elongated and medially prominent

Manota Williston (PA, NE, OR, AF, AU, NT)

- $M_{1}$ present or absent, if present, connected to $\mathrm{M}_{2} ; \mathrm{M}_{1+2}$ connecting to $\mathrm{r}-\mathrm{m} ; \mathrm{R}_{5}$ originating at or beyond midpoint of wing, running close to C mostly on distal end (figs. 46-47); proepimeron rectangular...

5(4). Face squared; postgena prominent medially; last palpomere extremely long, much longer than others

....Eumanota Edwards (OR, AU, NT) - fig. 47

- Face rectangular, dorsoventrally elongated; postgena triangular or as a straight line; last palpomere more than $1.5 \times$ length of the penultimate, but not extremely elongated ....
6(5). Postgena as a straight line; median ocellus divided into two; subcostal vein very short, curved abruptly toward $\mathrm{C} ; \mathrm{A}_{1}$ complete, reaching wing margin (fig. 48 )

Paramanota Tuomikoski (OR)

- Postgena triangular; median ocellus as large as or slightly smaller than lateral ones; subcostal vein incomplete, inclined toward $R$ but ending free; $A_{1}$ incomplete, ending at basal third toward margin (fig. 46) Promanota Tuomikoski (OR)

7(1). Laterotergite bare .8

- Laterotergite setose, often long setae along posterior margin, but sometimes few and short .............................................................18

$8(7)$. Mouthparts reduced, 2 palpomeres. $\mathrm{R}_{1}$ more than twice length of $\mathrm{r}-\mathrm{m}$ (fig. 24) Thoracotropis Freeman (NT)

- Mouthparts developed, sometimes small, 5 palpomeres. $\mathrm{R}_{1}$ shorter or longer than $\mathrm{r}-\mathrm{m}$ (figs. 22-23, 25, 30, 33-34, 36-40) ..........9

9(8). Sc complete, reaching C (figs. 22-23, 33-34)

- Sc incomplete, ending free (figs. 25, 30, 36-40) .........................................................13

10(9). $C$ ending at $R_{5} ; r-m$ longer than $R_{1} ; C u A$ gradually curved (fig. 22) .... Garretella Vockeroth (NE)

- $C$ ending in $\mathrm{R}_{5}$; $\mathrm{r}-\mathrm{m}$ shorter than $\mathrm{R}_{1}$; $\mathrm{CuA}$ sinuous (figs. 23, 33-34) .... 11

11(10). Lateral ocelli separated from eye margin by a distance as wide as lateral ocellus or smaller. $\mathrm{C}$ ending slightly beyond $\mathrm{R}_{5} ; \mathrm{r}-\mathrm{m}$ longer than $\mathrm{R}_{1}$ (fig. 23)

Paraleia Tonnoir (NT, AU)

- Lateral ocelli separated from eye margin by a distance larger than width of lateral ocellus. C extending well beyond $\mathrm{R}_{5} ; \mathrm{r}-\mathrm{m}$ shorter than $\mathrm{R}_{1}$ (figs. 33-34)

$12(11) . R_{4}$ present (fig. 165); medial and cubital forks with $\mathrm{M}_{2}$ and $\mathrm{M}_{4}$ obsolete basally (fig. 33) Waipapamyia Jaschhof and Kallweit (AU)

- $\mathrm{R}_{4}$ absent; medial and cubital with only $\mathrm{M}_{4}$ obsolete basally (fig. 34) Cawthronia Tonnoir and Edwards (AU) 
13(9). Medial fork incomplete or absent (figs. 30, 38-39) .... 14

- Medial fork complete (figs. 25, 36-37, 40) ...

14(13). CuP fused distally to CuA (fig. 38) Cycloneura Marshall (AU)

- CuP free distally (figs. 30, 39) ..... 15

15(14). $\mathrm{M}_{4}$ originating beyond origin of $\mathrm{M}_{1+2}$; $\mathrm{CuA}$ nearly straight beyond origin of $\mathrm{M}_{4}$ (fig. 30)

Paracycloneura Tonnoir and Edwards (AU)

- $\mathrm{M}_{4}$ originating closer to wing base, more basally than origin of $\mathrm{M}_{1+2}$; $\mathrm{CuA}$ sinuose on distal half (fig. 39) .

Tonnwardsia Jaschhof and Kallweit (AU)

16(13). $M_{1}, M_{2}$, and $M_{4}$ not reaching wing margin; $\mathrm{CuP}$ free (fig. 25).

..Gracileia Matile (AU)

- $\mathrm{M}_{1}, \mathrm{M}_{2}$, and $\mathrm{M}_{4}$ reaching wing margin; $\mathrm{CuP}$ fused distally to $\mathrm{CuA}$ (figs. 36-37, 40) ... 17

17(16). $M_{1+2}$ and $M_{1}$ obsolete basally (fig. 40). Lateral ocelli separated from eye margin by distance similar to lateral ocellus width ... Procycloneura Edwards (NT)

- $\mathrm{M}_{1+2}$ e $\mathrm{M}_{1}$ complete basally (figs. 36-37). Lateral ocelli separated from eye margin by $2 \times$ lateral ocellus width

Paradoxa Marshall (AF, AU)

18(7). $\mathrm{C}$ ending at $\mathrm{R}_{5}$ (figs. 41-42, 52-63) ... 19

- C extending beyond $\mathrm{R}_{5}$ (figs. 26-29, 31-32, $35,49-51)$.

19(18). Lateral ocelli close to or in contact with eye margin; middle ocellus very small. $M_{1}$ obsolete basally (figs. 41-42) .

Leiella Enderlein (NT)

- Lateral ocelli separated from eye margin; middle ocellus only slightly smaller than lateral ocelli or absent. $\mathrm{M}_{1}$ complete basally (figs. 52-63) 20

20(19). One preocellar seta in front of lateral ocelli. Hind femur not flattened anteroposteriorly 21

- No preocellar seta in front lateral ocelli. Hind femur flattened anterodorsally ...... 22

21(20). Hind tibial spurs shorter than first tarsomere. Sc bare; $R_{5}$ straight or almost straight from origin to apex; $\mathrm{M}_{2}$ reaching wing margin (fig. 55) .

Greenomyia Brunetti (PA, NE, OR)

- Hindi tibial spurs longer than first tarsomere. Sc pubescent; $R_{5}$ curved distally; $M_{2}$ not reaching wing margin (fig. 54) ........

Neoclastobasis Ostroverchova (PA)

22(20). Middle ocellus absent; frons partially pubescent; face wider than clypeus; mouthparts reduced; two palpomeres .....

Caledonileia Matile (AU) - fig. 52

- Mid ocellus as larger or slightly smaller than lateral ones; frons bare; face and clypeus ratio 1:1; mouth parts as a typical labella, one palpomere 23

23(22). Mid ocellus presente or absent, lateral ocelli touching or nearly touching eye margin. Origin of $\mathrm{M}_{4}$ anterior to level of apex of Sc; sc-r ausente (figs. 57, 60, 62) ....

Clastobasis Skuse (PA, OR, AF, AU)

- Mid ocellus presente, lateral ocelli not touching eye margin. $\mathrm{M}_{4}$ originating at or beyond level of apex of Sc; sc-r present (figs. 53, 56, $58-59,61,63)$

...... Leia Meigen (PA, NE. OR. AF, NT, AU)

24(18). Mouthparts reduced, only two palpomeres; $\mathrm{CuP}$ distally fused to $\mathrm{CuA}$ (fig. 35)

Sigmoleia Tonnoir and Edwards (AU)

- Mouthparts normally developed, five palpomeres; CuP not fused to CuA (figs. 26-29, $31-32,49-51)$ 25

25(24). Mouthparts modified into a proboscid. Tibial setation arranged in regular rows ....... 26

- Mouthparts not modified into a proboscid. Tibial setation not arranged in regular rows 28

26(25). Few interocelar setae; no distinct longer seta at apex of pedicel. $R_{1}$ longer than $r-m$ (fig. 27)

...Megophthalmidia Dziedzicki (PA, NE, NT)

- Interocelar setae dense or absent; a distinct longer seta at apex of pedicel. $\mathrm{R}_{1}$ as long as r-m (figs. 28-29) 27

27(26). No interocelars; antennal flagelomeres laterally flattened. A pair of long scutellar 
setae. First sector of CuA bare (fig. 29). Forecoxa about as long as mid and hind coxae... Aphrastomyia Lane and Coher (NT)

- Many interocelars setae; antennal flagelomeres cylindrical. Two pairs of longer scutellar setae. First sector of $\mathrm{CuA}$ pubescent (fig. 28). Forecoxa about half of mid and hind coxae length Mohelia Matile (AF) 28(25). $\mathrm{r}-\mathrm{m}$ shorter than $\mathrm{R}_{1}$ (figs. $26,31-32$ ) ......

- $\quad \mathrm{r}-\mathrm{m}$ longer than $\mathrm{R}_{1}$ (figs. 49-51) .............. 31

29(28). Head positioned under anterior margin of scutum; scutum with longer acrostichals, dorsocentrals, intraalars, and supraalars; a pair of longer scutellars; laterotergite vertical. Sc ending free, bare (fig. 26)

Trichoterga Tonnoir and Edwards (AU)

- Head not positioned under anterior margin of scutum; no long scutum setae except for some marginal setae; two pairs of scutellars; laterotergite inclined. Sc ending at C, pubescent (figs. 31, 32

30(29). Two ocelli, many interocelar setae. $r-m$ almost longitudinal; $\mathrm{M}_{1}$ longer than $\mathrm{M}_{1+2}$, not obsolete basally (fig. 31) Indoleia Edwards (OR, AU)

- Three ocelli, few interocelar setae. $r$-m nearly transverse; $M_{1}$ shorter than $M_{1+2}$, obsolete basally (fig. 32)

Rondaniella Johannsen (PA, OR)

31(28). Lateral ocelli separated from eye margin by more than ocellus width. Anepisternum smaller than katepisternum. Sc-r present; $M_{1}$ obsolete basally; $\mathrm{M}_{2}$ not reaching wing margin (fig. 50) Ateleia Skuse (AU)

- Lateral ocelli separated from eye margin by less than ocellus width. Anepisternum and katepisternum of similar size. Sc-r present or absent; $M_{1}$ complete; $M_{2}$ reaching wing margin (figs. 49, 51) . 32

32(31). Sc-r present; $M_{1}$ and $M_{2}$ clearly divergent; $\mathrm{M}_{4}$ obsolete basally (fig. 51)

Acrodicrania Skuse (OR, AF, AU)

- Sc-r absent; $\mathrm{M}_{1}$ and $\mathrm{M}_{2}$ parallel; $\mathrm{M}_{4}$ complete basally (fig. 49) ...... Anomalomyia Hutton (AU)

\section{Mesozoic Fossil Record of the Leirnae}

The phylogenetic analysis of the Leiinae in this paper provides not only hypotheses of relationships for the subfamily, but also a more rigorous basis for fitting fossils into the framework of evolution of the group. Cenozoic fossils of Mycetophilidae basically belong to the Recent genera or are sister clades to Recent genera. The Cretaceous genera, however, clearly belong to the early diversification of mycetophilid cladesmuch harder to precisely place into the classification of living genera, but particularly informative about the evolution of the group.

The most important published paper in this context is Blagoderov and Grimaldi's (2004) study of sciaroids from six major early to late Cretaceous amber deposits-Lebanon (ca. 125 Ma), northern Spain (ca. 105-108 Ma, Albian), northern Myanmar (98-99 Ma), northern Siberia (134-131 Ma, ca. $100 \mathrm{Ma}$, and 90-94 Ma), New Jersey (90-94 Ma), and western Canada (ca. $78 \mathrm{Ma}$ ).

Blagoderov and Grimaldi (2004) described species related to the Sciophilinae, the Gnoristinae, the Manotinae, and the Leiinae (as tribes of Sciophilinae s.l., in their system)-with the tetragoneurine genera considered leiines. Most of the species described in their paper belong to extinct genera, but some species fit into extant genera: the sciophiline Neuratelia Rondani and Allocotocera Mik, the gnoristine Apolephthisa Grzegorzek, Synapha Meigen, Dziedzickia Johannsen, Saigusaia Vockeroth, and Syntemna Winnertz, and the tetragoneurine Ectrepesthoneura. Blagoderov (1997, 1998a, 1998b, 2000) described an important number of Lower and Upper Cretaceous, and Paleocene compression fossils from Transbaikalia and Siberia in Russia, and from Mongolia. There are also compression and amber mycetophilids from the Lower Cretaceous of Spain (Blagoderov and Martínez-Delclòs, 2001; Blagoderov and Arillo, 2002).

Most described Cretaceous fossils are clearly sciophilines and gnoristines, but an important number can be assigned especially to the tetrago- 
neurines and some to the leiines. We consider below each of the Cretaceous genera assigned to the leiines, manotines, and tetragoneurines, and discuss the phylogenetic and biogeographical implications of these fossils. We do not intend this to be an extensive taxonomic treatment of these fossils. This is rather an effort, relying on the original descriptions and using our phylogenetic analysis as a framework, to better interpret the biogeographical evolution of the Leiinae. This will be useful to calibrate molecular phylogenies in the future. All known mycetophilid fossils are added to the phylogeny in figure 107, overlapped with biogeographical information and a temporal scale.

\section{Alavamanota Blagoderov and Arillo}

Genus: Alavamanota Blagoderov and Arillo, 2002: 6, figs. 5 (photo of specimen), 6 (habitus).

SPECIES INCLUded: Alavamanota hispanica Blagoderov and Arillo (type species), amber, Lower Cretaceous (Aptian-middle Albian, 120$110 \mathrm{Ma}$ ), Alava, Spain; Alavamanota burmitina Blagoderov and Grimaldi, amber, mid Cretaceous (approximately Cenomanian, $99 \mathrm{Ma}$ ), Kachin, Myanmar.

Alavamanota was originally described based on Alavamanota hispanica (Blagoderov and Arillo, 2002), to which later Alavamanota burmitica was added (Blagoderov and Grimaldi, 2004). A. hispanica has a crown of setae on the occiput around the eyes. This feature was not used here as a character, but was already mentioned by Søli (1997) as a feature present in Allactoneura and in Manota. A setose frons (char. 22) is known, among the manotines, in Allactoneura, Eumanota, Paramanota, and Promanota. This character overlaps extensively with the presence of setation on the face (char. 23). These features are also known in part of the Megophthalmidiini, in the Rondaniellini, part of the Cycloneurini, and a few Leiini. Flagellomeres as long as wide are known in some but not all manotines, and are also present in a number of other leiine groups.
Both Alavamanota hispanica and A. burmitina have the mediotergite and the laterotergite bare. A bare mediotergite is seen in most leiines. In most manotines, the laterotergite is setose, but not in Paramanota, in which it is bare, and in both Alavamanota species. A setose laterotergite is seen in most leiine tribes, but in most genera of Cycloneurini the laterotergite is bare, with only a few exceptions.

The wing of $A$. hispanica has no macrotrichia and microtrichia not arranged in rows, while in $A$. burmitica there are setae on the membrane. A setose wing membrane, very interestingly, is present in Promanota and Eumanota. Sc in both Alavamanota species is very short. The photo of $A$. burmitica seems to show (Blagoderov and Arillo, 2002: fig. 1) Sc directed toward bR, as in higher manotines, while the illustration of the species (Blagoderov and Arillo, 2002: fig. 2) represents this short stump quite straight. $\mathrm{C}$ clearly extends beyond the tip of $\mathrm{R}_{5}$ (char. 82) in A. hispanica, over half the distance to $\mathrm{M}_{1}$; in $A$. burmitica $\mathrm{C}$ is described as running very close to each other at the apical part of $R_{5}$. C extending beyond the tip of $\mathrm{R}_{5}$ is consistent across the clade Manota, Eumanota, Promanota, and Paramanota.

There are some additional features particular interesting in the discussion of the position of Alavamanota. Both species of Alavamanota have $\mathrm{R}_{5}$ straight and longitudinal along the wing, basally running very close to $R_{1}$. This apomorphic condition is also seen only in Paramanota, although the distal part of $\mathrm{R}_{5}$ in Alavamanota is more plesiomorphic, similar to what is seen in most other manotines. Also, there is a shift of the point of origin of $\mathrm{M}_{1+2}$ toward a more basal position in the wing. This is seen in Paramanota and, even more modified, in Manota, but not in other genera of Manotini. Additionally, slender cells $\mathrm{c}$ and $\mathrm{r} 1$ are share by Alavamanota and Manota.

The second sector of Rs concurrent with a more or less longitudinal $\mathrm{r}-\mathrm{m}$ is a general feature of Leiinae (also seen, e.g., in the Tetragoneurinae). In most leiine genera, however, $r-m$ is actually slightly oblique, only in some few cases $r-m$ is strictly lon- 
gitudinal along the wing-the "bent" r-m in Allactoneura due to the fold of the wing is a uniquely derived feature in flies. A strictly longitudinal $r-m$ is seen in both species of Alavamanota, with $r-m+R s$ running very close to $R_{1}$. This condition is also shared by Paramanota and Manota.

The presence of two transverse short veins between Rs and $R_{1}$ is puzzling. $R_{4}$ is absent in all leiines except Alavamanota and Waipapamyia. In itself this feature suggests a de novo origin in these two genera of $\mathrm{R}_{4}$. In other words, the retention of $\mathrm{R}_{4}$ from earlier levels of mycetophilid evolution is highly unlikely. There are consistent differences between Alavamanota and Waipapamyia. It is not a parsimonious solution to consider these two genera sister taxa and, hence, this crossvein would not be homologous even between them alone. Accepting that there is a secondary transverse vein in Alavamanota, however, poses another problem: is the first sector of Rs the more basal or the more distal crossvein? In fact, this question is not trivial because of the measurement of the length of $R_{1}$ : if the first sector of Rs is the more basal, $\mathrm{R}_{1}$ would be particularly long. Apparently, the basal crossvein seems to be the first sector of Rs, the more distal one being a secondary $r-r$ ( $\mathrm{R}_{4}$-like) vein.

The obsolete $\mathrm{M}_{1}$ seen in Alavamanota is shared with the genera of the higher Manotini-Manota, Eumanota, Promanota, and Paramanota-but an unsclerotized $\mathrm{M}_{1+2}$ is shared only by Alavamanota, Paramanota, and Manota. $\mathrm{M}_{4}$ in both species of Alavamanota, on the other hand, is connected to $\mathrm{CuA}$ at the basal fourth of the wing. Most other manotines have $\mathrm{M}_{4}$ disconnected basally from $\mathrm{CuA}$ (char. 112) and originating nearly at the wing base. An $\mathrm{M}_{4}$ obsolete basally is such a widespread feature in the Leiinae, in our tree originating at the node corresponding to the Paracycloneura ${ }^{+}$, that $\mathrm{M}_{4}$ connected to $\mathrm{CuA}$ in genera within any of the tribes among the higher leiines-e.g., some species of Leia, Anomalomyia, and Sigmoleia-would be a secondary condition. All higher manotines
(Manota, Eumanota, Promanota, and Paramanota) have $\mathrm{M}_{4}$ connected to CuA basally.

This analysis corroborates Blagoderov and Arillo's (2002) and Blagoderov and Grimaldi's (2004) hypothesis that Alavamanota belongs in the Manotini s.s. In their studies, they suggest that the recent genus Manota would be the closest to Alavamanota. We do not have Alavamanota as a terminal in our matrix, but the set of features shown by both species of the genus, from the setation on the occiput around the eyes to details of the wing venation, strongly suggests that Alavamanota would be a stem species at the clade with the recent species Manota.

\section{Baisepesthoneura Blagoderov}

Genus: Baisepesthoneura Blagoderov, 1998a: 58, fig. 2c (wing). SPECIES INCLUdED: Baisepesthoneura mesozoica Blagoderov (type species), compression, Lower Cretaceous (earliest Barriasian to Valanginian, 145-132 Ma), Baisa, Russia.

Baisepesthoneura has bM connecting directly to $\mathrm{M}_{4}$, a condition never present in the Mycetophilidae. A very basal origin of $\mathrm{M}_{4}$ connected to $\mathrm{bM}$ is the plesiomorphic condition in the sciaroids, seen, e.g., in the bibionids, in the cecidomyid genus Catotricha Edwards, in extant rangomaramids, bolitophilids, diadocidids, and keroplatids, (Amorim and Rindal, 2007), and in extinct sciaroid clades, e.g., the Archizelmiridae (Grimaldi et al., 2003). Baisepesthoneura has $\mathrm{R}_{4}$, connected to $\mathrm{R}_{1}$, a condition also seen, e.g., in the Chilean extant genus Freemanomyia Jaschhof and in Bolitophila Meigen (both of which have bM connected to $\mathrm{M}_{4}$ ). The position of $\mathrm{R}_{4}$ in Baisepesthoneura, however, is much closer to the origin of Rs. This is a particularly interesting apomorphic condition (compared to other nonmycetophilid sciaroids), shared with typical mycetophilids, such as some sciophilines or some species of Tetragoneura. For the time being, we consider Baisepesthoneura as unplaced in the Sciaroidea. 


\section{Disparoleia Blagoderov and Grimaldi}

Genus: Disparoleia Blagoderov and Grimaldi, 2004: 48, fig. 69 (habitus), plate 7A (photo habitus). Fossil species included: Disparoleia cristata Blagoderov and Grimaldi (type species), amber, mid-Cretaceous (approximately Cenomanian, 99 Ma), Kachin, Myanmar.

Disparoleia has mediotergite and laterotergites bare. The wing has $\mathrm{C}$ extending well beyond tip of $R_{5}$, Sc complete, very short, ending at $C, R_{1}$ much shorter than $r-m$, with a straight, very long $\mathrm{r}-\mathrm{m} . \mathrm{M}_{1+2}$ originates very basally on wing, with a complete $\mathrm{M}_{4}$, originating basally on the wing.

Most tetragoneurines have the laterotergite bare-except for some species of Docosia. A long $\mathrm{r}-\mathrm{m}$, with $\mathrm{M}_{1+2}$ having a very basal origin is hardly seen in leiines (with the exception of some Cycloneurini genera). In Disparoleia, however, $\mathrm{CuP}$ does not fuse to $\mathrm{CuA}$ to create a closed cell or even a sigmoid CuA. Other features that could suggest proximity to the cycloneurines are missing. The extension of $\mathrm{C}$ beyond the tip of $R_{5}$ agrees with a tetragoneurine kinship of the genus. A complete Sc is intriguing and would make the genus possibly sister to the rest of the tetragoneurines. We prefer to keep the genus here as a possible Tetragoneurinae.

\section{Ectrepesthoneura Enderlein}

Genus: Ectrepesthoneura Enderlein, 1911: 155. Extant. Fossil species included: E. succinimontana Blagoderov and Grimaldi, amber, Late Cretaceous (upper Albian, about $100 \mathrm{Ma}$ ), Taimyr Peninsula, Russia; E. swolenskyi Blagoderov and Grimaldi, amber, Late Cretaceous (Turonian, 90-94 Ma), Sayreville, New Jersey.

The two species of Ectrepesthoneura described by Blagoderov and Grimaldi (2004: plate 5D, habitus photo) are vey similar to the recent species of the genus, indicating that Ectrepesthoneura was already differentiated in the Late Cretaceous.

\section{Hemolia Blagoderov and Grimaldi}

Genus: Hemolia Blagoderov and Grimaldi, 2004: 48: figs. 70 and 72 (wings), 71 (male genitalia), plate 7B (habitus photo). Species included: Hemolia matilei Blagoderov and Grimaldi (type species) and Hemolia glabra Blagoderov and Grimaldi, both amber, mid-Cretaceous (approximately Cenomanian, $99 \mathrm{Ma}$ ), Kachin, Myanmar.

In Hemolia, the laterotergite has long setae. Ocelli in line. C extends beyond the tip of $\mathrm{R}_{5}$ and the first sector of Rs is transverse; $r-m$ is considerably short, curved at its basal half. $\mathrm{M}_{4}$ is complete basally, long, connected to $\mathrm{CuA}$. $\mathrm{CuP}$ produced, straight.

Ocelli in line are seen in Docosia, all Selkerkiini, Aphrastomyia, Paracycleneura, Indoleia, most Manotini, all Anomalomyiini, Caledonileia, and all (Leia + Clastobasis). Other features, however, suggest that the genus belongs in the Tetragoneurinae. The relatively short $\mathrm{M}_{4}$, and $\mathrm{R}_{5}$ not running too close to $R_{1}$ suggest that this species does not belongs to the crown Docosia. This is most certainly a tetragoneurine, but the plesiomorphic conditions of $M_{4}$ and $R_{5}$ indicate that these species indeed should be in a separate genus.

\section{Izleiina Blagoderov and Grimaldi}

Genus: Izleiina Blagoderov and Grimaldi, 2004: 41: figs. 52 (habitus), 53 (wing), 54 (male genitalia), plate $5 \mathrm{~F}$ (habitus photo). Izleiina mirifica Blagoderov and Grimaldi (type species), amber, Mid Cretaceous (approximately Cenomanian, 98-92 Ma), Katchin, Myanmar; Izleiina spinitibialis Blagoderov and Grimaldi, amber, Late Cretaceous (Turonian, 90-94 Ma), Sayreville, New Jersey.

The laterotergite and the mediotergite are bare in Izleiina. $\mathrm{R}_{1}$ is short and $\mathrm{Sc}$ is complete, reaching C. C extends well beyond the tip of $R_{5}$ and $R_{1}$ is slightly longer than $r-m$. The basal section of Rs is oblique and $M_{4}$ apparently originates very basally at the wing. The wing venation of this genus is very distinct from any leiine and most probably does not belong in the subfamily. 
Indeed, the short, straight $\mathrm{R}_{5}$ and a $\mathrm{C}$ extending considerably beyond the tip of $R_{5}$ suggests it may rather be a Tetragoneurinae, possibly close to Ectrepesthoneura.

\section{Lecadonileia Blagoderov and Grimaldi}

Genus: Lecadonileia Blagoderov and Grimaldi, 2004: 47: figs. 65 (habitus), 66 (wing), 67-68 (male genitalis), plate 6E (habitus photo). Species included: Lecadonileia parvistyla Blagoderov and Grimaldi (type species), amber, Late Cretaceous (Santonian-Campanian, 85-80 Ma), Cedar Lake, Manitoba, Canada.

In Lecadonileia, the laterotergite setose. The wing membrane is setulose. $C$ extends considerably beyond the tip of $\mathrm{R}_{5}$ and $\mathrm{Sc}$ is incomplete. $R_{1}$ is longer than $r-m$, while the first sector of Rs oblique. There is a long medial fork and $r-m$ is leiinelike. $\mathrm{M}_{4}$ is incomplete basally.

This genus runs into Trichoterga in our key, but these two genera are evidently not related. Lecadonileia is fairly hard to place. As mentioned above, only a few tetragoneurines have setose laterotergites. In the leiines, the Megophthalmidiini, the Rondaniellini, a few Cycloneurini, most Manotini, and all Anomalomyiini ${ }^{+}$have setae on the laterotergites. Neither the Cycloneurini nor the Manotini have a setose mediotergite. In the leiines, however, only some Cycloneurini (Waipapamyia, some Paradoxa, Sigmoleia, Cawthronia, and some Procycloneura) and some Manotini (Promanota and Eumanota) have setose wing membranes. As discussed above, an incomplete $\mathrm{M}_{4}$ basally (112:1), a feature present in Lecadonileia, is possibly a feature acquired as a synapomorphy of the clade Paracycloneura ${ }^{+}$, with secondary fusions of $\mathrm{M}_{4}$ to $\mathrm{CuA}$ in Sigmoleia and in some species of Leia. $\mathrm{CuA}$ is gradually curved toward the base of the wing in Lecadonileia, without any sinuosity, a feature that definitely excludes it from the crown Cycloneurini. Leiella, Sticholeia, and Allactoneura, in the Manotini, have a complete Sc. Its placement in the Manotini is plausible, but Lecadonileia has some plesiomorphic features that make its posi- tion as sister of (Eumanota + Promanota) unlikely. This genus clearly does not fit into the tetragoneurines. For now we consider the genus as an unplaced leiine-although its position as sister to the remaining Manotini should be considered carefully in the future.

\section{Nedocosia Blagoderov and Grimaldi}

Genus: Nedocosia Blagoderov and Grimaldi, 2004: 36: figs. 45 (habitus), 46 (male genitalia), plate $4 \mathrm{~F}$ and $5 \mathrm{~A}$ (photo habitus). Species included: Nedocosia exsanguis Blagoderov and Grimaldi (type species) and Nedocosia sibirica Blagoderov and Grimaldi, amber, Late Cretaceous (upper Albian, about $100 \mathrm{Ma}$ ), Taimyr Peninsula, Russia; Nedocosia canadensis Blagoderov and Grimaldi, amber, Late Cretaceous (Santonian-Campanian, 85-80 Ma), Cedar Lake, Manitoba, Canada; Nedocosia novacaesarea Blagoderov and Grimaldi, amber, Late Cretaceous (Turonian, 90-94 Ma), Sayreville, New Jersey; Nedocosia naiba Blagoderov, amber, Paleocene, Russia (Sakhalin).

The laterotergite and the mediotergite are bare in Neodocosia. The wing is elongated and $C$ extends beyond $R_{5}$. Sc ends in $R_{1}$ and $R_{1}$ is very long, with $\mathrm{r}-\mathrm{m}$ longitudinal and $\mathrm{R}_{4}$ absent. This combination of features suggests that Nedocosia is indeed close to Docosia, as proposed by Blagoderov and Grimaldi (2004). They mentioned that Docosia baisae Blagoderov and $D$. $z a z a$ Blagoderov (Blagoderov, 1998a) may actually belong to Nedocosia. N. naiba Blagoderov was later described (Blagoderov, 2007) from the Siberian Paleocene, showing one of the mycetophilid clades of generic rank that went across the K-T barrier, getting extinct in the Cenozoic. We are confident this genus fits into the tetragoneurines.

\section{Palaeodocosia Meunier}

Genus: Palaeodocosia Meunier, 1904c: 161 (1904d: 172). Type species: Palaeodocosia brachy- 
pezaides Meunier, 1904, by monotypy. Included fossil species included: Palaeodocosia brachycamptites (Meunier), Baltic amber, Eocene (44.3 Ma); Palaeodocosia brachypezoides Meunier, Baltic amber, Eocene (44.3 Ma); Palaeodocosia johannseni (Meunier), Baltic amber, Eocene (44.3 Ma); Palaeodocosia magdanica Blagoderov, compression, Upper Cretaceous (90-94 Ma), Siberia, Russia; Palaeodocosia rara Meunier, Baltic amber, Eocene (44.3 Ma).

In Palaeodocosia, Sc fuses to R at level of origin of Rs and $C$ does not extend beyond the tip of $R_{5} . R_{1}$ is about twice the length of bR (basal to origin of Rs), $R_{1}$ is about 10 times $r-m$ length and $\mathrm{r}$-is $\mathrm{m}$ oblique, about $2 \times$ the first section of Rs. $M_{1+2}$ is $1.6 \times \mathrm{r}-\mathrm{m}$ length. $\mathrm{M}_{4}$ is very long, with its origin more basal than the tip of Sc. Thoracic sclerites are entirely bare. The hind tibia has long apical spurs, about three times as long as the tibial width at tip. Palaeodocosia has four extant species, distributed in the Nearctic and Palearctic regions, besides six extinct species, from the Upper Cretaceous and from the Paleogene. Our analysis support Blagoderov's (2000) indication that the genus does not fit with the genera in the Tetragoneurinae-e.g., all tetragoneurine genera have a very long extension of $C$ beyond the tip of $R_{5}$, etc.

\section{Protragoneura Blagoderov and Grimaldi}

Genus: Protragoneura Blagoderov and Grimaldi, 2004: 52: figs. 73 (habitus), 74-75 (male genitalia), plate 7D (habitus photo). Species included: Protragoneura platycera Blagoderov and Grimaldi (type species), amber, Mid Cretaceous (approximately Cenomanian, 98-92 Ma), Katchin, Myanmar.

The laterotergite and mediotergite are bare in Protragoneura. C apparently ends at the tip of $\mathrm{R}_{5}$, while $S c$ is very short, incomplete. $R_{1}$ is very long and $\mathrm{R}_{4}$ is present, with $\mathrm{r}-\mathrm{m}$ long, longitudinal. $M_{1+2}$ is long; $M_{4}$ is also very long, complete basally. There are macrotrichae on the anal lobe of the wing. With a single species described, the genus is similar to Ectrepesthoneura, though with relevant differences. $\mathrm{R}_{4}$, for example, is placed more distally in $\mathrm{R}_{4+5}$, with the closed cell more elongated as a consequence. Also, $\mathrm{M}_{4}$ is connected to $\mathrm{CuA}$, not obsolete basally as in Ectrepesthoneura. Sc is short in Protragoneura, an apomorphic condition in relation to Ectrepesthoneura. We accept the genus here as a Tetragoneurinae. Unfortunately, the tip of the wing is missing, so it is not possible to confirm whether $\mathrm{C}$ extends well beyond $\mathrm{R}_{5}$, as it does in other members of the subfamily.

\section{Temaleia Blagoderov and Grimaldi}

Genus: Temaleia Blagoderov and Grimaldi, 2004: 45. Species included: Temaleia birmitica Blagoderov and Grimaldi, amber, Mid Cretaceous (approximately Cenomanian, 98-92 Ma), Katchin, Myanmar.

Temaleia has laterotergite and mediotergite setose. The wing membrane has macrotrichia. $\mathrm{C}$ ends at the tip of $\mathrm{R}_{5}$, $\mathrm{Sc}$ is complete, and $\mathrm{R}_{1}$ is very short. The first sector of Rs is oblique and $r-m$ quite short, strongly curved on its basal half. $\mathrm{M}_{4}$ is not obsolete basally and $\mathrm{CuP}$ is produced. This is one of the Cretaceous fossils that clearly belong to the Leiinae, as the length of $\mathrm{R}_{1}$ and the shape and length of $\mathrm{r}-\mathrm{m}$ strongly suggest (Blagoderov and Grimaldi, 2004: fig. 64, habitus, plate 6D, habitus photo). A complete $\mathrm{Sc}$ is present only in part of the leiine genera. The combination of some other features, as both $M_{1}$ and $M_{2}$ complete basally, a short $R_{5}$ and $C$ not extending beyond its tip, the wing pattern of Temaleia can be seen basically in the Leiini s.s. The illustration of the wing of Temaleia birmitica (Blagoderov and Grimaldi, 2004: fig. 64) shows $M_{4}$ attached to $\mathrm{CuA}$ (i.e., not obsolete) and probably not sinuous. As discussed above, most but not all Leiini species have $M_{4}$ obsolete, as in Leia winthemi Lehmann and Leia spinifera Edwards (figs. 59 and 61, respectively). In Leiini with $\mathrm{M}_{4}$ complete basally, $\mathrm{R}_{5}$ runs close to C, as in T. burmitica. None of the extant Leiini have wing membranes with macrotrichia. Our hypothesis is that Temaleia is a true Leiini, maybe 
sister of all remaining extant members of the clade. This position of Temaleia sets the Cenomanian as the minimum age for all other Leiinae clades with tribal rank. This is consistent with the fact that Docosia baisae Blagoderov and Docosia zaza Blagoderov, which are clearly members of the Tetragoneurinae, are known from the late Valanginian, in the Lower Cretaceous.

\section{Zeliinia Blagoderov and Grimaldi}

Genus: Zeliinia Blagoderov and Grimaldi, 2004: 43. Species included: Zeliinia occidentalis Blagoderov and Grimaldi (type species), amber, Lower Cretaceous (approximately Cenomanian, 98-92 Ma), Katchin, Myanmar; Zeliinia orientalis Blagoderov and Grimaldi, amber, Late Cretaceous (Santonian-Campanian, 85-80 Ma), Cedar Lake, Manitoba, Canada.

Sc is long and incomplete in Zeliina, not fused to $\mathrm{R}$. C extends slightly beyond the tip of $R_{5} \cdot R_{5}$ itself is short and $r-m$ is longitudinal. The medial fork has a weird shape, apparently with only the distal end of $M_{1}$ preserved. $M_{4}$ originates very basally at the wing. This combination of features, as happens with Izleiina, puts Zeliinia close to Ectrepesthoneura, particularly the very long $\mathrm{M}_{4}$. We consider this genus a Tetragoneurinae.

Overall, it is clear that there are few Cretaceous fossils that can be definitively associated to the Leiinae. This seems obviously related to the fact that the distribution of most taxa of the Leiinae phylogeny in the Cretaceous were in southern Gondwanan terranes, while most Cretaceous fossil deposits are in the northern hemisphere. Also, figure 107 shows that the oldest fossils associated to the mycetophilids, in the transition from the Valanginian to the Hauterivian in the Lower Cretaceous, belong to the sciophilines, the gnoristines, and the tetragoneurines. The oldest fossil record for the Leiinae is the Upper Albian Taimyr amber fossil Temaleia burmitica. The oldest fossil record for the Mycomyinae is from the midPaleocene Sakhalin amber fossil Mycomya palaeocenica Blagoderov, while the oldest fossil record for the Mycetophilinae is Exechiites tadushensis
Blagoderov, 2000, from the Palaeocene of easternmost Russia. The absence so far of known Lower Cretaceous Lebanon amber fossils assigned to the mycetophilids is worthy of note.

\section{Biogeographic Evolution of the LeIINAE}

Understanding the history of the geographical distribution of animals and plants is one of the most challenging areas of the biological sciences. The reason is twofold: first, it demands a large amount of technically precise data, not often available; and second, biogeographical evolution itself is an extremely complex process that masks over time original distribution patterns-it involves successive events of vicariance, biotic expansion, biotic overlap, reiteractive barriers, replicated patterns, extinction, individual dispersal across preexisting barriers, and so on. Besides, there are methodological issues that add up to the complexity of the evolutionary process, including incongruous patterns, taxonomic and geographic undersampling, and limitation of many of available algorithms, to name a few.

The enthusiastic optimism over biogeography in the 1980s turned more recently to the other extreme, with considerable skepticism about the possibility of fully recovering the biogeographical evolution of areas and taxonomic groups. The extent of conflicting analytical approaches led Nelson and Ladiges (2001) to refer to a "mess of methods" in biogeography.

One of the major problem concerns the divergence between cladistic ages inferred through a bigeographical approach versus those inferred through other sources of data-fossils, molecular clocks, etc. In some groups of flies, for example, an interpretation of Gondwanan origin for intercontinental disjunction in the southern hemisphere does not find corroboration from fossils (see Amorim and Silva, 2002). The conflict between biogeographical patterns and molecular data in different groups of animals and plants led to a naïve neodispersalism, with transoceanic 
dispersal proposed again to explain intercontinental disjunctions.

Alternative solutions have been advanced more recently to explain intercontinental disjunction of groups with tropical and with temperate distributions. Temperate groups disjunct between southern South America and Australia can be explained as the result of vicariance during the middle of the Cenozoic (Amorim et al., 2009) - neither Gondwanan origin nor transoceanic dispersal-when physical connection between Australia, Antarctica, and South America was finally broken. This was later corroborated by inferences with molecular data of colletid bees (Almeida et al., 2011) and of scionine tabanids (Lessard et al., 2013).

In other words, the fact that a group is not old enough to be Gondwanan does not mean that its disjunction is necessarily explained by transoceanic dispersal. Amorim et al. (2018), on the other hand, proposed a solution for transtropical distribution patterns assuming an association of vicariance and extinction at the second half of the Cenozoic. Many or most cases of transtropical patterns actually correspond to a pseudocongruence with true Gondwanan patterns. There is plenty of documention of a large tropical biota in the northern hemisphere during the late Cretaceous and first half of the Cenozoic in different groups of plants and animals-with secondary expansion from North America into South America, from Europe into Africa, and from Asia into northern Australia (see discussion in Amorim et al., 2018). The Eocene-Oligocene global cooling led to the extinction of huge portions of this Laurasian tropical fauna and flora mostly in North America and Europe. The connection, hence, between the rich and diversified Oriental tropical biota with tropical elements in Africa and South America is, hence, a false congruence with true Gondwanan patterns. This is seen in groups of flies-as in the manotine genus Eumanota, a clade basically with Oriental distribution and a species in the high Andean areas in Colombia (Amorim et al., 2018)-but it is also known from many other groups of insects, plants, and vertebrates.
In this context, true Laurasian and true Gondwana patterns are not very easy to find. A rare clear case was recently published for the bombyliid subfamily Bombyliinae (Diptera: Bombyliidae) (Li and Yeates, 2019). The bombylid fossil record and the age of the group inferred from molecular data make it possible to recognize a "Gondwanan backbone" with disjunction between Australia, Africa, and South America, and expansion toward Laurasian terranes (Li and Yeates, 2019).

The interpretation in this study of biogeographical patterns of the Leiinae can be made with the support of fossils associated to a formal phylogenetic reconstruction with ample taxonomic sampling in the subfamily (fig. 107). The discussion above shows that most mycetophilid fossil species described by Blagoderov and Grimaldi (2004) belong in the Tetragoneurinae. Among the fossils that actually fit in the Leiinae, Lecadonileia may be a Cycloneurini, whereas the Lower Cretaceous Myanmar amber genus Temaleia clearly fits in a clade nested within the Leiinae, as sister to the extant genera of the Leiini. Temaleia birmitica comes out as Cenomanian-92-98 Ma-providing a minimum age for the Leiini.

Additionally, the association of Alavamanota-with Aptian-middle Albian (120-110 Ma) fossils in Spain and Cenomanian (99 Ma) fossils in Myanmar-with the Manotini, possibly as sister of the Recent genus Manota, sets the entire backbone of the subfamily in the Lower Cretaceous. This set of evidence suggests that the origin and initial diversification of the crown mycetophilids may have occurred in the late Jurassic or earliest Cretaceous. There are fossils of the subfamilies Sciophilinae, Gnoristinae, and Tetragoneurinae already known from the Valanginian to the very early Aptian, between 134 and $125 \mathrm{Ma}$ (fig. 107).

Highly relevant to this discussion is that a Lower Cretaceous age for the Leiinae backbone is perfectly consistent with the geological age of separation of New Zealand from the rest of the southern Gondwana, assumed to have occurred at about $80 \mathrm{Ma}$ (see clades of New Zealand distribution marked with NZ in fig. 107). The pres- 
ence of -a large number of endemic elements of Leiinae in New Zealand and in other southern temperate areas do not demand any ad hoc hypotheses of dispersal. In other words, the age of the Manotini and the Leiini fossils and the age of the geological separation of New Zealand from the rest of southern Gondwana clearly sets southern temperate Gondwanan terranes as the original area of distribution of the nodes connecting the tribes of Leiinae (fig. 107).

It would not be a coincidence, then, that Cretaceous fossils of the Manotini and Leiini are known from deposits in the northern hemisphere, while other main leiine clades are still unknown from the Cretaceous fossil record. The Manotini and the Leiini are two of the seven groups of the subfamily that are hypothesized here to have expanded out of southern Gondwana terranes (blue numbered arrows in fig. 107). The recent discovery of Triassic to Paleogene amber in Australia (Stilwell et al., 2020) may bring exceptional light on our understanding of large parts of the history of the Leiinae and thereby allow us to test the hypotheses raised here.

This general interpretation of the leiine biogeographical evolution provides support for understanding the endemic southern temperate distribution of several small extant clades of the subfamily as corresponding to an original distribution in Gondwana; these clades include: (1) Paraleia, in temperate Australia and South America; (2) certain genera with uncertain position within the Leiinae, as Thoracothropis, Trichoterga, and Paracycloneura; (3) the entire Cycloneurini clade (except for Procycloneura, which expanded into more northern areas in South America); (4) the temperate species of Leiella in the Neotropical region; and (5) the Anomalomyiini in New Zealand and Australia. Their presence in southern areas do not represent a secondary occupation of these regions, but rather these taxa are original members of the southern Gondwanan biota.

Correspondingly, the presence of Leiinae groups in more northern areas of the globe, frequently in the northern hemisphere, can be understood as cases of independent secondary expansion of these clades from their southern Gondwana distribution to the north. Tectonic movements of Gondwanan terranes that are now separate continents began in the early Jurassic, about 182 Mya, but south to north seafloor spreading in the Atlantic began only about 135-130 Mya, in the earliest Cretaceous. Low-latitude connections between these continents remained until 119-105 million years ago. Latitudinal zonation of faunas and floras in Gondwana seems an inevitable scenario, but the first stages of the separation between Africa and the rest of the Gondwana in the south apparently may have been too early to affect the basal leiine clades.

The distribution of nonsouthern temperate clades in the Leiinae must be understood as biotic expansion (fig. 107). This includes: (1) Garretella, in the Selkirkiini, into the Nearctics; (2) the Megophthalmidiini, into tropical Neotropical areas as well as into the Afrotropical, Oriental, Nearctic, and Palaearctic regions; (3) the Rondaniellini, with the Oriental-Holarctic distribution of Rondaniella, and the Oriental and Australasian distribution of Indoleia; (4) the Afrotropical species of Paradoxa; (5) the Manotini except Leiella, including one species known from Baltic amber; (6) a subclade of Anomalomyia in Africa; and (7) the Leiini, worldwide in distribution, mostly in tropical areas (with the exception of the New Caledonian genus Caledonileia). The cases of Acrodicrania and Paradoxa are less clear. More robust explanations for their distribution depends on molecular inferences for the age of divergence within each of these genera. Species of Procycloneura and of Leiella in tropical areas in South and Central America also represent shifts in smaller scales.

It is worth remembering that the Lower Cretaceous flora was extensively composed of gymnosperm forests (including fungi associated to these forests). The diversification of the Mycetophilidae beginning in the Lower Cretaceous, to reach the extant diversity of the family, is connected to this turnover of gymnosperm to angiosperm forest 
and the correspondent shift in associated fungi. The turnover happened mostly during the second half of the Cretaceous, angiosperms becoming dominat in forests in tropical areas or mixed temperate forests on both hemispheres.

The mycophagy of most mycetophilid larvae, therefore, implies that the evolution of the family is largely affected by the evolution of the fungi and the forest turnover. The southern hemisphere conifer components in extant forests includes primarily Araucaria Jussieu and Agathis Salisbury and Podocarpaceae, restricted to temperate South America, New Zealand, New Caledonia, and/or Australia. These conifer elements were probably in large scale the original forest components in the leiine southern Gondwanan distribution. A molecular phylogeny of the Mycetophilidae with wide generic and geographic sampling, associated to information on Mesozoic fossils and to the evolution of the fungi will provide a very special understanding of evolution of the family.

At least some of the extant mycetophilid clades (e.g., certain genera of sciophilines and gnoristines) have temperate distribution in the northern hemisphere. The presence of these clades in tropical areas may also be secondary, following the diversification of angiosperm forests in tropical areas in the late Cretaceous.

Finally, no Lebanon amber mycetophilid fossils are known yet. Blagoderov and Grimaldi (2004: 5) note that Lebanon amber includes a great range of ages, from the uppermost Jurassic (152 Ma) to the Albian (112 Ma), and that sciaroids in Lebanese amber are the oldest known amber fossils of the superfamily. Mycetophilid fossils from Lebanon and Australia deposits would fill an important gap and would be extremely helpful in understanding the early stages of the evolution of the family.

\section{ACKNOWLEDGMENTS}

We are deeply indebted to Maria Isabel P.A. Balbi for continuous support in our lab along the entire development of this study, helping from sorting to slide mounting specimens, indispensable for the achievements in this paper. We are thankful to Andrea Carolina Henao-Sepúlveda for the photo of the habitus of the holotype of Eumanota wolffae and to Jan Ševčík for the photo of the wing of Paramanota furcillata. We are extremely thankful for a number of researchers and curators who shared material of leiines with us: Eirik Rindal, Olavi Kurina, Peter Kerr, and Jan Ševcík, for the donation of material and photographs of key specimens; Mathias Jaschhof, Heikki Hippa, Peter Chandler, Mitsuhiro Sasakawa, Vladimir Blagoderov, Geir Søli, and Neal Evenhuis for help with the literature; and all the curators and staff of the institutions that D.S.A. visited-New Zealand Arthropod Collection, Auckland, New Zealand-and that S.S.O. visited during her Ph.D. and postdoctoral research, who provided material in loans for this study-Australian Museum, Sydney, Australia; Australian National Insect Collection, Canberra, Australia; Colección de Entomología of the University of Antioquia, Medellin, Colombia; Canadian National Collection of Arachnids, Nematodes and Insects, Ottawa, Canada; Coleção de Entomologia Padre Jesus Santiago Moure da Universidade Federal do Paraná, Curitiba, Brazil; Finnish Museum of Natural History, Zoological Museum, University of Helsinki, Helsink, Finland; Instituto de Investigación de Recursos Biológicos Alexander von Humboldt, Bogota, Colombia; Instituto Nacional de la Biodiversidad, San José, Costa Rica; Instituto Nacional de Pesquisas Amazônicas, Manaus, Brazil; Muséum National d'Histoire Naturelle, Paris, France; Museu Paraense Emílio Goeldi, Belém, Brazil; Museu de Zoologia da Universidade de São Paulo, São Paulo, Brazil; Natural History Museum, London, United Kingdom; Kwa-Zulu-Natal Museum South Africa, Pietermaritzburg, South Africa; Iziko South Africa Musuem, Cape Town, South Africa; South African National Collection of Insects, Pretoria, South Africa. We are particularly grateful to David Grimaldi and Vladimir Blagoderov for very careful reviews of the manuscript, with suggestions, corrections, and criticisms that greatly improved the manuscript. S.S.O. benefitted 
from a Geddes Postgraduate Awards from the AMSA, FAPESP Ph.D. and postdoc grants (2008/52324-6, 2012/51577-3, and 2014/084477), and CNPq grant (428471/2016-1); D.S.A. had grants from FAPESP (2016/50369-9) and CNPq (309240/2013).

\section{REFERENCES}

Almeida, E.A.B., M.R. Pie, S.G. Brady, and B.N. Danforth. 2011. Biogeography and diversification of colletid bees (Hymenoptera: Colletidae): emerging patterns from the southern end of the world. Journal of Biogeography 39: 526-544.

Alonso, J., et al. 2000. A new fossil resin with biological inclusions in Lower Cretaceous deposits from Alava (northern Spain, Basque-Cantabrian Basin). Journal of Paleontology 74: 158-178.

Amorim, D.S. 1982. Classificação por sequenciação: uma proposta para a denominação dos ramos retardados. Revista Brasileira de Zoologia 1: 1-9.

Amorim, D.S., and E. Rindal. 2007. A phylogenetic study of the Mycetophiliformia, with creation of the subfamilies Heterotrichinae, Ohakuneinae, and Chiletrichinae for the Rangomaramidae (Diptera, Bibionomorpha). Zootaxa 1535: 1-92.

Amorim, D.S., and V.C. Silva. 2002. How far advanced was Diptera evolution in Pangaea. Annales de la Société Entomologique de France 38: 177-200.

Amorim, D.S., and. D.K. Yeates. 2006. Pesky gnats: ridding dipteran classification of the "Nematocera." Studia Dipterologica 13: 3-9.

Amorim, D.S., C.M.D. Santos, and S.S. Oliveira. 2009. Allochronic taxa as an alternative model to explain circumantarctic disjunctions. Systematic Entomology 34: 2-9.

Amorim, D.S., S.S. Oliveira, and A.C. Henao-Sepulveda. 2018. A new species of Eumanota Edwards (Diptera: Mycetophilidae: Manotine) from Colombia: evidence for a pseudogondwanan pattern. American Museum Novitates 3915: 1-19.

Bechev, D.N. 1995. Allactoneura papuensis spec. nov. from New Guinea (Insecta: Diptera: Mycetophilidae). Reichenbachia 31: 81-82.

Bechev, D.N. 2000. World distribution of the genera of fungus gnats (Diptera: Sciaroidea, excluding Sciaridae). Studia Dipterologica 7: 543-552.

Blagoderov, V.A. 1997. Fungus gnats of the tribe Gnoristini (Diptera, Mycetophilidae) from the Lower Cretaceous of Transbaikalia. Paleontological Journal 31: 44-49.
Blagoderov, V.A. 1998a. Fungus gnats of the tribes Gnoristini and Leiini (Diptera, Mycetophilidae) from the Early Cretaceous of Transbaikalia. Paleontological Journal 32: 54-59.

Blagoderov, V.A. 1998b. Fungus gnats (Diptera, Mycetophilidae) from the Lower Cretaceous of Mongolia. Paleontological Journal 32: 598-604.

Blagoderov, V.A. 2000. New fungus gnats (Diptera: Mycetophilidae) from the Cretaceous and Paleogene of Asia. Paleontological Journal 34: S355-S359.

Blagoderov, V.A. 2007. New Species of Fungus Gnats (Diptera: Mycetophilidae) from the Palaeocene Sakhalin Amber, Russia. Alavesia 1: 27-36.

Blagoderov, V.A., and A. Arillo. 2002. New Sciaroidea (Insecta: Diptera) in Lower Cretaceous amber from Spain. Studia Dipterologica 9: 31-40.

Blagoderov, V.A., and D. Grimaldi. 2004. Fossil Sciaroidea (Diptera) in Cretaceous ambers, exclusive of Cecidomyiidae, Sciaridae, and Keroplatidae. American Museum Novitates 3433: 1-76.

Blagoderov, V.A., and X. Martínez-Delclòs. 2001. Two new fungus gnats (Insecta, Diptera, Mycetophilidae) from the Lower Cretaceous of Spain. Geobios 34: 63-67.

Borkent, C.J., and T.A. Wheeler. 2013. Phylogeny of the tribe Sciophilini (Diptera: Mycetophilidae: Sciophilinae). Systematic Entomology 38: 407-427.

Bremer, K. 1994. Branch support and tree stability. Cladistics 10: 295-304.

Brunetti, E. 1912. Diptera Nematocera (excluding Chironomidae and Culicidae). In A.E. Shipley and G.A.K. Marshall (editors), Fauna of British India, including Ceylon and Burma: 1-581, pls 1-12. London: Taylor and Francis.

Burdíková, N., et al. 2019. Molecular phylogeny of the Paleogene fungus gnat tribe Exechiini (Diptera: Mycetophilidae) revisited: Monophyly of genera established and rapid radiation confirmed. Journal of Zoological Systematics and Evolutionary Research 57: 806-821.

Chandler, P.J. 1994. The fungus gnats of Israel (Diptera: Sciaroidea, excluding Sciaridae). Israel Journal of Entomology 28: 1-100.

Chandler, P.J. 2001. Fungus gnats (Diptera: Sciaroidea) new to Britain. British Journal of Entomology and Natural History 13: 215-243.

Chandler, P.J. 2004. Fauna Europaea: Mycetophilidae. Fauna Europaea version 1.2. (http://www.faunaeur. org), accessed 29 April 2009.

Chandler, P.J., and J. Blasco-Zumeta. 2001. The fungus gnats (Diptera: Bolitophilidae, Diadocidiidae and 
Mycetophilidae) of the Monegros region (Zaragoza, Spain) and five other new European species of Pyratula Edwards and Sciophila Meigen. Zapateri Revista Aragonesa de Entomologia 9: 1-24.

Chandler, P.J., D.N. Bechev, and N. Caspers. 2006 ("2005"). The fungus gnats (Diptera: Bolitophilidae, Diadocidiidae, Ditomyiidae, Keroplatidae and Mycetophilidae) of Greece, its islands and Cyprus. Studia Dipterologica 12: 255-314.

Clifford, D.J., et al. 1997. The nature and fate of natural resins in the geosphere. VIII. NMR and Py-GC-MS characterization of soluble labdanoid polymers, isolated from Holocene class I resins. Organic Geochemistry 27, 449-464.

Cranston, P.S. 2005. Biogeographic patterns in the evolution of Diptera. In B.M. Wiegmann and D.K. Yeates (editors), The evolutionary biology of flies: 274-311. New York: Columbia University Press.

Cumming, J.W., and D.M. Wood. 2017. Adult morphology and terminology. In A.H. Kirk-Spriggs and B.J. Sinclair (editors), Manual of Afrotropical Diptera, vol. 1. Introductory chapters and keys to Diptera families: 89-133. Suricata 4. Pretoria: South African National Biodiversity Institute.

De Meijere, J.C.H. 1913. Praeda itineris a L.F. de Beaufort in archipelago indico facti annis 19091910. VI. Dipteren I. Bijdragen tot de Dierkunde 19: 45-69.

Eberth, D.A., and A.P. Hamblin. 1993. Tectonic, stratigraphic, and sedimentological significance of a regional discontinuity in the Judith River Group (Belly River Wedge) of southern Alberta, Saskatchewan and northern Montana. Canadian Journal of Earth Sciences 30: 174-200.

Edwards, F.W. 1925. British fungus-gnats (Diptera, Mycetophilidae). With a revised generic classification of the family. Transactions of the Royal Entomological Society of London 1924: 505-670.

Edwards, F.W. 1928. Diptera Nematocera from the Federated Malay States Museum. Journal of the Federated Malay States Museums 14: 1-139.

Edwards, F.W. 1932. Diptera Nematocera from the Dutch East Indies. Treubia 14: 137-152.

Edwards, F.W. 1933. Diptera Nematocera from Mount Kinabalu. Journal of the Federated Malay States Museuns 17: 223-296.

Enderlein, G. 1911. Neue Gattungen und Arten aussereuropaischer Fliegen. Stettiner Entomologische Zeitung 72: 135-209.

Enderlein, G. 1940. Die Dipteren Fauna der Juan-Fernandez Inseln und der Oster-Inseln. In C. Skotts- berg (editor), Natural History of the Juan Fernandez Island and Easter Island (Zool.) 3: 643-680. Uppsala: Almqvist \& Wiksells Boktryckeri.

Evanoff, E., W.C. Mcintosh, and P.C. Murphey. 2001 Stratigraphic summary and 40Ar/39Ar geochronology of the Florissant Formation, Colorado. In E. Evanoff, K.M. Gregory-Wodzicki, and K.R. Johnson (editors), Fossil Flora and Stratigraphy of the Florissant Formation, Colorado. Proceedings of the Den ver Museum of Nature and Science Series 4: 1-16.

Evenhuis, N.L. 2014. Family Mycetophilidae. In Catalog of the fossil flies of the world (Insecta: Diptera) website. Online resource (http://hbs.bishopmuseum.org/fossilcat/fossmyceto.html), accessed 1 September 2019.

Fitch, W.N. 1971. Toward defining the course of evolution: minimum change for a specified tree topology. Systematic Zoology 20: 406-416.

Freeman, P. 1951. Diptera of Patagonia and South Chile based mainly on material in the British Museum (Natural History). Part III-Mycetophilidae. London, British Museum (Natural History).

Gaudant, J., A. Nel, D. Nury, M. Véran, and G. Carnevale. 2018. The uppermost Oligocene of Aix-enProvence (Bouches-du-Rhône, Southern France): A Cenozoic brackish subtropical Konservat-Lagerstätte, with fishes, insects and plants. Comptes Rendus Palevol. 7, 460-478.

Goloboff, P.A. 1993. Estimating character weights during tree search. Cladistics 9: 83-91.

Goloboff, P.A. 1999. Analyzing large data sets in reasonable times: solutions for composite optima. Cladistics 15: 415-428.

Goloboff, P.A., J.S. Farris, and K.C. Nixon. 2008. TNT, a free program for phylogenetic analysis. Cladistics 24: 774-786.

Gray, J., and L.R. Kittleman. 1967. Geochronology of the Columbia River Basalt and associated floras of eastern Washington and western Idaho. American Journal of Science 265: 257-291.

Grimaldi, D.A., and M.S. Engel. 2005. Evolution of the insects. New York: Cambridge University Press.

Grimaldi, D.A., and P.C. Nascimbene. 2010. Raritan (New Jersey) amber. In D. Penney (editor), Biodiversity of fossils in amber from the major world deposits: 167-191. Manchester: Siri Scientific Press.

Grimaldi, D.A., D.S. Amorim, and V. Blagoderov. 2003. The Mesozoic family Archizelmiridae (Diptera: Insecta). Journal of Paleontology 77: 368-381.

Hackman, W., P. Lastovka, L. Matile, and R. Väisanen. 1988. Mycetophilidae. In A. Soós and L. Papp (editors.), Catalogue of Palaearctic Diptera. Vol. 3. Cer- 
atopogonidae-Mycetophilidae: $\quad 220-328$. Amsterdam: Elsevier Science Publishers.

Hendel, F. 1936. 26. Ordnung der Pterygogenea (Dreißigste Ordnung der Insecta). Diptera oder Fliegen. In W. Kükenthal and T. Krumbach (editors), Handbuch der Zoologie 4 (2): 1729-1998. Berlin: Walter de Gruyter \& Co.

Hennig, W. 1973. Diptera (Zweiflügler). Handbuch der Zoologie 4 (2) 2/31, 1-337. Berlin: Walter de Gruyter.

Herman, A.B., L.B. Golovneva, S.V. Shczepetov, and A.A. Grabovsky. 2016. The late Cretaceous Arman flora of Magadan oblast, Northeastern Russia. Stratigraphy and Geological Correlation 24: 651-760.

Hippa, H. 2007. The genus Manota Williston (Diptera: Mycetophilidae) in Melanesia and Oceania. Zootaxa 1502: 1-44.

Hippa, H. 2008. Notes on Afrotropical Manota Williston (Diptera: Mycetophilidae), with the description of seven new species. Zootaxa 1741: 1-23.

Hippa, H. 2009. New species and new records of Manota Williston (Diptera, Mycetophilidae) from Thailand. Zootaxa 2017: 1-33.

Hippa, H. 2010. Review of the genus Paramanota Tuomikoski (Diptera, Mycetophilidae), with the description of new fossil and recent species. Zootaxa 2618: 47-60.

Hippa, H., and O. Kurina. 2012. New species and new records of Afrotropical Manota Williston (Diptera, Mycetophilidae), with a key to the species. Zootaxa 3455: 1-48.

Hippa, H., and O. Kurina. 2013. New species and new records of Manota Williston (Diptera, Mycetophilidae) in the Neotropical region. Zootaxa 3686: 101-139.

Hippa, H., and O. Kurina. 2018. Four new species and new records of Manota (Diptera: Mycetophilidae) from Sulawesi, Indonesia. Acta Entomologica Musei Nationalis Pragae 58: 249-256.

Hippa, H., and L. Papp. 2007. The genus Manota WilIiston (Diptera: Mycetophilidae) in Thailand, with the description of seven new species. Zootaxa 1528: 41-60.

Hippa, H., and T. Saigusa. 2016. Notes on Oriental and East Palaearctic Manota Williston (Diptera, Mycetophilidae), with the description of seven new species. Zootaxa 4084: 377-390.

Hippa, H., and J. Ševčík. 2010. Notes on Oriental and Australasian Manotinae (Diptera, Mycetophilidae), with the description of thirteen new species. Zootaxa 2333: 1-25.

Hippa, H., and J. Ševčík. 2013. Five new species and a new record of Manota (Diptera: Mycetophilidae) from Sulawesi. Acta Entomologica Musei Nationalis Pragae 53: 763-775.

Hippa, H., M. Jaschhof, and P. Vilkamaa. 2005. Phylogeny of the Manotinae, with a review of Eumanota Edwards, Paramanota Tuomikoski and Promanota Tuomikoski (Diptera, Mycetophilidae). Studia Dipterologica 11: 405-428.

Hippa, H., D. Kaspř́k, S.R.H. Abd Kahar, and J. Ševčík. 2016. Two new Oriental species of Paramanota Tuomikoski (Diptera: Mycetophilidae), with DNA sequence data. Raffles Bulletin of Zoology 64: 360-367.

Hippa, H., O. Kurina, and I. Sääksjärvi. 2017. The genus Manota Williston (Diptera: Mycetophilidae) in Peruvian Amazonia, with description of sixteen new species. Zootaxa 4236: 1-40.

Huber, F., and F.H. Reis. 2011. Técnica alternativa para montagem de insetos em lâminas permanentes para visualização em microscopia óptica. EntomoBrasilis 4: 13-19.

Iturralde-Vinent, M.A., and R.D.E. MacPhee. 1996. Age and paleogeographical origin of Dominican amber. Science 273, 1850-1852.

Jaschhof, M. 2006. Even more paradoxical: Paradoxa paradoxa sp. n. (Diptera: Mycetophilidae) from South Africa, closest relative of the New Zealand Paradoxa fusca Marshall. African Invertebrates 47: 229-235.

Jaschhof, M., and H. Hippa. 2005. The genus Manota in Costa Rica (Diptera: Mycetophilidae). Zootaxa 1011: $1-54$.

Jaschhof, M., and C. Jaschhof. 2010. The genus Manota Williston (Diptera: Mycetophilidae) in New Zealand. Zootaxa 2387: 28-38.

Jaschhof, M., and U. Kallweit. 2004. The genus Aphrastomyia Coher and Lane, 1949 in Costa Rica (Insecta: Diptera: Mycetophilidae). Faunistische Abhandlungen 25: 107-123.

Jaschhof, M., and U. Kallweit. 2009. The Cycloneura Marshall group of genera in New Zealand (Diptera: Mycetophilidae: Leiini). Zootaxa 2090: 1-39.

Jaschhof, M., and M. Mostovski. 2006. First record of Manota (Diptera: Mycetophilidae: Manotinae) from southern Africa, with description of two new species. African Invertebrates 47: 237-242.

Jaschhof, M., C. Jaschhof, B. Rulik, and J. Kjærandsen. 2011. New records of Manota Williston (Diptera: Mycetophilidae) in Europe and North America, including a redescription of Manota unifurcata Lundström and pointers towards the interrelationships among Palaearctic species. Studia dipterologica 17: 55-66. 
Johannsen, O.A. 1909. Diptera. Fam. Mycetophilidae. In P. Wytsman (editor), Genera Insectorum 93. Bruxelles.

Kaspřák, D., P. Kerr, V. Sýkora, A. Tóthová, and J. Ševčík, J. 2019. Molecular phylogeny of the fungus gnat subfamilies Gnoristinae and Mycomyinae, and their position within Mycetophilidae (Diptera). Systematic Entomology 44: 128-138.

Kerr, P.H. 2014. The Megophthalmidia (Diptera, Mycetophilidae) of North America including eight new species. ZooKeys 386: 29-83.

Kodrul, T.M. 1999. Paleogene phytostratigraphy of the southern Sakhalin. Nauka, Moscow. [in Russian]

Kotthoff, U., T. Wappler, and M.S. Engel. 2011. Miocene honey bees from the Randeck Maar of southwestern Germany (Hymenoptera, Apidae). ZooKeys 96, 11-37.

Kurina, O. 2004. Notes on fungus gnats from the East Mediterranean with description of two new species (Diptera: Sciaroidea excl. Sciaridae). Beiträge zur Entomologie 54: 343-355.

Kurina, O. 2008. 4.3.23 Sciaroidea excl. Sciaridae. Diptera stelviana. Studia Dipterologica Supplement 16: 245-293.

Kurina, O., and H. Hippa. 2014. The genus Manota Williston (Diptera: Mycetophilidae) in the Congo basin with description of five new species. Zootaxa 3827: 214-230.

Kurina, O., and H. Hippa. 2015. A review of the South Pacific Manota Williston (Diptera, Mycetophilidae), with description of thirteen new species. Zootaxa 4020: 257-288.

Kurina, O., K. Hedmark, M. Karström, and J. Kjaerandsen. 2011. Review of the European Greenomyia Brunetti (Diptera, Mycetophilidae) with new descriptions of females. ZooKeys 77: 31-50.

Kurina, O., H. Hippa, and D.S. Amorim. 2017. New species and new records of Manota Williston (Diptera: Mycetophilidae) from Colombia, Brazilian Amazonia, and Costa Rica. ZooKeys 668: 83-105.

Kurina, O., H. Hippa, and D.S. Amorim. 2018. A contribution to the systematics of the genus Manota Williston (Diptera: Mycetophilidae) in Brazil. Zootaxa 4472: 1-59.

Kurina, O., H. Hippa, and D.S. Amorim. 2019. Notes on Manota Williston (Diptera: Mycetophilidae) from Australia and Papua New Guinea, with description of two new species. Zootaxa 4555: 385-395.

Lambert, J.B., J.S. Frye, T.A. Lee, C.J. Welch, G. Poinar, Jr. 1989. Analysis of Mexican amber by carbon-13 NMR spectroscopy. Archaeological Chemistry 4: 381-388.
LaPolla, J.S., G.M. Dlussky, and V. Perrichot. 2013. Ants and the Fossil Record. Annual Review of Entomology 58: 609-630.

Lapparent de Broin, F., and R.E. Molnar. 2001. Eocene chelid turtles from Redbank Plains, Southeast Queensland, Australia. Geodiversitas 23: 41-79.

Lane, J. 1952. Some new Brazilian Mycetophilidae (Diptera, Nematocera). Dusenia 3: 131-140.

Lane, J. 1954a. The genus Megaphthalmidia in Brazil (Diptera, Mycetophilidae, Sciophilinae). Revista brasileira de Entomologia 2: 105-110.

Lane, J. 1954b. Revision of the genus "Leiella" Enderlein, 1911 (Diptera, Nematocera, Mycetophilidae). Revista brasileira de Biologia 14: 449-453.

Lane, J. 1962. Mycetophilidae from Chile (Diptera, Nematocera). Studia Entomologica 5: 527-548.

Laštovka, P., and J. Ševčík. 2016. A review of the Czech and Slovak species of Docosia Winnertz (Diptera: Mycetophilidae), with atlas of the male and female terminalia. Časopis Slezského Muzeum Opava (A) 55: $1-37$.

Lee, D.C., and H.N. Bryant. 1999. A reconsideration of the coding of inapplicable characters: assumptions and problems. Cladistics 15: 373-378.

Lessard, B.D., S.L. Cameron, K.M. Bayless, B.M. Wiegmann, and D.K. Yeates. 2013. The evolution and biogeography of the austral horse fly tribe Scionini (Diptera: Tabanidae: Pangoniinae) inferred from multiple mitochondrial and nuclear genes. Molecular Phylogenetics and Evolution 68: 516-540.

Li, X., and D.K. Yeates. 2019. Phylogeny, classification and biogeography of bombyliine bee flies (Diptera, Bombyliidae). Systematic Entomology 44: 1-24.

Lielke, K., S. Manchester, and H. Meyer. 2012. Reconstructing the environment of the northern Rocky Mountains during the Eocene/Oligocene transition: constraints from the palaeobotany and geology of south-western Montana, USA. Acta Palaeobotanica 52: 317-358.

Loew, H. 1850. Dipterologische Beiträge. Vierter Theil. Öffentl. Prüf. D. Schüler Fridrich-Wilhelms Gymnasium zu Posen 1850: 1-40.

Marshall, P. 1896. New Zealand Diptera: No. 2.凶Mycetophilidae. Transactions of the New Zealand Institute 28: 250-309.

Matile, L. 1973. Diptéres Mycetophilidae de l'Afrique Orientale. Stuttgarter Beiträge zur Naturkunde 250: 1-6.

Matile, L. 1978. Diptères Mycetophilidae de l'Archipel des Comores. Mémoires du Museum National d'Histoire Naturelle 109: 247-306. 
Matile, L. 1989. Superfamily Sciaroidea. In N.L. Evenhuis (editor) Catalog of the Diptera of the Australasian and Oceanic Regions: 123-145. Honolulu: Bishop Museum Press.

Matile, L. 1990. Recherches sur la systématique et l'évolution des Keroplatidae (Diptera, Mycetophiloidea). Mémoires du Museum National d'Histoire Naturelle 148: 1-682.

Matile, L. 1993. Diptères Mycetophiloidea de NouvelleCaledonie. 5. Mycetophilidae Leiinae et Manotinae. In L. Matile, J. Najt, and S. Tillier (editors), Zoologia Neocaledonica, vol. 3. Mémoires Museum National d'Histoire Naturelle 157: 165-210.

Matile, L. 2002. Notes sur le genre Greenomyia Brunetti et description d'une espèce nouvelle des Alpes et des Apennins (Diptera: Mycetophilidae). Annales de la Société Entomologique de France 38: 13-16.

Matsumura, S. 1915. Konchu Bunruigaku [Insect taxonomy]. II. Tokyo: Keiseisha Shoten. [in Japanese]

Mercadé, L. 1991. Sedimentology of the Lower Cretaceous lithographic limestones from the Serra del Montsec (Spain). In X. Martínez-Delclòs (editor), The Lower Cretaceous lithographic limestones of Montsec, 10 years of paleontological expeditions: 25-31. Lleida, Spain: Institut d'Estudis Illerdens.

Meunier, F. 1900. Über die Mycetophiliden (Sciophilinae) des Bernsteins. Illustrierte Zeitschrift für Entomologie 5: 68-70.

Meunier, F. 1904. Monographie des Cecidomyidae, des Sciaridae, des Mycetophilidae et des Chironomidae de l'ambre Baltique. Annales de la Société scientifique de Bruxelles 28: 14-265.

Nelson, G., and P.Y. Ladiges. 2001. Gondwana, vicariance biogeography and the New York School revisited. Australian Journal of Botany 49: 389-409.

Mörs, T. 1995. Die Sedimentationsgeschichte der Fossillagerstätte Rott und ihre Alterseinstufung anhand neuer Säugetierfunde (Oberoligozän, Rheinland). Courier Forschungsinstitut Senckenberg 187: 1-129.

Nel, A. 1994. Revision of the Miocene genus Lithobibio (Diptera: Bibionidae). European Journal of Entomology 91: 451-454.

Nixon, C.K., and J.M. Carpenter. 1993. On outgroups. Cladistics 9: 413-426.

Nixon, K.C. 1999. The parsimony ratchet, a new method for rapid parsimony analysis. Cladistics 15: 407-414.

Okada, I. 1939. Studien über die Pilzmücken (Fungivoridae) aus Hokkaido (Diptera, Nematocera). Journal of the Faculty of Agriculture, Hokkaido Imperial University 42: 267-336.
Oliveira, S.S. 2009. Dziedzickia Johannsen e Schnusea Edwards (Diptera, Mycetophilidae): diversidade das espécies neotropicais e análise filogenética. M.Sc. thesis. Ribeirão Preto.

Oliveira, S.S. 2015. On Afrotropical Mohelia Matile (Diptera, Mycetophilidae): new species and phylogenetic comments. Zootaxa 3947: 251-263.

Oliveira, S.S., and D.S. Amorim. 2011. Docosia adusta sp. n. (Diptera, Mycetophilidae) from the Colombian Andes: a Holarctic element in northwestern South America. Canadian Entomologist 143: 688-696.

Oliveira, S.S., and D.S. Amorim. 2012. Six new species of Paraleia Tonnoir (Diptera, Mycetophilidae): amphinotic elements at the northern range of the Andes. Zootaxa 3186: 1-24.

Oliveira, S.S., and D.S. Amorim. 2014. Catalogue of the Neotropical Diptera. Mycetophilidae. Neotropical Diptera 25: 1-87.

Oliveira, S.S., D.S. Amorim, and V. Blagoderov. 2012. Redescription of the enigmatic Thoracotropis cypriformis Freeman (Diptera, Mycetophilidae). Revista Brasileira de Entomologia 56: 458-462.

Oliveira, S.S., and B. Muller. 2012. The types of Lygistorrhinidae and Mycetophilidae (Diptera: Bibionomorpha) in the KwaZulu-Natal Museum, Pietermaritzburg, South Africa. African Invertebrates 53: 703-714.

Ostroverkhova, G.P. 1970. New data on the fauna of fungus-gnats (Diptera, Mycetophilidae) from Siberia. Entomologicheskoye Obozreniye 49: 452-458. [translation in Entomological Review 49: 271-274; original in Russian]

Pape, T., V. Blagoderov, and M.B. Mostovski. 2011. Order Diptera Linnaeus, 1758. In Z.-Q. Zhang (editor). Animal biodiversity: an outline of higher-level classification and survey of taxonomic richness. Zootaxa 3148: 222-229.

Papp, L. 2004. Seven new species of Manotinae (Diptera: Mycetophilidae) from Asia and Papua New Guinea. Acta Zoologica Academiae Scientiarum Hungaricae 50: 227-244.

Polevoi, A., and J. Salmela. 2016. New data on poorly known species of the genus Leia Meigen (Diptera, Mycetophilidae) from the Palaearctic region. Zootaxa 4103: 487-500.

Popov, V.K., and A.V. Grebennikov. 2001. New data on the age of effusives from the Bogopol Formation in Primorye. Tikhookeanskaya Geologiya 3: 47-54. [in Russian]

Poinar, G.O., Jr. 1999. Cenozoic fauna and flora in amber. Estudios del Museo Ciencias Naturales de Álava 14, 151-154. 
Radley, J.D. 2005. Derived fossils in the southern English Wealden (non-marine early Cretaceous): a review. Cretaceous Research 26: 657-664.

Rasnitsyn, A.P., and V.V. Zherikhin. 2002. Selected insect fossil sites: Impression fossils. In A.P. Rasnitsyn and D.L.J. Quicke (editors), History of insects: 437-444. Kluwer Academic Publishers, Dordrecht.

Rindal, E., and G.E.E. Søli. 2006. Phylogeny of the subfamily Mycetophilinae (Diptera: Mycetophilidae). Zootaxa 1302: 43-59.

Rindal, E., G.E.E. Søli, J. Kjærandsen, and L. Bachmann. 2007. Molecular phylogeny of the fungus gnat tribe Exechiini (Mycetophilidae, Diptera). Zoologica Scripta 36: 327-335.

Rindal, E., G.E.E. Søli, and L. Bachmann. 2009a. Molecular phylogeny of the fungus gnat family Mycetophilidae (Diptera, Mycetophiliformia). Systematic Entomology 34: 524-532.

Rindal, E., G.E.E. Søli, and L. Bachmann. 2009b. On the systematics of the fungus gnat subfamily Mycetophilinae (Diptera): a combined morphological and molecular approach. Journal of Zoological Systematics and Evolutionary Research 47: 227-233.

Ritzkowski, S. 1997. K-Ar Altersbestimmungen der bernsteinführenden Sedimente des Samlandes (Paläogen, Bezirk Kaliningrad). In M. Ganzelewski, T.H. Rehren, and R. Slotta (editors), Metalla, Sonderheft 66 zum Symposium Neue Erkenntnisse zum Bernstein: 19-23. Deutsches Bergbau Museum, Bochum, Germany.

Rohdendorf, B.B. 1964. Historical development of dipterous insects. Trudy Paleontologicheskogo Instituta 100: 1-311. [in Russian; English translation in Rohdendorf, 1974.]

Ross, A.J., and A. Self. 2014. The fauna and flora of the Insect Limestone (late Eocene), Isle of Wight, UK: introduction, history and geology. Earth and Environmental Science Transactions of the Royal Society of Edinburgh 104, 233-244.

Sabrosky, C.W. 1999. Family-group names in Diptera. An annotated catalog. Myia 10: 1-360.

Sasakawa, M. 2005. Fungus gnats, lauxaniid and agromyzid flies (Diptera) of the Imperial Palace, the Akasaka Imperial Gardens and the Tokiwamatsu Imperial Villa, Tokyo. Memoirs of the National Science Museum 39: 273-312.

Schlee, D. 1984. Notizen über einige Bernstein und Kopale aus aller Welt. Stuttgarter Beiträge zur Naturkunde, Serie C 18: 29-47.

Schluter, T., and F. von Gnielinski. 1987. The Easl African Copal, its geologic, stratigraphic, palaeontologic significance and comparison with fossil resins of similar age. Occasional paper (National Museum of Tanzania) 8: 1-32.

Ševčík, J., D. Kaspřák, and A. Tóthová. 2013. Molecular phylogeny of fungus gnats (Diptera: Mycetophilidae) revisited: position of Manotinae, Metanepsiini, and other enigmatic taxa as inferred from multigene analysis. Systematic Entomology 38: 654-660.

Ševčík, J., H. Hippa, and R. Abdul Wahab. 2014. Diversity of Manota Williston (Diptera, Mycetophilidae) in Ulu Temburong National Park, Brunei. ZooKeys 428: $57-77$.

Shaw, F.R., and M.M. Shaw. 1951. Relationship of certain genera of fungus gnats of the family Mycetophilidae. Smithsonian Miscellaneous Collections 117: 1-23.

Shi, G., et al. 2012. Age constraint on Burmese amber based on $\mathrm{UePb}$ dating of zircons. Cretaceous Research 37, 155-163.

Skuse, F.A. 1888. Diptera of Australia. Part III. Proceedings of the Linnean Society of New South Wales (2) 3 [whole ser. 12]: 1123-1222.

Skuse, F.A. 1890. Diptera of Australia. Nematocera. Supplement II. Proceedings of the Linnean Society of New South Wales (2) 5 [whole ser. 14]: 595-640.

Søli, G.E.E. 1996. Sticholeia-a new genus of Leiini, with comments on the systematic position of Allactoneura de Meijere (Diptera: Mycetophilidae). Entomologica Scandinavica 27: 1-10.

Søli, G.E.E. 1997. The adult morphology of Mycetophilidae (s. str.), with a tentative phylogeny of the family (Diptera, Sciaroidea). Entomologica Scandinavica Supplement 50: 5-55.

Søli, G.E.E. 2002a. Sticholeia loici sp. n., a new species from Indonesia (Diptera :Mycetophilidae). Annales de la Société Entomologique de France 38: 55-56.

Søli, G.E.E. 2002b. New species of Eumanota Edwards, 1933 (Diptera: Mycetophilidae). Annales de la Société Entomologique de France 38: 45-53.

Søli, G.E.E., J.R. Vockeroth, and L. Matile. 2000. Families of Sciaroidea. In L. Papp and B. Darvas (editors), Contributions to a manual of Palaeartic Diptera, appendix: 49-92. Budapest: Science Herald.

Stilwell, J.D., et al. 2020. Amber from the Triassic to Paleogene of Australia and New Zealand as exceptional preservation of poorly known terrestrial ecosystems. Scientific Reports 10: 5703.

Strong, E.E., and D. Lipscomb. 1999. Character coding and inapplicable data. Cladistics 15: 363-371.

Théobald, N. 1937. Les insectes fossiles des terrains oligocènes de France. G. Thomas, Nancy.

Tonnoir, A.L. 1929. Australian Mycetophilidae. Synopsis of the genera. Proceedings of the Linnean Society of New South Wales 54: 584-614. 
Tonnoir, A.L., and F.W. Edwards. 1927. New Zealand fungus gnats (Diptera, Mycetophilidae). Transactions of the New Zealand Institute 57: 747-878.

Tozoni, S.H.S. 1998. Sistemática filogenética dos Mycetophilidae (Diptera: Bibionomorpha). Tese de Doutoramento, Universidade Federal do Paraná, Curitiba. 124 pp.

Tuomikoski, R. 1966. Generic taxonomy of the Exechiini (Dipt., Mycetophillidae). Annales entomologici Fennici 32: 159-194.

Väisänen, R. 1984. A monograph of the genus Mycomyia Rondani in the Holarctic region (Diptera, Mycetophilidae). Acta Zoologica Fennica 177: 1-346.

Väisänen, R. 1986. The delimitation of the Gnoristinae: criteria for the classification of recent European genera (Diptera, Mycetophilidae). Annales Zoologici Fennici 23: 197-206.

Villeneuve, M.E., and Mathewes, R.W. 2005. An Early Eocene age for the Quilchena fossil locality, southern British Columbia. Geological Survey of Canada, Current Research (Online) A4: 1-7.

Vockeroth, J.R. 1980. New genera and species of Mycetophilidae (Diptera) from the Holarctic region, with notes on other species. Canadian Entomologist 112: 529-544.

Vockeroth, J.R. 1981. Mycetophilida. In J.F. McAlpine et al. (editors), Manual of Nearctic Diptera, vol. 1: 223-255. Monograph 27. Ottawa: Research Branch Agriculture Canada.

Vockeroth, J.R. 2009. Mycetophilidae. In B.V. Brown et al. (editors), Manual of Central America Diptera, vol. 1: 267-278. Ottawa: National Research Council of Canada.
Walker, A.K., and T.K. Crosby. 1988. The preparation and curation of insects. DSIR, information series 163. Wellington, New Zealand: Science Information Publishing Centre.

Wang, B., et al. 2014. A diverse paleobiota in Early Eocene Fushun amber from China. Current Biology 24: 1606-1610.

Winnertz, J. 1863. Beitrag zu einer Monographie der Pilzmücken. Verhandlung der Zoologischbotanischen Gesellschaft in Wien 13: 637-964.

Yu, X.-X., and H. Wu. 2009. Two new species of genus Rondaniella Johannsen (Diptera: Mycetophilidae) from China. Entomotaxonomia 31: 221-224.

Yu, X.-X., H. Wu, X.-x. Chen, M. Shi, and Q. Wu. 2004. Two new species of the genus Rondaniella Johannsen (Diptera: Mycetophilidae) from China. Entomotaxonomia 26: 289-292.

Yu, X.-x., H. Wu, and X.-x. Chen. 2008. Three new species of Rondaniella Johannsen (Diptera: Mycetophilidae) from China. Entomotaxonomia 30: 45-49.

Zaitzev, A.I. 1982a. Composition and systematic position of the genus Allactoneura de Meijere (Diptera, Mycetophilidae). Entomologicheskoye Obozreniye 60: 901-913. [in Russian]

Zaitzev, A.I. 1982b. Greenomyia and Neoclastobasis, fungus-gnats (Diptera, Mycetophilidae) of the USSR. Vestnik Zoologii 1982: 25-32.

Zandler, R.H. 2003. Glycerin jelly as a substitute for Hoyer's solution mountant. Res Botanica, Missouri Botanical Garden. Online resource (http://www. mobot.org/plantscience/ResBot/Meth/GlycerinJelly. htm), accessed January, 2008.

\section{APPENDIX 1}

\section{LIST OF CHARACTERS}

In brackets the consistency index and retention index for each character.

\section{Head}

1. Head position relative to thorax: $\mathbf{0}$, top of vertex at same level than scutum; 1, head fit under anterior end of scutum. [20,50]

2. Position of occipital foramen: $\mathbf{0}$, at center of foramen; $\mathbf{1}$, displaced dorsally. $[33,96]$

3. Head shape (lateral view): $\mathbf{0}$, rounded, height and width similar; 1, ovoid, higher than long. [20,87]

4. Ventral setae on postgena: $\mathbf{0}$, all short; $\mathbf{1}$, with 2 or 3 setae longer than others; 2 , all postgenal setae long. $[33,90]$
5. Postgena: $\mathbf{0}$, with normal setae; $\mathbf{1}$, with numerous erect or curved bristles behind eye; 2 , with a row of bristles. $[33,91]$

6. Occiput: 0, flat; $\mathbf{1}$, depressed. [100, 100]

7. Shape of postgena: $\mathbf{0}$, rectangular; $\mathbf{1}$, triangular; $\mathbf{2}$, as a straight line; 3 , prominent medially. $[42,91]$

8. Median ocellus: $\mathbf{0}$, as large as or slightly smaller than lateral ones; 1 , extremely reduced; 2 , divided into two; 3, absent. [33, 62]

9. Arrangement of ocelli: $\mathbf{0}$, triangular; $\mathbf{1}$, in line. $[8,80]$ 10. Interocellar setae: $\mathbf{0}$, many; $\mathbf{1}, \mathrm{few} ; \mathbf{2}$, none. $[14,69]$ 11. Distance of lateral ocelli from eye margin: 0 , larger than ocellus diameter; 1, smaller than ocellus diameter. $[7,75]$ 
12. Preocellar bristle (in front lateral ocelli): $\mathbf{0}$, absent; 1 , present. $[33,83]$

13. Frontal furrow: $\mathbf{0}$, present; $\mathbf{1}$, absent. $[8,52]$

14. Male antenna length: $\mathbf{0}$, longer than head and thorax together; $\mathbf{1}$, as long as or shorter than head and thorax together. [4, 48]

15. Scape and pedicel: $\mathbf{0}$, both rounded; $\mathbf{1}$, scape rounded and pedicel elongated in its base; 2 , scape elongated in its base and pedicel rounded. $[22,87]$

16. Dense setation on anterior surface of scape and pedicel: $\mathbf{0}$, absent; $\mathbf{1}$, present. $[8,57]$

17. Long apical-posterior bristle on pedicel: $\mathbf{0}$, absent; 1, present. $[9,76]$

18. Shape of male antennal flagellomeres: $\mathbf{0}$, cylindrical or subcylindrical; 1, clearly laterally compressed. [100, 100]

19. Length of antennal flagellomeres: $\mathbf{0}$, as wide as long; 1, wider than long; 2 , longer than wide. [12, 69]

20. Length of first antennal flagellomere: $\mathbf{0}$, as long as distal ones; 1 , longer than distal ones. $[16,64]$

21. Length of setae on last antennal flagellomere: $\mathbf{0}$, all setae of similar length; $\mathbf{1}$, a pair longer than remaining setae. $[50,85]$

22. Frons: $\mathbf{0}$, bare; $\mathbf{1}$, partially pubescent; $\mathbf{2}$, entirely pubescent; 3 , with a single seta close to eye margin and antennal base. [16, 65]

23. Face: $\mathbf{0}$, pubescent; $\mathbf{1}$, bare. $[25,50]$

24. Face shape: 0, ovoid; $\mathbf{1}$, approximately rectangular, dorsal margin triangular; 2, narrow rectangular; 3, squared; 4 , rectangular, wide; $\mathbf{5}$, rectangular, dorsoventrally elongated; $\mathbf{6}$, rounded dorsally, wider and concave ventrally. $[46,88]$

25. Face/clypeus ratio: $\mathbf{0}$, about $1: 1 ; \mathbf{1}$, face wider than clypeus; 2 , face narrower than clypeus. [13, 75]

26. Clypeus: 0, pubescent; $\mathbf{1}$, bare. $[100,100]$

27. Clypeus: 0, not projected beyond ventral margin of head; 1 , extending beyond ventral margin of head. $[11,68]$

28. Clypeus shape: $\mathbf{0}$, ovoid; $\mathbf{1}$, rectangular; $\mathbf{2}$, triangular; 3, squared. [33, 77]

29. Clypeus anterior protrusion: $\mathbf{0}$, absent; 1, present. $[50,95]$

30. Labrum well elongate, longer than clypeus: $\mathbf{0}$, absent; 1, present. $[100,100]$

31. Mouth parts: $\mathbf{0}$, short, a typical labella; 1, slightly elongate, forming a short proboscis; 2, very elongate, forming a long proboscis; 3 , reduced. $[60,80]$

32. Number of palpomeres: $\mathbf{0}$, four; $\mathbf{1}$, two. $[33,33]$

33. Third palpomere: $\mathbf{0}$, rounded; $\mathbf{1}$, slightly elongated; 2, longer than others. $[20,69]$
34. Length of last palpomere relative to penultimate: $\mathbf{0}$, about $1.5 \times$; 1 , more than $1.5 \times ; 2$, about $1: 1 ; 3$, extremely long, much longer than others; 4 , smaller than $1: 1 .[15,47]$

\section{Thorax}

35. Thorax: $\mathbf{0}$, not dorsoventrally depressed; $\mathbf{1}$, moderately dorsoventrally depressed; 2 , strong dorsoventrally depressed. $[22,83]$

36. Shape of scutum: $\mathbf{0}$, dorsal surface convex; $\mathbf{1}$, projected dorsoanteriorly; 2 , slightly flatenned dorsoventrally; 3, projected dorsomedially; 4, flatenned dorsoventrally, dorsal surface approximately straight. $[33,73]$

37. Scutum posterior margin setation: $\mathbf{0}$, with bristles of similar length; 1, two longer lateral bristles; 2 , four longer bristles, two laterals and two central; $\mathbf{3}$, two longer central bristles; $\mathbf{4}$, six longer bristles, four laterals and two central. [50, 75]

38. Scutum chaetotaxy: $\mathbf{0}$, densely pubescent with long and robust bristles randomly distributed; $\mathbf{1}$, only acrosticals, intraalars, supraalars, and dorsocentrals present; 2, only equal bristles, except some marginals longer. $[22,86]$

39. Scutellar stronger bristles (besides setulae): 0, absent; 1, two long, strong bristles; 2, four long, strong bristles; 3 , six long, strong bristles. [13, 58]

40. Scutellum shape: $\mathbf{0}$, ovoid, anterior and posterior margins parallels; 1 , approximately triangular, posterior margin mesially prominent. $[33,60]$

41. Suture between antepronotum and proepisternum: 0, absent; $\mathbf{1}$, present. $[10,75]$

42. Pronotum shape: $\mathbf{0}$, ovoid; $\mathbf{1}$, narrow rectangular; $\mathbf{2}$, wide medially, with tapered ends; $\mathbf{3}$, long rectangular; 4, as a "drop," anterior end tapered and posterior end rounded; 5, elongated, posterior end tapered. $[100,100]$

43. Pronotum pubescence: $\mathbf{0}$, strong, long bristles randomly distributed; 1, all setae of same length; 2, predominantly equal setae, except some long bristles in the ventral margin. $[66,85]$

44. Connection of proepimeron and ventral-posterior end of pronotum: $\mathbf{0}$, by a very narrow region; $\mathbf{1}$, until its median region; 2, almost its entire extension; 3, minimally connected and covered by the proepisternum. [30, 87]

45. Ventral portion of proepimeron: $\mathbf{0}$, rounded; $\mathbf{1}$, tapered; 2, angle, approximately, 90 . [20, 77]

46. Proepimeron shape: $\mathbf{0}$, triangular; $\mathbf{1}$, digitiform; $\mathbf{2}$, rectangular; 3 , approximately ovoid; 4 , elongated and medially prominent. $[30,78]$ 
47. Basisternum in lateral view, laterally to proepisternum: 0, weakly developed, present as a narrow band; 1, shieldlike, well developed, wide. [100, 100]

48. Basisternum pubescence: $\mathbf{0}$, with microtrichia and scattered setae, without bristles; $\mathbf{1}$, setae and bristles scattered; 2, dense setae for all surface. [22, 72]

49. Mesepimeron: $\mathbf{0}$, bare; $\mathbf{1}$, pubescent. [100, 100]

50 . Ventral region of mesepimeron: $\mathbf{0}$, ending at ventral margin of pleura; $\mathbf{1}$, ending at level of dorsal margin of katepisternum; 2, ending at level of mesopleurotrochantin. $[66,97]$

51. Shape of mesepimeron: $\mathbf{0}$, elongated, narrow ventrally; 1, dorsally short, narrow ventrally; 2, approximately rectangular, ventral anterior end inconspicuous; 3, approximately ovoid, depressed on its median region. [37, 88]

52. Laterotergite: $\mathbf{0}$, bare; $\mathbf{1}$, pubescent. $[7,71]$

53. Laterotergite shape: $\mathbf{0}$, ovoid; $\mathbf{1}$, approximately rectangular. $[20,91]$

54. Longer axis of laterotergite: $\mathbf{0}$, approximately vertical; 1 , inclined. $[33,96]$

55. Mesopleurotrochantin: $\mathbf{0}$, hidden ventrally on thorax; 1 , visible laterally. $[100,100]$

56. Width of anepisternum and katepisternum relative to laterotergite width: $\mathbf{0}$, as wide as or narrow; $\mathbf{1}$, wider. [25, 78]

57. Anapleural suture: $\mathbf{0}$, complete; $\mathbf{1}$, incomplete. [20, 75]

58. Anepisternum: 0, bare; 1, pubescent. $[16,50]$

59. Area of the anepisternum relative to katepisternum: $\mathbf{0}$, smaller; $\mathbf{1}$, as larger as; 2 , larger. $[13,75]$

60. Katepisternum shape: $\mathbf{0}$, rectangular; $\mathbf{1}$, ovoid; 2 , triangular; 3, squared. $[16,73]$

61. Anteroventral margin of katepisternum relative to posteroventral margin: $\mathbf{0}$, contiguous in a horizontal line; 1 , projected ventrally in a transversal line. $[14,89]$

62. Dorsoposterior angle of katepisternum: $\mathbf{0}$, sligthly groove that fits the anterior ventral region of mesepimeron; 1, angle projection that fits the anterior ventral region of mesepimeron. [16, 86]

63. Mediotergite: $\mathbf{0}$, sligthly prominent in the anterior region, increasing the height of the sclerite; $\mathbf{1}$, short and straight; 2 , strong curvature, forming a fold and reducing the height of the sclerite; 3 , strongly bulging medially. [33, 85]

64. Mediotergite: $\mathbf{0}$, bare; $\mathbf{1}$, pubescent. $[33,71]$

65. Foreleg relative to mid- and hindlegs: $\mathbf{0}$, of equal length; $\mathbf{1}$, about half. $[25,87]$

66. Forecoxa pubescence: $\mathbf{0}$, dense on anterior face; $\mathbf{1}$, uniformly distributed for all surface. $[7,76]$

67. Mid coxa: 0 , no differentiated apical bristle; 1 , with a long and well sclerotized apical bristle. [100, 100]
68. Mid- and hind coxa width/length proportion: $\mathbf{0}$, width a third of length; 1 , width half of length. $[20,66]$

69. Apex of fore- and midcoxa: $\mathbf{0}$, with bristles not regularly distributed; $\mathbf{1}$, with long bristles regularly distributed. [33, 86]

70. Forefemur: 0, cylindrical; 1, flattened anteroposteriorly. [50, 94]

71. Hind femur: 0, cylindrical (width less than twice width at apex); 1, flattened anteroposteriorly (width 2-3 times width at apex); 2, strongly flattened (width more than 3 times width at apex). [20,86]

72. Tibial setation arrangement: $\mathbf{0}$, irregular; $\mathbf{1}$, regular. $[20,81]$

73. Hind tibial spines: $\mathbf{0}$, shorter than tibial diameter at apex; 1 , longer than tibial diameter at apex. $[10,80]$

74. Hind tibial spines: $\mathbf{0}$, irregularly distributed; $\mathbf{1}$, regularly distributed. [12, 84]

75. Line of setae on the apex of the hind tibia: $\mathbf{0}$, composed by few setae; 1 , composed by many setae regularly arranged. $[33,85]$

76. Hind tibial spur: $\mathbf{0}$, shorter than the first tarsomere; 1 , as long as the first tarsomere. $[20,66]$

77. Tarsal claws: $\mathbf{0}$, bifid; $\mathbf{1}$, simple. [100, 100]

\section{Wing}

78. Wing membrane: $\mathbf{0}$, hyaline; $\mathbf{1}$, with transverse darker bands; 2, maculated apically; 3, entirely smoky; 4, with scattered maculation. [18, 63]

79. Alar membrane: $\mathbf{0}$, distended; $\mathbf{1}$, folded as a handheld fan. [100, 100]

80. Wing membrane macrotrichia: $\mathbf{0}$, disperse over entire surface; $\mathbf{1}$, scattered at anal region; 2 , absent. $[28,66]$

81. Microtrichia over wing membrane: $\mathbf{0}$, irregularly arranged; 1, partially arranged in regular rows; 2, distinctly arranged in regular rows. $[66,80]$

82. Costal vein: $\mathbf{0}$, ending slightly beyond $R_{5} ; \mathbf{1}$, ending at $R_{5} ; 2$, extending much beyond $R_{5} .[13,80]$

83. Subcostal vein: $\mathbf{0}$, complete, ending at $\mathrm{C}$; $\mathbf{1}$, incomplete, straight and ending free; 2, incomplete, inclined toward R but ending free; 3, very short, curved abruptly toward C. $[25,82]$

84. Sc: 0 , bare; 1 , with some macrotrichia. $[10,65]$

85. Vein sc-r: $\mathbf{0}$, present; $\mathbf{1}$, absent. $[6,69]$

86. Veins of radial sector of wing: $\mathbf{0}$, with scattered setae; 1 , densely covered with setae. $[100,100]$

87. Level of wing where $R_{1}$ reaches $C: \mathbf{0}$, apical third; $\mathbf{1}$, midpoint of the wing; 2 , basal third. $[28,84]$

88. $\mathrm{R}_{1}$ length: $\mathbf{0}$, more than 3 times $\mathrm{r}$ - $\mathrm{m}$ length; $1,1.1-$ 3.0 times $\mathrm{r}-\mathrm{m}$ length; 2 , shorter than $\mathrm{r}-\mathrm{m}$ length; 3 , as long as $\mathrm{r}-\mathrm{m}$ length. [15, 73] 
89. $\mathrm{R}_{1}$ shape: $\mathbf{0}$, slightly oblique or longitudinal close to tip; 1, curved anteriorly toward wing margin; 2, clearly transverse. $[18,80]$

90. Origin of first sector of Rs: $\mathbf{0}$, at basal third of wing; $\mathbf{1}$, at about midpoint of wing; 2 , absent. $[9,56]$

91. Basal sector of Rs: $\mathbf{0}$, oblique; $\mathbf{1}$, transverse. $[6,67]$

92. $\mathrm{R}_{4}: \mathbf{0}$, absent; $\mathbf{1}$, present. $[16,73]$

93. Level of wing that $\mathrm{R}_{5}$ reaches $\mathrm{C}: \mathbf{0}$, at wing apex; $\mathbf{1}$, clearly before wing apex. $[12,83]$

94. $\mathrm{R}_{5}: \mathbf{0}$, following the wing curvature; $\mathbf{1}$, entirely straight; 2, straight and distally curved dorsally; 3, straight with a distal curvature ventrally. $[20,71]$

95. r-m: 0, straight, longitudinal; 1, straight, oblique; 2, straight, transverse; 3 , with a curve midway between Rs and $\mathrm{M} 1+2 ; 4$, with a pair of $90^{\circ}$ bents midway between Rs and $M 1+2 ; 5$, absent. [16, 67]

96. Proportion $\mathrm{r}-\mathrm{m} /$ first Rs sector length: $\mathbf{0}$, less than 2 times; 1, 2-4 times; 2, more than 4 times; 3, about as long as; 4 , less than 1.0. [13, 55]

97. r-m: $\mathbf{0}$, bare; $\mathbf{1}$, pubescent. $[33,66]$

98. $\mathrm{M}_{1}: \mathbf{0}$, present; $\mathbf{1}$, not produced, medial fork absent. $[50,50]$

99. $\mathrm{M}_{1+2}: 0$, bare; 1 , pubescent. $[11,81]$

100. Base of $\mathrm{M}_{1+2}: \mathbf{0}$, sclerotized; $\mathbf{1}$, obsolete, not reaching Rs. $[16,66]$

101. Proportion of $\mathrm{M}_{1+2} /$ medial fork length: $\mathbf{0}$, about $1 / 3 ; 1$, about of same length; 2 , about $1 / 2 ; 3$, medial fork longer than $M 1+2 ; 4$, about $1 / 5 ; 5$, about $1 / 4$; 6, extremely reduced. $[19,67]$

102. $\mathrm{M}_{1}: \mathbf{0}$, complete; $\mathbf{1}$, obsolete basally; 2 , absent. $[16,60]$

103. $\mathrm{M}_{1}: \mathbf{0}$, bare; $\mathbf{1}$, pubescent. $[25,57]$

104. $M_{1}$ sinuosity: $\mathbf{0}$, absent; $\mathbf{1}$, present. $[50,50]$

105. $\mathrm{M}_{2}: \mathbf{0}$, complete; $\mathbf{1}$, obsolete basally; 2 , absent. $[15,47]$

106. $\mathrm{M}_{2}: \mathbf{0}$, bare; $\mathbf{1}$, pubescent. $[16,54]$

107. $\mathrm{M}_{2}$ apex: $\mathbf{0}$, complete, reaching wing margin; $\mathbf{1}$, incomplete, not reaching margin. [16, 50]

108. $\mathrm{M}_{1}$ and $\mathrm{M}_{2}: \mathbf{0}$, parallel; $\mathbf{1}$, divergent; 2 , convergent. $[8,62]$

109. Extension of first sector of $\mathrm{CuA}$ (from wing base to fork): $\mathbf{0}, 1 / 3$ or less extension of second sector; $\mathbf{1}$, as long as second sector; $\mathbf{2}$, about half second sector;
3 , extremely reduced; 4 , longer than second sector; 5, absent. $[16,56]$

110. First sector of CuA: 0, bare; 1, pubescent. $[10,62]$

111. Bifurcation $\mathrm{CuA}+\mathrm{M}_{4}: \mathbf{0}$, at same level of apex of Sc; 1, more distal than apex of Sc; 2, more basal than apex of Sc. [10,69]

112. $\mathrm{M}_{4}: \mathbf{0}$, complete; $\mathbf{1}$, obsolete basally. $[8,77]$

113. $M_{4}: 0$, bare; 1 , pubescent. [20,50]

114. $\mathrm{M}_{4}$ apex: 0 , complete, reaching wing margin; $\mathbf{1}$, incomplete, not reaching wing margin. [20,55]

115. Shape of the second sector of $\mathrm{CuA}$ : $\mathbf{0}$, continuously curved toward wing margin; 1 , with a slight median depression; 2, with a deep median depression; $\mathbf{3}$, with an almost $90^{\circ}$ angle midway to apex; 4 , straight. $[26,78]$

116. $\mathrm{A}_{1}: \mathbf{0}$, incomplete, ending midway to margin; $\mathbf{1}$, incomplete, ending at basal third toward margin; 2 , complete, reaching wing margin. $[18,35]$

117. $A_{1}: 0$, free from $\mathrm{CuA} ; \mathbf{1}$, fused or nearly fused to CuA. [50, 83]

118. $\mathrm{A}_{1}: \mathbf{0}$, bare; $\mathbf{1}$, pubescent. $[14,83]$

119. $\mathrm{A}_{1}: \mathbf{0}$, convergent toward $\mathrm{CuA} ; \mathbf{1}$, divergent from $\mathrm{CuA} ; 2$, parallel with $\mathrm{CuA} .[14,72]$

120. Alar folds across mid of $\mathrm{r}-\mathrm{m}$ and between medial fork and M4: 0, absent; 1, present. [100, 100]

\section{Male Terminalia}

121. Male terminalia relative to abdomen: $\mathbf{0}$, aligned; $\mathbf{1}$, flexed; 2, flexed twice. [100, 100]

122. Gonostylus: 0, simple; 1, bifid; 2, ornamented, with differentiated regions. $[12,76]$

123. Gonostylus spines: $\mathbf{0}$, absent; $\mathbf{1}$, present. $[7,71]$

124. Height of the gonostylus relative to height of gonocoxite (without its projections): $\mathbf{0}$, shorter; $\mathbf{1}$, as long as; 2 , longer. $[15,57]$

125. Cercus: 0, membranous; 1, with sclerotized regions. $[50,83]$

126. Cercus: 0, simple; 1, bilobed. [50, 66]

127. Spines regularly distributed at the cercus: $\mathbf{0}$, absent; 1, present. [33, 71]

128. Cercus length relative to length of distal projection of gonocoxite: $\mathbf{0}$, about the same or smaller; $\mathbf{1}$, extremely elongated. [100, 100] 


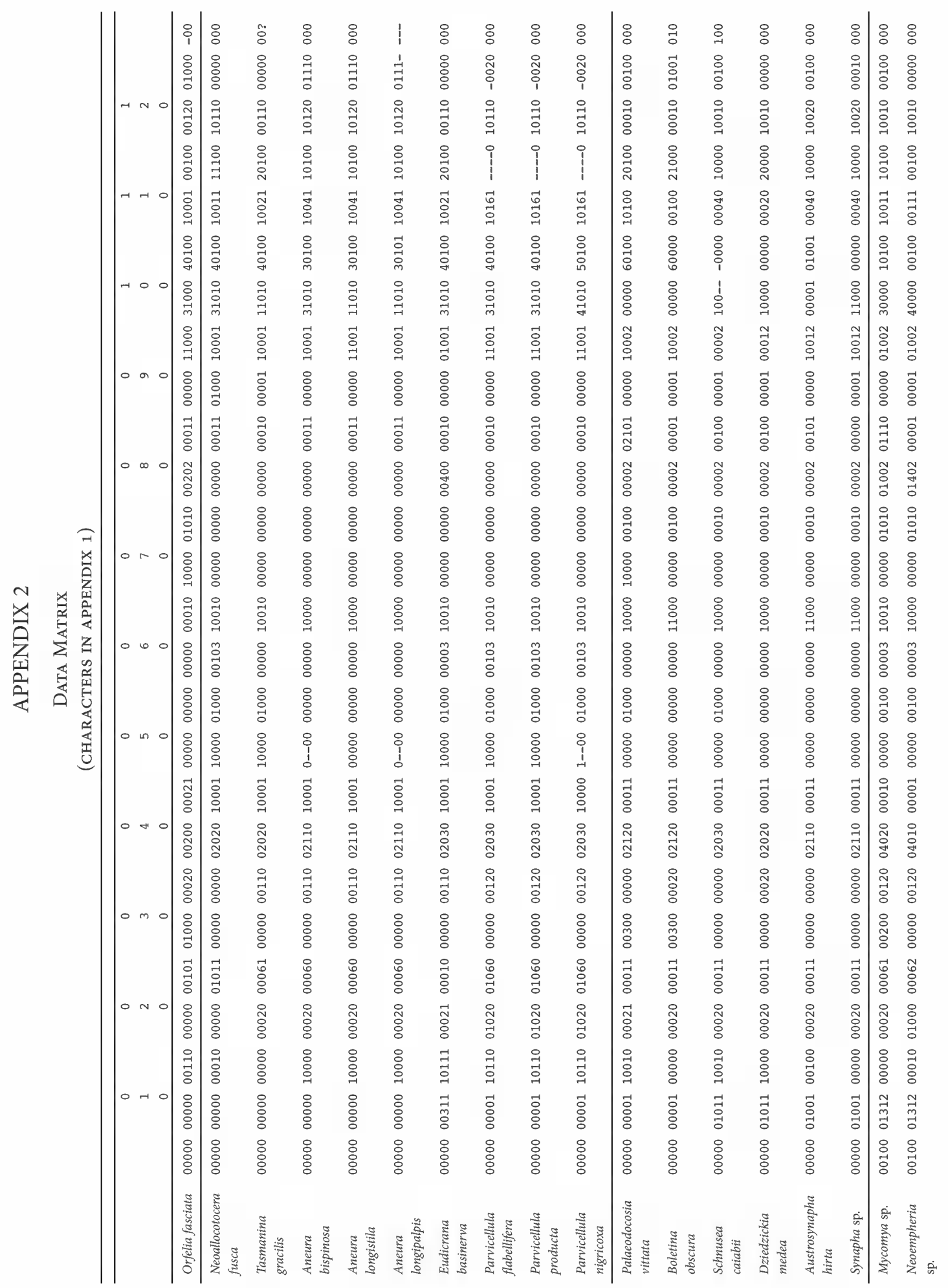




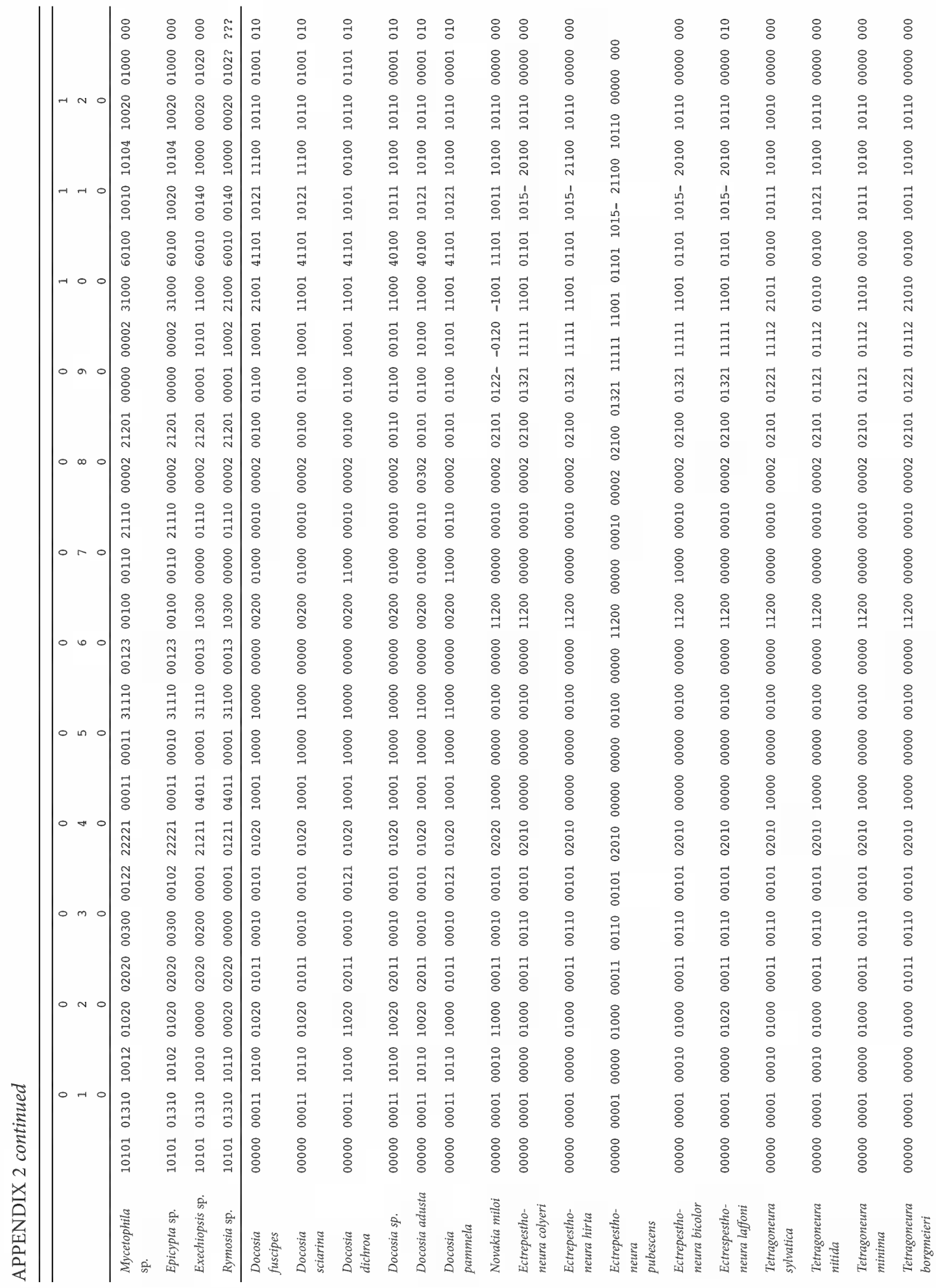




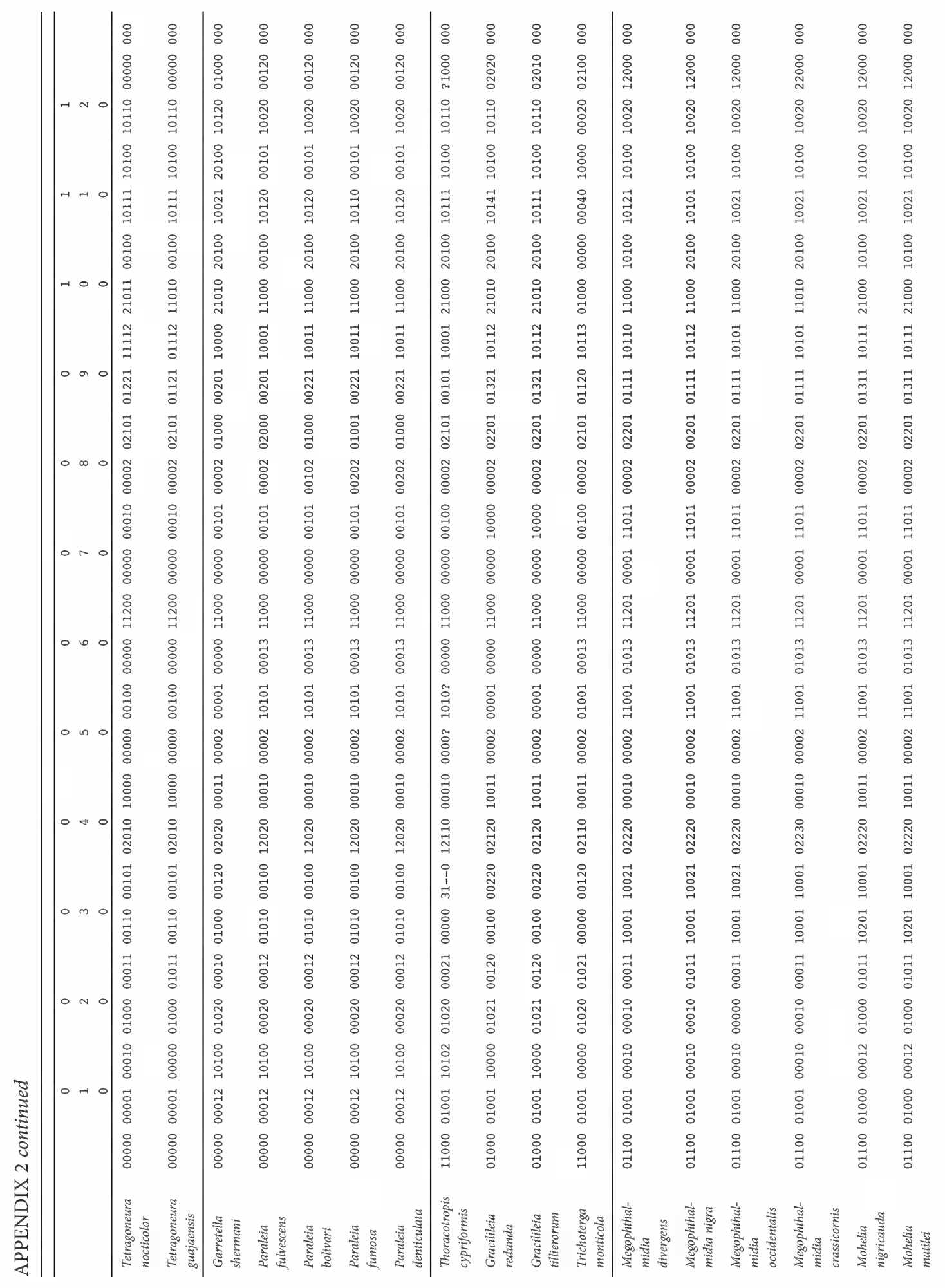




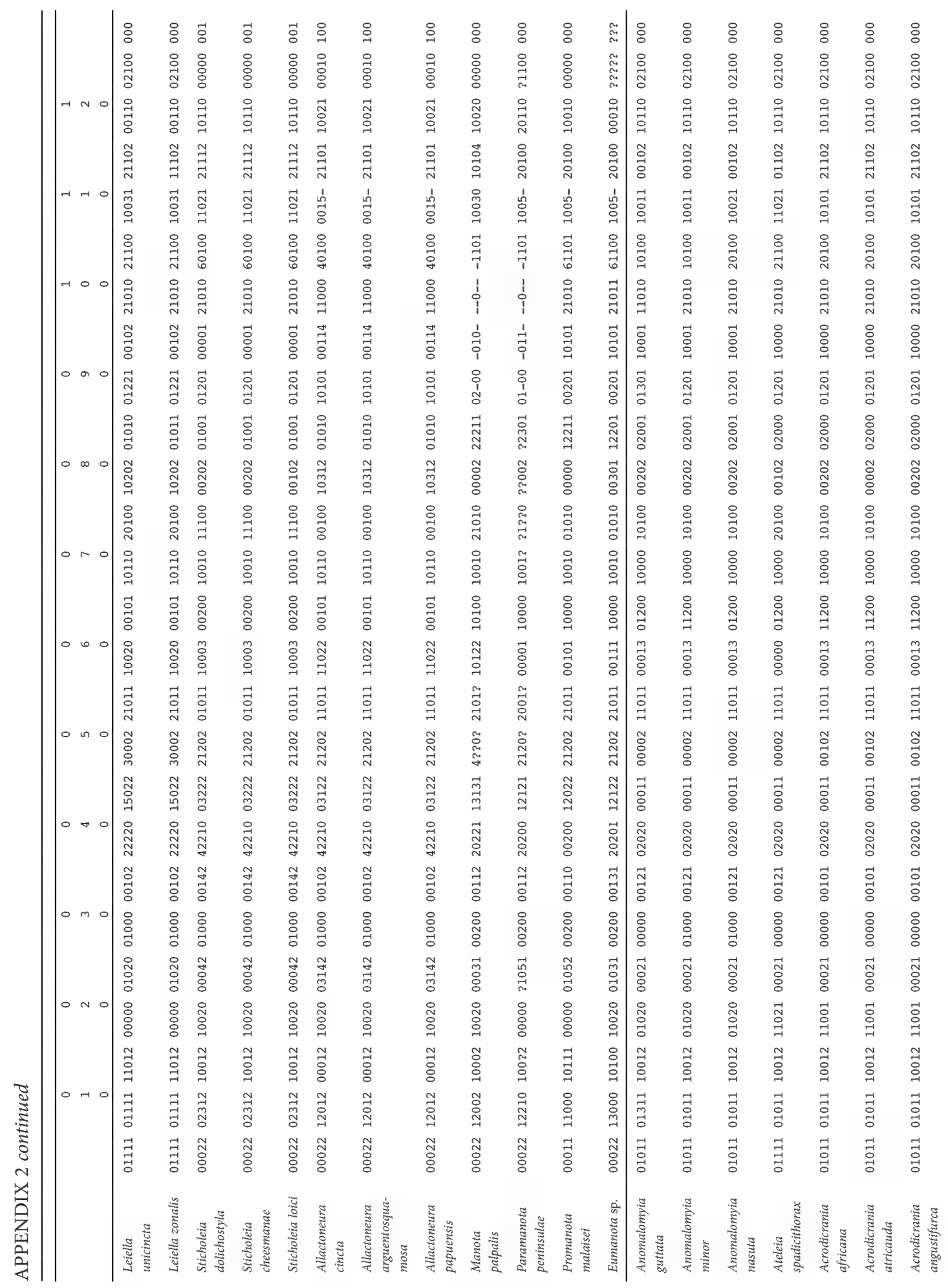




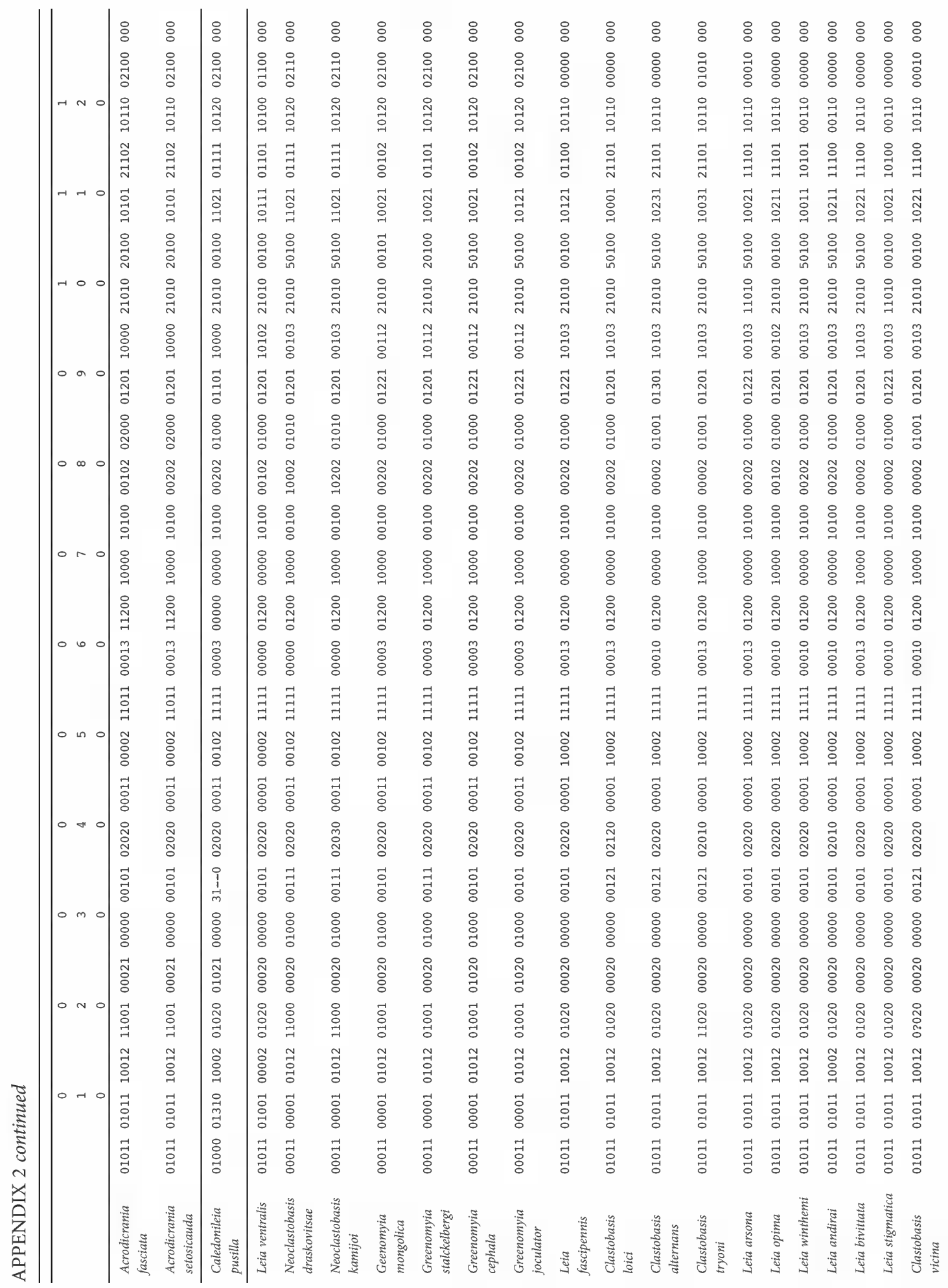




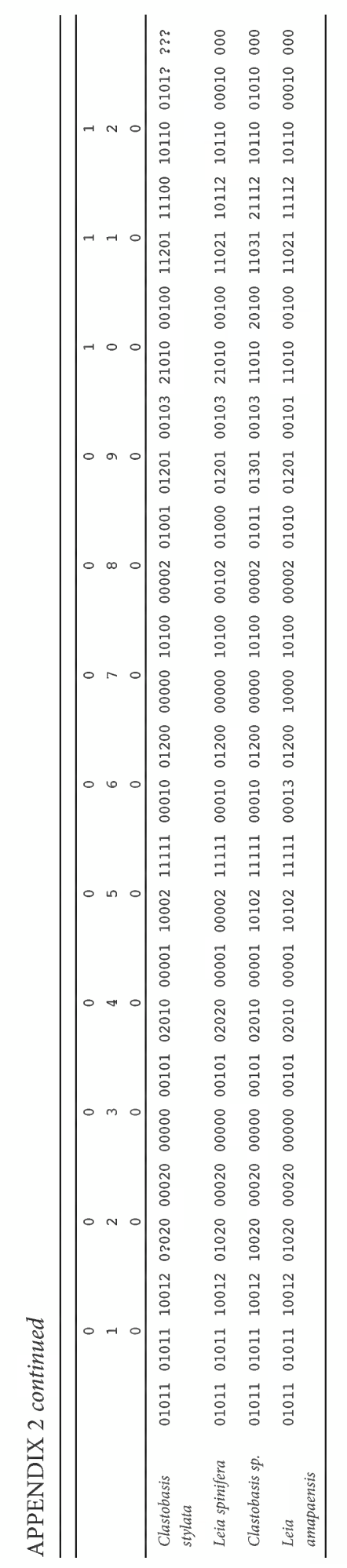




\section{APPENDIX 3}

List of MATERIAL EXAMined

Sources of information for characters in the data matrix: complete list of specimens analyzed to run the phylogenetic analyzes and/or to illustrate the paper (wing and habitus) and papers from which information on terminal species were taken. Specimens from which photos of the wings were made are indicated. Genera in alphabetic order within each subfamily.

\section{Orfelia}

\section{KEROPLATIDAE}

\section{Orfelia fasciata Meigen}

10ิ, ROMANIA, Retezatului, Mts. Nr Hobita Cabana, 29.vi.1969, 4000', Mature pine forests, B.H. and M.C. Cogan, R.I. and R. Vane-Wright, B.M. 1970152, det. P.J. Chandler [NHM]

1ô, CROATIA, Plitvice, 4-10.vii.1955, in old forest, R.L. Coe, B.M. 1955-460, det. P.J. Chandler [NHM] 1 ㅇ, CYPRUS, Mt. Troodos, 4000ft, 17.ix.1951, G.A. Mavromoustakls, B.M. 1952-527, det. P.J. Chandler [NHM]

1 q , FRANCE, Rennes, L. Bleuse, Pres. by E. Brunetti, B.M. 1927-184, det. P.J. Chandler [NHM]

\section{MYCETOPHILIDAE}

\section{SCIOPHILINAE}

\section{Neoallocotocera}

Neoallocotocera fusca Tonnoir

1ô, AUSTRALIA, Tasmania, Cradle Valley, 12.i.1923, A. Tonnoir. Holotype. A. Tonnoir det. [ANIC]

1?, AUSTRALIA, Victoria, Sassafras, 22.x.1922, A. Tonnoir. Paratype. A. Tonnoir det. [ANIC]

9ô, AUSTRALIA, Tas., 4Km E. Rosebery, 41.47S 145.35E, 16.i-1.ii.1983, Malaise ethanol, I.D. Naumann and J.C. Cardale. Oliveira, S.S. det. 2011 [ANIC] (fig. 1)

\section{Aneura}

Aneura bispinosa Edwards

10ิ, NEW ZEALAND, Raethi Hill, 3900 ft, xi.1923, T.R. Harris, B.M. 1924-22. Holotype, det. J.E. Chainey, 1995. BMNH(E) \#257885 [NHM]

1 ㅇ, NEW ZEALAND, Ohakune, x-xi.1923, T.R. Harris, B.M. 1923-584. Paratype, det. J.E. Chainey, 1995. $\mathrm{BMNH}(\mathrm{E})$ \#257886 [NHM]

1 ㅇ, NEW ZEALAND, Ohakune, i.1924, T.R. Harris, B.M. 1924-99, Paratype, det. J.E. Chainey, 1995. $\mathrm{BMNH}(\mathrm{E}) \# 257890$ [NHM]
19 , NEW ZEALAND, Nelson, 15.xii.1921, A. Tonnoir, No62b, B.M. 1922-348 [NHM]

Aneura longistila Freeman

10, ARGENTINA, Terr. Rio Negro, Lago Gutierrez, 3-14.xi.1926, B.M. 1927-63, Paratype, F.M. Edwards, BMNH \#257916 [NHM]

2 ㅇ, CHILE, Llanquihue Prov., Puerto Montt., 24.xii.1926, B.M. 1927-63. Paratype, F.M. Edwards [NHM]

$10^{\star}$, ARGENTINA, Neuquen, P.N. Lauin, 28.xi.1971, 8141, J.P. Duret det., 1972 [MNHN]

Aneura longipalpis Tonnoir and Edwards 1 đ1․ NEW ZEALAND, Ohakune, $x$-xii.1923, T.R. Harris, B.M. 1923-584 [NHM]

201 ㅇ, NEW ZEALAND, Ohakune, ii.1924, T.R. Harris, B.M. 1924-278 [NHM]

Aneura sp.

10, Chile, Parque Nacional Puyehue, Termas, $440 \mathrm{~m}$, sweeping, Jan14-Feb3.2017, D.S. Amorim and V.C. Silva [MZUSP] (fig. 2)

\section{Eudicrana}

Eudicrana basinerva Freeman

10, ARGENTINA, Terr. Rio Negro, Lago Gutierrez, 3-14.xi.1926, B.M. 1927-63, Paratype, F.M. Edwards, $\mathrm{BMNH} \# 253797$ [NHM]

10, CHILE, Llanquihue Prov., Puella, 12-13.xii.1926, B.M. 1927-63, Paratype, F.M. Edwards, BMNH \#253798 [NHM]

1 , CHILE, Llanquihue Prov., Casa Pangue, 04-10. xii.1926, B.M. 1927-63, Paratype, F.M. Edwards, $\mathrm{BMNH} \# 253796$ [NHM]

Eudicrana splendens Lane

1 đo, BRAZIL, São Paulo, Salesópolis, Estação Biológica de Boracéia, Holotype [MZUSP] (fig. 4)

\section{Parvicellula}

Parvicellula flabellifera Freeman

$1 ð 29$, ARGENTINA, Terr. Rio Negro, Lago Correntoso, 18-25.xi.1926, F. and M. Edwards, B.M. 192763. Paratype [NHM]

10, ARGENTINA, Neuquen, P.N. Lauin, 15.xi.1973, col. Duret, 10661, J.P. Duret det. [MNHN]

Parvicellula producta Freeman

2 ㅇ, ARGENTINA, Terr. Rio Negro, Lago Correntoso, 18-25.xi.1926, F. and M. Edwards, B.M. 1927-63. Paratype. 
Parvicellula producta Freeman [NHM]

10 , ARGENTINA, Terr. Rio Negro, N. Huapi, Isla Victoria, 16.ii.1972, 8480. Det. J.P. Duret, 1975 [MNHN]

Parvicellula nigricoxa Tonnoir

10, NEW ZEALAND, Waiho river, 18.i.1922, No37, A. Tonnoir, B.M. 1922-348 [NHM]

10, NEW ZEALAND, Queenstown, 1250ft, 11.ii.1922, L. Curtis, B.M. 1922-193 [NHM]

1 ㅇ, NEW ZEALAND, Queenstown, 03.ii.1924, L. Curtis, B.M. 1925-141 [NHM]

Parvicellula sp.

10, CHILE, Osorno Parque Nacional Puyehue, Malaise trap, Jan-Fev 2017, D.S. Amorim and V.C. Silva cols. [MZUSP] (fig. 5)

\section{Tasmanina}

Tasmanina gracilis Tonnoir

10 , AUSTRALIA, Tasmania, Mount Wellington, 30. xi.1922, A. Tonnoir. Holotype. A. Tonnoir det. 65. Australian National Insect Collection [ANIC]

90, AUSTRALIA, Tas., 4Km E. Rosebery, 41.47S 145.35E, 16.i-1.ii.1983, Malaise ethanol, I.D. Naumann and J.C. Cardale. Oliveira, S.S. det. 2011 [ANIC] (fig. 3)

\section{GNORISTINAE}

Austrosynapha

Austrosynapha hirta Tonnoir

1 ․ AUSTRALIA, Tasmania, Burnie, 26.x.1922, A. Tonnoir, Holotype [ANIC]

1ㅇ, AUSTRALIA, Tasmania, Mt. Wellington, 27. xi.1922, A. Tonnoir, Paratype [ANIC]

$3{ }^{\widehat{x}} 5$ 우, AUSTRALIA, Tas., Ewart Ck., 41.58S 145.28E, 16.i-2.ii.1983, Malaise ethanol, I.D. Naumann and J.C. Cardale. Oliveira, S.S. det. 2011 [ANIC] (fig. 10)

\section{Boletina}

Boletina obscura Johhansen

1ơ, CANADA, Ont., Ottawa, 27.iv.1955, J.F. McAlpine, Rockcliffe Mc Kay Leg. Oliveira, S.S. det. 2012 [CNC] (fig. 7)

10, CANADA, Que., Old Chelsea, 6.v.1956, at birch sap. J.R. Vockeroth. Oliveira, S.S. det. 2012 [CNC]

10, CANADA, Ont., Marmora, 21.v.1952, J.F. McAlpine. Oliveira, S.S. det. 2012 [CNC]

\section{Dziedzickia}

Dziedzickia medea Lane

Oliveira (2009)
Dziedzickia metallica Lane

10 , BRAZIL, SP, Salesopolis, E.B. Boraceia, Malaise trap, 25.Feb.2005, Nogueira and Aguiar cols. [MZUSP] (fig. 9)

\section{Palaeodocosia}

Palaeodocosia vittata (Coquillett)

10 , CANADA, BC, Squamish, Diamond Head Trail 3500 ft., 17.viii.1953, G.J. Spencer. Oliveira, S.S. det. 2012 [CNC]

19 , CANADA, BC, Squamish, Diamond Head Trail 4000 ft., 19.viii.1953, G.J. Spencer. Oliveira, S.S. det. 2012 [CNC] (fig. 6)

$1 \hat{o}^{\hat{}}$, USA, Calif, Lily Pond, Alpine Lk., Marion Co., $1500^{\prime}$, Malaise trap, v.1976, D.D. Munroe. Oliveira, S.S. det. 2012 [CNC]

10, CANADA, Que., Hull, 10.viii.1965, Malaise trap. Oliveira, S.S. det. 2012 [CNC]

19, CANADA, MB, Fort Churchill, 12.viii.1952, J.G. Chillcott. Ecological data f. E. 21. Oliveira, S.S. det. $2012[\mathrm{CNC}]$

\section{Schnusea}

Schnusea caiabii Lane

10 , BRAZIL, SP, Ribeirão Grande, Parque Estadual Intervales, Malaise trap, 13-16.Dec.2000, M.T. Tavares col., S.S. Oliveira det. [MZUSP] (fig. 8)

Oliveira (2009)

Synapha

Synapha sp.

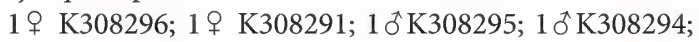

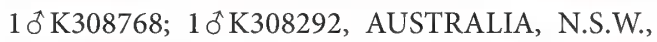
Warrumbungies, 15.ix.1983, D.K. McAlpine and B.J. Day. Oliveira, S.S. det. 2011 [AMSA] (fig. 11)

\section{MYCOMYINAE}

Mycomya

Mycomya sp.

10 69, BRAZIl, SC, Urubici, Morro Igreja, 18.viii-5. xii.2005, Malaise, Pinho and Bizzo Col. Oliveira, S.S. det. 2012 [MZUSP] (fig. 12)

\section{Neoempheria}

Neoempheria sp.

$20^{\top}+$, BRAZIL, SP, Ribeirão Preto, EERP - MST, $21^{\circ} 13^{\prime} 30^{\prime \prime} \mathrm{S} 47^{\circ} 51^{\prime} 01^{\prime \prime} \mathrm{W}, 13.1 i i .2009$, em tronco podre, Biffi, G. and Nascimento, E.A. Col. [LMED] (fig. 8) 


\section{MYCETOPHILINAE}

\section{Epicypta}

Epicypta sp.

20ิ5오, BRAZIL, SP, Sertãozinho, Res. Biol. Augusto Ruschi, 22.ix-13.x.2010, Malaise fragment 2 (borda), Silva, V.C., Donda, P.F. and Ignácio, G. Leg. Oliveira, S.S. det. 2011 [MZUSP] (fig. 17)

\section{Exechiopsis}

Exechiopsis sp.

7 đิ 1 , BRAZIL, AM, Ipixuna, Rio Liberdade, Estirão da Preta, 07²1'46.7'S 7152'07.1"W, 11-15.v.2011, Malaise, J.A. Rafael, J.T. Câmara, R.F. Silva, A. Somavilla, C. Gonçalves Leg. Oliveira, S.S. det. 2012 [INPA] (fig. 15)

\section{Mycetophila}

Mycetophila sp.

1 ธิ 2 ㅇ, BRAZIl, SP, Ribeirão Grande, Pq. Est. Intervales, $24^{\circ} 15^{\prime} \mathrm{S} 48^{\circ} 10^{\prime} \mathrm{W}, 13-16 . x i i .2000$, Malaise ponto T3, M.T. Tavares and eq. col. Oliveira, S.S. det. 2011 [MZUSP] (fig. 16)

\section{Rymosia}

Rymosia sp.

1 ô 2 ㅇ, BRAZIL, SC, São Bento do Sul, CEPA - Rugendas, Bosque B5, 16-19.x.2001, refuge. Oliveira, S.S. det. 2012 [MZUSP] (fig. 14)

\section{TETRAGONEURINAE}

\section{Docosia}

Docosia adusta Oliveira and Amorim

Source: Oliveira and Amorim (2011)

\section{Docosia dichroa Loew}

10ิ, CANADA, Que., North Ck., Mt. St. Hilaire, 3-6.v.1982, B.M. Nelson. Oliveira, S.S. det. 2012 [CNC]

10ิ, CANADA, Ont., Metcalfe, 12.v.1983, B.E. Cooper. Oliveira, S.S. det. 2012 [CNC]

10, CANADA, Que., Dunkan Lake nr. Rupert, 13.v.1973, J.F. McAlpine. Oliveira, S.S. det. 2012 [CNC]

1 ㅇ, CANADA, Que., Dunkan Lake nr. Rupert, 20.v.1973, J.F. McAlpine. Oliveira, S.S. det. 2012 [CNC]

1ô, CANADA, Que., Old Chelsea, 14.v.1980, J.R. Vockeroth, sweept over bare path in Acer wood. Oliveira, S.S. det. 2012 [CNC]
1 \% , CANADA, Que., Old Chelsea, 16.v.1901, J.R. Vockeroth. Oliveira, S.S. det. 2012 [CNC]

1 , , USA, PA: Sullivan Co., Myoming State For., 5Km NW Laporte, 6.v.1987, J.M. Cumming. Oliveira, S.S. det. 2012 [CNC]

Docosia fuscipes (von Roser)

$2 \widehat{\jmath}$, CZECH REPUBLIQUE, Silesia Otice near Opava, Otická sopka Nat. Monument, 16.iv.2007, Sweeping veget. Jan Ševčik leg., Jan Ševčik det. 2010 [LMED]

Additional source: Laštovka and Ševčik (2006)

Docosia pammela Edwards

$1 \delta^{\top} 1$ ㅇ, BRAZIL, SC, Seara, Nova Teutônia, $27^{\circ} 11^{\prime}$ S $52^{\circ} 23^{\prime} \mathrm{E}, 300-500 \mathrm{~m}$, ix.1971, Fritz Plaumann. Oliveira, S.S. det. 2012 [MZUSP]

$10^{\star} 19$, BRAZIL, SC, Seara, Nova Teutônia, $27^{\circ} 11^{\prime} \mathrm{S}$ $52^{\circ} 23^{\prime} \mathrm{E}, 300-500 \mathrm{~m}$, 10.vii.1937, Fritz Plaumann. Oliveira, S.S. det. 2012 [MZUSP]

$10^{\dagger}$, BRAZIL, SC, Seara, Nova Teutônia, $27^{\circ} 11^{\prime} \mathrm{S}$ $52^{\circ} 23^{\prime} \mathrm{E}, 300-500 \mathrm{~m}$, ix.1970, Fritz Plaumann. Oliveira, S.S. det. 2012 [MZUSP]

$10^{\star}$, BRAZIL, SC, Seara, Nova Teutônia, $27^{\circ} 11^{\prime} \mathrm{S}$ $52^{\circ} 23^{\prime} \mathrm{E}, 300-500 \mathrm{~m}, 15 . v i i .1938$, Fritz Plaumann. Oliveira, S.S. det. 2012 [MZUSP]

Docosia sciarina (Meigen)

10 , CZECH REPUBLIQUE, Silesia Otice near Opava, Otická sopka Nat. Monument, 16.iv.2007, Sweeping veget. Jan Ševčik leg., Jan Ševčik det. 2010 [LMED] (fig. 18)

19, Docosia sciarina Meigen compare au type par Loic Matile, 1974. BMNH(E) \#236685 [NHM]

Docosia sp.

2 đ3 9 , USA, Calif., Baldy Mesa 7mi. E. Phelan San Bd no Co., ii.1981. [CNC]

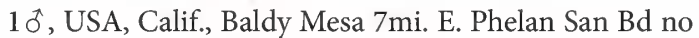
Co., 15-30.vi.1982, J.T. Huber [CNC]

Ectrepesthoneura

Ectrepesthoneura bicolor (Coquillett)

$2{ }^{\dagger}$, USA, Laurel, MD., 20.v.1965, Malaise trap, Oliveira, S.S. det. 2012 [CNC]

10, CANADA, QC: Gatineau Park, King Moutain trail, Ca. $45^{\circ} 29^{\prime} 27^{\prime \prime} \mathrm{N} 75^{\circ} 51^{\prime} 51^{\prime \prime} \mathrm{W}$, 13.v.2009, S.E. Brooks. Oliveira, S.S. det. 2012 [CNC]

19, CANADA, Ont, Simcoe, 5.vi.1939, G.E. Shewell Oliveira, S.S. det. 2012 [CNC]

Ectrepesthoneura colyeri Chandler 
20, SWEDEN, Sm: Ulvsdal. Malaise trap. $\mathrm{N}=58^{\circ} 32^{\prime}$; $\mathrm{E}=16^{\circ} 13^{\prime}$, Leg. N. Franc and Co. 14.v-14.vi.2002, Det. O. Kurina 2009 [LMED] (fig. 20)

\section{Ectrepesthoneura hirta (Winnertz)}

40ิ, SWEDEN, Sm: Långhult. Malaise trap. $N=56^{\circ} 49^{\prime}$; $\mathrm{E}=14^{\circ} 15^{\prime}$, Leg. N. Franc and Co. 10.v-10.vi.2004. Det. O. Kurina 2009 [LMED]

1 , ENGLAND, Crowborough, Sussex, 19.viii.1907, F. Jenkinson, 1913-9 [NHM]

\section{Ectrepesthoneura laffooni Chandler}

20, CANADA, Que., Old Chelsea, Summit King Mt. 1150 ', 11.vii.1965, Malaise trap, mounted from ethanol. Oliveira, S.S. det. 2012 [CNC]

1 , CANADA, Que., Old Chelsea, Summit King Mt. $1150^{\prime}$, 16.vi.1965, J.R. Vockeroth col. Oliveira, S.S. det. 2012 [CNC]

1 ㅇ, USA, NIC., Cligman's Dome, 5.viii.1957, W.R. Richards. Oliveira, S.S. det. 2012 [CNC]

1ô, CANADA, Ont., 6 mi. W.R. Richmond, 1.vii.1971, J.E.H. Martin. Oliveira, S.S. det. 2012 [CNC]

Ectrespesthoneura pubescens (Zetterstedt)

20, SWEDEN, Ög: Fagerhult. Malaise trap. $\mathrm{N}=58^{\circ} 4^{\prime}$; $\mathrm{E}=15^{\circ} 31^{\prime}$, Leg. N. Franc and Co. 14.v-14.vi. 2002, Det. O. Kurina 2009 [LMED]

1o, NORWAY, Dovrefjell, Kongsvoll, 1000-1500m, 25.vi-03.vii.1966, J.E. and R.B. Benson, B.M. 1966372, P.J. Chandler det. [NHM]

\section{Novakia}

Novakia miloi Kerr

4 ô 8 ㅇ , USA, CA: Humboldt Co., Humboldt Bay NWR, Lanphere Dunes, MT\#1 (6m), -6masl, 10.vi-18. viii.2008, $40^{\circ} 53.488^{\prime} \mathrm{N} 124^{\circ} 08.580^{\prime} \mathrm{W}$, P.H.Kerr, P. Haggard Leg. CSCA09L111. Mycetophilidae 09D204, Peter Kerr det. Jul2009 [LMED] (fig. 19)

\section{Tetragoneura}

Tetragoneura borgmeieri Edwards

$34{ }^{\star}$, BRAZIL, SP, Salesópolis, Res. Biol. Boracéia, Trilha dos Pilões, $23^{\circ} 39^{\prime} 02,9^{\prime \prime} \mathrm{S} 45^{\circ} 53^{\prime} 39^{\prime \prime} \mathrm{W}, 2-5$. iv.2001, Malaise Trilha 2, S.T.P. Amarante and eq. col. Oliveira, S.S. det. 2012 [MZUSP] (fig. 21)

\section{Tetragoneura guajaensis Lane}

1 §, BRAZIL, SP, Cantareira, vii.1945, J. Lane col. Holotype, det. John Lane 1957 [MZUSP]

20ิ, BRAZIL, SP, Santo Amaro, vii.1945, J. Lane and E. Coher col. Paratype [MZUSP]
1 ð̊, BRAZIL, SP, Morumbi, 1.xi.1949, light, E. Coher col. Paratype [MZUSP]

140̃, BRAZIl, SC, Urubici, 5.xii.2004-8.ii.2005, Malaise, Bizzo and Hugo Leg. Oliveira, S.S. det. 2012 [MZUSP]

Tetragoneura minima Tonnnoir and Edwards

10ิ, NEW ZEALAND, Campbell I., Tucker Cave, 1-50m, 12-17.xii.1961, J.I. Gressit Collector. Tetragoneura minima Tonn. $q$ det. 1962, R.A. Harrison [ANIC]

1 ๙ , NEW ZEALAND, Campbell I., Mt. Dumas, slope, 20.xii.1961, Sedge, J.I. Gressit Col., det. 1962, R.A. Harrison [ANIC]

10, NEW ZEALAND, Campbell I., Tucker Cave, 4m, 1-3.xii.1961, Malaise trap, J.I. Gressit Col., det. 1962, R.A. Harrison [ANIC]

1 , , NEW ZEALAND, Campbell I., Courejolles Penin., 200m, 14.xii.1961, Gray headed Mollymamk nests, J.I. Gressit Col., det. 1962, R.A. Harrison [ANIC]

10 , NEW ZEALAND, Campbell I., Tucker Cave, 4m, 16-18.xii.1961, J.I. Gressit Col., det. 1962, R.A. Harrison [ANIC]

10े, NEW ZEALAND, Campbell I., Tucker Cave, 4m, 18-21.xii.1961, Malaise trap, J.I. Gressit Collector. Tetragoneura minima Tonn. ơ det. 1962, R.A. Harrison [ANIC]

Tetragoneura nitida Adams

$2 ð 2$ ․ USA, Laurel, MD., 20.v.1965, Malaise trap. Oliveira, S.S. det. 2012 [CNC]

10, USA, NC, Clingman Dome, 6647', 21.v.1965, Great Smoky M.N.P., J.G. Chillcott. Oliveira, S.S. det. 2012 [CNC]

Tetragoneura nocticolor Edwards

54 đ̊, BRAZIl, SC, Urubici, 5.xii.2004-8.ii.2005, Malaise, Bizzo and Hugo Leg. Oliveira, S.S. det. 2012 [MZUSP]

$8{ }^{\star} 3$ ㅇ, BRAZIl, SC, São Francisco do Sul, Vila da Glória, Malaise trilha 5, 17-20.x.2001, refugo. Oliveira, S.S. det. 2012 [MZUSP]

Tetragoneura sylvatica (Curtis)

1 $\tilde{}$, SLOVAKIA, Centr. Polana B.R., 1250m, Lubletovský Vepor N.N.R., 6.ii.2006, Sweeping, Jan Ševčik Leg., Jan Ševčik det. 2010 [LMED]

10 , NETHERLANDS, Waarder (Z.H.), 28.vii.1975, C. van Achterberg. Oliveira, S.S. det. 2012 [CNC]

19 , NETHERLANDS, Waarder (Z.H.), vii.1975, C. van Achterberg. Oliveira, S.S. det. 2012 [CNC] 
10ิ, NETHERLANDS, Steckelheek duin, Rochanjezh, 10.viii.1976, C. van Achterberg. Oliveira, S.S. det. $2012[\mathrm{CNC}]$

\section{LEIINAE}

Acrodicrania

Acrodicrania africana Edwards

$30^{3} 3$ ㅇ, SOUTH AFRICA, Western Cape, Grootvadersbosch Nature Reserve, 33⒌ $030^{\prime} \mathrm{S} 20^{\circ} 49.128^{\prime} \mathrm{E}$, 340m, 29.iii-23.vii.2010, S. van Noort, Malaise Trap, Afromontane Forest GVB10-FOR1-M03. Oliveira, S.S. det. 2011 [SAMC]

Additional source: Oliveira and Muller (2012)

\section{Acrodicrania angustifurca Skuse}

19 , AUSTRALIA, N.S.W., Sydney, Mossman's Bay, September, Skuse. Holotype [ANIC]

3 ․, AUSTRALIA, Queensland, Lamington NP, Mycetophilidae, Malaise - Ground, $28^{\circ} 13^{\prime} \mathrm{S} 153^{\circ} 07^{\prime} \mathrm{E}, \mathrm{R}$. Kitching, July 1996. Oliveira, S.S. det. 2011 [AMSA]

10̃, AUSTRALIA, N.S.W., Carral SF, 11-16.i.1998, $1055 \mathrm{~m}, 30^{\circ} 54^{\prime} 19^{\prime \prime} \mathrm{S} 152^{\circ} 17^{\prime} 36^{\prime \prime} \mathrm{E}$, Stick trap on $E$. obliqua, E. Tasker Leg, CC-DP-018-4. Oliveira, S.S. det. 2011 [AMSA]

$1{ }^{\widehat{T}} 1$ 우, AUSTRALIA, N.S.W., Carral SF, 3-8.xii.1998, $1055 \mathrm{~m}, 30^{\circ} 54^{\prime} 33^{\prime \prime} \mathrm{S} 152^{\circ} 16^{\prime} 28^{\prime \prime} \mathrm{E}$, Stick trap on $E$. campanulata, E. Tasker Leg, CC-CR-127-5. Oliveira, S.S. det. 2011 [AMSA]

10ิ, AUSTRALIA, A.C.T., Black Mt., Light trap, 29. viii.1961, I.F.B. Common. Oliveira, S.S. det. 2011 [AMSA]

10 ${ }^{*}$, AUSTRALIA, N.S.W., Macquaire Pass, 9.x.1969, Common and Upton, Light trap. Oliveira, S.S. det. 2011 [AMSA] (fig. 51)

\section{Acrodicrania atricauda Skuse}

10, AUSTRALIA, N.S.W., Sydney, Holotype [ANIC]

19 , AUSTRALIA, N.S.W., Sydney, Alotype [ANIC]

4ㅇ, AUSTRALIA, Queensland, Lamington NP, M3, Malaise, Ground, $28^{\circ} 13^{\prime} \mathrm{S} 153^{\circ} 07^{\prime} \mathrm{E}$, R. Kitching, January 1995. Oliveira, S.S. det. 2011 [AMSA]

101 ㅇ, AUSTRALIA, Queensland, Lamington NP, M1, Malaise, Ground, $28^{\circ} 13^{\prime} \mathrm{S} 153^{\circ} 07^{\prime} \mathrm{E}$, R. Kitching, January 1995. Oliveira, S.S. det. 2011 [AMSA]

10 , AUSTRALIA, N.S.W., Clyde Mt., Cabbage Tree Ck. 26.x.1960, D.H. Colless. Oliveira, S.S. det. 2011 [ANIC]

Acrodicrania fasciata Skuse

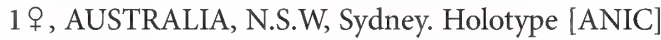

$3 \%$, AUSTRALIA, Queensland, Lamington NP, Malaise trap, ground, $28^{\circ} 13^{\prime} \mathrm{S} 153^{\circ} 07^{\prime} \mathrm{E}, \mathrm{R}$. Kitching, July 1996. Oliveira, S.S. det. 2011 [AMSA]

10 , AUSTRALIA, N.S.W., Snowy-Thredbo Junction, 8.xi.1961, D.H. Colless. Oliveira, S.S. det. 2011 [ANIC] (fig. 83)

Acrodicrania setosicauda Skuse 10 , AUSTRALIA, N.S.W., Sydney. Holotype [ANIC] 2 \% , AUSTRALIA, N.S.W., Epping, 13.v.1987, Malaise trap, I. Buddle Leg. Oliveira, S.S. det. 2011 [AMSA] 1 to, AUSTRALIA, Victoria, Buxton, 22.x.1961, D.H. Colless Leg. Oliveira, S.S. det. 2011 [ANIC]

$10^{\star}$, AUSTRALIA, A.C.T., 20.x.1960, D.H. Colless, Leg., Oliveira, S.S. det. 2011 [ANIC]

1 , AUSTRALIA, S.A., Mt. Crawford, State Forest, 6.viii.1968, Colless and Liepa Leg., Oliveira, S.S. det. 2011 [ANIC]

\section{Allactoneura}

Allactoneura argentosquamosa (Enderlein)

10 t, MADAGASCAR, Sambirano Lokobe Nosse Bé $6 \mathrm{~m}$, 9-23.xi.1957, B. Stuckenberg, det. B. Stuckenberg 1959. Natal Museum, Pietermaritzburg, South Africa [NMSA] (figs. 78-79)

19 , MAURITUS, Ehatmard Falls, 20.vi.1971, A.M. Hutson, B.M. 1971-346, det. A.M. Hutson, 1973. [NHM]

Allactoneura cincta de Meijere

1 ㅇ, S. INDIA, Coimbatore, viii.1953, P.S. Nathan. Oliveira, S.S. det. 2012 [CNC]

$10^{\dagger} 1$, S. INDIA, Walayar Forests, S. Malabar $.000^{\prime}$, x.1952, P.S. Nathan. Oliveira, S.S. det. 2012 [CNC]

10 , S. INDIA, Ammatti, S. Coorg 3100', x.1952, P.S. Nathan. Oliveira, S.S. det. 2012 [CNC]

10 , S. INDIA, Cherangode, Niguiri Hills, $3500 \mathrm{ft}$, x.1950, P.S. Nathan. Oliveira, S.S. det. 2012 [CNC]

Allactoneura papuensis Bechev

PAPUA NEW GUINEA, Bainyik, 20.xii.1963, D.K. McAlpine. Oliveira, S.S. det. 2011 [AMSA] -

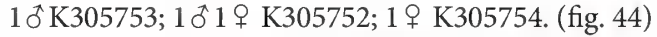

10 , PAPUA NEW GUINEA, Bainyik, 17.xii.1963, D.K. McAlpine. K305756. Oliveira, S.S. det. 2011 [AMSA]

19 , AUSTRALIA, N. Qld., Middle Claudie River, Iron Range, 1.x.1974, G. Daniels. K305761. Oliveira, S.S. det. 2011 [AMSA]

1 ㅇ, AUSTRALIA, N. Qld., Middle Claudie River, Iron Range, 28.ix.1974, G. Daniels. K305761. Oliveira, S.S. det. 2011 [AMSA] 


\section{Anomalomyia}

Anomalomyia guttata (Hutton)

40ิ, NEW ZEALAND, Ohakune, 8.iii.1923, A.L. Tonnoir, det. D.H. Colless [ANIC]

2 9 , NEW ZEALAND, Kanaeranga Vly., 23.i.1970, H.A. Oliver, Malaise trap. Oliveira, S.S. det. 2011 [ANIC] (fig. 49)

\section{Anomalomyia minor (Marshall)}

10 ${ }^{\star}$, NEW ZEALAND, Nelson, 14.xi.1923, A.L. Tonnoir, A. Tonnoir det. [ANIC]

10, NEW ZEALAND, Christchurch, 24.xi.1924, A.L. Tonnoir, A. Tonnoir det. [ANIC]

10 ${ }^{\star}$, NEW ZEALAND, Governor's Bay, 17.viii.1923, J.F. Tapley, B.M. 1924-83. [NHM]

10ิ, NEW ZEALAND, Governor's Bay, 29.ix.1922, J.F. Tapley, B.M. 1923-20. [NHM]

1오, NEW ZEALAND, Governor's Bay, 21-27.viii.1922, J.F. Tapley, B.M. 1923-20. [NHM]

\section{Anomalomyia nasuta Matile}

19 , FRANCE, Nouvelle Calédonie, Rivière Bleue, Parc. 7, Alt. 170m, 11.viii-01.ix.1986, LBDL-JC-AST, L. Matile det. 1991 [MNHN]

10 , FRANCE, Nouvelle Calédonie, Rivière Bleue Pardo, Alt. 160m, Forêt humide sur alluvions, 31.i-12.ii.1987, L.B. de L., J.C. and A. et S.T., Paratype [MNHN]

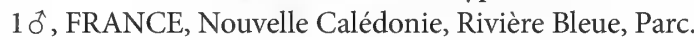
5, Alt. 150m, Forêt humide sur alluvions, 15-29. ix.1986, L.B. de L., J.C. and A. et S.T., Paratype [MNHN]

Additional source: Matile (1993).

\section{Ateleia}

Ateleia spadicithorax Skuse

10, AUSTRALIA, N.S.W., Bowral. Holotype [ANIC]

1 , , AUSTRALIA, N.S.W., 0,5 mi. NW of Bruxner Pk., 16.iv.1970, D.H. Colless. Oliveira, S.S. det. 2011 [ANIC] (fig. 50)

1 ㅇ, AUSTRALIA, A.C.T., Black Mt., Malaise site 1, 30.i.1980, D.H. Colless. Oliveira, S.S. det. 2011 [ANIC]

10, AUSTRALIA, A.C.T., Black Mt., Light trap, 23.x.1960, I.F.B. Common. Oliveira, S.S. det. 2011 [ANIC]

10ิ, AUSTRALIA, A.C.T., Black Mt., Light trap, 28. ii.1963, I.F.B. Common. Oliveira, S.S. det. 2011 [ANIC] (fig. 82)

10 , AUSTRALIA, N.S.W., 30 mls. S of Singleton, Putty Road, 6.ii.1968, D.H. Colless. Oliveira, S.S. det. 2011 [ANIC]
10, AUSTRALIA, N.S.W., Colo Heights, Putty Road, 6.ii.1968, D.H. Colless. Oliveira, S.S. det. 2011 [ANIC]

10 , AUSTRALIA, A.C.T., Black Mt., xii.1987, M. Irwin, Malaise trap. Oliveira, S.S. det. 2011 [ANIC]

10 , AUSTRALIA, N.S.W., Clyde Mt., East slope., 26.x.1960, D.H. Colless. Oliveira, S.S. det. 2011 [ANIC]

\section{Aphrastomyia}

Aphrastomyia cerquerai Lane

10े, BRAZIL, AM, Manaus, Ig. Francês, 12.xii.1957, Col. Elias, N.1299. Holotype [MZUSP]

20, BRAZIL, AM, Ipixuna, Rio Liberdade, Estirão da Preta, $07^{\circ} 21^{\prime} 46.7^{\prime \prime} \mathrm{S} 71^{\circ} 52^{\prime} 07.1^{\prime \prime} \mathrm{W}, 11-15 . v .2011$, Malaise, J.A. Rafael, J.T. Câmara, R.F. Silva, A. Somavilla, C. Gonçalves Leg. Oliveira, S.S. det. 2012 [INPA]

$2{ }^{\star} 2$ 오, BRAZIL, RO, Porto Velho, 3,2 Km across Rio Madeira from Porto Velho, $8^{\circ} 43.401^{\prime} \mathrm{S} 63^{\circ} 5.448^{\prime \prime} \mathrm{W}$, Malaise trap 1, 4-14.xii.2011, Amorim, Ament and Riccardi col. Oliveira, S.S. det. 2012 [MZUSP]

10, BRAZIL, AM, Ipixuna, Rio Gregório, Com. Lago Grande, $07^{\circ} 10^{\prime} 11.7^{\prime \prime} \mathrm{S} 70^{\circ} 49^{\prime} 10.3^{\prime \prime} \mathrm{W}, 18-23 . v .2011$, Malaise, J.A. Rafael, J.T. Câmara, R.F. Silva, A. Somavilla, C. Gonçalves Leg. Oliveira, S.S. det. 2012 [INPA]

Aphrastomyia cramptoni Coher and Lane

10 , BRAZIL, SP, Salesópolis, Res. Biol. Boracéia, vii.1949, Lane and Coher col. Holotype [MZUSP]

10 , BRAZIL, SP, Salesópolis, Res. Biol. Boracéia, viii.1947, Lane col. Paratype [MZUSP]

$10^{\dagger}$, BRAZIL, SP, Salesópolis, Res. Biol. Boracéia, Trilha dos Pilões, $23^{\circ} 39^{\prime} 05,8^{\prime \prime} \mathrm{S} 45^{\circ} 53^{\prime} 44,6^{\prime \prime} \mathrm{W}, 30$. iii- 2 . iv.2001, Malaise Trilha 4, S.T.P. Amarante and eq. col. Oliveira, S.S. det. 2012 [MZUSP]

$10^{\star}$, BRAZIL, SP, Salesópolis, Res. Biol. Boracéia, Trilha dos Pilões, $23^{\circ} 39^{\prime} 02,9^{\prime \prime} \mathrm{S} 45^{\circ} 53^{\prime} 39^{\prime \prime} \mathrm{W}, 30 . \mathrm{iii}-2$. iv.2001, Malaise Trilha 2, S.T.P. Amarante and eq. col. Oliveira, S.S. det. 2012 [MZUSP]

3 ơ, BRAZIL, SP, Salesópolis, Res. Biol. Boracéia, Trilha dos Pilões, $23^{\circ} 39^{\prime} 02,9^{\prime \prime}$ S $45^{\circ} 53^{\prime} 39^{\prime \prime} \mathrm{W}, 2-5$.iv.2001, Malaise Trilha 2, S.T.P. Amarante and eq. col. Oliveira, S.S. det. 2012 [MZUSP]

$20^{\star}$, BRAZIL, SP, Salesópolis, Res. Biol. Boracéia, Trilha dos Pilões, $23^{\circ} 39^{\prime} 04,8^{\prime \prime} \mathrm{S} 45^{\circ} 53^{\prime} 41,8^{\prime \prime} \mathrm{W}, 2-5 . i v .2001$, Malaise Trilha 3, S.T.P. Amarante and eq. col. Oliveira, S.S. det. 2012 [MZUSP] (fig. 69)

$10^{\star}$, BRAZIL, SP, Salesópolis, Res. Biol. Boracéia, Trilha dos Pilões, $23^{\circ} 39^{\prime} 04,8^{\prime \prime} \mathrm{S} 45^{\circ} 53^{\prime} 41,8^{\prime \prime} \mathrm{W}, 30 . \mathrm{iii}-2$. 
iv.2001, Malaise Trilha 3, S.T.P. Amarante and eq. col. Oliveira, S.S. det. 2012 [MZUSP]

10ิ, BRAZIL, SP, Salesópolis, Res. Biol. Boracéia, $23^{\circ} 39^{\prime} 05^{\prime \prime} \mathrm{S} 45^{\circ} 53^{\prime} 51^{\prime \prime} \mathrm{W}, 1-4 . x i 1.2008$, Malaise trap forest, Amorim, Falaschi and Miranda col. Oliveira, S.S. det. 2012 [MZUSP]

10ิ, BRAZIL, SP, Salesópolis, Res. Biol. Boracéia, Trilha dos Pilões, $23^{\circ} 39^{\prime} 05,1^{\prime \prime S} 45^{\circ} 53^{\prime} 51,8^{\prime \prime} \mathrm{W}, 27 . i i .2005$, 16h00-17h00, Malaise, L.K. Nogueira and A.P. Aguiar col. Oliveira, S.S. det. 2012 [MZUSP]

Aphrastomyia shannoni Lane

1 ㅇ, BRAZIL, AP, Serra do Navio, 29.xi.1957, J. Lane Leg., Alotype [MZUSP]

20ิ, BRAZIL, AM, Ipixuna, Rio Liberdade, Estirão da Preta, 07²1'46.7"S 71 52'07.1"W, 11-15.v.2011, Malaise, J.A. Rafael, J.T. Câmara, R.F. Silva, A. Somavilla, C. Gonçalves Leg. Oliveira, S.S. det. 2012 [INPA]

40ิ, BRAZIL, RO, Porto Velho, $3,2 \mathrm{Km}$ across Rio Madeira from Porto Velho, $8^{\circ} 43.401^{\prime} \mathrm{S} 63^{\circ} 5.448^{\prime \prime} \mathrm{W}$, Malaise trap 1, 4-14.xii.2011, Amorim, Ament and Riccardi col. Oliveira, S.S. det. 2012 [MZUSP] (fig. 29)

1 , PERU, Loreto, Genaro Herrera, Rio Ucayali, 01. ii.1984, primary forest non-flood, malaise, S. Poulain col., Loic Matile det. 1989 [MNHN]

\section{Caledonileia}

Caledonileia pusilla Matile

10, FRANCE, Nouvelle Calédonie, Haule Rivière Bleue, 250m, Forêt humide, $155^{\circ} 37^{\prime} 24^{\prime \prime} \mathrm{E} 22^{\circ} 34^{\prime} 40^{\prime \prime} \mathrm{S}$, station 243, S. Tillier, Ph. Bouchet and M.P. Triclot, Holotype [MNHN]

20ิ, FRANCE, Nouvelle Calédonie, Haule Rivière Bleue, 250m, Forêt humide, $166^{\circ} 37^{\prime} 24^{\prime \prime} \mathrm{E} 22^{\circ} 34^{\prime} 40^{\prime \prime} \mathrm{S}$, station 243, piège de Malaise, 11.xi.1984, S. Tillier, Ph. Bouchet and M.P. Triclot Leg., Paratype [MNHN] (fig. 52)

Additional source: Matile (1993).

\section{Cawthronia}

Cawthronia nigra Tonnoir

10, NEW ZEALAND, South Is., Canterbury Prov., Craigieburn Forest, Nervous Knob, 5000', 24.ii.1976, S.E. Slope, W.J. Knight, B.M. 1976-572 [NHM]

10, NEW ZEALAND, BR, Rotorora 450-540 m, 17. Jan-26.Feb.2001, Malaise trap [NZAC] (fig. 34)

\section{Clastobasis}

Clastobasis alternans (Winnertz) $10^{\top} 1$, ITALY, South Tyrol, N. Park Stifser Joch, Schmeiz (SW of Prad), 940m, 46³6' 42.1N 10³4'35.6E, Malaise, 11-27.vi.2005, Lange and Ziegler Leg., Olavi Kurina det. 2010 [LMED] (figs. 57, 88)

\section{Clastobasis loici Chandler}

2 ๙ , NETHERLANDS, Waarder (Z.H.), 28.vii.1975, C. van Achterberg. Oliveira, S.S. det. 2012 [CNC]

10, LUXEMBURG, Diekirch, 20.vi.1966, A.W. Steffan. Oliveira, S.S. det. 2012 [CNC]

1 §, NETHERLANDS, Nearder (Z.H.), vii.1975, C. van Achterberg. Oliveira, S.S. det. 2012 [CNC]

Additional source: Chandler (2001)

Clastobasis sp.

4 đo, BRAZIL, RJ, Nova Iguaçu, Reserva Biológica do Tinguá, 22 $34^{\prime} 32^{\prime \prime} \mathrm{S} 43^{\circ} 26^{\prime} 07,6^{\prime \prime} \mathrm{W}$, Malaise Bosque ponto 3, 8-11.iii.2002, S.T.P. Amarante and eq.col. Oliveira, S.S. det. 2010 [MZUSP] (fig. 62)

$30^{\star}$, BRAZIL, RJ, Nova Iguaçu, Reserva Biológica do Tinguá, $22^{\circ} 34^{\prime} 27^{\prime \prime} \mathrm{S} 43^{\circ} 26^{\prime} 11,4^{\prime \prime} \mathrm{W}$, Malaise Bosque ponto 6, 8-11.iii.2002, S.T.P. Amarante and eq.col. Oliveira, S.S. det. 2010 [MZUSP]

$1{ }^{\star} 1$ ㅇ, BRAZIL, RJ, Nova Iguaçu, Reserva Biológica do Tinguá, $22^{\circ} 34^{\prime} 30^{\prime \prime} \mathrm{S} 43^{\circ} 26^{\prime} 07^{\prime \prime} \mathrm{W}$, Malaise Trilha ponto 1, 8-11.iii.2002, S.T.P. Amarante and eq.col. Oliveira, S.S. det. 2010 [MZUSP]

$1{ }^{\Im} 2$ 오, BRAZIL, RJ, Nova Iguaçu, Reserva Biológica do Tinguá, $22^{\circ} 34^{\prime} 28^{\prime \prime} \mathrm{S} 43^{\circ} 26^{\prime} 09^{\prime \prime} \mathrm{W}$, Malaise Trilha ponto 5, 5-8.iii.2002, S.T.P. Amarante and eq.col. Oliveira, S.S. det. 2010 [MZUSP]

$1{ }^{\dagger} 2$ ㅇ, BRAZIL, RJ, Nova Iguaçu, Reserva Biológica do Tinguá, $22^{\circ} 34^{\prime} 28^{\prime \prime} \mathrm{S} 43^{\circ} 26^{\prime} 10,7^{\prime \prime} \mathrm{W}$, Malaise Bosque ponto 5, 8-11.iii.2002, S.T.P. Amarante and eq.col. Oliveira, S.S. det. 2010 [MZUSP]

Clastobasis stylata Matile

20 , FRANCE, New Caledonia, Plage de Poé, $15 \mathrm{Km}$ W. Bourail, 15.vii.1995, YPT. Oliveira, S.S. det. 2012 [CNC] (figs. 90-91)

Clastobasis tryoni Skuse

1 오 , AUSTRALIA, Brisbane, H. Tryon., Museum, 5. iii.1890, window, Holotype, F.A.A. Skuse K2319 [AMSA]

4 ․ AUSTRALIA, Qld., Repulse Ck. 23Km NE of Bauhinia Downs, 22.iv.1981, at light, D.H. Colless. Oliveira, S.S. det. 2012 [ANIC]

10 , AUSTRALIA, N. Qld., 7-14m W of Herberton, via Watsonville, 1.v.1967, D.H. Colless. Oliveira, S.S. det. 2012 [ANIC] 
10े, AUSTRALIA, Qld., nr. Rosewood, Brigalow scrub, 20.xii.1961, R. Lindsay. Oliveira, S.S. det. 2012 [ANIC]

10, AUSTRALIA, N.T., Cooper Creek, 19Km E by S of Mt. Borradaile, 5.vi.1973, D.H. Colless. Oliveira, S.S. det. 2012 [ANIC] (fig. 89)

10ิ, AUSTRALIA, N.T., Rimbijá Is., Wessel Islands, 11.01S 136.45E, 18.i.1977, E.D.Edwards. Oliveira, S.S. det. 2012 [ANIC]

Clastobasis vicina Matile

1ô, FRANCE, New Caledonia, Plage de Poé, 15Km W. Bourail, 15.vii.1995, YPT. Oliveira, S.S. det. 2012 [CNC] (fig. 60)

\section{Cycloneura}

Cycloneura flava Marshall

$1 \widehat{\jmath} 1$ ㅇ, NEW ZEALAND, Whangamea Saddle, Nelson, South Is., 12-15.v.1970, H.A. Oliver, Malaise trap. Oliveira, S.S. det. 2011 [ANIC] (fig. 38)

2 ㅇ, NEW ZEALAND, S. Island, Lower Buller Gorge, Ohikanui Riv. Near Westport, Malaise trap in rain forest, 11-16.xii.1970, H.A. Oliver. Oliveira, S.S. det. 2011 [ANIC]

1ô, NEW ZEALAND, Kanaeranga Vly., 23.i-2.ii.1970, Malaise trap, H.A. Oliver. Oliveira, S.S. det. 2011 [ANIC]

1 ㅇ, NEW ZEALAND, Kanaeranga Vly., 23.i.1970, Malaise trap, H.A. Oliver. Oliveira, S.S. det. 2011 [ANIC]

1 , NEW ZEALAND, North Island, Central Plateau, Kaimanawa Forest Park, ex. Malaise trap Nothofagus bush, 24-31.i.1971, H.A. Oliver. Oliveira, S.S. det. 2011 [ANIC]

1 ㅇ, NEW ZEALAND, Cass., 29.xi.1924, A. Tonnoir, det. A. Tonnoir 1923 [ANIC]

1 ㅇ, NEW ZEALAND, Dun Mt. 3000ft, 5-7.i.1922, A. Tonnoir, det. A. Tonnoir 1923 [ANIC]

\section{Eumanota}

\section{Eumanota wolfae}

1o, COLOMBIA, Holotype male, Colombia, Antioquia, Yarumal, Vereda El Respaldo, Farm La Maruja, $6^{\circ} 55^{\prime} 05^{\prime \prime} \mathrm{N}, 75^{\circ} 24^{\prime} 48^{\prime \prime} \mathrm{W}$, Malaise trap, Bosque, 2,300 m, 15.Dec.2016, C.H.-Sepúlveda and J. Medina cols. [CEUA] (figs. 80-81)

\section{Eumanota sp.}

1 옹 PAPUA NEW GUINEA, Oomsis, Lae, $06^{\circ} 40^{\prime} \mathrm{S}$ $146^{\circ} 48^{\prime} 0 \mathrm{E}$, Mycetophilidae, Malaise ground 1, 26.vii.2000, R.L. Kitching. Oliveira, S.S. det. 2011 [AMSA]
19 , PAPUA NEW GUINEA, Oomsis, Lae, $06^{\circ} 40^{\prime} \mathrm{S}$ $146^{\circ} 48^{\prime} 0 \mathrm{E}$, Mycetophilidae, Malaise ground 2, 25.vii.2000, R.L. Kitching. Oliveira, S.S. det. 2011 [AMSA] (fig. 47)

Additional source: Søli (2002b).

\section{Garretella}

Garretella shermanni (Garrett)

1 ô, USA, Calif, Lily Pond, Alpine Lk., Marion Co., $1500^{\prime}$, Malaise trap, iv-v.1970, D.D. Munroe, det. J.R. Vockeroth [ANIC] (figs. 22, 64)

1 ㅇ, USA, Calif, Lily Pond, Alpine Lk., Marion Co., 1500, Malaise trap, 17-25.v.1971, D.D. Munroe, det. J.R. Vockeroth [ANIC]

2 ㅇ, USA, Calif, Lily Pond, Alpine Lk., Marion Co., 1500', Malaise trap, 17-25.vi.1971, D.D. Munroe. Oliveira, S.S. det. 2012 [CNC]

$1{ }^{\dagger}$, USA, Calif, Lily Pond, Alpine Lk., 1500', Malaise trap, 22.iv.1971, D.D. Munroe. Oliveira, S.S. det. 2012 [CNC]

10 , USA, Calif, Lily Pond, Alpine Lk., Marion Co., $1500^{\prime}$, Malaise trap, 22.iii.1967. Oliveira, S.S. det. 2012 [CNC]

10 , USA, Calif, Lily Pond, Alpine Lk., Marion Co., $1500^{\prime}$, Malaise trap, 17.v.1969. Oliveira, S.S. det. 2012 [CNC]

\section{Gracilileia}

Gracilileia redunda Matile

$1 ㅇ$, FRANCE, Nouvelle Calédonie, Rivière Bleue, Forêt Trantition, 12-27.v.1989, LBDL-JC-5279, L. Matile det. 1992 [MNHN]

10 , FRANCE, Nouvelle Calédonie, Rivière Bleue, Parc 7, Alt. 170m, Forêt humide sur pente Plège de Malaise, 13-26.iii.1987, LBL, JC, A and ST. [MNHN] (fig. 25)

10 , FRANCE, Nouvelle Calédonie, Rivière Bleue, Forêt Trantition, 26.viii-07.ix.1989, LBDL-JC-526b [MNHN]

$10^{\dagger}$, FRANCE, Nouvelle Calédonie, Vallé de la Coulée, $166^{\circ} 35^{\prime} 38^{\prime \prime} \mathrm{E} 22^{\circ} 10^{\prime} 52^{\prime \prime} \mathrm{S}$, maquis haut, bord rivière s/ périotites, 24.x.1985, Ph. Bouchet. Oliveira, S.S. det. 2011 [ANIC]

Gracilileia tillierorum Matile

101 ㅇ, FRANCE, Nouvelle Calédonie, Rivière Bleue, Forêt Trans., 24.viii-7.ix.1989, LBDL-JC-526b, L. Matile det. 1992 [MNHN]

\section{Greenomyia}

Greenomyia cephala (Garrett) 
19 , CANADA, B.C., Aspen Grove, 20.vi.1973, H.J. Taskey. Oliveira, S.S. det. 2012 [CNC]

1 i, USA, Colo., Mt. Evans, Echo L. 10,600', 8.viii.1961, S.M. Clark. Oliveira, S.S. det. 2012 [CNC]

1 ㅇ, CANADA, Que., Old Chelsea, 4.vi.1964, J.R. Vockeroth. Oliveira, S.S. det. 2012 [CNC]

20ิ, CANADA, Que., Old Chelsea, 25.v.1964, J.R. Vockeroth. Swept from Pedicularis canadensis L. Oliveira, S.S. det. 2012 [CNC]

10, CANADA, Que., Old Chelsea, 28.v.1963, J.R. Vockeroth. Oliveira, S.S. det. 2012 [CNC]

Greenomyia joculator (Laffoon)

10ิ, USA, Colo., Doolittle Ranch, Mt. Evans 9,800', 31.vii.1961, C.H. Mann. Slide HCW 7.xii.1976 n D. Oliveira, S.S. det. 2012 [CNC]

2 ㅇ, USA, Ore., 9 mi. W. Unity Baker, Co. $4500^{\prime}$, 2.vii.1965, Malaise trap. Oliveira, S.S. det. 2012 [CNC]

Greenomyia mongolica Laštovka and Matile

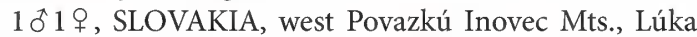
env., 13-20.ix.1999, M. Kozánek Leg., Malaise trap, Jan Ševčik det. 2010 [LMED]

Additional source: Kurina et al. (2011)

Greenomyia stackelbergi Zaitzev

20, NORWAY, EIS 28 AK, Oslo, Hengsenga, 8.viii-7. ix.2007, UTMWG58432 VNM93414318, Malaise trap [propgly/ethanol], Leg. Anders Endrestor, Eirik Rindal det. 2010 [LMED] (figs. 55, 87)

Additional source: Kurina et al. (2011)

\section{Indoleia}

Indoleia bisetosa (Edwards)

$10 \hat{1}$ ㅇ, PAPUA NEW GUINEA, New Britain, Bismarck Isl., Yalom, 1000m. 20.v.1962, Noona Dan Exp. 61-62. Oliveira, S.S. det. 2011 [ANIC] (fig. 70)

10 , PAPUA NEW GUINEA, Waitape, Wharton Ra., 19.x.1963, D.K. McAlpine. K305788. Oliveira, S.S. det. 2011 [AMSA]

10, PAPUA NEW GUINEA, Buri near Sasembata, Popondetta subdist., 31.x.1963, D.K. McAlpine. K305789. Oliveira, S.S. det. 2011 [AMSA]

10, PAPUA NEW GUINEA, Wau, 21.vii.1972, B.S. Cheary, Malaise trap $\mathrm{n}^{\circ} 1$. K305784. Oliveira, S.S. det. 2011 [AMSA]

10ิ, PAPUA NEW GUINEA, Wau, 23.ix.1972, B.S. Cheary, Malaise trap n². K305786. Oliveira, S.S. det. 2011 [AMSA]
1 ${ }^{\star}$, PAPUA NEW GUINEA, Wau, 5.viii.1972, B.S. Cheary, Malaise trap ${ }^{\circ} 1$. K305785. Oliveira, S.S. det. 2011 [AMSA]

19 , PAPUA NEW GUINEA, Wau, 5.viii.1972, B.S. Cheary, Malaise trap n². K305779. Oliveira, S.S. det. 2011 [AMSA]

1 9 , PAPUA NEW GUINEA, Wau, 28.vii.1972, B.S. Cheary, Malaise trap $n^{\circ} 1$. K305777. Oliveira, S.S. det. 2011 [AMSA]

1 \%, PAPUA NEW GUINEA, Wau, 28.vii.1972, B.S. Cheary, Malaise trap n ${ }^{\circ} 2$. K305778. Oliveira, S.S. det. 2011 [AMSA]

1 , PAPUA NEW GUINEA, Wau, Marabe District., 1158m, 26.xi.1972, G.A. Holloway. K305782. Oliveira, S.S. det. 2011 [AMSA] (fig. 31)

Leia

Leia amapaensis Lane

20 , BRAZIL, AP, Serra do Navio, 24.ix.1957, J. Lane Leg. Paratype [MZUSP]

20 , BRAZIL, AP, Serra do Navio, 24.ix.1957, J. Lane Leg., Paratype [MZUSP]

10 , BRAZIL, AP, Serra do Navio, 24.x.1957, J. Lane Leg. [MZUSP]

101 으, BRAZIL, AM, Barcelos, Rio Padauari, Com. Ararinha, $00^{\circ} 30^{\prime} 18^{\prime \prime} \mathrm{N} 64^{\circ} 03^{\prime} 30^{\prime \prime} \mathrm{W}, 5-8 . v i .2010$, Malaise, R. Machado, P. Dias, J.A. Rafael Leg. Oliveira, S.S. det. 2012 [INPA]

1오, BRAZIL, AM, Barcelos, Rio Aracá, Com. Bacuquara, $00^{\circ} 09^{\prime} 17.5^{\prime \prime} \mathrm{N} 63^{\circ} 10^{\prime} 35.2^{\prime \prime} \mathrm{W}, 12-14$. vi.2010, Malaise, J.A. Rafael, R. Machado, R. Chavichioli, D. Takiya, P. Dias Leg. Oliveira, S.S. det. 2012 [INPA]

$10^{\star}$, BRAZIL, AM, Barcelos, Rio Aracá, Boca Rio Curuduri, $00^{\circ} 05^{\prime} 50.2^{\prime \prime} \mathrm{N} 63^{\circ} 17^{\prime} 22.3^{\prime \prime} \mathrm{W}, 15-19 . v i .2010$, Malaise, J.A. Rafael, R. Machado, R. Chavichioli, D. Takiya, P. Dias Leg. Oliveira, S.S. det. 2012 [INPA] (fig. 63)

Leia andirai Lane

1․ BRAZIL, SP, Campos do Jordão, xii.1945, J. Lane col., Holotype [MZUSP]

10ે, BRAZIL, GO, Corumbá, Barretto col., Paratype [MZUSP]

10, BRAZIL, SP, Santo Amaro, ix.1962. J. Lane col. Alotype. Desen, det. John Lane 1961 [MZUSP] (fig. 93)

2 ㅇ, BRAZIL, SP, Morumbi, 1.xi.1949, J. Lane col. Paratype [MZUSP]

2ㅇ, BRAZIL, SP, Santo Amaro, ix.1962. J. Lane col. [MZUSP] 
3 , BRAZIL, SP, Santo Amaro, xi.1960. J. Lane col., det. John Lane 1962 [MZUSP]

1 ㅇ, BRAZIL, RJ, Nova Iguaçu, Cascata, v.1960, D. Travassos col. Oliveira, S.S. det. 2012 [MZUSP]

2 ơ, BRAZIL, SP, Santo Amaro, xi.1962. J. Lane col., det. John Lane 1962 [MZUSP]

10ิ, BRAZIL, SC, Seara, Nova Teutônia, $27^{\circ} 11^{\prime} \mathrm{S}$ $52^{\circ} 23^{\prime} \mathrm{E}, 300-500 \mathrm{~m}, 11 . v i i .1958$, Fritz Plaumann. Brit. Mus. 1938-682. Oliveira, S.S. det. 2012 [MZUSP]

1ðิ, ARGENTINA, Buenos Aires, Cap. Fed., 21.x.1950, en casa, Duret Coll. det. John Lane 1954 [MZUSP]

Leia arsona Hutson

7ô, 3 ㅇ, SOUTH AFRICA, KwaZulu Natal, Pietermaritzburg, Hilton, 24.xii.2003-14.i.2004, Malaise trap / garden, M. Mostovski Coll. NMSA-DIP57658. Oliveira, S.S. det. 2011 [NMSA] (fig. 58)

1亏े, SOUTH AFRICA, KwaZulu Natal, Louwsberg, Sanyati Farm, 1090m, 273' $\mathrm{S} 31^{\circ} 17,9^{\prime} \mathrm{E}, 1-24$. iii.2006, Malaise trap, M. Mostovski Coll. NMSADIP57724. Oliveira, S.S. det. 2011 [NMSA]

$101+$, SOUTH AFRICA, KwaZulu Natal, Pietermaritzburg, Hilton, 13-23.xi.2003, Malaise trap / garden, M. Mostovski Coll. NMSA-DIP57659. Oliveira, S.S. det. 2011 [NMSA]

1 oิ 1 ㅇ, CZECH REPUBLIQUE, Moravia, Polanka n. O. Přemišov res., $49^{\circ} 47^{\prime} 24^{\prime \prime} \mathrm{W} 18^{\circ} 11^{\prime} 23^{\prime \prime} \mathrm{N}, 10 . v i i .2008$, boggy md. ex. Gliceria maxima (B5) emerg. 20.ix24.x, L. Rohaček Leg., Jan Ševčik det. 2010 [LMED]

Additional source: Oliveira and Muller (2012)

Leia bivittata Say

10, CANADA, Ont., Ottawa, 19.vii.1997, Montfort Hosp wood aerial sweep, J.R. Vockeroth. Oliveira, S.S. det. 2012 [CNC]

10े, CANADA, Ont., Ottawa, 12.x.2003, Woods Nepean Sportflex, J.R. Vockeroth. Oliveira, S.S. det. 2012 [CNC]

10, CANADA, Ont., Ottawa, 25.vii.1993, Damp second growth Acer betula wood, J.R. Vockeroth. Oliveira, S.S. det. 2012 [CNC] (fig. 92)

1 ㅇ , USA, FL., Gainesville, 15-22.iv.1987, Hardwd. For, Malaise trap, Wahl and Mason. Oliveira, S.S. det. 2012 [CNC]

10 , USA, MO, Williamsville, x-xi.1968, J.T. Becker. Oliveira, S.S. det. 2012 [CNC]

Leia fascipennis Meigen

10ิ, ENGLAND, Alfiston bussex, 22.vi.1942, G.E. Shewell Coll. Oliveira, S.S. det. 2012 [CNC]
2ㅇ, ENGLAND, Woodstock Oxon, 23.x.1952, J.R. Vockeroth. Oliveira, S.S. det. 2012 [CNC]

10, SWEDEN, Vmld. Ekshärad, 22.vii.1960, W.R.M. Mason. Oliveira, S.S. det. 2012 [CNC] (fig. 55, 94)

1 ㅇ, SWEDEN, Vmld. Ekshärad, 20.vii.1960, W.R.M. Mason. Oliveira, S.S. det. 2012 [CNC]

Additional source: Kurina (2008)

Leia opima (Loew)

10\%, CANADA, Manitoba, 2 mi. NE Treesbank, along Souris R., 11.viii.1993, 4940'N 99³6' W, Malaise trap, B. Gallaway. Oliveira, S.S. det. 2012 [CNC]

10े, USA, NE, Mt. Katahdin, 4.vii.1968, Abol, D.M. Wood. Oliveira, S.S. det. 2012 [CNC]

10, CANADA, Ont., Ottawa, 16.vii.1989, Damp second growth Acer betula wood, J.R. Vockeroth. Oliveira, S.S. det. 2012 [CNC]

1ㅇ, CANADA, Ont., Ottawa, 9.vii.1989, Damp second growth Acer betula wood, J.R. Vockeroth. Oliveira, S.S. det. 2012 [CNC]

1 ㅇ, CANADA, Ont., Ottawa, 8.vii.2003, Damp second growth Acer betula wood, J.R. Vockeroth. Oliveira, S.S. det. 2012 [CNC]

$2{ }^{\star}$, UNITED STATES, Ledges State Park, Boone Co. 10wa, 25.vi.1950, Jean Laffoon, B.M. 1950-546, J. Laffoon det. 1950. [NHM]

1 đ., CANADA, Quebec, Old Chelsea, 25.vi.1963, J.G. Chillcott, J.R. Vockeroth det. 1977. [NHM]

Leia spinifera Edwards

$20^{\circ}$ ㅇ, BRAZIL, AM, Barcelos, Rio Padauari, Com. Ararinha, $00^{\circ} 30^{\prime} 18^{\prime \prime} \mathrm{N} 64^{\circ} 03^{\prime} 30^{\prime \prime} \mathrm{W}$, 5-8.vi.2010, Malaise, J.A. Rafael, R. Machado, P. Dias Leg. Oliveira, S.S. det. 2012 [INPA]

9 , BRAZIL, AM, Barcelos, Rio Aracá, Boca Rio Curuduri, $00^{\circ} 05^{\prime} 50.2^{\prime \prime} \mathrm{N} 63^{\circ} 17^{\prime} 22.3^{\prime \prime} \mathrm{W}, 15-19 . v i .2010$, Malaise, J.A. Rafael, R. Machado, R. Chavichioli, D. Takiya, P. Dias Leg. Oliveira, S.S. det. 2012 [INPA]

12 ㅇ, BRAZIL, AM, Barcelos, Rio Aracá, Com. Bacuquara, $00^{\circ} 09^{\prime} 17.5^{\prime \prime} \mathrm{N} 63^{\circ} 10^{\prime} 35.2^{\prime \prime} \mathrm{W}, 12-14$. vi.2010, Malaise, J.A. Rafael, R. Machado, R. Chavichioli, D. Takiya, P. Dias Leg. Oliveira, S.S. det. 2012 [INPA] (fig. 61)

1 오 , BRAZIL, AM, Barcelos, Rio Aracá, Boca Rio Curuduri, $00^{\circ} 05^{\prime} 50.2^{\prime \prime} \mathrm{N} 63^{\circ} 17^{\prime} 22.3^{\prime \prime} \mathrm{W}, 15-19 . v i .2010$, Suspensa septo amarelo lâmina d'água, J.A. Rafael, R.F. Silva Leg. Oliveira, S.S. det. 2012 [INPA]

Leia stigmatica Edwards

$3{ }^{\Im} 2$ 오, SOUTH AFRICA, KwaZulu Natal, Natuer Reserve Gudu Forest, $1680-1730 \mathrm{~m}, 28^{\circ} 40.90^{\prime} \mathrm{S} 28^{\circ} 55.78^{\prime} \mathrm{E}$, 
29.i-28.v.2006, Malaise trap, M. Mostovski Coll. NMSA-DIP57656. Oliveira, S.S. det. 2011 [NMSA]

10ิ, SOUTH AFRICA, KwaZulu Natal, Louwsberg, Sanyati Farm, 1090m, 273' $\mathrm{S} 31^{\circ} 17,9^{\prime} \mathrm{E}, 1-24$. iii.2006, Malaise trap, M. Mostovski Coll. NMSADIP57724. Oliveira, S.S. det. 2011 [NMSA]

10, SOUTH AFRICA, KwaZulu Natal, Pietermaritzburg, Hilton, 4-23.x.2004, Malaise trap / garden, M. Mostovski Coll. NMSA-DIP57651. Oliveira, S.S. det. 2011 [NMSA]

10, SOUTH AFRICA, Western Cape, Grootvadersbosch Nature Reserve, 340m, 3359.030'S $20^{\circ} 49.128^{\prime} \mathrm{E}$, 29.iii-23.vii.2010, Malaise trap, Afromontane Forest, S. van Noort, GVB10-FOR1M03. Oliveira, S.S. det. 2011 [SAMC]

Additional source: Oliveira and Muller (2012)

Leia ventralis Say

1 ㅇ, USA, MD, Laurel, 25.vi.1965, Malaise trap. Oliveira, S.S. det. 2012 [CNC]

1ô, CANADA, Que., Duncan Lake, Nr. Rupert, 6. vii.1970, J.F. McAlpine. Oliveira, S.S. det. 2012 [CNC]

10, CANADA, Ont., Black Sturgeon Lake, 19.viii.1963, Emerg. ex. club cop f black spruce. Oliveira, S.S. det. 2012 [CNC]

10, CANADA, Ont., N. Burguess Twp., Lanark Co., 12.vii.1970, D.M. Wood. Oliveira, S.S. det. 2012 [CNC]

\section{Leia winthemi Lehmann}

$30^{\star} 2$ 오, NORWAY, EIS 38 HES, Kongsvinger, Abborhøgda, 10.vii-06.ix.2003, UTMWGS84 33VUG591746, Karsten Sund Leg. Oliveira, S.S. det. 2012 [LMED]

1 ㅇ, CANADA, Ont., Mer Bleu 5 mi. E. Ottawa, 1. vii.1987, Malaise trap B, D.D. Munroe. Oliveira, S.S. det. 2012 [CNC]

10ิ, CANADA, Ont., Ottawa, Iroquois Falls, 21.vi.1987, Populus-Picea wood, rich underground, J.R. Vockeroth. Oliveira, S.S. det. 2012 [CNC]

10, CANADA, Ont., Ottawa, Iroquois Falls, 22.vi.1987, Populus-Picea wood, rich underground, J.R. Vockeroth. Oliveira, S.S. det. 2012 [CNC]

1 ㅇ, CANADA, Ont., 7 mi. E. Griffith, 10-16.xi.1983, B.E. Cooper. Oliveira, S.S. det. 2012 [CNC]

20ิ, GERMANY, Teutoburger Wald., 4.viii.1963, J.C. Deeming. Leia winthemi, P.J. Chandler det. [NHM]

Leiella

Leiella ochreocalcar Enderlein
5 ㅇ, BRAZIL, SC, Seara, Nova Teutônia, 2711'S

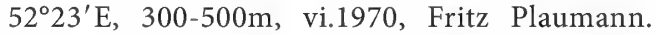
Oliveira, S.S. det. 2012 [MZUSP]

1 ㅇ, BRAZIL, SC, Seara, Nova Teutônia, $27^{\circ} 11^{\prime} \mathrm{S}$ $52^{\circ} 23^{\prime} \mathrm{E}, 300-500 \mathrm{~m}$, vii.1971, Fritz Plaumann. Oliveira, S.S. det. 2012 [MZUSP]

$100^{\star} 1$ \&, BRAZIL, SC, Seara, Nova Teutônia, $27^{\circ} 11^{\prime} \mathrm{S}$ 52²3'E, 300-500m, ix.1971, Fritz Plaumann. Oliveira, S.S. det. 2012 [MZUSP] (fig. 42)

1 ㅇ, BRAZIL, SC, Seara, Nova Teutônia, $27^{\circ} 11^{\prime} \mathrm{S}$ 522'ㄹ, $300-500 \mathrm{~m}$, vii.1967, Fritz Plaumann. Oliveira, S.S. det. 2012 [MZUSP]

3 ơ, BRAZIL, PR, Rondon, vii.1952, Fritz Plaumann, B.M. 1951-341 [NHM]

Leiella unicincta Edwards

1 đิ1 9 , PARAGUAY, Piyapó, 28-31.xii.1971, L.E. Peña col. Oliveira, S.S. det. 2012 [MZUSP] (figs. 76-77)

1 đo, BRAZIL, GO, Corumbá, xi.1945, Barretto col. Alotype, det. John Lane, 1949 [MZUSP]

1 , , BRAZIL, SC, Massiambú Pq., v.1957., F. Neto col. Leiella unicincta det. John Lane, 1958 [MZUSP]

1 ㅇ, BRAZIL, MT, Poconé, Fr. Valelte, i.1951, det. John Lane, 1956 [MZUSP]

1 , , BRAZIL, AM, Ipixuna, Rio Gregório, Com. Lago Grande, $07^{\circ} 10^{\prime} 11.7^{\prime \prime S} 70^{\circ} 49^{\prime} 10.3^{\prime \prime} \mathrm{W}, 18-20 . v .2011$, Malaise, J.A. Rafael, J.T. Câmara, R.F. Silva, A. Somavilla, C. Gonçalves Leg. Oliveira, S.S. det. 2012 [INPA]

1 ㅇ, BRAZIL, AM, Barcelos, Rio Aracá, Boca Rio Curuduri, $00^{\circ} 05^{\prime} 50.2^{\prime \prime} \mathrm{N} 63^{\circ} 17^{\prime} 22.3^{\prime \prime} \mathrm{W}, 15-19 . v i .2010$, Malaise, J.A. Rafael, R. Machado, R. Chavichioli, D. Takiya, P. Dias Leg. Oliveira, S.S. det. 2012 [INPA]

1오 BRAZIL, AM, Barcelos, Rio Aracá, Com. Bacuquara, $00^{\circ} 09^{\prime} 17.5^{\prime \prime} \mathrm{N} 63^{\circ} 10^{\prime} 35.2^{\prime \prime} \mathrm{W}, 12-14$. vi.2010, Malaise, J.A. Rafael, R. Machado, R. Chavichioli, D. Takiya, P. Dias Leg. Oliveira, S.S. det. 2012 [INPA]

Leiella zonalis Edwards

10َ, ARGENTINA, Tucumán, Queb: Cainzo, 18-19. xii.1950, Coll. R. Golbach, det. John Lane, 1956 [MZUSP]

1 ð̊, ARGENTINA, Tucumán, La Cavera, 23-28.xi.1954, Aczel-Golbach. Oliveira, S.S. det. 2012 [MZUSP]

1 đo, ARGENTINA, La Cavera, Dep. Tafi, 23-28.xi.1961, M. Aczel and R. Golbach, det. John Lane, 1953 [MZUSP]

1 đิ, BRAZIL, SP, São Paulo, iii.1955, E. Camera col., det. John Lane, 1956 [MZUSP]

10َ, ARGENTINA, Santa Fé, Vera, 20.xii.1950, Coll. Duret, det. John Lane, 1954 [MZUSP] 
10ิ, ARGENTINA, Chaco, Laguna Limpia, 2.xii.1949, Col. Duret. Oliveira, S.S. det. 2012 [MZUSP] (fig. 41)

1 ㅇ, BRAZIL, RJ, Angra dos Reis, x.1945, L. Trav. Fo col., det. John Lane, 1945 [MZUSP]

1 ㅇ, ARGENTINA, Chaco, Colonia Benitez, 1-7. xii.1948, Coll. R. Golbach. Oliveira, S.S. det. 2012 [MZUSP]

1 ㅇ , TRINIDAD, U.S. Naval Station, T.H.G. Aitnen, det. John Lane, 1956 [MZUSP]

1 ㅇ, BRAZIL, GO, Corumbá, xi.1945, Barretto col. Oliveira, S.S. det. 2012 [MZUSP]

1 , BRAZIL, SP, São Paulo, ii.1944, Navajas col., det. John Lane, 1945 [MZUSP]

1 , BRAZIL, SP, São Paulo, xi.1924, det. F.W. Edwards, 1931 [MZUSP]

1 , , PARAGUAY, Canindeyú, Reserva Natural Bosque, Mbaracayú: Jejuí-mi, Malaise 5, bosque médio, 2-10.iv.1996, A.C.F. Costa Col. Oliveira, S.S. det. 2012 [DZUP]

\section{Megophthalmidia}

Megophthalmidia crassicornis (Curtis)

10, NORWAY, EIS 28 AK, Oslo, Bleikøya [N], UTMWG584 32VNM 97504035, 3.vi-15.vii.2008, Malaise trap forest edge, Anders Endrestøl Leg., Eirik Rindal det. 2010 [LMED]

1 ô, SLOVAKIA, West Velká Fatra Mts., Mošovce env., 24.vii.1992, Malaise trap, M. Kozánek Leg., Jan Ševčik det. 2010 [LMED]

1 , ENGLAND. Holotype, Cordyla valida Walker, 1856, ex. coll Stephens 5346, det. N.P. Wyatt, 2002. BMNH \#236681 [NHM]

Megophthalmidia divergens Edwards

$4{ }^{\top} 1$ 오 , BRAZIL, SC, Seara, Nova Teutônia, $27^{\circ} 11^{\prime} \mathrm{S}$ $52^{\circ} 23^{\prime} \mathrm{E}, 300-500 \mathrm{~m}$, viii.1971, Fritz Plaumann. Oliveira, S.S. det. 2012 [MZUSP] (fig. 67)

$4{ }^{\star}$, BRAZIL, SC, Seara, Nova Teutônia, $27^{\circ} 11^{\prime} \mathrm{S}$ $52^{\circ} 23^{\prime} \mathrm{E}, 300-500 \mathrm{~m}$, vi.1970, Fritz Plaumann. Oliveira, S.S. det. 2012 [MZUSP]

Megophthalmidia nigra Freeman

4 ô 3 ㅇ, CHILE, Estera la Jaula, Curico, i.1964, Nothofagus, L.E. Peña Col. Oliveira, S.S. det. 2012 [CNC] (fig. 27)

10े, CHILE, Santiago, Cantillana, 2000m, Cord. De La Costa, xii.1969, L.E. Peña Col. Oliveira, S.S. det. 2012 [MZUSP]

1 ô, CHILE, Nuble, $40 \mathrm{Km}$ E. of San Carlos, xii.1950, Ross and Michelbacher Leg. Oliveira, S.S. det. 2012 [MZUSP]
Megophthalmidia occidentalis Johhansen

10, USA, Calif., Loop Trail nr Phillipisville, Alt. Hwy. 101, 5.vii.1968, B.V. Peterson. Oliveira, S.S. det. 2012 [CNC] 1 ô, USA, Calif, Lily Pond, Alpine Lk., Marion Co., $1500^{\prime}$, Malaise trap 2, 17-25.v.1971. Oliveira, S.S. det. 2012 [CNC]

1 o, CANADA, BC, Victoria, 21.v.1965, at light, D. Evans. Oliveira, S.S. det. 2012 [CNC]

1 ․ USA, Calif, Lily Pond, Alpine Lk., Marion Co., 1500', Malaise trap, v-vi.1976, D.D. Munroe. Oliveira, S.S. det. 2012 [CNC]

1 , , USA, Calif, Mc Bride Spr. Cpgd., Mt. Shasta, 5200', 20.vii.1968, D.D. Munroe. Oliveira, S.S. det. 2012 [CNC]

Mohelia

Mohelia matilei Oliveira

10, SOUTH AFRICA, KwaZulu Natal, Louwsburg, Sanyati Farm, $27^{\circ} 34^{\prime} \mathrm{S} 31^{\circ} 17,9^{\prime} \mathrm{E}, 1090 \mathrm{~m}, 1-24$. iii.2006, Malaise trap, M. Mostovski coll. NMSADIP 57723 [NMSA] (figs. 28, 68)

Additional source: Oliveira (2015)

Mohelia nigricauda Matile

1 0 , ARCH. DES COMORES, Mohéli Djoumadounia, 100-150m, 29.xi.1973, L. Matile Leg. Holotype [MNHN]

1 đ1오, ARCH. DES COMORES, Mohéli Djoumadounia, 100-150m, 29.xi.1973, L. Matile Leg. Paratypes [MNHN]

Manota

Manota palpalis Lane

10 , BRAZIL, SP, São Luis do Paraitinga, Parque Estadual da Serra do Mar, Núcleo Santa Virgínia, $23^{\circ} 19^{\prime} 27.1^{\prime \prime}$ S 4505'38.4" W, 22.x.2010, Malaise trap, Ponto \#6, N.W. Perioto and team cols. (slide \#180) [MZUSP]

Manota sp. 1

1 đo, BRAZIL, AM, Barcelos, Rio Padauari, Com. Ararinha, $00^{\circ} 30^{\prime} 18^{\prime \prime} \mathrm{N} 64^{\circ} 03^{\prime} 30^{\prime \prime} \mathrm{W}, 5-8 . v i .2010$, Malaise, J.A. Rafael, R. Machado, P. Dias Leg. Oliveira, S.S. det. 2012 [INPA]

201 오 BRAZIL, AM, Ipixuna, Rio Gregório, Com. Lago Grande, $07^{\circ} 10^{\prime} 11.7^{\prime \prime} \mathrm{S} \quad 70^{\circ} 49^{\prime} 10.3^{\prime \prime} \mathrm{W}$, 18-23.v.2011, Malaise, J.A. Rafael, J.T. Câmara, R.F. Silva, A. Somavilla, C. Gonçalves Leg. Oliveira, S.S. det. 2012 [INPA]

$1{ }^{\widehat{\jmath}} 1$ 오 , BRAZIL, AM, Ipixuna, Rio Liberdade, Estirão da Preta, $07^{\circ} 21^{\prime} 46.7^{\prime \prime} \mathrm{S} 71^{\circ} 52^{\prime} 07.1^{\prime \prime} \mathrm{W}, 11-15 . v .2011$, 
Malaise, J.A. Rafael, J.T. Câmara, R.F. Silva, A. Somavilla, C. Gonçalves Leg. Oliveira, S.S. det. 2012 [INPA]

\section{Manota sp. 2}

1ơ, Brazil, Santa Catarina, São Bento do Sul, Rugendas, Malaise trap, 13-16.Oct.2001, M.V. Yamada leg. [MZUSP] (fig. 45)

\section{Neoclastobasis}

Neoclastobasis draskovitsae Matile

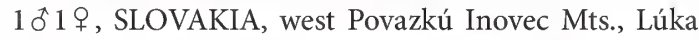
env., Ihelnik Nat. Res., 27.ix-4.x.1999, M. Kozánek Leg., Malaise trap, Jan Ševčik det. 2010 [LMED]

Neoclastobasis kamijoi (Sasakawa)

$1 \delta 1$ 오, SOUTH KOREA, S. Corée-Sanan, 21 i (Keumsan), 5-12.vi.1998, P. Tripotin rec. det. Kurina, O. 2008 [MNHN]

10ิ, SOUTH KOREA, S. Corée-Sanan, 11i (Keumsan), 21.ix.1997, P. Tripotin rec., det. Kurina, O. 2008 [MNHN] (fig. 54)

\section{Paracycloneura}

Paracycloneura apicalis Tonnoir and Edwards

1 ㅇ, NEW ZEALAND, Kanaeranga Vly., 23.i-2.ii.1970, H.A. Oliver. Oliveira, S.S. det. 2011 [ANIC] (fig. 30)

10, NEW ZEALAND, Ohakune, ix.1923, T.R. Harris, B.M. 1923-263 [NHM]

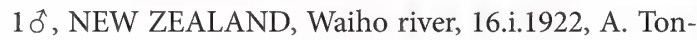
noir, B.M. 1923-50 [NHM]

Additional sources: Jaschhof and Kallweit (2009), Tonnoir and Edwards (1927)

\section{Paradoxa}

Paradoxa fusca Marshall

10ิ, NEW ZEALAND, Campbell I., Tucker Cave, 4m, Malaise trap, 27.xi-1.xii.1961, J.I. Gressit col., det. 1962, R.A. Harrison [ANIC]

10ิ, NEW ZEALAND, Campbell I., Tucker Cave, 4m, Malaise trap, 16-18.xii.1961, J.I. Gressit col., det. 1962, R.A. Harrison [ANIC]

1 ㅇ, NEW ZEALAND, Hongi's Track, Rotorua, 7. xi.1970, H.A. Oliver, Malaise trap. Oliveira, S.S. det. 2011 [ANIC]

1ô, NEW ZEALAND, Campbell I., Tucker Cave, 4m, Malaise trap, 03-05.xii1961, J.I. Gressit col., det. 1962, R.A. Harrison [NHM]

19 , NEW ZEALAND, Campbell I., Tucker Cave, 4m, Malaise trap, 01-03.xii1961, J.I. Gressit col., det. 1962, R.A. Harrison [NHM]
10 , NEW ZEALAND, Hinewai reserve, beach forest, M.T., 15-20.iv.1997, J. Ward, Loic Matile det. 1977 [NHM]

Additional source: Jaschhof and Kallweit (2009)

Paradoxa paradoxa Jaschhof

1 옹 SOUTH AFRICA, Natal, $75 \mathrm{Km}$ WSW Estcourt Cathedral Peaks For Stn. 1500m, 7-31.xii.1979, S. and J. Peck. Oliveira, S.S. det. 2012 [CNC] (fig. 36)

Additional sources: Jaschhof (2006), Oliveira and Muller (2012)

\section{Paraleia}

Paraleia bolivari Oliveira and Amorim

Source: Oliveira and Amorim (2012)

Paraleia denticulata Oliveira and Amorim

Source: Oliveira and Amorim (2012)

Paraleia fulvescens Tonnoir

10, AUSTRALIA, Tasmania, Eaglehawk Neck, 18. xi.1922, A. Tonnoir, Holotype [ANIC]

1 ㅇ, AUSTRALIA, Tasmania, St. Patrick R., 30.x.1922,

A. Tonnoir. ALLOTYPE [ANIC]

1 o, AUSTRALIA, Tasmania, St. Patrick R., 11.xi.1922,

A. Tonnoir, Paratype, [ANIC]

1 0 , AUSTRALIA, Tasmania, Burnie, 1.ii.1923, A. Tonnoir, Paratype [ANIC]

1?, AUSTRALIA, Tasmania, Fern Tree, 11.xi.1922, A. Tonnoir, Paratype [ANIC]

10, AUSTRALIA, Tasmania, Eaglehawk Neck, 17. xi.1922, A. Tonnoir, Paratype, [ANIC]

1 을 AUSTRALIA, Tasmania, Eaglehawk Neck, 22. xi.1922, A. Tonnoir, Paratype, [ANIC]

1 ㅇ, AUSTRALIA, Tasmania, Eaglehawk, 18.xi.1922, A. Tonnoir, Paratype [ANIC]

1 ㅇ, AUSTRALIA, Tasmania, Harz Moutain, 10.x.1922, A. Tonnoir, Paratype [ANIC]

1?, AUSTRALIA, Tasmania, Barington Tops, ii.1925, SU Zoo Exp., Paratype [ANIC]

1 오, AUSTRALIA, Tas., Lake St. Clair, Site: SCRE 8, 0434682E 5355692N, 30.ix.1999, Pitfall, Oliveira, S.S. det. 2011 [AMSA]

1 , , AUSTRALIA, Tas., 4Km E. Rosebery, 41.47S 145.35E, 16.i-1.ii.1983, Malaise ethanol, I.D. Naumann and J.C. Cardale, Oliveira, S.S. det. 2011 [ANIC]

1 đ3오, AUSTRALIA, N.S.W., Monga, 19.vii.1962, D.H. Colless, Oliveira, S.S. det. 2011 [ANIC]

1 ㅇ, AUSTRALIA, Tas., $14 \mathrm{Km}$ SW by S Wilmot, $41.30 \mathrm{~S}$ 145.05E, 31.i.1983, ex. ethanol, I.D. Naumann and J.C. Cardale, Oliveira, S.S. det. 2011 [ANIC] 
10, AUSTRALIA, Tas., 12mls. S Deloraine, $2200 \mathrm{ft}, 5$. iii.1963, I.F.B. Common and M.S. Upton, Oliveira, S.S. det. 2011 [ANIC]

10 , AUSTRALIA, Tas., Hellyer Gorge, 14.ii.1963, I.F.B. Common and M.S. Upton, Oliveira, S.S. det. 2011 [ANIC]

20\%, AUSTRALIA, Tas., Nelson R., 42.06S 145.44E, 22.i.1983, ex. ethanol, I.D. Naumann and J.C. Cardale, Oliveira, S.S. det. 2011 [ANIC]

1ơ, AUSTRALIA, Vic., Cement Cr., 1800', 25.xii.1965, N. Dobrotworsky, Oliveira, S.S. det. 2011 [ANIC]

Paraleia fumosa Oliveira and Amorim

Source: Oliveira and Amorim (2012)

Paraleia nubilipennis (Walker)

1 ㅇ, ARGENTINA, Tierra del Fuego, Lago Fagnano [MZUSP]

1ơ, CHILE, Osorno, Argallanes, Monte Alto, Puyehue, J.P. Duret leg. [MZUSP] (fig. 65)

\section{Paramanota}

Paramanota furcillata Hippa

1ô, THAILAND [SMOC - photograph] (fig. 48)

Paramanota peninsulae Hippa, Jaschhof and Vilkamaa Additional sources: Hippa et al. (2005), Tuomikoski (1966)

\section{Procycloneura}

Procycloneura paranensis Edwards

$2{ }^{\dagger} 6$ ㅇ, BRAZIL, SC, Seara, Nova Teutônia, $27^{\circ} 11^{\prime} \mathrm{S}$ $52^{\circ} 23^{\prime} \mathrm{W}, 300-500 \mathrm{~m}, \mathrm{x} .1971$, Fritz Plaumann Leg. Oliveira, S.S. det. 2011 [MZUSP]

2 ㅇ, BRAZIL, SC, Seara, Nova Teutônia, 2711'S 52²3'W, 300-500m, ix.1971, Fritz Plaumann Leg. Oliveira, S.S. det. 2011 [MZUSP]

$1{ }^{\circ}$, BRAZIL, SC, Seara, Nova Teutônia, $27^{\circ} 11^{\prime} \mathrm{S} 52^{\circ} 23^{\prime} \mathrm{W}$, 300-500m, 11.x.1938, Fritz Plaumann Leg. BMNH(E) \#950074. Oliveira, S.S. det. 2011 [NHM] (fig. 73)

1 ㅇ, BRAZIL, SC, Palhoça, Massiambu Pequeno, v.1957, E. Neto Leg. Oliveira, S.S. det. 2011 [MZUSP]

1 ㅇ, BRAZIL, PA, Ponta Grossa, Vila Velha, Res. IAPAR, Malaise trap, 29.xii.1986, PROFAUPAR. Oliveira, S.S. det. 2011 [MZUSP]

10ิ, BRAZIL, RJ, Itatiaia, Macieiras, i.1948, D. Andretta Leg. Oliveira, S.S. det. 2011 [MZUSP]

103 ㅇ, BRAZIL, SP, Campos do Jordão, iv.1957, Antunes. Oliveira, S.S. det. 2011 [MZUSP]

1 ㅇ, BRAZIL, SP, Campos do Jordão, xii.1955, J. Lane Leg. Oliveira, S.S. det. 2011 [MZUSP]
3 , , BRAZIL, SP, Cantareira, viii.1945, J. Lane Leg. Oliveira, S.S. det. 2011 [MZUSP]

2 ㅇ BRAZIL, SP, Cantareira, vii.1945, J. Lane Leg. Oliveira, S.S. det. 2011 [MZUSP]

4 오, BRAZIL, SP, Salesópolis, Reserva Biológica Bora-

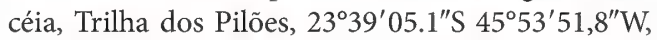
Malaise, 22.ii.2005, L.K. Nogueira and A.P. Aguiar Leg. Oliveira, S.S. det. 2011 [MZUSP]

1 ㅇ, BRAZIL, SP, Jundiaí, Serra do Japi, 28.xii.1992, D.S. Amorim Leg. Oliveira, S.S. det. 2011 [MZUSP]

1ㅇ, BRAZIL, MG, Botelhos, Córrego da Onça, $21^{\circ} 40^{\prime} 90^{\prime \prime} \mathrm{S} 46^{\circ} 22^{\prime} 05^{\prime \prime} \mathrm{W}$, Varredura, 02-05.xi.2006, D.S. Amorim, R.L. Falaschi and S.S. Oliveira Leg. Oliveira, S.S. det. 2011 [MZUSP]

1 ㅇ, BRAZIL, MG, Botelhos, Córrego da Onça, $21^{\circ} 40^{\prime} 90^{\prime \prime} \mathrm{S} 46^{\circ} 22^{\prime} 05^{\prime \prime} \mathrm{W}$, Luz mata, 02-05.xi.2006, D.S. Amorim, R.L. Falaschi and S.S. Oliveira Leg. Oliveira, S.S. det. 2011 [MZUSP]

1 ․, BRAZIL, MG, Botelhos, Córrego da Onça, $21^{\circ} 40^{\prime} 90^{\prime \prime} \mathrm{S} 46^{\circ} 22^{\prime} 05^{\prime \prime} \mathrm{W}$, Luz mata, 15-19.vi.2007, D.S. Amorim, S.S. Oliveira and R.S. Capellari Leg. Oliveira, S.S. det. 2011 [MZUSP]

1 ㅇ, BRAZIL, MG, Botelhos, Córrego da Onça, $21^{\circ} 40^{\prime} 90^{\prime \prime} \mathrm{S} 46^{\circ} 22^{\prime} 05^{\prime \prime} \mathrm{W}$, Luz mata, 5-20.xi.2006, D.S. Amorim, R.L. Falaschi and S.S. Oliveira Leg. Oliveira, S.S. det. 2011 [MZUSP]

Procycloneura similis Freeman

10, CHILE, Cameron, S. Bahia Inutil, T. d. Fuego, Magellanes, 14-17.xi.1960, E. Peña. Oliveira, S.S. det. 2012 [CNC] (figs. 74-75)

10 , CHILE, Estancia Vicina, SE of Cameron, Magellanes, 1-5.xii.1960, E. Peña. Oliveira, S.S. det. 2012 [CNC]

1 , , CHILE, Magallanes, Isla Deecif, xi.1972, col. Duret, $16358 / 16359$ respectively [MNHN]

1 , CHILE, Osorno, Puyehue, Aguas Calientes, 15. xii.1981, col. Duret, 20770 [MNHN]

\section{Procycloneura sp.}

10, COLOMBIA, Risaralda, SFF Otún Quimbaya Cuchilla Camino, $04^{\circ} 43^{\prime} \mathrm{N} 75^{\circ} 35^{\prime}$ W, 2,050 m, Malaise trap, 25.xi-03.xii.2002, D. Campos Leg. M. 3679, S.S. Oliveira det. [IAvH] (fig. 40)

\section{Promanota}

Promanota malaisei Tuomikoski

10, INDIA, N.E. Burma, Kambaiti, 2000m, 11.v.1934, Malaise. Mus. Zool. Helsinki, Loan nr. D00-171. Mus. Zool. Helsinki Loan no. DIP2011 34 [FMNH] 10 , INDIA, N.E. Burma, Kambaiti, 2000m, 4.vi.1934, Malaise. Mus. Zool. Helsinki, Loan nr. D00-173. 
Mus. Zool. Helsinki Loan no. DIP2011 33 [FMNH]

10, INDIA, N.E. Burma, Kambaiti, 2000m, 4.vi.1934, Malaise. Mus. Zool. Helsinki, Loan nr. D00-172. Mus. Zool. Helsinki Loan no. DIP2011 35 [FMNH]

10ิ, THAILAND, Chiang Mai Doi Inthanon NP, Checkpoint $2,1700 \mathrm{~m}, 18^{\circ} 31.559^{\prime} \mathrm{N} 98^{\circ} 29.941^{\prime} \mathrm{E}$, 29.vi-2.vii.2006, Malaise trap, Y. Areeluck Leg. T44. Promanota malaise Tuom., 1966, det. Jan Ševčik 2011 [LMED] (fig. 46)

Additional source: Hippa et al. (2005)

\section{Rondaniella}

\section{Rondaniella dimidiata (Meigen)}

1 i , CANADA, Ont., Ottawa, 27.viii.1992, J.R. Vockeroth. Damp second-growth Acer-Bettulla wood. Oliveira, S.S. det. 2012 [CNC]

19, CANADA, Ont., Ottawa, 30.x.1950, J.R. Vockeroth. Oliveira, S.S. det. 2012 [CNC]

10ิ, CANADA, Ont., Ottawa, 21.ix.1989, J.R. Vockeroth. Swept over barc path in Acer wood. Oliveira, S.S. det. $2012[\mathrm{CNC}]$

10, CANADA, Que., Old Chelsea, 9.viii.1961, J.R. Vockeroth. Oliveira, S.S. det. 2012 [CNC]

1 ㅇ, CANADA, NB, Kouchibouguac Nat. Park, 26. vi.1977, J.R. Vockeroth. Code 5381Y. Oliveira, S.S. det. 2012 [CNC]

10, CANADA, NB, Kouchibouguac Nat. Park, 5. vii.1977, J.R. Vockeroth. Code 5486Z. Oliveira, S.S. det. 2012 [CNC] (figs. 32, 71)

10ิ, SLOVAKIA, centr. Muránska planina Nat. Park, Muráň, Hrdzavá dolina, 28.vi-26.vii.2010, Malaise trap, Jan Ševčik Leg., Jan Ševčik det. 2010 [LMED]

\section{Rondaniella sp.}

10 ${ }^{\star}$, NEPAL, Ktmd., Godavari 6000', 17.viii.1967, Can. Nepal Exped. Oliveira, S.S. det. 2012 [CNC]

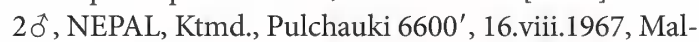
aise trap, Can. Nepal Exped. Oliveira, S.S. det. 2012 [CNC]

10 , NEPAL, Ktmd., Pulchauki $6600^{\prime}$, 10.viii.1967, Malaise trap, Can. Nepal Exped. Oliveira, S.S. det. 2012 [CNC]

\section{Sigmoleia}

Sigmoleia melanoxantha Tonnoir and Edwards

50ิ, NEW ZEALAND, North Island, Central Plateau, Kaimanawa Forest Park, ex. Malaise trap Nothofagus bush, 24-31.i.1971, H.A. Oliver. Oliveira, S.S. det. 2011 [ANIC]
1 ㅇ, NEW ZEALAND, North Island, Kauaeranga, Vly. Thames, Malaise trap, 27-29.xi.1970, H.A. Oliver. Oliveira, S.S. det. 2011 [ANIC] (fig. 35)

10 , NEW ZEALAND, Kanaeranga Vly., 23.i-2.ii.1970, Malaise trap, H.A. Oliver. Oliveira, S.S. det. 2011 [ANIC]

10. NEW ZEALAND, Hongi's Track, Rotorua, 7.v.1970, H.A. Oliver, Malaise trap. Oliveira, S.S. det. 2011 [ANIC]

$10^{\dagger} 19$, NEW ZEALAND, M.C. Hinewaires, Banks Pen, Malaise trap Quiet Stm., 1.v-10.vii.1994, J.B. Ward, L. Matile det. 1997 [ANIC]

Sigmoleia peterjohnsi Jaschhof and Kallweit

102․ NEW ZEALAND, Huia, Auckland, 25-26. iv.1970, Malaise trap, H.A. Oliver. Oliveira, S.S. det. 2011 [ANIC]

\section{Sticholeia}

Sticholeia cheesmanae Søli

10 , AUSTRALIA, Queensland, Claudie R., 5 miles W. Mt. Lamond, 14.i.1972, D.K. McAlpine and G.A. Holloway. K305801. Oliveira, S.S. det. 2011 [AMSA]

19 , AUSTRALIA, N. Queensland, Earl Hill, N. of Cairns, 8.v.1967, D.H. Colless [ANIC]

$10^{\dagger}$, AUSTRALIA, N.T., Baroalba Ck., Springs, $19 \mathrm{Km}$ NE by E of Mt. Cahill, 17.xi.1972, D.H. Colless [ANIC] (fig. 43)

Sticholeia dolichostyla Søli

PAPUA NEW GUINEA, Kokoda, 6.i.1964, D.K. McAlpine. Oliveira, S.S. det. 2011 [AMSA] - $3 \widehat{O}^{\hat{~}} \mathrm{~K} 305810$; 1 우1우 K305811; 1 아 K305814; 1 우 K305815; 1 우 K305816; 1 ठठ K305818.

10 , PAPUA NEW GUINEA, Brown R. near Pt. Moresby, 21.x.1963, D.K. McAlpine. K305821. Oliveira, S.S. det. 2011 [AMSA]

PAPUA NEW GUINEA, Bubia near Lae, 27.xii.1963, D.K. McAlpine. Oliveira, S.S. det. 2011 [AMSA] -

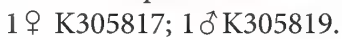

10 , PAPUA NEW GUINEA, Bambu R., $8 \mathrm{Km}$. N. Lae, Morabe District, 29.xi.1972, G.A. Holloway. K305813. Oliveira, S.S. det. 2011 [AMSA]

\section{Sticholeia loici Søli}

PAPUA NEW GUINEA, Bainyik, 20.xii.1963, D.K. McAlpine. Oliveira, S.S. det. 2011 [AMSA] -

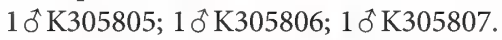

PAPUA NEW GUINEA, Apangai near Maprik, 15. xii.1963, D.K. McAlpine. Oliveira, S.S. det. 2011 [AMSA] - 1 우 K305808; 1 우 K305809. 
10ิ, PAPUA NEW GUINEA, Kuminibus near Maprik, 17.xii.1963, D.K. McAlpine. K305803. Oliveira, S.S. det. 2011 [AMSA]

10ิ, PAPUA NEW GUINEA, Imbia near Maprik, 18. xii.1963, D.K. McAlpine. K305804. Oliveira, S.S. det. 2011 [AMSA]

19 , PAPUA NEW GUINEA, Oomsis, Lae, $06^{\circ} 40^{\prime} \mathrm{S}$ $146^{\circ} 48^{\prime} 0$ E, Mycetophilidae, Yellow Pan 3, 25.vii.2000, R.L. Kitching. Oliveira, S.S. det. 2011 [AMSA]

$10^{\circ}$, PAPUA NEW GUINEA, Oomsis, Lae, $06^{\circ} 40^{\prime} \mathrm{S}$ $146^{\circ} 48^{\prime} 0 \mathrm{E}$, Mycetophilidae, Malaise ground 1, 24.vii.2000, R.L. Kitching. Oliveira, S.S. det. 2011 [AMSA]

\section{Thoracotropis}

Thoracotropis cypriformis Freeman

1 ô, CHILE, Osorno, Pireatrihue, 12.ii.1980, col. Duret, 13116, Det. J.P. Duret, 1981 [MNHN]

1ô, Holotype, CHILE, Ancud, 17-19.Dec.1926, Llanquihue Prov., F. and M. Edwards, 254350 [NHM] (fig. 24)

Additional source: Oliveira et al. (2012)

\section{Tonnwardsia}

Tonnwardsia aberrans (Tonnoir)

2ㅇ, NEW ZEALAND, Kanaeranga Vly., 23.i-2.ii.1970, Malaise trap, H.A. Oliver. Oliveira, S.S. det. 2011 [ANIC]

$10{ }^{\star}, 1$ 오 , NEW ZEALAND, North Island, S.E. National Park, Central Plateau, Malaise trap Nothofagus bush, 28.xii.1970-2.i.1971, H.A. Oliver. Oliveira, S.S. det. 2011 [ANIC] (fig. 39, 72)

1 ㅇ, NEW ZEALAND, North Island, Central Plateau, Kaimanawa Forest Park, ex. Malaise trap Nothofagus bush, 24-31.i.1971, H.A. Oliver. Oliveira, S.S. det. 2011 [ANIC]

\section{Trichoterga}

Trichoterga monticola Tonnoir and Edwards

10ิ, NEW ZEALAND, Ohakune, v-vii.1923, T.R. Harris, B.M.1923-419 [MZUSP]

10, NEW ZEALAND, North Island, Central Plateau, Kaimanawa Forest Park, ex. Malaise trap Nothofagus bush, 24-31.i.1971, H.A. Oliver. Oliveira, S.S. det. 2011 [ANIC] (fig. 66)

10 , NEW ZEALAND, Whangamea Saddle, Nelson, South Island, Malaise trap, 12-15.v.1970, H.A. Oliver. Oliveira, S.S. det. 2011 [ANIC] (fig. 26)

$1 \delta 2$ ㅇ, NEW ZEALAND, BR Nelson Lakes N.P., Mt. Robert 1100m, 18-23.xii.1983, L. Masner, MT. Oliveira, S.S. det. 2012 [CNC]
Waipapamyia

Waipapamyia elongata Jaschhof and Kallweit

1 ¿ 2 ㅇ, NEW ZEALAND, N. Island, Pirongia West Road, near Hamilton, 17.xi.1970, Malaise trap, H.A. Oliver. Oliveira, S.S. det. 2011 [ANIC] (fig. 33)

5 o, NEW ZEALAND, North Island, Kauaeranga, Vly. Thames, Malaise trap, 27-29.xi.1970, H.A. Oliver. Oliveira, S.S. det. 2011 [ANIC]

20 , NEW ZEALAND, North Island, Kaimai Ra., ca. 3000ft, ex. Malaise trap, 22.xii.1970, H.A. Oliver. Oliveira, S.S. det. 2011 [ANIC]

10 , NEW ZEALAND, North Island, Upp. Kauaeranga, Vly. Thames, Malaise trap, 27-29.xi.1970, H.A. Oliver. Oliveira, S.S. det. 2011 [ANIC] 


\section{APPENDIX 4}

Mrcetophilid FossiLs (MODIFIEd FROM Evenhuis, 2014) Assignable to Subfamilies

(PLACED AT STEMS IN FIG. 107)

Fossils in chronological order. Unassigned fossils at subfamily level at the end. Number before each fossil species correspond to fossil sites in appendix 5 . Generic assignment of fossils described in some older papers not necessarily trustful, subfamily assignment considerably reliable. Fossils assigned to the Leiinae and Tetragoneurinae were revised and their placement discussed along the text. $[\mathrm{A}]=$ amber; $[\mathrm{C}]=$ compression. * Mycetophilid fossils unplaced at the subfamily level without further examination or at the generic level within the Leiinae.

\section{Subfamily Sciophilinae}

1. Polylepta olinguiensis Blagoderov, $2000 /$ Russia (Siberia, Karymsk District, Turga Group) (Lower Cretaceous) [C].

1. Pollicitator baisae Blagoderov, 1995 / Russia (Siberia, Zaza Formation) (Lower Cretaceous) [C].

1. Baisodicrana incompleta Blagoderov, 1997 / Russia (Siberia, Zaza Formation) (Lower Cretaceous) [C].

1. Baisodicrana secunda Blagoderov, 1997 / Russia (Siberia, Zaza Formation) (Lower Cretaceous) [C].

1. Ekhirtus dissanus Blagoderov, 1997 / Russia (Siberia, Zaza Formation) (Lower Cretaceous) [C].

1. Prospeoleptasimplex Blagoderov, 1997 / Russia (Siberia, Zaza Formation) (Lower Cretaceous) [C].

1. Prospeoleptatrapezia Blagoderov, 1997 / Russia (Siberia, Zaza Formation) (Lower Cretaceous) [C].

1. Syntemna mesozoica Blagoderov, 1997 / Russia (Siberia, Zaza Formation) (Lower Cretaceous) [C].

1. Zazicia innuba Blagoderov, 1997 / Russia (Siberia, Zaza Formation) (Lower Cretaceous) [C].

2. Sciophila unidentified sp. (Jarzembowski, 1984 / UK (England, Wealden Group) (Lower Cretaceous) [C].

4. Syntemna zhuzhan Blagoderov, 1998b / Mongolia (Bayan-Hongor Aymag) (Lower Cretaceous, ?Barremian-Aptian) [C].

4. Syntemna tele Blagoderov, 1998b / Mongolia (BayanHongor Aymag) (Lower Cretaceous, ?BarremianAptian) $[\mathrm{C}]$.

4. Baisodicrana mongolica Blagoderov, 1998b / Mongolia (Bayan-Hongor Aymag) (Lower Cretaceous, ?Barremian-Aptian) [C].

4. Polylepta lyptolape Blagoderov, 1998b / Mongolia (Bayan-Hongor Aymag) (Lower Cretaceous, ?Barremian-Aptian)[C].
4. Prospeolepta brevicubita Blagoderov, 2000 / Mongolia (Bayan-Hongor Aymag) (Lower Cretaceous, ?Barremian-Aptian $)[C]$.

4. Prospeolepta parallelimedia Blagoderov, 1998b / Mongolia (Shar-Tolgoy) (Lower Cretaceous, ?BarremianAptian) [C].

5. Allocotocera xavieri Blagoderov and Arillo, 2002 / Spain (Alava) (Lower Cretaceous) [A].

6. Neuratelia maimecha Blagoderov and Grimaldi, 2004 / Russia (Taimyr Peninsula) (Upper Cretaceous) [A].

7. Allocotocera burmitica Blagoderov and Grimaldi, 2004 / Myanmar (Upper Cretaceous) [A].

7. Pseudomanota perplexa Blagoderov and Grimaldi, 2004 / Myanmar (Upper Cretaceous) [A].

9. Pollicitator pollicitator Blagoderov, 2000 / (Siberia, Obeshchayushchii) (Upper Cretaceous,Cenomanian) $[\mathrm{C}]$.

9. Syntemna zherikhini Blagoderov, 2000 / Russia (Siberia, Obeshchayushchii) (Upper Cretaceous,Cenomanian) [C].

10. Syntemna fissurata Blagoderov and Grimaldi, 2004 / Canada (Upper Cretaceous) [A].

11. Sciophila takoyensis Blagoderov, 2007 / Russia (Sakhalin) (Paleocene) [A].

11. Syntemna falcata Blagoderov, 2007 / Russia (Sakhalin) (Paleocene) $[\mathrm{A}]$.

13. Aneura apicalis Riek, 1954 / Australia (Redbank Plains) (Eocene) [C].

13. Prototasmanina nana Riek, 1954 / Australia (Redbank Plains) (Eocene) [C].

15. Acnemia bolsuisi Meunier, 1904c / Baltic Region (Eocene) [A].

15. Anaclileia anacliniformis Meunier, 1904c / Baltic Region (Eocene) [A].

15. Anaclileia dissimilis Meunier, 1904c / Baltic Region (Eocene) [A].

15. Anaclileia gazagnairei Meunier, 1904c / Baltic Region (Eocene) [A].

15. Anaclileia sylvatica Meunier, $1904 \mathrm{c} /$ Baltic Region (Eocene) [A].

15. Azana rarissima Meunier, 1904c / Baltic Region (Eocene) [A].

15. Leptomorphus sepultus (Meunier, 1917a) / Baltic Region (Eocene) [A].

15. Neuratelia gibbosa (Meunier, 1904c) / Baltic Region (Eocene) [A].

15. Neuratelia giebeli (Meunier, 1904c) / Baltic Region (Eocene) [A].

15. Sciophila armipes Meunier, 1899e / Baltic Region (Eocene) [A]. 
15. Sciophila atra Giebel, 1856 / Baltic Region (Eocene) [A]. 15. Sciophila carbonaria Meunier, 1899e / Baltic Region (Eocene) [A].

15. Sciophila curvipetiolata (Meunier, 1904c) / Baltic Region (Eocene) [A].

15. Sciophila dilatata Loew, 1850b / Baltic Region (Eocene) [A].

15. Sciophila inermis Meunier, 1899e / Baltic Region (Eocene) [A].

15. Sciophila loewi Giebel, 1856 / Baltic Region (Eocene) [A].

15. Sciophila micropora Meunier, 1899e / Baltic Region (Eocene) [A].

15. Sciophila socialis Giebel, 1856 / Baltic Region (Eocene) [A].

15. Syntemna compressa Meunier, 1904c / Baltic Region (Eocene) [A].

15. Syntemna dama Meunier, 1917a / Baltic Region (Eocene) [A].

15. Syntemna elongata Meunier, 1904c / Baltic Region (Eocene) $[\mathrm{A}]$.

15. Syntemna johannseni Meunier, 1922b / Baltic Region (Eocene) [A].

15. Syntemna lundstromi Meunier, 1922b / Baltic Region (Eocene) [A].

15. Syntemna minuta Meunier, 1917a / Baltic Region (Eocene) [A].

15. Syntemna oblita Meunier, 1917a / Baltic Region (Eocene) [A].

15. Syntemna pinites Meunier, 1904c / Baltic Region (Eocene) [A].

15. Syntemna prolongata Meunier, 1904c / Baltic Region (Eocene) [A].

15. Syntemna sciophiliformis Meunier, 1904c / Baltic Region (Eocene) [A].

15. Syntemna subcylindrica Meunier, 1904c / Baltic Region (Eocene) [A].

15. Syntemna subquadrata Meunier, 1904c / Baltic Region (Eocene) [A].

16. Acnemia cyclosoma Cockerell, 1924a / USA (Florissant) (Eocene/Oligocene) [C].

16. Leptomorphus palaeospilus (Cockerell, 1920a) / USA (Florissant) (Eocene/Oligocene) [C].

16. Sciophila hyatti Scudder, 1890 / USA (Florissant) (Eocene/Oligocene) [C].

16. Sciophila mirandula (Cockerell, 1909b) / USA (Florissant) (Eocene/Oligocene).

16. Syntemna unidentified sp. (Lewis, 1987). / USA (Oligocene) [C]

17. Acnemia simplex Cockerell, 1921c / UK (England, Wealden Group) (Eocene/Oligocene) [C].
22. Phthinia longipoda Statz, 1944a / Germany (Oligocene) $[\mathrm{C}]$.

22. Sciophila minutissima (Meunier, 1915c) / Germany (Oligocene) [C].

30. Leptomorphus africanus Meunier, 1907a / Madagascar (Holocene) [K].

Subfamily Tetragoneurinae

1. Docosia baisae Blagoderov, 1998a / Russia (Siberia, Zaza Formation) (Lower Cretaceous) [C].

1. Docosia zaza Blagoderov, 1998a / Russia (Siberia, Zaza Formation) (Lower Cretaceous) [C].

6. Ectrepesthoneura succinimontana Blagoderov and Grimaldi, 2004 / Russia (Taimyr Peninsula) (Upper Cretaceous) $[\mathrm{A}]$.

6. Izleiina mirifica Blagoderov and Grimaldi, 2004 / Russia (Taimyr Peninsula) (Upper Cretaceous) [A].

6. Nedocosia exsanguis Blagoderov and Grimaldi, 2004 / Russia (Taimyr Peninsula) (Upper Cretaceous) [A].

6. Nedocosia sibirica Blagoderov and Grimaldi, 2004 / Russia (Taimyr Peninsula) (Upper Cretaceous) [A].

7. Disparoleia cristata Blagoderov and Grimaldi, 2004 / Myanmar (Upper Cretaceous) [A].

7. Hemolia glabra Blagoderov and Grimaldi, 2004 / Myanmar (Upper Cretaceous) [A].

7. Hemoliamatilei Blagoderov and Grimaldi, 2004 / Myanmar (Upper Cretaceous) [A].

7. Protragoneura platycera Blagoderov and Grimaldi, 2004 / Myanmar (Upper Cretaceous) [A].

7. Zeliinia orientalis Blagoderov and Grimaldi, 2004 / Myanmar (Upper Cretaceous) [A].

8. Ectrepesthoneuras wolenskyi Blagoderov and Grimaldi, 2004 / USA (New Jersey) (Upper Cretaceous) [A].

8. Izleiina spinitibialis Blagoderov and Grimaldi, 2004 / USA (New Jersey) (Upper Cretaceous) [A].

8. Nedocosia novocaesarea Blagoderov and Grimaldi, 2004 / USA (New Jersey) (Upper Cretaceous) [A].

10. Nedocosia canadensis Blagoderov and Grimaldi, 2004 / Canada (Upper Cretaceous) [A].

10. Zeliinia occidentalis Blagoderov and Grimaldi, 2004 / Canada (Upper Cretaceous) [A].

11. Nedocosia naiba Blagoderov, 2007 / Russia (Sakhalin) (Paleocene) [A].

15. Docosia archaica Meunier, 1916b / Baltic Region (Eocene) [A].

15. Docosia elegantula Meunier, 1922b / Baltic Region (Eocene) [A].

15. Docosia meijerei Meunier, 1923b / Baltic Region (Eocene) [A].

15. Docosia petiolata Meunier, 1904c / Baltic Region (Eocene) [A]. 
15. Docosia subtilis Meunier, 1904c / Baltic Region (Eocene) $[\mathrm{A}]$.

15. Docosia subvaria Meunier, 1916b / Baltic Region (Eocene) [A].

15. Docosia uniciliata Meunier, $1916 \mathrm{~b}$ / Baltic Region (Eocene) [A].

15. Docosia varia Meunier, 1904c / Baltic Region (Eocene) [A].

15. Ectrepesthoneura magnifica Meunier, 1904a / Baltic Region (Eocene) [A].

15. Tetragoneura borussica Meunier, 1904c / Baltic Region (Eocene) [A].

15. Tetragoneura detecta Meunier, 1923b / Baltic Region (Eocene) [A].

15. Tetragoneura elongata Meunier, 1904c / Baltic Region (Eocene) [A].

15. Tetragoneura elongatissima Meunier, 1904c / Baltic Region (Eocene) [A].

15. Tetragoneura fixa Meunier, 1923b / Baltic Region (Eocene) [A].

15. Tetragoneura glabra Meunier, 1904c / Baltic Region (Eocene) $[\mathrm{A}]$.

15. Tetragoneura gracilis Meunier, 1904c / Baltic Region (Eocene) [A].

15. Tetragoneura minuta Meunier, 1904c / Baltic Region (Eocene) [A].

15. Tetragoneura mycetophiliformis (Meunier, 1904a) / Baltic Region (Eocene) [A].

15. Tetragoneura passa Meunier, 1923b / Baltic Region (Eocene) [A].

15. Tetragoneura rectangulata Meunier, 1904c / Baltic Region (Eocene) [A].

15. Tetragoneura tenera (Loew, 1850b) / Baltic Region (Eocene) $[\mathrm{A}]$.

16. Tetragoneura peritula Cockerell, 1909b / USA (Florissant) (Eocene/Oligocene) [C].

19. Tetragoneura sannoisiensis Meunier, 1915a / France (Oligocene) [C].

22. Docosiapilosa Statz, 1944a / Germany (Oligocene) [C].

22. Ectrepesthoneura rottensis Statz, 1944a / Germany (Oligocene) [C].

28. Prodocosia rondaniellides Armbruster, 1938 / Germany (Miocene) [C].

28. Pronovakia incerta Armbruster, 1938 / Germany (Miocene) [C].

Subfamily Leiinae

5. Alavamanota hispanica Blagoderov and Arillo, 2002 / Spain (Alava) (Lower Cretaceous) [A].

6. Alavamanota burmitina Blagoderov and Grimaldi, 2004 / Myanmar (Upper Cretaceous) [A].
7. Temaleia birmitica Blagoderov and Grimaldi, 2004 / Myanmar (Upper Cretaceous) [A].

10. Lecadinaleia parvistyla Blagoderov and Grimaldi, 2004 / Canada (Upper Cretaceous) [A].

15. Leia crassipalpis (Meunier, 1904c) / Baltic Region (Eocene) [A].

15. Leia curvipetiolata (Meunier, 1904c) / Baltic Region (Eocene) [A].

15. Leia frequens Loew, $1850 \mathrm{~b}$ / Baltic Region (Eocene) [A].

15. Leia longipalpis (Meunier, 1904c) / Baltic Region (Eocene) [A].

15. Leia longipetiolata (Meunier, 1904c) / Baltic Region (Eocene) [A].

15. Leia platypus Loew, $1850 \mathrm{~b} /$ Baltic Region (Eocene) [A].

15. Manota longipalpis (Meunier, 1904a) / Baltic Region (Eocene) [A].

15. Paramanota grandaeva Hippa, 2010 / Baltic Region (Eocene) [A].

15. Rondaniellainterrupta (Loew, 1850b) / Baltic Region (Eocene) [A].

16. Leia miocenica Cockerell, 1911 / USA (Florissant) (Eocene/Oligocene).

19. Allactoneura veiti Théobald, 1937 a / France (Oligocene) $[\mathrm{C}]$

20. Manota unidentified sp. (Gagné, 1980 / Mexico (Oligocene/Miocene) [A].

22. Leia aberrans Statz, 1944a / Germany (Oligocene) [C].

22. Leia crassiuscula (Förster, 1891) / Germany Oligocene) $[\mathrm{C}]$

22. Leia exhumata Statz, 1944a / Germany (Oligocene) [C].

22. Leia gracillima (Förster, 1891) / Germany Oligocene) $[\mathrm{C}]$

22. Leia longipes (Förster, 1891) / Germany Oligocene) [C].

22. Leia vetusta (Meunier, 1919) / Germany (Oligocene) $[\mathrm{C}]$.

22. Manota concolor Statz, 1944a / Germany (Oligocene) $[\mathrm{C}]$.

23. Leiella maculicauda Baxter/ Dominican Republic. (Miocene) [A].

23. Aphrastomyia planistylus Baxter, 1994 / Dominican Republic (Miocene) [A].

23. Manota unidentified sp. (N.L. Evenhuis, unpubl.) / Dominican Republic (Oligocene/Miocene) [A].

Subfamily Gnoristinae

1. Drepanorzeckia plana Blagoderov, 1997 / Russia (Zaza Formation) (Lower Cretaceous) [C]. 
1. Drepanorzeckia exlrunculipennis Blagoderov, 1997 / Russia (Zaza Formation) (Lower Cretaceous) [C].

1. Ipsaneusidalys communis Blagoderov, 1998a / Russia (Zaza Formation) (Lower Cretaceous) [C].

1. Ipsaneusidalys latipennis Blagoderov, 1998a / Russia (Zaza Formation) (Lower Cretaceous) [C].

1. Ipsaneusidalys longipennis Blagoderov, 1998a / Russia (Zaza Formation) (Lower Cretaceous) [C].

1. Metahadroneura major Blagoderov, 1998a / Russia (Zaza Formation) (Lower Cretaceous) [C].

1. Metahadroneura minor Blagoderov, 1998a / Russia (Zaza Formation) (Lower Cretaceous) [C].

1. Palaecomoptera longimedia Blagoderov, 1997 / Russia (Zaza Formation) (Lower Cretaceous) [C].

1. Palaecomoptera lukashevichae Blagoderov, 1997 / Russia (Zaza Formation) (Lower Cretaceous) [C].

1. Palaecomoptera shcherbakovi Blagoderov, 1997 / Russia (Zaza Formation) (Lower Cretaceous) [C].

1. Palaeothoracotropis truculentus Blagoderov, 1998a / Russia (Zaza Formation) (Lower Cretaceous) [C].

1. Paradzickia huor Blagoderov, 1997 / Russia (Zaza Formation) (Lower Cretaceous) [C].

1. Paradzickia hurin Blagoderov, 1997 / Russia (Zaza Formation) (Lower Cretaceous) [C].

1. Paradzickia tuor Blagoderov, 1997 / Russia (Zaza Formation) (Lower Cretaceous) [C].

1. Paradzickia turin Blagoderov, 1997 / Russia (Zaza Formation) (Lower Cretaceous) [C].

3. Palaeodocosia cabruae Blagoderov and Martínez-Delclòs, 2001 / Spain (Alava) (Lower Cretaceous) [C].

3. Synapha rubiesensis Blagoderov and Martínez-Delclòs, 2001 / Spain (Alava) (Lower Cretaceous) [C].

4. Apolephthisa mesozoica Blagoderov, 1998b / Mongolia (Bayan-Hongor Aymag) (Lower Cretaceous, ?Barremian-Aptian) [C].

4. Ipsaneusidalys shato Blagoderov, 1998b / Mongolia (Bayan-Hongor Aymag) (Lower Cretaceous, ?Barremian-Aptian) [C].

4. Palaecomoptera curvicosta Blagoderov, 1998b / Mongolia (Bayan-Hongor Aymag) (Lower Cretaceous, ?Barremian-Aptian)[C].

4. Palaecomoptera subcosta Blagoderov, 1998b / Mongolia (Bayan-Hongor Aymag) (Lower Cretaceous, ?Barremian-Aptian) [C].

4. Palaeothoracotropis dundulensis Blagoderov, 1998b / Mongolia (Bayan-Hongor Aymag) (Lower Cretaceous, ?Barremian-Aptian) [C].

4. Paradzickia hador Blagoderov, 1998b / Mongolia (Bayan-Hongor Aymag) (Lower Cretaceous, ?Barremian-Aptian)[C].
4. Paradzickia morwen Blagoderov, 1998b / Mongolia (Bayan-Hongor Aymag) (Lower Cretaceous, ?Barremian-Aptian) [C].

6. Apolephthisa bulunensis Blagoderov and Grimaldi, 2004 / Russia (Taimyr Peninsula) (Upper Cretaceous) [A].

7. Gaalomyia carolinae Blagoderov and Grimaldi, 2004 / Myanmar (Upper Cretaceous) [A].

7. Saigusaia pikei Blagoderov and Grimaldi, 2004 / Canada (Upper Cretaceous) [A].

7. Synapha longistyla Blagoderov and Grimaldi, 2004 / Canada (Upper Cretaceous) [A].

8. Dziedzickia nashi Blagoderov and Grimaldi, 2004 / USA (New Jersey) (Upper Cretaceous) [A].

8. Gregikia pallida Blagoderov and Grimaldi, 2004 / USA (New Jersey) (Upper Cretaceous) [A].

9. Palaeodocosia magdanica Blagoderov, 2000 / Russia (Siberia) (Upper Cretaceous) [C].

11. Apolephthisa sakhalina Blagoderov, 2007 / Russia (Sakhalin) (Paleocene) [A].

11. Synapha zherikhini Blagoderov, 2007 / Russia (Sakhalin) (Paleocene) [A].

13. Sinoboletina acropteris (Hong, 1981) / China (Eocene) [A].

15. Boletina anacliniformis Meunier, 1904c / Baltic Region (Eocene) [A].

15. Boletina brahmi Meunier, 1917a / Baltic Region (Eocene) [A].

15. Boletina conspicua Meunier, 1904c / Baltic Region (Eocene) [A].

15. Boletina fimbriata Meunier, 1904c / Baltic Region (Eocene) [A].

15. Boletina hirta Meunier, 1904c / Baltic Region (Eocene) [A].

15. Boletina hirtella Meunier, 1904c / Baltic Region (Eocene) [A].

15. Boletina oustaleti Meunier, 1904c / Baltic Region (Eocene) [A].

15. Boletina pilosa Meunier, 1904c / Baltic Region (Eocene) [A].

15. Boletina serrata Meunier, 1904c / Baltic Region (Eocene) [A].

15. Boletina subhirta Meunier, 1904c / Baltic Region (Eocene) [A].

15. Boletina uniciliata Meunier, 1916b / Baltic Region (Eocene) [A].

15. Coelosia aberrans (Meunier, 1904c) / Baltic Region (Eocene) [A].

15. Dziedzickia hadroneuroides Meunier, 1922b / Baltic Region (Eocene) [A].

15. Dziedzickia johannseni Meunier, 1917a / Baltic Region (Eocene) [A]. 
15. Dziedzickia sedula Meunier, 1922b / Baltic Region (Eocene) $[\mathrm{A}]$.

15. Loewiella asinduloides Meunier, 1904c / Baltic Region (Eocene) [A].

15. Loewiella brevitarsis Meunier, 1923b / Baltic Region (Eocene) [A].

15. Loewiella ciliata Meunier, 1904c / Baltic Region (Eocene) [A].

15. Loewiella empalioides Meunier, 1904c / Baltic Region (Eocene) [A].

15. Loewiella incompleta Meunier, 1904c / Baltic Region (Eocene) [A].

15. Loewiella indistincta Meunier, 1904c / Baltic Region (Eocene) [A].

15. Loewiella modesta Meunier, 1923b / Baltic Region (Eocene) $[\mathrm{A}]$.

15. Loewiella mucronata Meunier, 1904c / Baltic Region (Eocene) [A].

15. Loewiella tenebrosa Meunier, 1904c / Baltic Region (Eocene) [A]

15. Palaeoboletina elongatissima Meunier, 1904c / Baltic Region (Eocene) [A].

15. Palaeoboletina grandis Meunier, 1904c / Baltic Region (Eocene) [A].

15. Palaeodocosia brachycamptites (Meunier, 1904c)/ Baltic Region (Eocene) [A].

15. Palaeodocosia brachypezoides Meunier, 1904c / Baltic Region (Eocene) [A].

15. Palaeodocosia johannseni (Meunier, 1922b) / Baltic Region (Eocene) [A].

15. Palaeodocosia rara (Meunier, 1922b) / Baltic Region (Eocene) [A].

15. Palaeodocosia sclerosa (Meunier, 1923b) / Baltic Region (Eocene) [A].

15. Palaeoempalia broeckii Meunier, 1904c / Baltic Region (Eocene) [A].

15. Palaeoempalia brongniarti Meunier, 1904c / Baltic Region (Eocene) [A].

15. Palaeoempalia crassipes Meunier, 1904c / Baltic Region (Eocene) [A].

15. Palaeoempalia cylindrica Meunier, 1904c / Baltic Region (Eocene) [A].

15. Palaeoempalia interrupta Meunier, 1916b / Baltic Region (Eocene) [A].

15. Palaeoempalia mutabilis Meunier, 1904c / Baltic Region (Eocene) [A].

15. Palaeoempalia notata Meunier, 1923b / Baltic Region (Eocene) [A].

15. Palaeoempalia ornata Meunier, 1922b / Baltic Region (Eocene) [A].
15. Palaeoempalia servata Meunier, 1922b / Baltic Region (Eocene) [A].

15. Palaeoempalia succinea Meunier, 1904c / Baltic Region (Eocene) [A].

15. Palaeoempalia urbana Meunier, 1922b / Baltic Region (Eocene) [A].

15. Palaeosynapha kovalevi Evenhuis, 1994b / Baltic Region (Eocene) [A].

15. Proboletina syntemniformis Meunier, 1904c / Baltic Region (Eocene) [A].

15. Synapha subtriangularis (Meunier, 1904c) / Baltic Region (Eocene) [A].

16. Boletina hypogaea Melander, 1949 / USA (Florissant) (Eocene/Oligocene).

16. Boletina paludivaga Scudder, 1890 / USA (Florissant) (Eocene/Oligocene) [C].

16. Boletina umbratica Scudder, 1890 / USA (Florissant) (Eocene/Oligocene) [C].

16. Gnoriste dentoni Scudder, 1877a / USA (Florissant) (Eocene/Oligocene) [C].

19. Gnoriste meigeniana Heer, 1856 / France (Oligocene)

21. Boletina sepulta Scudder, 1877b / Canada (Oligocene) [C].

22. Boletina angustipennis Statz, 1944a / Germany (Oligocene) [C].

22. Boletina brunnescens Statz, 1944a / Germany (Oligocene) [C].

22. Boletina graciosa Statz, 1944a / Germany (Oligocene) $[\mathrm{C}]$.

22. Boletina longicornis Statz, 1944a / Germany (Oligocene) $[\mathrm{C}]$.

22. Boletina meigeniana Förster, 1891 / Germany (Miocene) $[\mathrm{C}]$.

22. Boletina philydra Heyden, 1870 / Germany (Oligocene) [C].

22. Dziedzickia lepida Statz, 1944a / Germany (Oligocene) $[\mathrm{C}]$.

22. Dziedzickia sepulta (Meunier, 1917b) / Germany (Oligocene) [C].

24. Gnoriste meigeniana Heer, 1856 / Croatia (Miocene) [C].

28. Proapolephthisa manotides Armbruster, 1938 / Germany (Miocene) [C].

28. Prohadroneura dziedzickides Armbruster, 1938 / Germany (Miocene) [C].

29. Boletina unidentified sp. (Rohdendorf, 1964) / Russia (Siberia) (Pliocene) [C].

30. Boletina unidentified sp. (Fujiyama and Iwao, 1975) / Japan (Pliocene/ Pleistocene) [C]. 
Subfamily Mycomyinae

11. Mycomya palaeocenica Blagoderov, 2007 / Russia (Sakhalin) (Paleocene) [A].

15. Mycomya crassicornis (Meunier, 1904c) / Baltic Region (Eocene) $[\mathrm{A}]$.

15. Mycomya helmii (Meunier, 1904c) / Baltic Region (Eocene) $[\mathrm{A}]$.

15. Mycomya peduncularis (Loew, 1850b) / Baltic Region (Eocene) $[\mathrm{A}]$.

15. Mycomya subquadrata (Meunier, 1904c) / Baltic Region (Eocene) [A].

15. Neoempheria bella (Meunier, 1922b) / Baltic Region (Eocene) [A].

15. Neoempheria major (Meunier, 1904c) / Baltic Region (Eocene) $[\mathrm{A}]$.

15. Neoempheria minor (Meunier, 1904c) / Baltic Region (Eocene) [A].

16. Mycomya cockerelli Johannsen, 1912 / USA (Eocene/ Oligocene) [C].

16. Mycomya lithomendax Cockerell, 1915a / USA (Eocene/Oligocene) [C].

17. Mycomya oblita Cockerell, 1921c / UK (England, Wealden Group) (Eocene/Oligocene) [C].

19. Mycomya curvithoracis Théobald, 1937a / France (Oligocene) [C].

19. Mycomya hubaulti Théobald, 1937a / France (Oligocene) [C].

19. Neoempheria wittenheimiana Quiévreux, $1938 /$ France (Oligocene) [C].

22. Mycomya fossilis Statz, 1944a / Germany (Oligocene) $[\mathrm{C}]$.

22. Mycomya kuhni Statz, 1944a / Germany (Oligocene) [C].

22. Mycomya reisingeri Statz, 1944a / Germany (Oligocene) $[\mathrm{C}]$.

22. Mycomya umbonata Statz, 1944a / Germany (Oligocene) $[C]$.

22. Mycomya unicolor Statz, 1944a / Germany (Oligocene) $[\mathrm{C}]$.

26. Mycomya vetusta (Heer, 1849) / Switzerland (Miocene) $[C]$.

27. Mycomya vetusta (Heer, 1849) / Austria (Miocene) [C].

30. Mycomya aristei Cockerell, 1923 / Colombia (?Pleistocene/Holocene) [K].

30. Mycomya sp. (Saigusa, 1974).

30. Neoempheria maculata (Meunier, 1907a) / Tanzania (Pleistocene/Holocene) [K].

Subfamily Mycetophilinae

12. Exechiites tadushensis Blagoderov 2000 / Russia (Tadushi) (Late Paleocene-Early Eocene) [C]
15. Allodia antiqua (Meunier, 1904c) / Baltic Region (Eocene) [A].

15. Allodia brevicornis Meunier, 1904c / Baltic Region (Eocene) [A].

15. Allodia clavata Meunier, 1917a / Baltic Region (Eocene) [A].

15. Allodia eridana Meunier, 1916b / Baltic Region (Eocene) [A].

15. Allodia extincta (Meunier, 1904c) / Baltic Region (Eocene) [A].

15. Allodia fungicola Meunier, 1904c / Baltic Region (Eocene) [A].

15. Allodia procera (Meunier, 1904c) / Baltic Region (Eocene) [A].

15. Allodia separata Meunier, 1904c / Baltic Region (Eocene) [A].

15. Allodia succinea Meunier, 1904c/Baltic Region (Eocene) [A].

15. Allodia tomentosa (Meunier, 1904c) / Baltic Region (Eocene) [A].

15. Allodia winnertzi Meunier, 1922b / Baltic Region (Eocene) [A].

15. Brachypeza grandis Meunier, 1917a / Baltic Region (Eocene) [A].

15. Cordyla furcula Meunier, 1917a / Baltic Region (Eocene) [A].

15. Cordyla mycotheriformis Meunier, 1917a / Baltic Region (Eocene) $[\mathrm{A}]$.

15. Exechia inflata Meunier, 1916b / Baltic Region (Eocene) [A].

15. Mycetophila agilis (Meunier, 1904c) / Baltic Region (Eocene) [A].

15. Mycetophila antennata Meunier, 1899b / Baltic Region (Eocene) [A].

15. Mycetophila compressa Loew, 1850b / Baltic Region (Eocene) $[\mathrm{A}]$.

15. Mycetophila cordyliformis (Meunier, 1904c) / Baltic Region (Eocene) $[\mathrm{A}]$.

15. Mycetophila leptocera Loew, $1850 \mathrm{~b} /$ Baltic (Eocene/ Oligocene) [A].

15. Mycetophila macrostyla Loew, 1850b / Baltic Region (Eocene) [A].

15. Mycetophila pulvillata Loew, 1850b / Baltic Region (Eocene) [A].

15. Mycetophila spinosa Jentzsch, 1892 / Baltic Region (Eocene) [A].

15. Phronia ciliata Meunier, 1904c/ Baltic Region (Eocene) [A].

15. Phronia unifurcata Meunier, 1917a / Baltic Region (Eocene) $[\mathrm{A}]$. 
15. Rymosia longicalcar (Meunier, 1904c) / Baltic Region (Eocene) [A].

15. Synplasta crassicornis (Meunier, 1904c) / Baltic Region (Eocene) [A].

15. Trichonta brachycamptoides Meunier, 1904c / Baltic Region (Eocene) [A].

15. Trichonta crassipes Meunier, 1904c / Baltic Region (Eocene) [A].

16. Anatella tacita Scudder, 1890 / USA (Florissant) (Eocene/Oligocene) [C].

16. Mycetophila bradenae Cockerell, 1915b / USA (Florissant) (Eocene/Oligocene) .

16. Rymosia strangulata Scudder, 1890 / USA (Florissant) (Eocene/Oligocene) [C].

16. Sackenia arcuata Scudder, 1877a / USA (Florissant) (Eocene/Oligocene) [C].

16. Sackenia gibbosa Cockerell, 1907 / USA (Florissant) (Eocene/Oligocene) [C].

17. Mycetophila vectensis Cockerell, 1915c / UK (England, Wealden Group) (Eocene/Oligocene) [C].

17. Phronia virgata Cockerell, 1921c / UK (England, Wealden Group) (Eocene/Oligocene) [C].

17. Rymosia edwardsi Cockerell, 1921c / UK (England, Wealden Group) (Eocene/Oligocene) [C].

17. Rymosia ferruginea Cockerell, 1921c / UK (England, Wealden Group) (Eocene/Oligocene) [C].

17. Rymosia grisea Cockerell, 1921c / UK (England, Wealden Group) (Eocene/Oligocene) [C].

17. Rymosia rufescens Cockerell, 1921c / UK (England, Wealden Group) (Eocene/Oligocene) [C].

18. Cordyla unidentified sp. (Lewis, 1987) / USA (Oligocene) $[\mathrm{C}]$.

19. Allodia pallipes (Heer, 1856) / France (Oligocene) [C].

19. Exechia distincta Théobald, 1937a / France (Oligocene) $[\mathrm{C}]$.

19. Mycetophila confusa Théobald, 1937a / France (Oligocene) [C].

19. Mycetophila longipennis Théobald, 1937a / France (Oligocene) [C].

19. Mycetophila morio Heer, 1856 / France (Oligocene) [C].

19. Mycetophila pumiliformis Piton in Piton and Théobald, 1935 / France (Oligocene) [C].

19. Phronia brevipennis Théobald, 1937a / France (Oligocene) $[\mathrm{C}]$.

19. Rymosia foersteri Théobald, 1937a / France (Oligocene) $[\mathrm{C}]$.

21. Brachypeza abita Scudder, 1877b / Canada (Oligocene) $[\mathrm{C}]$.

21. Brachypeza procera Scudder, $1877 \mathrm{~b} /$ Canada (Oligocene) $[\mathrm{C}]$.
21. Trichonta dawsoni Scudder, 1877b / Canada (Oligocene) $[\mathrm{C}]$.

22. Brachypeza graciosa Meunier, 1917b / Germany (Oligocene) [C].

22. Cordyla antiqua Heyden, 1870 / Germany (Oligocene) $[\mathrm{C}]$.

22. Cordyla hastata (Statz, 1944a) / Germany (Oligocene) $[\mathrm{C}]$.

22. Cordyla limnoria Heyden, 1870 / Germany (Oligocene) $[\mathrm{C}]$.

22. Cordyla renuda Heyden, 1870 / Germany (Oligocene) $[\mathrm{C}]$.

22. Cordyla rhenana Meunier, 1923a / Germany (Oligocene) $[\mathrm{C}]$.

22. Cordyla subaptera Heyden, 1870 / Germany (Oligocene) $[\mathrm{C}]$.

22. Cordyla vetusta Heyden, 1870 / Germany (Oligocene) $[\mathrm{C}]$.

22. Exechia priscula Melander, 1949 / USA (Florissant) (Eocene/Oligocene) [C].

22. Mycetophila orci Heer, 1864 / Germany (Oligocene) [C].

22. Mycetophila pusillima Heer, 1864 / Germany (Oligocene) $[\mathrm{C}]$.

22. Proallodia delopsides Armbruster, 1938 / Germany (Miocene) [C].

22. Proallodia rhymosides Armbruster, 1938 / Germany (Miocene) [C].

22. Prodelopsis epicyptides Armbruster, 1938 / Germany (Miocene) [C].

22. Prodelopsis exechides Armbruster, 1938 / Germany (Miocene) [C].

22. Proepicypta obesa Armbruster, 1938 / Germany (Miocene) [C].

22. Prophronia dynatosomides Armbruster, 1938 / Germany (Miocene) [C].

22. Protrichonta delopsides Armbruster, 1938 / Germany (Miocene) [C].

24. Epicypta nigritella (Heer, 1849) / Croatia (Miocene) [C].

24. Mycetophila amoena Heer, 1849 / Croatia (Miocene) [C].

24. Mycetophila antiqua Heer, 1849 / Croatia (Miocene) [C].

24. Mycetophila latipennis Heer, 1849 / Croatia (Miocene) [C].

24. Mycetophila nana Heer, 1849 / Croatia (Miocene) [C].

24. Mycetophila pulchella Heer, 1849 / Croatia (Miocene) $[\mathrm{C}]$.

24. Mycetophila pumilio Heer, 1849 / Croatia (Miocene) [C]. 
25. Exechia juliaetta Lewis, 1969 / USA (Miocene) [C]. 25. Rymosia miocenica Lewis, 1969 / USA (Miocene) [C].

30. Exechia erupta Meunier, 1907a / Zanzibar (Holocene) $[\mathrm{K}]$.

30. Rymosia unidentified sp. (Saigusa, 1974) / Japan (Pleistocene) [K].

Unplaced*

Apatemosciaritis curta (Hong, 1981) / China (Eocene) [A].

Archaeboletina tipuliformis Meunier, 1904c / Baltic Region (Eocene) [A].

Arcicornia chrysitis (Hong, 1981) / China (Eocene) [A].

Armbrusteleiaminor (Armbruster, 1938) / Germany (Miocene) [C].

Armbrusteleia rhymosides (Annbruster, 1938) / Germany (Miocene) [C].

Bivalvula heteroceroidis (Hong, 1981) / China (Eocene) [A].

Chenosciaritis succinea (Hong in Hong et al., 1974) / China (Eocene) [A].

Dianepsia crassa Meunier, 1899b / Baltic Region (Eocene) [A].

Dianepsia hissa Meunier, 1899b / Baltic Region (Eocene) [A].

Dongbeimyceta melaina (Hong, 1981) / China (Eocene) [A].

Eosciaritis euryopteris Hong, 1981 / China (Eocene) [A].

Eosciophila microtrichodis Hong in Hong et al., 1974 / China (Eocene) [A].

Eomycetachlora (Hong, 1981) / China (Eocene) [A].

Fushunoboleta pulvinata (Hong, 1981) / China (Eocene) [A].

Fushunoboleta uda (Hong, 1981) / China (Eocene) [A].

Fushunosciaritis stenopteris (Hong, 1981) / China (Eocene) [A].

Huosciarites cona (Hong, 1981) / China (Eocene) [A].

Loewiella asinduloides Meunier, 1904c / Baltic Region (Eocene) [A].

Loewiella brevitarsis Meunier, 1923b / Baltic Region (Eocene) [A].

Loewiella ciliata Meunier, 1904c / Baltic Region (Eocene) [A].

Loewiella empalioides Meunier, 1904c / Baltic Region (Eocene) [A].

Loewiella incompleta Meunier, 1904c / Baltic Region (Eocene) [A].

Loewiella indistincta Meunier, 1904c / Baltic Region (Eocene) [A].
Loewiella modesta Meunier, 1923b / Baltic Region (Eocene) [A].

Loewiella mucronata Meunier, 1904c / Baltic Region (Eocene) [A].

Loewiella tenebrosa Meunier, 1904c / Baltic Region (Eocene) [A].

Microntos philadilphiaensis Kaddumi, 2005b / Jordan (Lower Cretaceous) [A].

Palaeoanaclinia affinis Meunier, 1904c / Baltic Region (Eocene) [A].

Palaeoanaclinia curvipetiolata Meunier, 1904c / Baltic Region (Eocene) [A].

Palaeoanaclinia distincta Meunier, 1904c / Baltic Region (Eocene) [A].

Prodocidia spectra Whalley, 1985 / UK (England, Wealden Group) (Lower Jurassic) [C].

Proleia landrocki Armbruster, 1938 / Germany (Miocene) $[\mathrm{C}]$.

Promycetomyia neoempherides Armbruster, 1938 / Germany (Miocene) [C].

Proneoglaphyroptera eocenica Meunier, 1904c / 169]

Prophthinia coelosides Armbruster, 1938 / Germany (Miocene) [C].

Prophthinia leides Armbruster, 1938 / Germany (Miocene) $[\mathrm{C}]$.

Rubsaameniella semibrachyptera Meunier, 1903b / Baltic Region (Eocene) [A].

Sciophilopsisbrodiei Handlirsch, 1906a / Germany (Upper Jurassic) [C].

Sciophilopsisunidentified sp. (Handlirsch, 1939) / UK (England, Wealden Group) (Lower Cretaceous) [C]. Scudderiella scudderi Evenhuis, 1994b / Baltic Region (Eocene) [A].

Sinosciophila meileyingziensis Hong, 1992a / China (Upper Cretaceous) [C].

Thimna defossa (Westwood in Brodie, 1845) / UK (England, Wealden Group) (Lower Cretaceous) [C]. 


\section{APPENDIX 5}

Age and Location of Mycetophilid Amber and Compression Fossil Sites

(FIG. 107)

1. Lower Cretaceous, Earliest Berriasian to Valanginian, Russia (Baisa) (134-131 Ma) - Rasnitsyn and Zherikhin, 2002.

2. Lower Cretaceous, Late Berriasian to Early Aptian, England (Wealden Group) (140-125 Ma) - Radley, 2005.

3. Lower Cretaceous, Barremian (129.4-125 Ma) Mercadé, 1991.

4. Lower Cretaceous, Mongolia (Bon-Tsagan) (125 Ma) - Rasnitsyn and Zherikhin, 2002.

5. Lower Cretaceous, Upper Aptian-middle Albian, Spain (Alava)120-110 Ma) - Alonso et al., 2000.

6. Lower Cretaceous, Upper Albian, Russia (Taimyr Peninsula) ( 100 Ma) - Blagoderov and Grimaldi, 2004.

7. Upper Cretaceous Cenomanian, Myanmar (Katchin) (99.41-98.17 Ma) - Shi et al., 2012.

8. Upper Cretaceous Turonian, USA (New Jersey) (90$94 \mathrm{Ma}$ ) - Grimaldi and Nascimbene, 2010.

9. Upper Cretaceous Coniacian-Santonian, Russia (Yantardakh, Siberia) (90-94 Ma) - Herman et al., 2016.

10. Upper Cretaceous Santonian-Campanian, Canada (Manitoba) (76.5-79.5 Ma) - Eberth and Hamblin, 1993.

11. Paleocene, Russia (Sakhalin) (60 Ma) - Kodrul, 1999.

12. Late Paleocene-Early Eocene, Russia (Tadushi) (61.27 to 51.92 Ma) - Popov and Grebennikov, 2001.

13. Eocene, China (Fushun) (50-53 Ma) - Wang et al., 2014.

14. Mid Eocene, Australia (Redbank Plains) (45 Ma) Lapparent de Broin and Molnar, 2001.

15. Mid Eocene, Baltic amber (44.3 Ma) - Ritzkowski, 1997.

16. Eocene/Oligocene, USA (Florissant) (34.07 Ma) Evanoff et al., 2001.

17. Eocene/Oligocene, England (Isle of Wight) (34.134.3 Ma) - Ross and Self, 2014.

18. Oligocene, USA (Ruby River Basin Group) (32.2 Ma) - Lielke et al., 2012.

19. Oligocene, France (Aix-en-Provence Formation) (23.0-27.8 M) - Gaudant et al., 2018.

20. Oligocene/Miocene, Mexico (20-30 Ma) - Lambert et al., 1989.
21. Oligocene, Canada (Quilchena) (25 Ma) - Villeneuve and Mathewes, 2005.

22. Oligocene, Germany (Rott) (24 Ma) - Mörs, 1995.

23. Early Miocene/Middle Miocene, Dominican Republic (15-20 Ma) - Iturralde-Vinent and MacPhee, 1996.

24. Miocene, Croatia (20.4-16.0 Ma) - LaPolla et al., 2013.

25. Miocene, USA (Latah Formation) (21.3-12.1 Ma) - Gray and Kittleman, 1967]

26. Miocene, Switzerland (16-17.3 Ma) - Grimaldi and Engel, 2005.

27. Miocene, Austria (16.0 Ma) - Nel, 1994.

28. Miocene, Germany (Randeck Maar) (16-13.7 Ma) - Kotthoff et al., 2011].

29. Pliocene, Russia (Siberia) (1.7-5.2 Ma) - Rohdendorf, 1964.

30. Pleistocene, Japan (33,000 y) - Schlee, 1984.

30. Pleistocene/Holocene, Tanzania (£ 1,000 y)) Schluter and von Gnielinski, 1987.

30. Pleistocene/Holocene, Madagascar ( $£ 1,000$ y) Poinar, 1999.

30. Pleistocene/Holocene, Colombia ( 200 y) - Clifford et al. 1997. 